
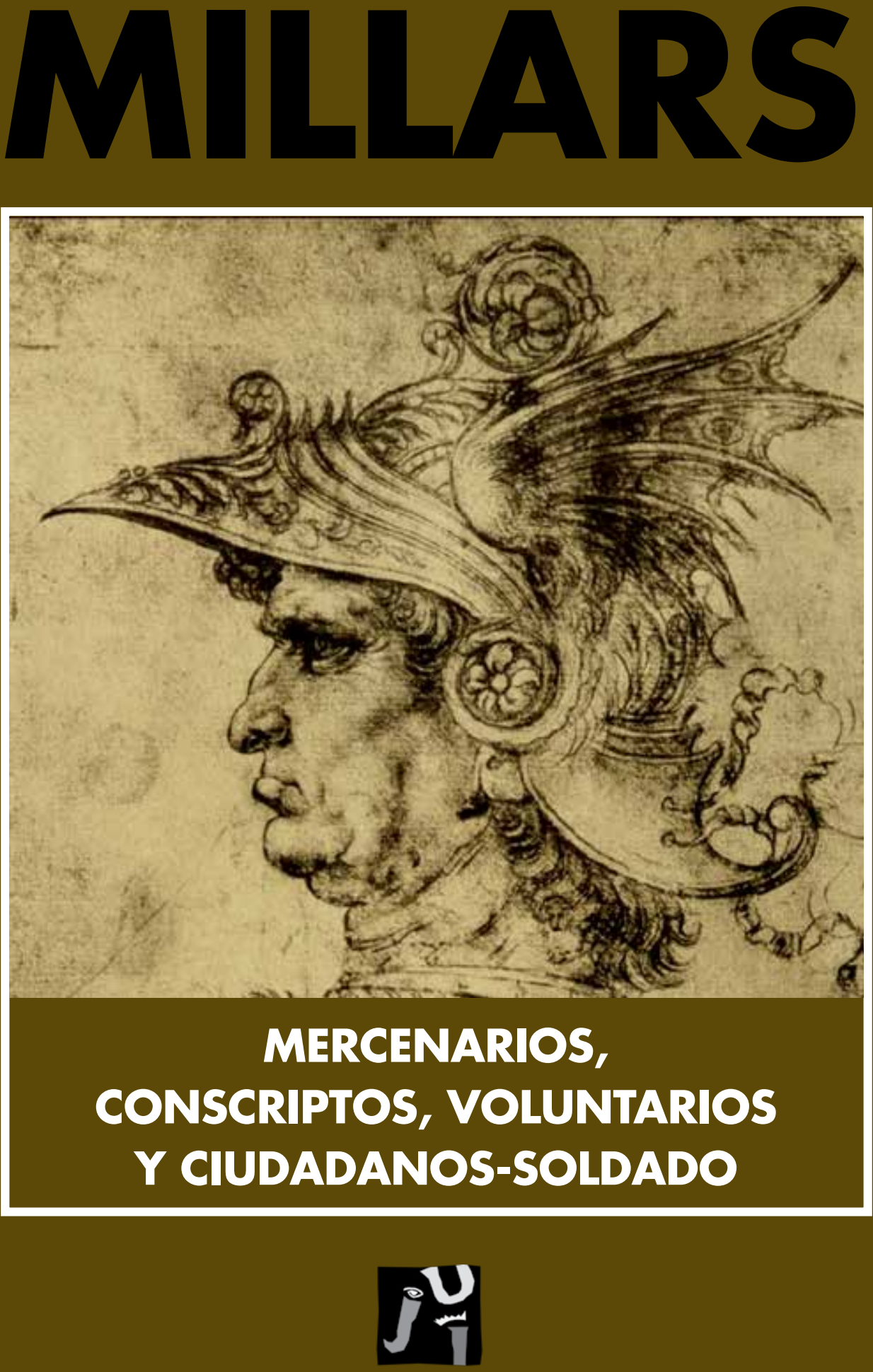

UNIVERSITAT JAUME•I 


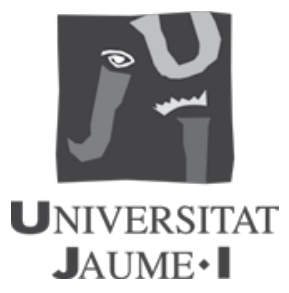

XLIII 2017/2

ESPAI I HISTÒRIA
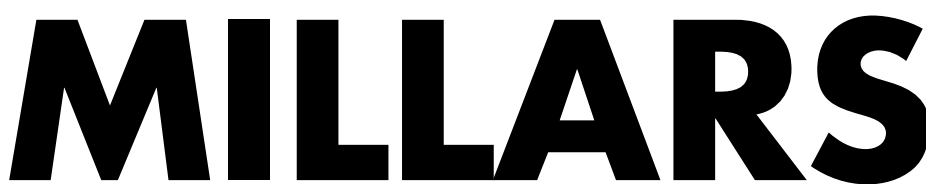

Departament d'Història, Geografia i Art 
REVISTA MILLARS. ESPAI I HISTÒRIA. -T. 1 (1974). - Castelló de la Plana: Publicacions de la Universitat Jaume I, [1974]-

v.; $24 \mathrm{~cm}$

És continuació de: Millars

Descripció basada en: n.17 (1994)

ISSN 1132-9823

I.Universitat Jaume I (Castelló). Publicacions de la Universitat Jaume I

15 TOMO XLIII (2017/2)

Director: Dr. Vicent Sanz Rozalén (Universitat Jaume I)

Secretaria: Cristina Igual Castelló (Universitat Jaume I)

\section{Consell de Redacció:}

Dr. Manuel Chust Calero (Universitat Jaume I); Dra. Carmen Corona Marzol (Universitat Jaume I); Dr. Juan José Ferrer Maestro (Universitat Jaume I); Dr. Juan Manuel Marín Torres (Universitat Jaume I); Dr. Víctor Mínguez Cornelles (Universitat Jaume I); Dr. Javier Soriano (Universitat Jaume I); Dr. Enrique Montón (Universitat Jaume I); Dr. Carles Rabassa Vaquer (Universitat Jaume I).

\section{Consell Assessor:}

Dr. Walther L. Bernecker (Universität Erlangen-Nüremberg); Dr. Pedro Barceló (Universität Potsdam); Dr. Antonio Gil Olcina (Universitat d'Alacant); Dra. Angeles González (Universidad de Sevilla); Dr. Robert Kent (California State University); Dr. Guiliano Pinto (Università degli Studi di Firenze); Dr. Christopher Storrs (University of Dundee)

Millars. Espai i història apareix indexada en els següents directoris i bases de dades:

- CARHUS Plus+ - CIRC (Clasificación Integrada de Revistas Científicas) - Díalnet - DICE (Difusión y Calidad Editorial de las Revistas Españolas de Ciencias Sociales y Jurídicas) - IN-RECS (Índice de impacto de Revistas Epañolas de Ciencias Sociales) - ISOC Índice Español de Ciencias Sociales y Humanidades (CSIC) - Latindex - MIAR (Matriu d'Informació per a I'Avaluació de Revistes) - RACO (Revistes Catalanes amb Accés obert) REGESTA IMPERII: Akademie der Wissenschaften und der Literatur - RESH (Revistas Españolas de Ciencias Sociales y Humanas) - Ulrich's

DOI: http://dx.doi.org/10.6035/Millars

http://dx.doi.org/10.6035/Millars.2017.43

Millars. Espai i història no s'identifica necessàriament amb els continguts dels artícles publicats. Prohibida la reproducció total o parcial dels artícles sense l'autorització prèvia.

Dipòsit legal: CS-84-96

Disseny: Espai Paco Bascuñán- www.espaciopacobascunan.com

Impressió: Ulzama Digital www.ulzama.com

Foto de portada: Leonardo da Vinci, Il Condottiere, 1480. British Museum. (Detall). 


\section{Sumari}

\section{Dossier}

\section{Miguel Alonso Ibarra y David Alegre Lorenz (Coords.) \\ MERCENARIOS, CONSCRIPTOS, VOLUNTARIOS $Y$ CIUDADANOS-SOLDADO}

\section{Miguel Alonso lbarra y David Alegre Lorenz}

Reclutamiento, encuadramiento y experiencia de guerra desde la Antigüedad hasta nuestros días

Conscription, binding and war experience from Antiquity to

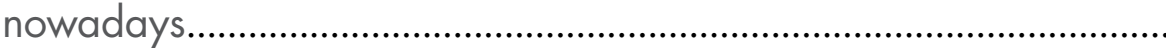

\section{Matthew Trundle}

Hiring Mercenaries in the Classical Greek World. Causes and Outcomes?

La contratación de mercenarios en la Grecia Clásica. ¿Causas y consecuencias?

\section{Eduardo Pitillas Salañer}

Los soldados del ejército romano durante la etapa del Alto Imperio. Sus componentes más básicos: el ciudadanosoldado (legionario) y el soldado auxiliar

The soldiers of the Roman army during the stage of the High

Empire. His more basic components: the

citizen-soldier (legionary) and the auxiliary soldier.

\section{Alan V. Murray}

Warriors and Civilians in the Crusade Movement. Military Identities and Status in the Liberation and Defence of the Holy Land (1096-1204)

Guerreros y civiles en las cruzadas. Identidades militares y estatus en la liberación y defensa de Tierra Santa (10961204) 


\section{William Caferro}

The Florentine Army in the Age of the Companies of Adventure

El ejército de Florencia en la época de las compañías de mercenarios.

\section{Antonio José Rodríguez Hernández}

El primer modelo de reclutamiento forzoso en España durante la Edad Moderna: las levas para los Presidios (1634-1642)

The first model of forced recruitment in Spain during the Early Modern period: the levies for the Presidios (16341642)

\section{Simon SarLin}

Mercenaries or soldiers of the faith? The Pontifical Zouaves in the defense of the Roman Church (1860-1870) ¿Mercenarios o soldados de la fe? Los zuavos pontificios en la defensa de la Iglesia católica (1860-1870)

\section{Samuel Fury Daly}

De trabajadores a soldados: trabajo forzado y conscripción en la Guinea Española y la Nigeria oriental, 1930-1970

Workers to Soldiers: Coerced Labor and Conscription in Spanish Guinea and Eastern Nigeria, 1930-1970.

\section{Estudis}

\section{Gerhard Lang-Valchs}

El correo carlista en el Maestrazgo (1872-1875)

The Carlist Mail in the Maestrazgo (1872-1875). 


\section{Dossier}

\section{Mercenarios, conscriptos, voluntarios Y ciudadanos-soldado}

\section{Miguel Alonso Ibarra David Alegre Lorenz Coordinadores}

\section{Miguel Alonso Ibarra y David Alegre Lorenz}

Reclutamiento, encuadramiento y experiencia de guerra desde la Antigüedad hasta nuestros días

\section{Matthew Trundle}

Hiring Mercenaries in the Classical Greek World. Causes and Outcomes?

\section{Eduardo Pitillas Salañer}

Los soldados del ejército romano durante la etapa del Alto Imperio. Sus componentes más básicos: el ciudadano-soldado (legionario) y el soldado auxiliar

\section{Alan V. Murray}

Warriors and Civilians in the Crusade Movement. Military Identities and Status in the Liberation and Defence of the Holy Land (1096-1204)

\section{Wiluam Caferro}

The Florentine Army in the Age of the Companies of Adventure

\section{Antonio José Rodríguez Hernández}

El primer modelo de reclutamiento forzoso en España durante la Edad Moderna: las levas para los Presidios (1634-1642)

\section{Simon SarLin}

Mercenaries or soldiers of the faith? The Pontifical Zouaves in the defense of the Roman Church (1860-1870)

\section{Samuel Fury Daly}

De trabajadores a soldados: trabajo forzado y conscripción en la Guinea Española y la Nigeria oriental, 1930-1970 


\title{
RECLUTAMIENTO, ENCUADRAMIENTO Y EXPERIENCIA DE GUERRA DESDE LA ANTIGÜEDAD HASTA NUESTROS DÍAS ${ }^{1}$
}

\author{
Miguel Alonso Ibarra \\ Universitat Autònoma de Barcelona \\ David Alegre Lorenz \\ Universitat Autònoma de Barcelona
}

Polemos panton men pater esti, panton de basileus, kai tous men theous edeixe tous de anthropus, tous men doulous epoiese tous de eleutherous

La guerra es padre y rey de todo, a unos los designa como dioses,

a otros como hombres, a unos los hace esclavos, a otros libres

Heráclito

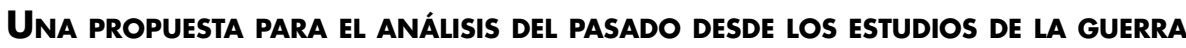 Y LA HISTORIA SOCIAL}

La guerra es un fenómeno recurrente en la historia de los seres humanos. En este sentido, cualquier teatro bélico constituye un campo de estudio extremadamente útil, valioso y fértil para los humanistas y científicos sociales que buscan abordar aspectos esenciales de la naturaleza humana. A través de ellos podemos aprehender la adaptabilidad y capacidad de supervivencia de individuos y comunidades en situaciones extremas, pero también su grado de adscripción a unos determinados valores y una ética dadas, así como su poder para organizarse y destruir de forma racional y consciente. Por tanto, sean cuales sean las razones que las impulsan, las guerras ponen de manifiesto e intensifican dinámicas y procesos clave en la vida del ser

1 Se inscribe en el Proyecto de I+D del Ministerio de Economía y Competitividad Culturas políticas, movilización y violencia en España (HAR2014-53498-P), dirigido por Francisco Morente Valero. 
humano, sobre todo porque se trata de un fenómeno que ha puesto y que pone en contacto un sinfín de realidades individuales y colectivas diferentes, unas veces transformándolas de forma irreversible y otras propiciando su desaparición. Así pues, los conflictos armados nos permiten observar, comparar y comprender mejor a lo largo del tiempo las motivaciones y el modus operandi de individuos y comunidades enteras, las diferentes formas de organización social, los variados códigos culturales que rigen las sociedades, las formas de solidaridad entre individuos y grupos humanos diferentes, los cambios sociales, las transformaciones de los imaginarios colectivos y las percepciones, etc. Al fin y al cabo, las guerras ponen a prueba la resistencia del tejido social y las cosmovisiones sobre las que se sustenta cualquier colectividad o sociedad, de ahí que necesariamente provoquen cambios y que éstos siempre sean traumáticos. $Y$ esto es así porque los promotores de los enfrentamientos bélicos exigen de los grupos y sociedades implicadas sacrificios y capacidad de adaptación, tanto como sea necesario para dotarse de los recursos materiales y humanos que permitan una organización capaz de alcanzar sus objetivos, y siempre partiendo de unos parámetros culturales y unos equilibrios sociales preexistentes. El fin último: conseguir la victoria o, cuanto menos, garantizarse la supervivencia, tanto a nivel individual como colectivo.

En este sentido, creímos que sería muy provechoso abordar diferentes formas de reclutamiento y encuadramiento, así como también distintas experiencias de guerra, todo ello a través de siete casos de estudio centrados en épocas y conflictos diferentes, desde la Antigüedad hasta nuestros días. Lo que proponemos con este dossier es un análisis de las diferentes fuentes humanas de las que se nutrirían las huestes y los ejércitos en cada momento. Dicho propósito comporta conocer los equilibrios sociales y los mecanismos legales, coercitivos e institucionales por medio de los cuales se accedería a los efectivos en cuestión y, finalmente, los incentivos y beneficios ofrecidos con el fin de atraer y conservar su lealtad y compromiso. En definitiva, nos interesa saber quiénes eran reclutados, de qué manera se llevaba a cabo su reclutamiento y, por ultimo, bajo qué condiciones se hacía y qué garantías se ofrecían a aquéllos que eran levados. Llegados a este punto cabe señalar que las contribuciones de este dossier parten de la necesidad de comprender de forma compleja el contexto espacial y temporal en que tiene lugar la recluta de tropas, que a su vez determina la composición de éstas, los objetivos que les son designados y, en última esencia, su desempeño en conflicto. Las formas de reclutamiento, en combinación con el escenario en que tienen lugar, nos permiten entrar en contacto con la naturaleza del poder que las impulsa, las relaciones de éste con las comunidades humanas y los territorios en los que impera su gobierno, pero 
también con los equilibrios, usos y costumbres vigentes en las comunidades locales, los sectores sociales y los territorios obligados (o invitados, si se trata de voluntarios) a proporcionar tropas para la guerra. Por tanto, a través de este objeto de estudio podemos comprender siquiera tangencialmente cómo responden las sociedades a las exigencias de la guerra $O$, dicho de otro modo, qué concepción tienen de ésta y qué lugar ocupa en sus vidas, cómo mantienen sus equilibrios y subsisten en situaciones de conflicto $y$, por último, qué posición tienen frente a los miembros de la comunidad que marchan a la batalla.

Por lo que respecta a la Edad Antigua proponemos dos casos de análisis. Por un lado, Matthew Trundle aborda las claves socio-culturales y políticas que motivarían y caracterizarían la intensa circulación de "mercenarios" griegos por todo el arco del Mediterráneo oriental a lo largo del siglo IV a. C., cuestionando la pertinencia de dicho concepto para referirse a ellos. ${ }^{2}$ Por su parte, Eduardo Pitillas Salañer estudia el reclutamiento por parte del ejército romano de auxiliares originarios del cuadrante noroccidental de la península ibérica, concretamente a comienzos de la época imperial, una política que formaría parte de los mecanismos de pacificación e integración de las comunidades autóctonas dentro de las estructuras sociales del imperio. En lo referido a la Edad Media contamos con dos casos distintos. El primero de ellos, abordado por Alan V. Murray, se centra en la composición social y la organización de los contingentes de las primeras cruzadas -incluyendo también a los no combatientes-, sus motivaciones y los procesos de adaptación sufridos en su modo de hacer la guerra fruto de las vicisitudes del viaje y las necesidades impuestas por su establecimiento en Oriente Próximo. Por su parte, William Caferro repasa las cambiantes formas de reclutamiento y modos de hacer la guerra en el norte de Italia durante los siglos XIII y especialmente XIV, concluyendo que éstas sólo son comprensibles dentro de lógicas político-militares regionales y transferencias socio-culturales a nivel continental. Para época moderna contamos con un estudio de Antonio José Rodríguez Hernández. Éste analiza los múltiples mecanismos puestos en marcha por parte de la monarquía hispánica con el fin de responder a las crecientes exigencias en materia de efectivos derivadas del mantenimiento de su hegemonía, todo ello en un tiempo de profun-

2 Repensar el uso historiográfico que se hace el concepto de "mercenario" y qué tipo de combatientes son definidos por esa etiqueta, que generalmente suelen representar una variedad mucho más compleja y rica que el simple servicio al mejor postor, es algo que también se ha realizado para el caso medieval. Véase DEVRIES, K. (2015), "Mercenarios medievales. Metodología, definiciones y problemas". Revista Universitaria de Historia Militar, vol. 4:8, pp. 183-199. 
da crisis demográfica y económica como es el siglo XVII, algo que tendría una gran incidencia en la experiencia de los reclutas. Finalmente, para la época contemporánea, Simon Sarlin aborda el caso de los voluntarios reclutados por el Papado en sus guerras contra el naciente estado italiano a mediados del siglo XIX. Éste se centra sobre todo en la importancia simbólica de dicho colectivo, en tanto que reflejo y estandarte de la creciente solidaridad, cooperación y organización dentro del espacio contrarrevolucionario a nivel transatlántico, sin renunciar a abordar los mecanismos de reclutamiento o la experiencia de guerra de estos voluntarios. El cierre de este dossier corre a cargo de Samuel Fury Daly, con un artículo que se enmarca en el Golfo de Guinea durante el periodo colonial y poscolonial. Concretamente, el autor analiza las continuidades entre las formas de reclutamiento y la experiencia de los trabajadores forzosos de la comunidad igbo, en la Nigeria suroriental, enviados a las plantaciones de Fernando Po (hoy Bioko) entre los años 30 y 60 del siglo XX, y su conscripción en el ejército biafrano durante la Guerra Civil nigeriana (1967-1970).

A menudo observamos que en un mismo periodo se combinan diferentes formas de reclutamiento, lo cual, como no podría ser de otro modo al hablar del pasado, da un plus de complejidad al muestreo que hemos realizado en este dossier. Al fin y al cabo, movilizar todos los recursos necesarios para conformar una fuerza de combate constituye un reto extraordinario. De la misma manera, es arriesgado hacer descansar todo el esfuerzo en una sola fuente de reclutamiento, salvo en los casos contemporáneos de movilización general, donde se convoca a filas a todos los varones capaces de empuñar las armas. En cualquier caso, es por eso que en casi cualquier periodo suelen combinarse tropas conscriptas del mismo origen que el poder o la institución encargados de la leva -aunque no siempre-; tropas auxiliares que por motivos étnicos, de procedencia, origen o fe religiosa disfrutan de un status inferior al núcleo del ejército y/o mercenarios de origen extranjero que han dedicado su vida a la guerra de forma profesional; $y$, por último, voluntarios que marchan a la guerra puntualmente por diferentes razones, entre las cuales pueden estar el ansia de aventura, las cuestiones de honor, el deseo de escapar de una situación fiscal o familiar comprometida, la necesidad económica o las motivaciones ideológicas o religiosas. Evidentemente, la línea entre estas dos últimas categorías es estrecha, porque un individuo que empieza como voluntario por las razones que fuere puede acabar convertido en un mercenario ante la falta de expectativas o la incapacidad para reintegrarse a la vida civil, pero también al experimentar placer y satisfacción en la vida militar. Por último, cabría no olvidar el papel jugado por las élites políticas en el reclutamiento y la composición de los contingentes surgidos de la leva: de qué 
modo contribuyen al proceso de recluta, qué encaje tienen en los ejércitos a la hora de marchar a la guerra, qué funciones cumplen y qué se espera de ellas social y culturalmente en el campo de batalla.

Somos conscientes de los riesgos que comporta plantear un dossier de tan amplio alcance, pero también estamos convencidos del enorme potencial que reside en estas propuestas más ambiciosas. Tenemos la certeza de que tanto nosotros, en tanto que coordinadores, como los autores y las potenciales lectoras y lectores se beneficiarán de este enfoque amplio en lo cronológico y lo espacial. Asumir retos de estas características supone romper la artificial compartimentación impuesta por la hiperespecialización, al tiempo que recuperamos espacios de diálogo y debate entre expertas y expertos dedicados al estudio de la guerra en diferentes épocas, desarrollamos nuevas herramientas de análisis y volvemos a visiones más omnicomprensivas y fundamentadas en lo que Braudel llamaba longue durée. Precisamente, esta perspectiva nos permite tantear múltiples cuestiones: las diferentes y cambiantes concepciones de lo militar y de la guerra, así como las distintas maneras de organizarla y de hacerla; las diversas naturalezas del poder sobre el territorio y las personas, que varían sobremanera desde las polis griegas hasta los actuales patriotismos constitucionales y soberanías nacionales; o, también, el sentido de pertenencia o del territorio, es decir, de lo que el individuo de a pie o el poder consideran como propio y como extraño. Todo ello es fundamental a la hora de abordar las diferentes formas de reclutamiento a lo largo de la historia y, por tanto, ocupa un lugar importante en los artículos de este dossier.

No obstante, las cuestiones que hemos venido mencionando también son cruciales para entender otros dos aspectos asociados al proceso de recluta, como son las formas de encuadrar y hacer operativas tropas de orígenes a menudo muy distintos, tanto en lo social como en lo cultural, pero también el modo en que los individuos experimentan la guerra bajo sus cascos y uniformes. Así pues, otro de los objetivos de este dossier es analizar cómo se intenta garantizar la cohesión de ejércitos heterogéneos y qué tipo de formación o adiestramiento recibirían en cada época, que al fin y al cabo son dos de los factores que garantizan la efectividad en combate y la identificación del individuo con la institución armada en cuestión, casi siempre a través de su unidad. Al mismo tiempo, se ha tratado de analizar directa o indirectamente la concepción que los propios combatientes pudieron tener de su experiencia militar allá donde esto ha sido posible, recuperando para ello la perspectiva individual. Nuestro empeño y el de los autores nos ha llevado a indagar en los diferentes perfiles socioculturales de los soldados, en sus diferentes estrategias de supervivencia, en sus relaciones con lo que se suele denominar grupo primario -sus compañeros de unidad-, 
con el resto de combatientes y con los civiles, sus condiciones de vida, pero también sus motivaciones para resistir y seguir adelante.

En definitiva, este dossier es una invitación a mirar al pasado desde una óptica complejizadora, transterritorial y comparada, que es a nuestro juicio el mejor modo de seguir avanzando y planteándonos nuevas preguntas. En este sentido, esta iniciativa se mueve dentro de unos debates y responde a unas problemáticas o inquietudes que ya vienen siendo planteadas por la historiografía desde hace tiempo con resultados muy notables. ${ }^{3}$ Sin embargo, su principal valor reside en su capacidad para abrir nuevos caminos al aunar de forma útil y coherente los esfuerzos de expertos dedicados al estudio de épocas y conflictos muy diferentes, lo cual nos permite observar algunas rupturas y continuidades esenciales en el modo de hacer y sufrir la guerra. No es necesario decir que la exigencia ha sido trabajar desde el máximo rigor y de acuerdo con el análisis contextual, los marcos de referencia, las categorías y los conceptos propios de cada ámbito de estudio, de ahí que todos los autores de este dossier sean voces autorizadas y expertas en sus respectivos campos. Por eso mismo, el objetivo de este dossier es fomentar un diálogo real entre épocas partiendo desde un eje común como es el análisis detenido del reclutamiento, el encuadramiento y la experiencia de guerra de los combatientes en cada caso de estudio, a la par que se van desgranando las diferentes líneas de trabajo propuestas en esta presentación.

\section{EsCenARIOS PROPICIOS PARA El RECLUTAMIENTO: UNA VISIÓN DE LA GUERRA DESDE LO LOCAL A LO UNIVERSAL ${ }^{4}$}

Una conclusión que extraemos de todas las aportaciones que componen este dossier es que las formas de reclutamiento siempre aparecen condicionadas por factores endógenos -las condiciones estructurales y coyunturales de la sociedad de origen de los combatientes y del sistema que se beneficia de su servicio militar-, pero también exógenos -las características, equilibrios y dinámicas propias del escenario regional e internacional más amplio en que se enmarca el caso de estudio concreto-. Todo ello hace que

3 En el ámbito de la época contemporánea contamos con trabajos colectivos de referencia como KRÜGER, C. G. y LEVSEN, S. (eds.) (2011), War Volunteering in Modern Times: From the French Revolution to the Second World War. Basingstoke, Macmillan; ARIELLI, N. y COLLINS, B. (eds.) (2013), Transnational Soldiers: Foreign Military Enlistment in the Modern Era. Basingstoke, Macmillan; y el monográfico de ARIELLI, N. y RODOGNO, D. (eds.) (2016), "Foreign War Volunteers in the Twentieth Century". Journal of Modern European History, n' 14. 
la guerra haya sido y siga siendo el principal motor de cambio, a la par que la experiencia transterritorial por excelencia a lo largo de la historia, por su capacidad para poner en contacto realidades de lo más diverso, con permiso de la trashumancia o el comercio.

Sin ir más lejos, el fenómeno de los soldados profesionales procedentes de las polis griegas en el siglo IV a. C. sólo puede entenderse dentro del periodo de caos político y guerras intestinas que marcó el devenir de la cuenca mediterránea y Oriente Próximo en aquellas décadas, tal y como destaca Trundle. Pero al mismo tiempo, tal y como ocurre hoy en día en algunos lugares del África subsahariana, la destrucción causada por los propios conflictos de la época no sólo provocó un agravamiento de la pobreza e hizo de la guerra un problema endémico, sino que al final acabó haciendo de ésta un negocio muy lucrativo para unos pocos y un modo de vida rentable para otros muchos. A ello se une que dos generaciones de griegos que habían vivido la Guerra del Peloponeso (431-404 a. C.) apenas habían conocido otro oficio que no fuera el de las armas. Así pues, se trata de la pescadilla que se muerde la cola, tal y como planteó de forma muy acertada Sauper en su escalofriante Darwin's Nightmare (2004), sobre los vínculos entre la explotación económica de los recursos naturales del Tercer Mundo, la globalización, la pobreza, el tráfico de armas y la guerra en todo el enorme espacio que giraría alrededor del Lago Victoria. ${ }^{5}$ Sin embargo, como también se encarga de recordarnos el propio Trundle, ese enorme remanente de profesionales de la guerra en la Grecia clásica

4 La idea del íntimo vínculo y las sinergias entre los escenarios locales y supralocales (o, dicho de otro modo, la forma en que los problemas universales se manifiestan en el ámbito de lo local) la tomamos de la obra colectiva coordinada por JANÉ, O. y SERRA, X. (eds.) (2013), Ultralocalisme. D'allò local a l'universal. Catarroja/Figueres/Perpinyà, Afers/Mirmanda. La obra de Óscar Jané, que va mucho más allá de los trabajos en los que consta como autor, ofrecen un planteamiento metodológico y conceptual renovador y de gran utilidad para pensar la historia en términos más complejos, de intercambio y dinamismo, pero también de continuidades.

5 El realizador consiguió dar con el testimonio de un veterano de guerra tanzano que había combatido en el conflicto entre Tanzania y Uganda en 1979, el cual aparece a falta de quince minutos para la conclusión del documental. Éste le confesó su deseo de un nuevo conflicto porque le permitiría mejorar su nivel de vida. Al preguntarle Hubert si muchos de sus conciudadanos tenían la esperanza de que estallara una guerra éste no duda en afirmar que "sí, que mucha gente espera una guerra". Reflexionando sobre el acto de matar señala que "si soy astuto te mato antes, si tú eres astuto me matas a mí", a lo cual Hubert contesta que "quizás tu no quieres matarme", entonces, el excombatiente tanzano con semblante serio se pregunta que "porqué no querría matarte mientras estamos luchando. Es la guerra, de lo que se trata es de matar." 
no habría encontrado salida para ejercer el oficio de no haber existido un escenario internacional tan propicio para dar expresión a sus habilidades como el del siglo IV a. C. ${ }^{6}$

Algo similar ocurre en casos como el de los auxiliares del ejército romano procedentes de los confines occidentales del imperio, que aportaron más de la mitad de las tropas de este tipo en época altoimperial. Por un lado, estamos ante una maquinaria militar que cambia y se profesionaliza para adaptarse a las nuevas necesidades defensivas marcadas por las políticas de "pacificación" y control fronterizo de Roma. Es posible que las cruentas guerras de ocupación impulsadas por el ejército romano en el noroeste de Hispania desde finales del siglo I a. C. causaran tal número de muertes y tan alto nivel de devastación que la misma continuidad de las comunidades autóctonas se viera puesta en cuestión. De este modo, los más jóvenes no debieron de ver ningún futuro en continuar con la resistencia de sus predecesores. Por otro lado, el acceso de los pueblos itálicos a la ciudadanía y la reticencia cada vez mayor de los ciudadanos romanos a alistarse en las legiones abrió un marco de oportunidad inigualable para la recluta de auxiliares entre los pueblos sometidos a lo largo de las últimas décadas de la República, de acuerdo con lo apuntado por Pitillas. En este sentido, dentro de la lógica que aconseja que si no puedes con tu enemigo te unas a él, alistarse en el ejército romano debió de representar una garantía de futuro irrechazable para muchos jóvenes, por no hablar de la fascinación que los victoriosos ocupantes, su organización y sus costumbres pudieron ejercer sobre éstos. ${ }^{7}$ Por tanto, este proceso no sólo dio lugar a sinergias socio-culturales de lo más diversas, al enviar a las unidades de combatientes indígenas a destinos situados a centenares de kilómetros de sus lugares de origen, sino que además debió ser con toda seguridad una de las más

6 No en vano, la intensidad bélica del periodo en el que se sitúa el texto de Trundle ha llevado a algunos autores a plantear la aplicabilidad del concepto guerra total a ese escenario. En buena medida, eso explicaría el importante número de individuos con experiencia militar que vieron la guerra como su única salida, alistándose en contingentes de distintos reinos e imperios y combatiendo en múltiples conflictos. Véase POPOWICZ, E. (1995), "La guerra total en la Grecia Clásica (431-338)". POLIS. Revista de ideas y formas políticas de la Antigüedad Clásica, $\mathrm{n}^{\circ} 7$, pp. 219-245.

7 La fascinación ejercida por los ejércitos invasores en escenarios de ocupación es una constante de la guerra, tal y como se constata en casos como el del colaboracionismo militar durante la Segunda Guerra Mundial. Véase CAPDEVILA, L. (2010), "The Quest for Masculinity in a Defeated France, 1940-1945". Contemporary European History, vol. 10:3, pp. 423-445. 
efectivas políticas para la romanización y consolidación de los dominios imperiales. ${ }^{8}$ También en el caso griego, por muy diferente que sea, Oriente, como espacio asociado a la abundancia sobre el que se proyectaban las quimeras de muchos ciudadanos de las polis, ejerció un innegable poder de atracción sobre ellos, constreñidos por las estrecheces de sus pobres economías agrarias $y$, en muchos casos, ansiosos de nuevas oportunidades. ${ }^{9}$

Para el caso de las cruzadas, algo bien señalado por Murray, la llamada a la guerra para la liberación de Tierra Santa tuvo una clara dimensión social, algo que a su vez nos permite adentrarnos en los problemas esenciales de las sociedades de la Europa occidental en los siglos XI y XII. En un momento en que empezaba a imponerse el feudalismo como forma de organización social y económica, el éxito de la convocatoria impulsada por el Papado pasaba por conseguir apelar al mayor número posible de miembros de la élite militar europea. Muchos de ellos pululaban por su entorno al servicio de élites político-eclesiásticas, pero también muy a menudo perturbando gravemente la paz social y expoliando a la población campesina. En tanto que personal militar especializado, dada su capacidad económica para costearse el armamento propio de la caballería pesada y su habilidad para utilizarlo montados a caballo, el Papa Urbano II vio en la Cruzada una posibilidad para canalizar su poder destructivo y aliviar los problemas sociales y políticos que generaban con su presencia. A cambio se les garantizaba la salvación eterna, aunque poca duda cabe que la perspectiva de más poder y nuevas riquezas debió ejercer un influjo importante sobre los caballeros cruzados. Sin embargo, nada de esto habría sido posible sin el marco propiciatorio abierto por la derrota de las fuerzas bizantinas en Manzikert (1071) frente a los turcos selyúcidas y las luchas

8 En referencia al ejército romano y su presencia sobre las provincias como instrumento clave en las políticas de romanización véase COCCOLUTO, M. (2014), Panis ad milites. L'approvvigionamento dell'esercito romano in Numidia da Augusto ai Severi. Ancona, Affinità Elettive.

9 Un efecto parecido al que tuvo la irrupción de los castellanos en la América precolombina, un continente que rápidamente se convirtió en el espacio sobre el cual se abocaron las fantasías de dominación y enriquecimiento de muchos europeos. Esto contribuyó a movilizar las energías para impulsar la colonización y explotación del territorio y sus pobladores. Dicha idea fue desarrollada desde un punto de vista interesante por THEWELEIT, K. (1987), Male Fantasies. Volume 1: Women, Floods, Bodies, History. Minneapolis, University of Minnesota Press [1977], pp. 307-308. 
intestinas por la púrpura imperial. Estos hechos acabaron por posibilitar la definitiva expansión del dominio turco sobre Anatolia, granero del imperio bizantino, y el comienzo de su declive como potencia militar. Tal era la situación que el emperador Alejo Comneno acudió a Urbano II en busca de auxilio para posibilitar el envío de tropas so pretexto de recuperar los lugares santos del cristianismo.

En lo que respecta a la ltalia de los siglos XIII y XIV volvemos a observar la importancia clave del modo en que encajan y se relacionan los escenarios locales, regionales e internacionales a la hora de determinar los modos de hacer la guerra, así como también los métodos y fuentes de reclutamiento. Según afirma Caferro, queda claro que en el caso de Florencia éstos se encontraron muy condicionados a lo largo de todo el periodo por el entorno regional, las alianzas políticas $y$, no menos importante, la influencia de la Guerra de los Cien Años (1337-1453). Por un lado, las ligas regionales surgidas de las alianzas político-militares entre ciudades en un intento por dar respuesta a los retos crecientes de la guerra, convertida en un problema casi endémico en la región, permitieron estrechar lazos entre diferentes realidades. Todo esto conllevó profundas transformaciones en la comprensión de cuestiones centrales de la vida en comunidad, como la economía o el propio servicio de armas. No obstante, también tuvo un papel muy importante la gran movilidad transterritorial de personas y grupos humanos, en este caso de ingleses procedentes de las guerras entre los reinos de Francia e Inglaterra, quienes cruzaron los Alpes para ofertar sus servicios en Italia, llevando consigo nuevas ideas en materia táctica. ${ }^{10}$ Esto comportó desde cambios a nivel operativo, en lo referente al uso de la caballería, hasta la disponibilidad de nuevas posibilidades para el reclutamiento de personal militar profesional. Así pues, como vemos, las oportunidades para el reclutamiento y los cambios en la forma de hacer la guerra aparecen absolutamente determinados por el entorno a diversos niveles. ${ }^{11}$

10 La función de esos contactos e intercambios, tanto a nivel individual como entre instancias más elevadas, como vector de modernización de las formas de hacer la guerra es una constante a lo largo de la historia. Un ejemplo en BARA, X. (2012), "The Kishū Army and the Setting of the Prussian Model in Feudal Japan, 1860-1871". War in History, vol. 19:2, pp. 153-171.

11 Sobre el papel de Italia como teatro bélico, punto de encuentro y espacio crucial en el intercambio de experiencias, conocimientos militares y transformaciones en el modo de hacer la guerra a lo largo de los siglos XV y XVI es muy recomendable SHERER, I. (2017), Warriors for a Living: The Experience of the Spanish Infantry during the Italian Wars, 1494-1559. Leiden, Brill. 
En el caso estudiado por Rodríguez, los métodos de reclutamiento de la monarquía hispánica en la primera mitad del siglo XVII, aún queda más clara esa íntima relación de lo que acontece en la esfera internacional con el modo en que se experimenta la guerra a nivel local y regional. El tema es tanto más interesante si tenemos en cuenta que coincide con una época de reforzamiento y concentración del poder político y económico en detrimento de las clases populares, que hasta hacía no mucho habían podido acogerse a los mecanismos de protección legales consuetudinarios que imponían límites al poder real y señorial. ${ }^{12}$ Es justo en este periodo cuando se consolida de forma paulatina la construcción del estado como eje vertebrador de la organización político-social, algo que tendría su manifestación en las formas de hacer la guerra y de reclutar a los hombres necesarios para ello. El hecho de que los conflictos armados pasaran a ser una realidad mucho más distante y ajena, dado que casi siempre tenían lugar a bastantes centenares de kilómetros de los núcleos de reclutamiento, hacía que resultara más difícil atraer a los hombres hacia el servicio militar, especialmente en décadas de crisis económica y demográfica. De este modo, las relaciones entre el estado y las comunidades locales, con sus autoridades a la cabeza, se hicieron mucho más conflictivas, con los segundos tratando de preservar sus derechos y de limitar los efectos de la guerra sobre sus vecinos y sus maltrechas economías. Por tanto, atender a las necesidades crecientes en materia de efectivos humanos se hizo más difícil con la aparición de ese primer sistema-mundo, en palabras de Wallerstein, surgido al calor del primer expansionismo colonial europeo y el tendido de nuevas redes comerciales por todo el globo desde finales del siglo XV y principios del XVI. Este nuevo escenario motivaría un agudizamiento y enquistamiento de las luchas por la primacía político-militar y el control de los nuevos recursos económicos y comerciales.

Por lo que respecta a los voluntarios de ambos lados del Atlántico que acudieron en auxilio del Papado en la década de 1860, su objetivo no era otro que combatir los intentos del nuevo reino de Italia por expandir sus posesiones sobre los cada vez más mermados territorios pontificios, considerados parte inalienable de la nación italiana. Su aparición en es-

12 Una cuestión señalada para los casos de Castilla y Cataluña por ALGARRA BASCÓN, D. (2015): El comú català. La història dels que no surten a la història. Vilanova del Camí, Potlach. Sobre la creciente irrupción del estado sobre los asuntos locales en época moderna y con la guerra como pretexto véase ESPINO LÓPEZ, A. (2017): La Cerdaña en armas. Conflicto e identidad en la frontera catalana, 1637-1714. Lleida, Milenio. 
cena sólo tiene sentido al calor de ciertos factores exógenos, entre los cuales cabe destacar las crecientes dificultades de los estados católicos como Francia y Austria para intervenir a favor de la Santa Sede, en parte a causa de la presión pública. Dicha circunstancia obligó al Vaticano a explorar otras vías para obtener apoyos frente a las amenazas externas e internas, representadas en este caso por revolucionarios y nacionalistas italianos de los propios estados pontificios, algo que hacía más difícil confiar en la población autóctona de cara a levar un ejército propio. En esta situación, parecía razonable y deseable apelar a la cristiandad católica con el fin de recabar apoyos, sustentándose para ello en las redes de solidaridad y cooperación forjadas desde finales del siglo XVIII por la contrarrevolución en su lucha contra el liberalismo a ambos lados del Atlántico. ${ }^{13}$ La aparición en escena de estos voluntarios, unos 7.000 en total, fue presentada por la Iglesia católica como una muestra de sus apoyos por todo el orbe, a la par que eran elevados a la condición de nuevos caballeros cruzados, ejemplo de pureza y entrega que entroncaría con toda una tradición de lucha por la verdadera fe. Además, este fenómeno coincidió con un proceso mucho más profundo y relevante impulsado por el Vaticano, como fue la centralización y homogeneización del culto y sus figuras más significativas, sustituyendo los santos locales por los romanos e impulsando la figura del Papa, la figura de la Virgen o el Sagrado Corazón de Jesús.

Dejando a un lado el mundo mediterráneo, que ocupa un lugar preponderante en este trabajo colectivo, la secesión de la República de Biafra en Nigeria oriental, la sangrienta guerra civil subsiguiente y los métodos empleados para alistar a los varones de la comunidad igbo en las filas del ejército biafrano cobran forma y tienen sentido dentro de un escenario mucho más amplio. Tal y como nos muestra Daly, los sistemas de dominación imperial y explotación económica impuestos por las potencias europeas sobre sus colonias africanas fueron afines y conniventes entre sí en la protección e impulso de sus intereses compartidos. Pero no sólo eso, sino que además dieron lugar a ciertas culturas políticas y formas de proceder que tuvieron continuidad en el marco de la descolonización y en la forja de los

13 Unas redes que continuaron existiendo en las sucesivas décadas, dando lugar a diversos fenómenos de voluntariado asociados a conflictos en los que la contrarrevolución, o una de sus mutaciones aparecidas en el siglo XX como fue el fascismo, combatía al "fantasma revolucionario". Dos ejemplos en KEENE, J. (2001): Fighting for Franco. International Volunteers in Nationalist Spain during the Spanish Civil War, Nueva York, Hambledon Continuum; y BOHLER, J. y GERWARTH, R. (eds.) (2017): The Waffen-SS. A European History. Oxford. Oxford University Press. 
nuevos estados africanos, así como también en sus prácticas políticas. Eso ayudaría a explicar la marginación de la comunidad igbo, originaria de Nigeria suroriental, a manos primero de las autoridades coloniales británicas y, más adelante, de los diferentes gobiernos nigerianos. Una situación de por sí penosa agravada durante treinta años por su empleo como mano de obra reclutada a menudo de forma ilegal por agentes autóctonos y sometida a condiciones de semiesclavitud en las plantaciones españolas -más tarde guineanas- de Fernando Po. Ambas experiencias quedaron grabadas en la memoria del pueblo igbo. En este sentido, no es casual que muchos experimentaran una suerte de amargo déjà vu al encontrarse con las formas de reclutamiento practicadas por la República de Biafra en el marco de la guerra civil nigeriana (1967-1970), un paralelismo que se agudizó al calor de su experiencia bélica en el seno del ejército biafrano.

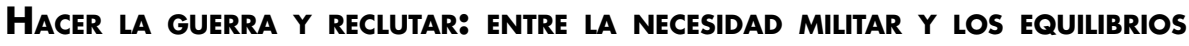 COMUNITARIOS}

En la actualidad existen debates en torno a las posibles causas del extendido uso de mercenarios griegos por parte de múltiples estados y agentes del Mediterráneo centro-oriental y el Creciente Fértil. Lo más probable es que haya que buscar la respuesta en los cambiantes modos de hacer la guerra, aunque tampoco se pueda descartar la lógica de la mímesis. Esto quiere decir que el uso de mercenarios por parte de un ejército acabaría motivando su empleo por parte de sus oponentes, simple y llanamente para no quedar en desventaja, tal y como ocurre también en la Italia septentrional del siglo XIV. Incluso hay quien sostiene que en el caso persa el reclutamiento de soldados a sueldo pudo venir determinado por la simple lógica de reunir al mayor número de hombres posible. Al fin y al cabo, se hace difícil pensar que el alto número de griegos presentes en ciertos ejércitos del Próximo Oriente durante la Antigüedad respondiera exclusivamente a su profesionalidad. En definitiva, lo que está fuera de toda duda es que este tipo de fenómenos respondieron a múltiples factores y motivaciones. Por un lado, el recurso de determinados poderes al reclutamiento de mercenarios pudo responder a los problemas para confiar en sus propios súbditos, dada la opresión a la que estaban sometidos. Tal pudo ser el caso de los tiranos griegos, los persas y sus sátrapas, que enfrentaron conflictos internos donde la contratación de soldados a sueldo era la forma más rentable, segura y eficaz de llevar a buen puerto sus luchas por el poder -o por la conservación de éste.

Sin embargo, no hay que olvidar otros posibles factores en el caso de las polis, donde el sentido cívico y la vocación de servicio que había caracte- 
rizado a una parte sustancial de sus ciudadanos décadas atrás bien pudo haber dado paso al agotamiento y la deslegitimación de la guerra, sobre todo al convertirse en el instrumento de ciertos intereses económicos. Dicha situación derivaría de inmediato en una profesionalización del ejército por medio de la contratación de mercenarios y el pago del servicio militar, una medida posibilitada por el creciente acuñamiento y circulación de moneda en la cuenca del Egeo. ${ }^{14}$ Paradójicamente, este escenario vino propiciado por el crecimiento de la flota ateniense al calor de las guerras y políticas expansionistas del siglo $\mathrm{V}$ a. $\mathrm{C}$. Al tener que reclutar a los remeros de los trirremes entre los estratos más bajos de la sociedad no quedó más remedio que pagarles por sus servicios, dado que no disponían de medios o fuentes de riqueza con los que mantener a sus familias durante su ausencia, algo que no ocurría con los hoplitas. No obstante, el enorme reto logístico y humano derivado de la expansión de la flota ateniense también implicaba la contratación del personal técnico especializado capaz de mantener esa flota en funcionamiento, tal y como explica Trundle. En este sentido, las exigencias de la guerra naval generaron un cambio en el modo de hacer y concebir la guerra, incluyendo las fuentes de reclutamiento, algo que también pudo estar relacionado con el deseo de evitar el empoderamiento y la reivindicación de derechos por parte de la ciudadanía en base a su participación en los conflictos. ${ }^{15} \mathrm{Al}$ fin y al cabo, no es casual que la época de mayor fortaleza de la democracia ateniense coincidiera con el periodo subsiguiente a los éxitos militares frente a los persas en las batallas navales

14 Salvando las distancias, podría establecerse un cierto paralelismo con la aparición de las modernas fuerzas armadas en las sociedades occidentales, donde el estado ha intentado hacer de la carrera militar un servicio público remunerado donde los soldados son funcionarios. Este proceso vino motivado en última instancia por el rechazo cada vez mayor de las guerras por parte de la opinión pública y la movilización de amplios sectores de la sociedad contra el servicio militar obligatorio.

15 No por nada, la relación entre participación bélica y empoderamiento político, por parte de todas las clases sociales pero de forma mucho más masiva a partir de la irrupción de los ejércitos formado mediante la levée en masse, siempre ha sido un elemento de transformación social. Véase, por ejemplo, HIPPLER, Th. (2006), "Conscription in the French Restoration: The 1818 Debate on Military Service". War in History, vol. 13:3, pp. 281-298. O, del mismo modo, la utilización de la participación en la guerra como forma de obtener aspiraciones políticas dentro de un contexto y una lógica de dominación colonial, recibiendo respuestas diversas por parte de los ejércitos de las metrópolis que se encontraban combatiendo, en este caso, en la Gran Guerra. Véase VARNAVA, A. (2015), "The Politics and Imperialism of Colonial and Foreign Volunteer Legions during the Great War: Comparing Proposals for Cypriot, Armenian and Jewish Legions". War in History, vol. 22:3, pp. 344-363. 
de Salamina (480 a. C.) y Mícala (479 a. C.), que se caracterizó por la hegemonía de la talasocracia ateniense sobre el mundo griego hasta el último tercio del siglo $\mathrm{V}$ a. $\mathrm{C}$.

El reclutamiento de auxiliares procedentes de comunidades poco romanizadas por parte del ejército romano también nos permite apuntar algunas reflexiones interesantes. Por lo que se refiere a Hispania, los orígenes de esta política datan de la Segunda Guerra Púnica (218 a. C.-201 a. C.). Como suele ocurrir con cualquier ejército empleado en guerras ofensivas y de ocupación, por tanto lejos del territorio, la comunidad y el poder al que representa, la colaboración del elemento autóctono se reveló vital para el esfuerzo militar romano en la Península lbérica, tanto por su conocimiento del terreno y las formas de combatir de sus coterráneos como por la potencial disponibilidad de nuevos efectivos. Los ejemplos de colaboracionismo, si se nos permite utilizar dicha etiqueta fuera del contexto de la Segunda Guerra Mundial, serían innumerables, tantos como conflictos.

En cualquier caso, parte del atractivo de servir en el ejército romano pudo venir dado por su particular forma de organizarse y operar en pequeñas unidades. De este modo no sólo quedaba garantizado un alto grado de maniobrabilidad en combate, sino que además se consiguió un principio básico en la historia de la guerra: la cohesión interna de la tropa, en este caso basada en la integración de combatientes de un mismo origen étnico dentro de las cohortes, algo que vino reforzado por la convivencia constante dentro de pequeños grupos primarios. ${ }^{16} \mathrm{He}$ aquí la clave del éxito militar romano, tanto en lo que se refiere al eficaz encuadramiento de efectivos muy diversos como al balance de victorias. De hecho, la política de destinos impuesta por el imperio respondió a una clara estrategia de pacificación de los territorios más conflictivos bajo su poder. Y es que las cohortes de auxiliares no sólo eran desplegadas lejos de sus lugares de origen, con lo cual un importante número de varones en edad militar eran desactivados en previsión de posibles revueltas, sino que además eran trasladados muy a menudo, según las necesidades, pero quizás también con objeto de evitar cualquier confraternización con los enemigos del imperio fruto de estancias prolongadas en un mismo escenario. Tampoco parece casual que entre sus principales misiones se encontrara sofocar revueltas y

16 Lo mismo puede decirse de los mercenarios griegos del siglo IV a.C., tal y como veremos. En este caso la voluntad de combate de los hombres se sostenía en la pertenencia a formaciones en los vínculos familiares o en los orígenes, caso de los arcadios. 
acabar con el bandidaje, consecuencias ambas de la asfixiante fiscalidad imperial y las destrucciones provocadas por las guerras de ocupación. ${ }^{17}$

Por su parte, las primeras cruzadas constituyen un laboratorio privilegiado para observar la evolución y los cambios en la forma de hacer la guerra, sobre todo por el esfuerzo adaptativo que las vicisitudes del arriesgado viaje por tierra impusieron sobre los cruzados, así como el contacto con un enemigo cuyos métodos de combate les eran desconocidos. Esto tiene una importancia crucial por el modo decisivo en que afectó a las políticas de reclutamiento, encuadramiento y organización de los ejércitos cruzados en Tierra Santa. Por lo que respecta al núcleo central de las fuerzas cruzadas, la caballería pesada, las exigencias y necesidades del extenuante trayecto obligaron a muchos a vender sus armas o a matar sus caballos para poder subsistir. Esto desembocó en el surgimiento de un abigarrado contingente donde no pocas veces hombres poderosos quedaron reducidos a la condición de tropas de infantería equipadas con armamento ligero capturado al enemigo. Pero no sólo eso. Al ser convocadas por el Papado como peregrinaje, las primeras cruzadas tuvieron un fuerte componente popular, arrastrando consigo a muchos civiles que se sumaron al importante número de sirvientes que los señores feudales llevaban consigo. Éstos, que por lo general no contaban con formación militar, a menudo supusieron un problema logístico muy grave -la primera cruzada debió de reunir un total de entre 50 y 60.000 personas-. Sin embargo, también acabaron ofreciendo soluciones en un contexto de gran necesidad como el que se vivió a lo largo del trayecto y a la llegada a Tierra Santa. Muchos de ellos se vieron obligados a combatir como infantería y tropas auxiliares, una situación que hubieron de acatar por las estrecheces del momento y porque los príncipes y señores, al mando de las expediciones, eran los únicos que podían garantizar el sustento. De esta forma apareció una nueva fuerza de combate donde los civiles sin experiencia previa acabaron revelándose como un elemento vital para sostener el esfuerzo de guerra cruzado, dada la importancia de la infantería para proteger la lenta y penosa preparación de las cargas de la caballería pesada, tan temidas por las fuerzas musulmanas. ${ }^{18}$

17 Una interesante visión sobre el fenómeno del bandidaje en época republicana e imperial en BLUMELL, L. H. (2012), "Beware of Bandits! Banditry and Land Travel in the Roman Empire". Journeys, vol. 8:1-2, pp. 1-20, que analiza los efectos de la presencia endémica de bandidos a lo largo y ancho del imperio y las políticas destinadas a acabar con ellos.

18 Un estudio que aborda en detalle la organización de las expediciones cruzadas y sus múltiples problemas en TYERMAN, Ch. (2016), Cómo organizar una cruzada. El trasfondo racional de las guerras de Dios. Barcelona, Crítica. 
No por nada, el problema que afectó de forma endémica a los estados cruzados en el Mediterráneo oriental fue la falta de efectivos para dotar ese núcleo central de sus ejércitos conformado por la caballería pesada. Esto impuso graves limitaciones a las fuerzas cristianas a la hora de operar, sobre todo por el miedo a que cada choque militar contra el enemigo pudiera ser decisivo y acabara con la destrucción de su precario control sobre Tierra Santa. Aún con todo, se idearon diferentes sistemas de organización y mantenimiento de los caballeros por parte de los príncipes, especialmente por medio del desembolso anual de una cantidad fija de dinero procedente del tributo pagado por las ciudades musulmanes sometidas al control de estos príncipes. Dada la gran circulación de moneda, mucho mayor que en Europa occidental, este sistema ofrecía muchas más garantías que la concesión de tierras con sus habitantes. Igualmente, muchos europeos de origen social dudoso encontraron oportunidades para prosperar. Por su parte, los cristianos autóctonos y otras comunidades opuestas al dominio selyúcida contribuyeron al esfuerzo de guerra de los cruzados sumándose a sus huestes como infantes o auxiliares, hasta el punto que algunos de ellos, miembros de las élites locales y regionales, se convirtieron en hombres de confianza de los nuevos soberanos y señores venidos de Europa occidental. Finalmente, las órdenes religiosas fundadas al calor del peregrinaje a Tierra Santa acabaron abriendo la puerta a la obtención de financiación, dado el gran número de propiedades que explotaban en Europa occidental, aportando también efectivos al esfuerzo de guerra. No obstante, el medio más eficaz para sumar nuevos hombres a los mermados contingentes cruzados era la convocatoria de nuevas cruzadas, que una y otra vez se encontraron con problemas similares a los de la primera. En este sentido, las dificultades de la travesía por tierra, a veces insalvables por el alto número de civiles, así como también los problemas para financiar las expediciones y atraer a un número suficiente de caballeros una vez se hicieron posibles los viajes por mar, condujeron a la destrucción de las fuerzas cristianas en Oriente Próximo.

En el ámbito militar suelen ser las derrotas militares las que propician los cambios más importantes en el modo de preparar y hacer la guerra. Eso es lo que ocurrió en la Florencia de los siglos XIII y XIV, especialmente fruto de su derrota contra Siena en la batalla de Montaperti (1260), donde las fuerzas enemigas contaban con un nutrido contingente de soldados a caballo de origen alemán. A partir de ese momento se empezó a pasar de un modelo de ejército compuesto de forma casi exclusiva por ciudadanos, con un número muy bajo de mercenarios a caballo de origen italiano, a otro donde los jinetes a sueldo de origen transalpino tendrían un papel cada vez más importante, muy influenciados por el modelo del archienemigo sie- 
nés. Sin embargo, Caferro señala un par de cuestiones que deberían llevar a reconsiderar el modo de hacer la guerra y las políticas de reclutamiento en la Italia septentrional de la época. Por un lado, como es natural la leva de los ejércitos se llevaba a cabo de acuerdo con la planificación del tipo de conflicto que se iba a librar y el terreno en que tendría lugar, haciendo particular hincapié en los especialistas necesarios para ello. En este sentido, el elemento autóctono seguía teniendo una importancia fundamental en la composición de los ejércitos florentinos por ser el que mejor conocimiento tenía del enemigo y de las particularidades del entorno. Por otro lado, la infantería siguió siendo la base de las fuerzas comunales, sobre todo porque el tipo de guerra más usual era de desgaste, lenta y recurrente, basada en los sitios o asedios y rehusando el combate en campo abierto. Esta realidad ha recibido poca atención por parte de los historiadores, lo cual ha redundado en favor de la caballería, y tiene mucho que ver con el mayor relieve que se les otorga a éstos en los textos de los cronistas, pero también con el mayor brillo y atracción que ejercen sus acciones sobre los contemporáneos. ${ }^{19}$

Así pues, lo que nos revela el modelo florentino es que los cambios en el modo de hacer la guerra suelen ser paulatinos, porque nada surge ex nihilo, es decir, las transformaciones de un modelo militar requieren del personal y los conocimientos adecuados para llevarlos a cabo de manera eficaz, y eso requiere tiempo. Es por eso que a pesar de los cambios de gobierno las autoridades comunales florentinas no sólo no renunciaron a la base sobre la que se sustentaban sus ejércitos, una infantería acostumbrada a operar en el terreno y al tipo de conflicto más usual a la región, sino que además combinaron diferentes unidades y formas de reclutamiento por lo que respecta a los mercenarios a caballo. Bien es cierto que fruto de la influencia de los jinetes ingleses procedentes de la Guerra de los Cien Años hubo un cambio en la organización y despliegue de la caballería, que pasó de reunirse en estandartes a hacerlo en lanzas. Sin embargo, ambas convivieron hasta que los jinetes italianos se adaptaron a ese nuevo tipo

19 Nada nuevo si atendemos al impacto mediático de los aviadores y los tanquistas de la Wehrmacht durante la Segunda Guerra Mundial, a pesar de que el alemán era un ejército esencialmente hipomóvil donde el peso de la guerra descansaba sobre los hombros de la infantería. Esto es señalado por el excelente trabajo de RUTHERFORD, J. (2014), Combat and Genocide on the Eastern Front: German Infantry's War, 1941-1944. Cambridge, Cambridge University Press. Quizás, hacer hincapié en las armas más modernas contribuía y contribuye a proyectar una visión más amable y aceptable de la guerra, por su dinamismo y porque se supone que su acción ahorra esfuerzos y muertes. 
de unidad que giraría en torno a un caballero con armamento pesado apoyado por un escudero y un asistente-aprendiz. A ello había que sumar el reclutamiento de auxiliares que conservaban sus formas de combatir y organizarse, como los arqueros húngaros a caballo. Por tanto, es cierto que el prolongado conflicto entre los reinos de Francia e Inglaterra proporcionó nuevas oportunidades de reclutamiento y dio lugar a ciertos cambios, sobre todo con la irrupción de grandes bandas o compañías de mercenarios a caballo dispuestos a prestar sus servicios en la península itálica. ${ }^{20}$ No obstante, también es verdad que se mantuvo el modelo y la continuidad de un núcleo duro de hombres al servicio de Florencia, lo cual es una muestra de su adaptación al tipo de conflicto que se libraba en la región.

Está claro que las políticas de reclutamiento varían cuando las necesidades militares aumentan o la fuente de la que se ha nutrido un ejército dado se agota. Eso es exactamente lo que le ocurrió a la monarquía hispánica en la Castilla del siglo XVII, su principal caladero de voluntarios para los tercios a lo largo de toda la anterior centuria. Fruto de las levas constantes y la crisis demográfica propiciada por las epidemias, las hambrunas y la crisis económica, el sistema de reclutamiento se mostró incapaz de responder a la necesidad siempre creciente de efectivos con los que nutrir sus ejércitos. Por si fuera poco, la naturaleza voluntaria del servicio militar, dentro de un proceso hasta entonces centralizado y sometido a un control directo de la administración, hacía imposible cualquier tipo de planificación del esfuerzo bélico. En este sentido, lo que se ideó fue un sistema de conscripción encubierto capaz de atender a los múltiples frentes abiertos de la monarquía fuera de la Península lbérica. El objetivo era conseguir poner al máximo de su capacidad el sistema de presidios o guarniciones defensivas situadas en los puntos más sensibles de los territorios peninsulares, Canarias y las

20 De forma constante, los conflictos armados representan un escenario de transformación en el que se alumbran nuevas formas de hacer y afrontar la guerra, producto de la naturaleza y tipología de los combates y movilizaciones que se llevan a cabo. Así, las guerras constituyen un vector de aceleración del tiempo histórico en lo que a la evolución del universo bélico se refiere. Un ejemplo de esto lo podemos ver en el caso de las Guerras Napoleónicas, donde la aparición de ejércitos de masas más móviles y destructivos condujo a una mayor incidencia, más brutal, de la guerra sobre la población civil. Véase HEWITSON, M. (2013), "Princes" Wars, Wars of the People, or Total War? Mass Armies and the Question of a Military Revolution in Germany, 1792-1815". War in History, vol. 20:4, pp. 452-490. Respecto a la teoría de la Revolución Militar véase, desde una perspectiva global, JACOB, F. y VISONI-ALONZO, G. (2014), "The Theory of a Military Revolution: Global, Numerous, Endless?". Revista Universitaria de Historia Militar, vol. 3:6, pp. 189-204. 
posesiones norteafricanas al otro lado del Estrecho de Gibraltar, habiendo de sumar en total 18.000 hombres. Para ello se impulsó un sistema de cuotas repartidas de forma equilibrada por provincias, que a su vez debían ser repartidas de manera proporcional entre pueblos, ciudades y estados señoriales. La anuencia de todas las autoridades competentes se consiguió bajo diferentes pretextos: los reclutas serían desplegados en territorios del reino garantizando su defensa, dicha política evitaría nuevas levas y el rey se haría cargo del mantenimiento de las tropas. Sin embargo, muy pronto se pusieron de manifiesto todo un conjunto de dificultades y contratiempos que no sólo comprometieron el nuevo sistema de reclutamiento, sino que sometieron las costuras del tejido social del reino a una prueba durísima, revelando además los graves problemas estructurales que aquejaban a la monarquía. ${ }^{21}$

Así pues, a pesar de que en primera instancia se cumplieron los objetivos numéricos, hubo un altísimo número de suicidios y deserciones derivado de la incapacidad de las estructuras del estado para llevar a cabo una concentración tan rápida y masiva de efectivos en condiciones dignas y garantizando su subsistencia. En las propias guarniciones destinadas a albergar a los soldados se carecía de la infraestructura necesaria para dar cabida a los hombres recién llegados, un problema agravado por la infradotación de medios económicos que sufrían, lo cual sometía a sus moradores a unas condiciones de vida infrahumanas. Además, el estado físico y la salud de muchos de los hombres reclutados, por lo general conscriptos procedentes de las clases populares, a menudo hacía que no fueran aptos para el servicio militar, lo cual aumentaba los costes derivados de su devolución a sus lugares de origen. De hecho, el mantenimiento de la tropa acabó quedando a cargo de una empobrecida población civil, gravada con impuestos sobre el consumo, y de las ya de por sí mermadas arcas municipales. A todo ello había que sumar la corrupción endémica de las autoridades responsables de las distintas etapas del proceso de

21 La consideración del Estado como un ente más allá de los institucional es lo que permite entender los desgarros que procesos como el de la recluta masiva producían en las sociedades sobre las que se implementaban. De esta forma, la movilización bélica no estaba exenta de sus propios riesgos en la medida en que, como veíamos, podía poner de manifiesto la existencia de severos problemas de índole social, generando inestabilidad añadida a la de propia guerra. Sea como fuere, lo que está claro es que procesos tan invasivos social y comunitariamente como la conscripción acaban por transformar al propio estado y la sociedad que los implementaba y sufría respectivamente. Véase un ejemplo para la Gran Guerra en PURSEIGLE, Pierre (2014), "La Primera Guerra Mundial y las transformaciones del Estado". Revista Universitaria de Historia Militar, vol. 3:5, pp. 165-186. 
reclutamiento, sometiendo a chantaje a no pocos varones en edad militar y ofreciéndoles la libertad a cambio de un pago. Finalmente, la lógica en la que se había basado el repartimiento de cupos dentro de las provincias respondía a múltiples privilegios, intereses cruzados y equilibrios de poder en el seno de la monarquía. Tal era la situación que al imponerse el llamado sistema del $1 \%$, según el cual se había de levar a uno de cien vecinos de cada población, los corregidores aprovecharon para deshacerse de aquellos individuos considerados socialmente indeseables, de manera que el reclutamiento afectara lo menos posible al tejido social y económico comunitario. No obstante, en la práctica siguieron conviviendo múltiples sistemas y agentes de reclutamiento que se solapaban entre sí y pululaban por todo el reino, provocando a su paso un tremendo caos, malestar social y protestas, impulsando fenómenos como el bandolerismo.

Si ya en el siglo XVII la guerra parecía entrar de forma paulatina en escenarios ignotos con la aparición de las primeras reclutas obligatorias, la irrupción de la modernidad conllevaría el surgimiento de nuevas concepciones de la guerra y el combatiente, así como de su legitimidad. Se trata de cuestiones fundamentales que ya habían hecho aparición en la Guerra de la Independencia de los Estados Unidos (1775-1783), donde la utilización de miles de mercenarios alemanes por parte del ejército británico fue condenada como algo execrable por los revolucionarios norteamericanos en su misma Declaración de Independencia (1776). Al fin y al cabo, dicha política de reclutamiento estaba en contra de una nueva idea de libertad construida sobre la existencia de derechos y obligaciones, según la cual la defensa de la familia y la propiedad privada correspondía a los propios ciudadanos en armas. Dentro de lo que no dejaba de ser una lucha por la legitimidad, su desprecio frente al modo de hacer la guerra del imperio radicaba en el hecho de que aquellos soldados a sueldo no eran una parte original de los bandos en conflicto, de ahí que no tuviera sentido su presencia más allá de la naturaleza despótica del poder británico. ${ }^{22}$ Esta fue una

22 KREBS, D. (2013), "Desperate for Soldiers: The Recruitment of German Prisoners of War during the American War of Independence, 1776-83". En ARIELLI, N. y COLLINS, B. (eds.), Transnational Soldiers: Foreign Military Enlistment in the Modern Era. Basingstoke, Macmillan, pp. 15-31, esp. 15-17. Los combatientes procedentes de diferentes principados alemanes eran criticados por «carecer de principios, así como también de honor, religión, espíritu público, consideración por la libertad o amor por la patria» (p. 17). Un caso similar se observa en el uso de voluntarios holandeses para restaurar la autoridad colonial en Indonesia tras el fin de la Segunda Guerra Mundial. Estos eran vistos como invasores y no como libertadores por parte 
de las cuestiones que a ojos de la opinión pública italiana acabaría justificando la guerra contra el Papado: el empleo de voluntarios extranjeros, los llamados zuaves, que serían reducidos a la condición de mercenarios. Sólo la soberanía popular-cuando así lo expresara y decidiera por los cauces políticos correspondientes- y la nación en armas estaban legitimadas para hacer la guerra en defensa de su propia integridad, hasta el punto que la suya era la única forma de pertenencia auténtica, y su sacrificio el más puro y noble. Por el contrario, a ojos del Papado y la Iglesia la lucha de los zuaves era una clara muestra de su poder de convocatoria, así como también de la pureza de la fe católica y los ideales inherentes a ella. En última instancia, las luchas por capitalizar o deslegitimar la experiencia de los voluntarios al servicio de la Santa Sede formaban parte de un conflicto político-cultural de largo alcance, uno donde dos cosmovisiones contrapuestas de la realidad pugnaban por establecer los principios ordenadores de la política y la vida en comunidad.

Aunque el papel de los zuaves fue bastante irrelevante en el ámbito militar, no es menos cierto que su proceso de reclutamiento revela algunas cuestiones de gran interés. En primer lugar, nos pone ante el papel clave de las redes de sociabilidad e institucionales de la Iglesia, que mostraron su vitalidad, así como la importancia de los lazos solidarios forjados en el ámbito de la contrarrevolución. Pero no sólo eso, dicho proceso también nos permite observar hasta qué punto los vínculos familiares y comunitarios se revelan como un elemento esencial en cualquier fenómeno de voluntariado, donde se actúa no sólo por afinidad y amistad, sino también por imitación y en disputa por el prestigio frente a los propios convecinos. Esto explica que un pequeño pueblo de 2.000 habitantes del Brabante Septentrional, en los Países Bajos, contribuyera a la iniciativa con 20 voluntarios, tal y como explica Sarlin. También tendrían importancia las jerarquías sociales y las relaciones verticales, con algunos caciques locales ocupando un lugar central a la hora de incentivar los reclutamientos. ${ }^{23}$ Al fin y al cabo, entre los zuaves encontramos individuos de todas las clases sociales, por mucho que los costes del viaje y el equipamiento sólo pudieran ser costeados por

del pueblo indonesio, algo que no respondía a cómo esos voluntarios percibían su labor allí. Esa disonancia en las formas de concebir la guerra coadyuvó en la comisión de atrocidades por parte de las fuerzas metropolitanas, muchas de las cuales, paradójicamente, habían combatido en la resistencia frente a la ocupación nazi. Véase ROMIJN, P. (2014), "Learning on 'the job': Dutch war volunteers entering the Indonesian war of independence, 1945-46", en LUTTIKHUIS, B. y MOSES, A.D. (eds.), Colonial Counterinsurgency and Mass Violence. The Dutch Empire in Indonesia. Londres, Routledge, pp. 91-110. 
aquéllos que contaran con ciertos recursos económicos. Y es que, en un interesante ejercicio de autogestión y organización, algunas comunidades de fieles realizaron colectas para permitir que los varones de las clases populares pudieran expresar su fe tomando las armas en favor del Papado. En última instancia, se trataba de presentar aquella iniciativa como la comunión del pueblo en torno a la fe, al tiempo que el propio catolicismo aparecía como una salida frente al conflicto de clases. Sea como fuere, como ocurre en todos los fenómenos de voluntariado de guerra, un descenso sobre la realidad de los individuos que toman parte en ellos nos plantea un panorama mucho más complejo donde confluyen motivaciones de todo tipo y donde los incentivos de tipo social y económico no siempre estarían reñidos con los ideales. ${ }^{24}$

Finalmente, existen indicios para pensar que las prácticas de dominio y explotación practicadas por las potencias europeas en sus posesiones ultramarinas condicionaron las propias políticas de reclutamiento en las guerras poscoloniales. Esto bien pudo tener que ver con el hecho de que ciertas élites locales fueron conniventes y participaron como correas de transmisión de las autoridades coloniales, integradas dentro del aparato administrativo y de gobierno como parte de una política imperialista basada en la lógica del divide et impera. Sin duda alguna, el desprecio por la vida y el uso de la marginación político-social de determinados grupos humanos o del conflicto interno como herramientas del poder, algo habitual en contextos coloniales, nos ayudan a explicar la desempatía y displicencia con que se implementaron ciertas políticas militares y formas de hacer la guerra en el marco poscolonial. Así se entiende que para muchos igbos fuera tan tenue

23 Algo similar se puede argumentar de la movilización voluntaria que se produjo en los primeros días tras el golpe del 17 de julio de 1936 que dio paso a la Guerra Civil Española, fundamentalmente en las provincias vascas y navarra donde las redes caciquiles y de patronazgo existentes en el mundo rural ejercieron de mecanismos de movilización y alistamiento en las filas sublevadas de muchos jóvenes de la zona. Véanse UGARTE TELLERÍA, Javier (1989), La Nueva Covadonga insurgente: orígenes sociales y culturales de la sublevación de 1936 en Navarra y el País Vasco. Madrid, Biblioteca Nueva; y RUIZ LLANO, Germán (2016), Álava, una provincia en pie de guerra. Bilbao, Ediciones Beta III Milenio.

24 Esta misma disonancia entre la imagen de los voluntarios, de cualquier conflicto, construida por el relato propagandístico y su realidad social, cultural e ideológica es una constante a lo largo de las guerras de la Humanidad. Un ejemplo para el caso de la Gran Guerra en WATSON, A. (2005), "«For Kaiser and Reich»: The Identity and Fate of the German Volunteers, 1914-1918". War in History, vol. 12:1, pp. 44-74. 
la línea entre su experiencia como trabajadores forzosos en Bioko, como súbditos británicos primero y ciudadanos nigerianos después y, por último, como conscriptos en el ejército biafrano. En cualquier caso, ya hemos visto que la aplicación de métodos de reclutamiento arbitrarios y formas de encuadramiento inhumanas no dependen tanto de herencias del pasado como de la naturaleza del poder que los implementa o de las propias necesidades y urgencias militares de cada momento. Buena muestra de ello, ya lo hemos visto, es el caso de la monarquía hispánica en el siglo XVII, que guarda paralelismos interesantes con las políticas de conscripción seguidas por la República de Biafra en la Guerra Civil Nigeriana.

En este último caso, la contienda estuvo muy marcada por los problemas de las autoridades biafranas para financiarse $y$, por tanto, para hacer frente al ejército nigeriano con una fuerza militar de garantías. De hecho, la cuestión de la financiación se revela como central en todos los casos de estudio y resulta clave en el éxito o fracaso de las políticas de reclutamiento y encuadramiento, determinando también las formas de hacer la guerra. Es por eso que el estallido del conflicto no tardó en sumir todo el territorio bajo el control efectivo de la República de Biafra en un estado de excepción permanente que se extendería a lo largo de tres largos años. Esto implicaba que la conscripción o las exacciones destinadas al esfuerzo bélico no estuvieron sujetas en ningún momento a controles legales, por más que existiera legislación a tal efecto, ni tampoco a procesos de negociación entre el estado y las comunidades locales, algo que sí observamos en otros casos. La ausencia de cualquier tipo de racionalidad en la movilización de recursos y efectivos humanos acabó por dislocar y llevar al borde de la destrucción a unas comunidades locales ya de por sí muy castigas por el conflicto a todos los niveles. Pero los terribles sufrimientos de la población civil no sólo tuvieron que ver con la incertidumbre y la arbitrariedad reinantes en el lado biafrano, donde un sinfín de agentes recaudadores y de reclutamiento pululaban sobre el terreno. A ello se unía también la utilización de la violación, el bombardeo contra población civil y las matanzas colectivas como armas de guerra por parte del ejército nigeriano, que además impuso un bloqueo sobre el territorio biafrano al perder éste su salida al mar. La consecuencia más visible de las políticas bélicas impulsadas por ambos bandos fueron las hambrunas y epidemias, que costaron la vida de hasta tres millones de civiles y que condenaron a centenares de miles a convertirse en refugiados, lejos de sus hogares. Por lo demás, no fueron mucho mejores las condiciones de vida experimentadas por los hombres encuadrados en el ejército biafrano, que en muchos casos eran individuos incapacitados para el servicio militar a causa de su edad y de problemas físicos o de salud mental. Por si esto fuera poco, la falta de medios impli- 
caba muy a menudo que los combatientes marcharan al frente sin las más mínimas garantías para su supervivencia, al no disponer del equipo ni del armamento necesarios, por no hablar de la ausencia total de cualquier forma de adiestramiento. Tal era la situación que el servicio militar podía quedar reducido al cumplimiento de trabajos forzados relacionados con el esfuerzo de guerra.

\section{EL SERVICIO MILITAR, LOS CÓDIGOS DE HONOR Y LAS CONCEPCIONES DE LA MASCU- LINIDAD A LO LARGO DEL TIEMPO}

La principal conclusión que extraemos del trabajo colectivo representado en este dossier apunta a la necesidad de hacer un esfuerzo por trasladarnos a diferentes épocas y marcos de referencia, un ejercicio sano para cualquier estudioso de la guerra y en general para cualquier historiador. Un esfuerzo de este tipo nos permite observar hasta qué punto aquello que suponemos extraordinario para nuestro ámbito de estudio puede no serlo tanto, sino más bien responder a ciertas continuidades de la naturaleza humana y su forma de relacionarse con la comunidad y con lo que es ajeno a ésta.

Por ejemplo, no deja de ser revelador que en la relación del ser humano con la guerra siempre resulte tan compleja la idea del soldado a sueldo. Dadas las connotaciones negativas inherentes a dicho concepto, en todas las épocas y culturas donde los mercenarios han tenido una presencia importante se han empleado subterfugios y fórmulas para intentar conferir un halo de respetabilidad y legitimidad a aquellos que combatían a cambio de una remuneración. Tal es el caso de la Grecia clásica durante el siglo IV a. C., donde dicha forma de servicio militar se fundamentaría sobre las amistades aristocráticas ritualizadas, correa de transmisión del reclutamiento, y una idea de la libertad basada en la no dependencia y en la disposición de los medios para hacer la guerra. ${ }^{25}$ Por tanto, más allá de las críticas, el vínculo del soldado a sueldo con su empleador se basaría en la existencia de determinados códigos de honor y fidelidad, los cuales

25 Una idea de la libertad muy similar tuvo un lugar clave entre los pueblos germánicos que invadieron el imperio romano, y se mantendría a través de la figura del ius sequellae o Heerfolge hasta la imposición del feudalismo y los vínculos basados en el vasallaje. Véase KEEGAN, J. (2014), Historia de la guerra. Madrid, Turner [1993], p. 316. 
variarían de una cultura a otra y también con el paso del tiempo, quizás hasta la irrupción del capitalismo más salvaje donde es posible que ya no sean tan necesarios los vínculos ritualizados. ${ }^{26}$

De hecho, aquí se pondría de manifiesto algo tan importante para el estudio de la guerra como los diferentes modelos de masculinidad. Y esto vale tanto para los griegos del siglo IV a. C. como para los alemanes reclutados por el ejército británico para su guerra contra las Trece Colonias, quienes se verían a sí mismos "como soldados honorables y profesionales en defensa de sus soberanos y del rey Jorge $11 \| » .{ }^{27}$ De hecho, el vínculo entre las formas de masculinidad dominantes en cada momento y el servicio militar ha sido una constante a lo largo de la historia, convertido éste en la forma más extrema de valentía y actuando como un instrumento de jerarquización social. En este sentido, la valía del individuo sería determinada por su posición dentro del ejército y su importancia en el curso de los combates, lo cual iría en función de la clase social y, por tanto, de las posibilidades de acceso a las posiciones de mando o a las unidades de élite. No por nada son éstas las que hasta hace muy poco han tenido un mayor peso en las crónicas y los relatos hegemónicos de la guerra, que no dejan de ser una forma más de sancionar un orden social vigente. Esta situación no varió hasta la irrupción de las guerras totales y las sociedades de masas y de la información, que no obstante han seguido situando al soldado de a pie en una posición subsidiaria y subalterna. A nivel historiográfico esto ha sido contestado por unos estudios de la guerra que han desbordado por completo el exiguo y pobre marco de análisis ofrecido por la historia militar tradicional durante muchos años. Así pues, esperamos que este dossier pueda contribuir a seguir impulsando ese necesario cambio de paradigma en la comprensión del mundo militar y la historia de los conflictos.

26 Un caso de estudio interesante es el de la Legión Extranjera francesa, donde tienen gran importancia los códigos de honor, los ritos de paso, las ceremonias y la identidad corporativa dentro de cada unidad. Véase KOLLER, C. (2013), Die Fremdenlegion. Kolonialismus, Söldnertum, Gewalt, 183 1-1962. Paderborn, Ferdinand Schöningh, pp. 79-115.

27 KREBS, "Desperate for Soldier", p. 26. 


\title{
HIRING MERCENARIES IN THE CLASSICAL GREEK WORLD. CAUSES AND OUTCOMES?
}

\section{LA CONTRATACIÓN DE MERCENARIOS EN LA GRECIA CLÁSICA. ¿CAUSAS Y CONSECUENCIAS?}

\author{
MatTHew TRUndle \\ The University of Auckland
}

\begin{abstract}
This paper explores the reasons why employers hired mercenaries in the Classical Greek World of the fifth and fourth century BCE. It discusses the rise of mercenary activity against the backdrop of socio-economic and political phenomena that created the conditions for a large number of men to find service overseas especially in the Persian Empire. Mercenary service in an ancient Greek context is complicated by traditions that valued heroic service of aristocrats and rulers abroad in the past, for example as extolled in the poems of Homer, and that 'mercenary' is perhaps not an accurate label for men serving others abroad. Ultimately, the paper affirms the demand driven nature of such service and the wars of the fourth century in which Greeks served as products of great events extraneous to the mercenary service itself.
\end{abstract}

Keywords: Classical Greek, mercenary, Misthophoros, Xenos, Persian Empire.

\section{RESUMEN}

Este artículo explora las razones por las que los distintos empleadores contrataban los servicios de mercenarios en la Grecia Clásica durante los siglos $\mathrm{V}$ y IV a.C. Analiza el aumento de la actividad mercenaria teniendo como telón de fondo los fenómenos de índole política y socioeconómica que crearon las condiciones para que un gran número de hombres pudieran encontrar empleos como tal en el extranjero, especialmente en el Imperio Persa. El mercenariado en el contexto Antigua Grecia es una cuestión complejizada por la existencia de tradiciones que valoraban servir heroicamente a aristócratas y gobernantes extranjeros, como por ejemplo se ensalzaba en los poemas de Homero, algo para lo que el término "mercenario" no sería quizá una definición adecuada. En última instancia, el presente artículo afirma que el mercenariado estaba claramente impulsado y respondía a una demanda existente que se tradujo en la presencia de griegos en buena parte de las guerras del siglo IV a.C., siendo protagonistas de eventos que iban más allá del propio servicio mercenario.

Palabras clave: Grecia Clásica, mercenario, Misthophoros, Xenos, Imperio Persa. 


\section{RESUM}

\section{La contractació de mercenaris en la Grècia Clàssica. ¿Causes i conseqüències?}

Aquest article explora les raons per les quals els diferents ocupadors contractaven els serveis de mercenaris en la Grècia Clàssica durant els segles V i IV a. de C. Analitza l'augment de l'activitat mercenària tenint com a teló de fons els fenòmens d'índole política i socioeconòmica que van crear les condicions per a que un gran nombre d'homes poguessin trobar ocupacions com a tal a l'estranger, especialment en l'Imperi Persa. El mercenariat en el context Antiga Grècia és una qüestió complexa per l'existència de tradicions que valoraven servir heroicament a aristòcrates i governants estrangers, com per exemple s'enaltia en els poemes d'Homer, cosa per a la que el terme "mercenari" no seria potser una definició adequada. En última instància, el present article afirma que el mercenariat estava clarament impulsat i responia a una demanda existent que es va traduir en la presència de grecs en bona part de les guerres del segle IV a. de C., sent protagonistes d'esdeveniments que anaven més enllà del propi servei mercenari. Paraules clau: Grècia Clàssica, mercenari, Misthophoros, Xenos, Imperi Persa. 
This paper explores the reasons why employers hire mercenaries through a specific analysis of ancient Greek poleis and their Mediterranean context in the later Classical period. The ancient Greeks are particularly interesting because they idealized the connection between citizenship and military service. ' Even though many who resided within Greek communities and who were not full citizens fought for the armies of those Greek states in some capacity or other, the Greeks still reified the connection between bearing arms and citizenship. ${ }^{2}$ Most Greek citizens were potential if not actual soldiers for their own cities and many who served did so as higher status heavily armed infantry men (hoplitai - hoplites) the cost of whose equipped excluded the poor and so cemented their status. They also appear to have served for others in great numbers and very willingly outside of their communities in the latter fifth and fourth centuries BCE as opportunities for military service and remuneration presented themselves. ${ }^{3}$ The classical Greek world represents an important period for understanding mercenary activity because of the scale of service in the period and the intricate socio-political relationships it and mercenary relationships demonstrated.

By the later classical age (431-323 BCE) many Greek citizens served other poleis on the mainland and non-Greek rulers overseas especially the Persian Kings in increasingly great numbers. ${ }^{4}$ There was essentially an explosion in

1 On hoplites and citizenship see van WEES (2004); HANSON (1995); PRITCHARD (2010: 1-62); RIDLEY (1979: 508-548); and CROWLEY (2013).

2 On the status and nature of non-hoplite troop types, for example, see SPENCE (2010: 111 138) on cavalry, TRUNDLE (2010: 139-160) on light troops.

3 On Greek mercenary service generally, see PARKE (1933); GRIFFITH (1935); AYMARD (1967: 487-498); SEIBT (1977); MILLER (1984: 153-160); MARINOVIC (1988); BETTALLI (1995); TRUNDLE (2004); GÓMEZ CASTRO (2012); TRUNDLE (2013: 407-441); and BETTALLI (2013).

4 On Greeks in the mercenary explosion of the later fifth and fourth century BCE see PARKE (1933); GRIFFITH (1935); MILLER (1984: 153-160); MARINOVIC (1988); AYMARD (1967: 487-498); ROY (1967: 292-323); WEISKOPF (1989); FIELDS (1994: 95-113); BETTALLI (1995); FIELDS (2001: 102-38); TRUNDLE (2004) and (2013: 407-441); BETTALLI (2013: 71-109, 147-195, 254-316). 
the numbers of Greek mercenaries in the fourth century BCE. Thus, over ten thousand mainland Greek hoplites served with Cyrus the Younger on his failed expedition against his brother the Great King in $401 \mathrm{BCE}$, several tens of thousands then found service on either side of Persia's attempts to recover Egypt in the 380s, 360s and late 340s, and several thousand also served Satraps and the Great King in the Great Satraps' Revolt of the 360s BCE. Finally, perhaps as many as 50,000 Greeks fought for the Great King of Persia against Alexander's invasion of the Empire in the 330s BCE. It is also possible, indeed likely, that Greeks were not the only mercenaries in service in this period. Thanks however to our Greek sources, we are particularly well informed about their numbers and their nature in the later Classical period.

Many factors, including political, social, demographic, and economic causes contributed to this 'explosion', not to mention military reasons why Persian Kings, their governors, and certain states employed outsiders on the battlefield. That all stated, I argued in my book Greek Mercenaries that increased and then major demand for military personnel lay behind most mercenary activity in the later classical age and that the political chaos and internecine wars of the period explained the rise in mercenary numbers, rather than supply driven by wars on the Greek mainland making men available for service through a combination of poverty and greed. ${ }^{5}$ This paper, therefore, explores the potential causes of mercenary activity through the lens of this fourth century mercenary flow in light of recent ideas with new analyses alongside recent discussions of our ancient evidence.

Many have argued that supply of soldiers available and willing to serve drove mercenary service beyond the mainland Greek states and stoked the explosion of mercenary numbers in the later Classical Period. ${ }^{6}$ Thus, the long drawn out Peloponnesian War produced a generation of Greek citizens trained and used to fighting for a living who then became 'mercenaries', for want of a better term, fighting for others. ${ }^{7}$ Similarly, the poverty of certain regions in the Greek world that provided disproportionately large numbers of mercenaries suggest that supply of available troops from these areas drove mercenary service. The best example of this supply comes from

5 TRUNDLE (2004: 44-79), specifically see 54-62 (supply); $63-68$ (attractions); $70-72$ (political considerations); and $72-79$ (demand).

6 MILLER (1984: 153); PARKE (1933: 228-230); MCKECHNIE (1989: 22-29); CARTLEDGE (1987: 315).

7 On the Peloponnesian Wars as a stimulus for mercenary service see PARKE (1933: 228); MILLER (1984: 153-160); and BETTALLI (2013: 51-69). 
the cities of Arcadia in the central Peloponnese. ${ }^{8}$ Worth noting, however, is perhaps that not all Arcadian mercenary service emanated from poverty. James Roy paints a more optimistic vision of Arcadia as more than simply a mountainous and inhospitable full of land of 'acorn-eaters' as other Greeks styled the Arcadians. ${ }^{9}$ Arcadians served prolifically with Cyrus the Younger in the Anabasis campaign making up a contingent of 4,000 men, a full third of the Greek forces. Greek states were not always able to provide for all their citizens adequately. Small wonder that we can find plenty of examples of men willing to follow others to seek service abroad. At the same time, Greek states were often powerless to control the movement and actions of their people. Two incidents from the fourth century BCE illustrate the limits of Athenian state power alongside the potential rogue military actions of Athenian citizens. The first, found in the corpus of legal speeches attributed to Isaeus concerns an Athenian called Macartatus. ${ }^{10}$ This Macartatus sold his land and bought and equipped a trireme with which he sailed to Crete, presumably on a plundering expedition. He almost started a war between Athens and Sparta. Fortunately for interstate relations he and his ship sank before matters could get out of control. The second incident comes in the form of an inscription seeking to prohibit Athenians from crossing the border to take military service in Boeotia and specifically then against Eretria, an Athenian ally. This decree discussed and translated by Toogood and dated to 357/6 BCE states that 'If anyone from henceforth attacks Eretria or any other of the allied poleis, whether he is from Athens or from one of the Athenians' allies, he is to be condemned to death and his property is to become the state's and a tithe is to be given to the goddess'. ${ }^{11}$

Both incidents cited above illustrate the loose nature of Athenian civic responsibility. On the one hand, individuals strove to better their circumstances, and that of their family, economically and socially through service with others, while on the other the state balanced its duty to its people with a finite resource base with which to redistribute a community's wealth. Nationalism and national identity, if we can apply such terminology, could not transcend the economic needs of the citizens of any Greek polis. Thus,

8 On Arcadian mercenaries see HERMIPPUS 63.18; ARISTOPHANES, Knights 795-800; XENOPHON, Anabasis 1.1.6 and especially XENOPHON, Hellenica 7.1.23; GRIFFITH (1935: 237-238); COOPER (1978 and 1996, vol. 1); FIELDS (1994: 95-113); FIELDS (2001: 102 138); MORGAN (2001: 20-44); NIELSEN (1999: 16-79); TRUNDLE (2004: 52-54); BETTALLI (2013: 182-186).

$9 \operatorname{ROY}(1999: 320-381)$.

10 ISAEUS, Hagnias $11.48-9$.

11 TOD (1948: 2.154. 10-15); TOOGOOD (1997: 295-297). 
mercenary service and associated activities like piracy offered enviable opportunities for enrichment overseas.

Another phenomenon that drove the supply of mercenaries from Greek cities were the exiles who regularly emerged from Greek political strife within poleis in the later fifth and more predominantly in the fourth century BCE. Parke considered these exiles were a potential source of mercenaries and more recently McKechnie has supported this notion. ${ }^{12}$ Certainly, the fourth century witnessed increased political strife within Greek communities. At the same time, more cities suffered destruction and the resulting diaspora of their inhabitants than we know about in the fifth century BCE. ${ }^{13}$ Demosthenes and Isocrates both considered that exiles were a considerable problem in the fourth century. ${ }^{14}$ Isocrates identified wandering Greek exiles in Asia as a potential threat to political stability. ${ }^{15}$ Ancient evidence alludes to exiles in mercenary armies, but specific evidence remains unclear regarding the scale of exiles in mercenary Greek armies. Some Greeks with Cyrus the Younger were exiles. Thus, an un-numbered group of Milesian exiles followed his cause, but Xenophon labels only five of those named Greek mercenaries with Cyrus as exiles. ${ }^{16}$ The evidence is complicated. Indeed, in a noteworthy passage Xenophon tells his readers that most of the men on the campaign had sailed from Greece not due to exile or penury, but because of the attractions of service with Cyrus. ${ }^{17}$ According to him, many had left behind families and homes to which they were keen to return. Other sources tell a different story. On the other hand, Isocrates, for example, stated that Xenophon's men left their homes due to their personal circumstances unable as they were to live in their own cities. ${ }^{18}$ It is still difficult to assess the role that Greek exiles and sheer desperation played in the mercenary phenomenon in the fourth century BCE. No doubt many mercenaries were poor and some had few opportunities elsewhere.

Alongside poverty and exile, one further factor might have influenced the growth of numbers in mercenary service from the Greek cities. Long ago Parke suggested that land shortage might well have underpinned some mer-

12 PARKE (1933: 228, n. 1); MCKECHNIE (1989: 22-29).

13 MCKECHNIE (1989: 28); TRUNDLE (2004: 55).

14 DEMOSTHENES 18 De Corona, 48; ISOCRATES 6 Archidamus, 68.

15 ISOCRATES 5.120-121; see MCKECHNIE (1989: 90).

16 XENOPHON, Anabasis, 1.1.7.

17 XENOPHON, Anabasis, 6.4.8.

18 ISOCRATES 4.146. 
cenary service. ${ }^{19}$ The Greeks did not practice primogeniture, which meant that all sons inherited an equal share of their father's property. The example described in a legal speech of Isaeus 2 in which one of two brothers worked the farm at home, while the other took mercenary service abroad illustrates the point specifically. ${ }^{20}$ Some mercenaries therefore did serve abroad due to issues of land-tenure in Greece. Demographic changes in Greece might also have forced more Greeks to seek opportunities abroad. Greece did suffer from limited supplies of good land, especially arable farmland. Its population even in the Archaic Age might have strained resources. Greek colonies in this earlier period no doubt assisted to alleviate population growth in that period. By the fifth century the founding of colonies overseas had all but ceased. Recent studies have suggested that the population of the Greek world might have risen sharply in the Classical Period peaking in the late fourth century BCE. ${ }^{21}$ Prior to Alexander the Great's conquests, the Persian Empire to the east and the cities of Italy and Sicily in the west provided employment opportunities for Greeks seeking a livelihood abroad. Alexander's eastern anabasis opened up a new world for thousands of colonists and emigrants who followed in his wake. Significantly, for mercenaries seeking employment such a livelihood before the time of Alexander was only possible if would be employers sought such Greeks for employment. Without employment they remained simply outsiders and wanderers without identities. It seems clear that the evidence both for classical Greek antiquity and for other eras of history does not support the idea that supply led to increased mercenary activity. More recent examples of conflicts that involved large numbers of men in military service show that training, availability and experience for large numbers of citizen soldiers does not in itself translate into large numbers of professionals finding employment in armies across the globe in the aftermath of conflicts. Three twentieth century examples demonstrate this well. The first and second world wars did not produce an explosion in the numbers of mercenaries in the 1920s or the late 1940s and 50s. Similarly, the Vietnam War did not see a marked impact of ex-American servicemen in the wars of decolonization in Africa and Asia. Indeed, the mercenaries who found themselves heavily involved in African wars of liberation and determination primarily came from Europe and often were Europeans who came from countries and had themselves strong links to the

19 PARKE (1933: 14, n. 1).

20 ISAEUS 2 Menecles 3-5.

21 See most recently OBER (2015: 3 and passim); for earlier discussion of such a hypothesis see SALLARES (1992), chapter 2 (Demography), especially 94-97. 
African countries in whose conflicts they found themselves. A good example of this is the Belgian servicemen, regularly labeled mercenaries who fought in the Congo in the 1960s and 1970s. Many of these were Belgians with connections to the Belgian colonial Congo and, indeed, strong evidence suggests that American funding deliberately hired men to serve who had such colonial connections. In this way, they might obscure the mercenary nature of the military personnel. ${ }^{22}$

The answer then to the reason why mercenaries exist at all is surely demand. Without the demand for military service there is no employment. Demand even lay at the root of the Belgians sought by American financiers, primarily the $\mathrm{CIA}$, fueling wars in central Africa. ${ }^{23}$ But, and this now worth considering, can demand by itself explain the root cause of all mercenary service. There were of course, and as noted above, always underlying phenomena that had little do with the context of the neo-liberal market-place or in other words supply and demand. In the Greek world, for example, the strong bonds of aristocratic ritualized friendships (xeniai) that cut across polis boundaries, many of which pre-dated the polis itself and which also valorized military service with fellow, but foreign leaders, gave mercenary service an acceptable veneer even in the classical period. ${ }^{24}$ Our evidence suggests that even before the boom in Greek mercenary employment of the later fifth and fourth century BCE of which Arcadians played a central role, Arcadian aristocrats had established military alliance-connections through ritualised friendships that almost certainly help to lay the foundations for the great mercenary opportunities that followed. Thus, Pindar's praise-poetry identifies several Arcadian nobles, Hagesias of Stymphalus, Phormis of Maenalus and Praxiteles of Mantinea in overseas service. ${ }^{25}$ These nobles followed an honourable tradition of the itinerant hero-soldier, like Achilles and other heroes of Troy, travelling abroad in search of war, glory and movable plunder.

In antiquity employment was always considered demeaning and professionalism not respected in the way it is today. Working for another person carried a stigma as it highlighted dependence, subordination and ultimately

22 On modern mercenaries and wars in Africa see GARRISON (1968: 131-141); and THOMAS (1984).

23 On the rise of Private Military Companies in the modern world see CHESTERMAN and LEHNARDT (2007).

24 See in general HERMAN (1987); and MITCHELL (1997).

25 PINDAR, Olympian 6; see Pausanias, 5.27.1; for discussion see BETTALLI (1995: 26). 
a lack of autonomy and even freedom. The Greeks idealised freedom (eleutheria) above most things. In a world in which chattel slavery (douleia) was common freedom represented the extreme and perfect end of a complex continuum. At the same time, of the many kinds of endeavours in which humans engaged, the Greeks idealised farming and fighting. Landholding had become intricately associable with military service in the idealised Greek polis of the fifth century BCE. The hoplite citizen-farmer represented the paradigm of what it meant to belong within the state. Farming and fighting, therefore, intrinsically connected as they were, each had become closely connected to citizenship and ideals of manhood in the world of the fifth and fourth century Greek states. This might explain another reason why Greek citizen males willingly served others as hoplites, even for wages, as military service was a natural part of a citizen's life. Furthermore, if plundered property provided remuneration for military service, then soldiers could hide their real motivation and subordinate their employed or "paid" status beneath a veneer of heroic redistribution of plunder. There was nothing dishonourable in receiving a part of the spoils of war. Homer's heroes set an important precedent in that regard.

Thus, despite the fact that mercenaries in the Greek world were paid they could conceal their employed status through contrived allegiances, motivations and relationships. Greek terminology is useful in this regard to identify mercenaries not as hirelings, but as allies or friends. In early Greek contexts, therefore, mercenaries were termed as epikouroi or xenoi literally fighters-alongside (allies) and foreigners, associable with guest or ritualised friendship. ${ }^{26}$ Even after the introduction of regular wages or misthos in the fifth century BCE, xenos and epikouros continued in use as common markers for Greek mercenaries and in some instances well into the fourth century BCE. ${ }^{27}$ Thucydides used the term epikouros in the early years of the Peloponnesian War as did Xenophon in the first half of the fourth century. ${ }^{28}$ The term misthophoros emerged as a term for mercenaries as the result of the spread of wages in coin in the fifth century BCE. ${ }^{29}$ Misthophoroi as 'wage-bearers' or '-takers' more accurately describes the status of most paid soldiers, but

26 LAVELLE (1997: 229-262); and TRUNDLE (2004: 12-14).

27 TRUNDLE (1998: 1-12).

28 For example, THUCYDIDES 1.115.4; XENOPHON, Hellenica 7.1.23; see LAVELLE (1989: 36-39).

29 TRUNDLE (2004: 15-17). 
even this term suggested others types of more acceptable relationships. The term first appears in Athenian military and political contexts. The Athenian democracy introduced misthos for state-service in juries. As political service was the privilege of citizenship and indeed a marker of identity, so those in receipt of misthos might still conceal their true identity. There was nothing intrinsically dishonourable in taking a wage for service for the state and especially a state that encouraged political service of its exclusive if relatively large citizen-group. Misthophoros and epikouros co-existed in our sources despite the proliferation of coinage as a means of payment. Indeed, Thucydides in the later fifth century uses epikouros (seventeen times) far more regularly than misthophoros (six times). ${ }^{30}$ This suggests the traditional and euphemistic attitude to mercenaries still prevailed.

Finally, in regard to the privileged place of military service in Greek states it was very rare to find slaves serving as infantrymen in Greek armies. Land warfare was the privileged domain of the free and indeed of citizens. Despite the fact that there are examples of non-citizens serving in the armies of Greek states, notably in Sparta where non-Spartiatae made up large numbers of the Spartan heavy infantry army as those who dwelt on the periphery of the state, the Perioekitae, and even freed helots, the so-called 'new-people' or Neodamodeis, most Greek state-armies contained heavy infantry drawn from the citizen group. ${ }^{31}$ This reinforced a citizen and elite identity in military service and gave honor to such service. Such a prestigious mantle meant that those taking service overseas for others could glean the honor of service and military identity regardless of the payment received.

The preconditions for the willingness of Greek citizens to seek service overseas for others that Greek ideology provided and that freedom, landholding and a warrior tradition all supported created the context for Greek mercenary service, but still, as I will continue to argue did not provide the impetus for the Greek mercenary explosion of the later Classical Period. Three separate but related phenomena fuelled the appearance, use and spread of large numbers of Greek mercenaries in classical antiquity: (1) the influence of the east on the Greek world and the demands that eastern rulers had for soldiers from the Greek mainland; (2) the rise of tyrannies in the Greek cities of the Greek mainland, who themselves sought to hire men to protect themselves and their regimes and finally; (3) the introduction and spread

30 TRUNDLE (2004: 13).

31 On the subject of helots and other un-free or even slave-soldiers see HUNT (1998: 31-41, 56 62). 
of coinage in the Aegean Basin and eastern Mediterranean that enabled the payment of professional servicemen on a larger scale than previously seen. ${ }^{32}$

Importantly, as we have just noted with reference to Arcadians, military tradition played its role in mercenary service too. Greeks had long found service at the courts of eastern rulers. lonians and Carians served in Egypt, Antimenidas in Babylonia, some suggest even Assyrian kings had Greeks in service in the seventh century. ${ }^{33}$ These numbers grew at a steady rate from the later Archaic period and through the fifth century. Traditional networks of friendships also fueled military-mercenary service. Networks connecting men to power and the potential of reward attracted many into service overseas. Personal relationships, like guest or ritualized-friendship (xenia) and more generally just friendship (philia) between ordinary Greeks and the powerful men of the eastern Mediterranean facilitated mercenary service. ${ }^{34}$ Xenophon's Anabasis reveals the importance of networks of relationships to the mercenary army's formation and maintenance. Xenophon highlights the important part played by the noble and generous nature of Cyrus in attracting men into his service and keeping them loyal. ${ }^{35}$ The men who came to Cyrus thought his friendship (philia) was worth more than their home poleis. For example, all who served Cyrus did so for more than a monthly wage. ${ }^{36}$ Proxenus told Xenophon that the friendship of Cyrus was worth more than his native state. ${ }^{37}$ Xenophon tells us that Cyrus told the Greeks that few would wish to return home after he had become king because of the life he could provide for them. ${ }^{38}$ Clearchus told Tissaphernes that he had set his heart on having Cyrus as a friend (philos) because he thought he was most able of anyone to benefit whoever he wanted. ${ }^{39}$ Mercenary service, there-

32 On the importance of Persia for the employment of mercenaries from Greece see TRUNDLE (2004: 73-79); TUPLIN (1987: 167-245); RHODES (2006: 221-222); and BETTALLI (2013: 235-315). On Tyranny's role in mercenary employment see TRUNDLE (2006: 65-76); BETTALLI (2013: 319-360). On the role of coinage in transforming warfare see TRUNDLE (2010: 227-252).

33 BROWN (1997: 300-303).

34 On xenia and philia and mercenary service see HERMAN (1987: 97-105); MITCHELL (1997: 1 1 1-147); PRITCHETT (1974: 59-116); and TRUNDLE (2004:147-164).

35 XENOPHON, Anabasis, 1.9.11-13.

36 XENOPHON, Anabasis, 1.9.17.

37 XENOPHON, Anabasis, 3.1.4.

38 XENOPHON. Anabasis, 1.7.4.

39 XENOPHON, Anabasis, 2.5.11. 
fore, provided opportunities for Greeks (elite and otherwise) to connect with the powerful. The Rhodian generals Mentor and Memnon, each of whom became second in command under the Persian King, demonstrate the point. Mentor first served an Egyptian Pharaoh. Later, he served the Persian King and became very powerful, perhaps as a recruiter of Greek mercenaries. ${ }^{40}$ Memnon replaced his brother and Darius considered him one of his best commanders and he led the Persians after Granicus until his death. ${ }^{41}$

As a testament to the deeper roots that lay behind mercenary relationships than simply mercenary-motivation, so-called Greek 'mercenaries' remained loyal to their employers, despite adverse circumstances. The fact that traditional ties, like xenia, might underpin this loyalty. Mercenaries were therefore less mercenary than we might think. As a result close ties that transcended simple financial reward and remuneration bound men and their so-called employers together. Thus, men appear serving with members of their family even in mercenary contexts, ${ }^{42}$ and from beyond the family connections they served in groups that came from their homes. ${ }^{43}$ Family and civic connections tied mercenaries together abroad. We might note here how the Arcadians in Xenophon's Anabasis showed much national feeling. ${ }^{44}$ Commanders linked these groups of men to their employers in hierarchies of elite- and ritualized-networking. As a result of these networks most mercenary Greeks had close connections to their employers through traditional roots of diplomatic bonds and ties of wider foreign-policy affiliation.

Ties to polis-civic traditional relationships, which themselves often reflected an environment whereby, the saying goes, 'my enemy's enemy is my friend', fed into pre-existing hostilities between Greek communities that might then play out in Greek military service abroad. Mercenary networks usually had much in common with polis 'foreign-policy'. This might explain how rarely Greeks baulked at attacking other Greeks, while serving Persian or Egyptian (or other) paymasters. In one rare example, Diodorus describes how Greeks fighting with Persian forces at Pelusium defended their Egyptian employed countrymen and allowed them to withdraw under a treaty from a Persian attack. ${ }^{45}$ Such panhellenic feeling was indeed rare. Greeks regularly fought

40 For Mentor's career and services see DIODORUS 16.45.1, 16.50.7, 16.52.1.

41 For Memnon as a mercenary commander see specifically DIODORUS 17.7.2, 29.1.

42 See TRUNDLE (2004: 139-143). Inscriptions like SEG 31. 1552, 1554, show family names in the same Greek units in overseas campaigns.

43 TRUNDLE (1999: 28-38).

44 For example, XENOPHON, Anabasis, 6.2.11.

45 DIODORUS 16.49.5. 
against other Greeks both for their own states and for other commanders. The Greeks with the Great King Darius III against Alexander the Great, for example, hated and feared the Macedonians. They knew their best interests lay with the Persians. Ultimately, these Greeks proved more loyal than Darius' fellow countrymen as they attempted to protect the Great King from those who conspired against him in the last days of his life. ${ }^{46}$

The process for hiring mercenaries developed into sophisticated systems, markets and networks. ${ }^{47}$ As we have suggested earlier, traditional relationships of ritualized friendships between aristocratic Greeks and major figures across the eastern Mediterranean initially facilitated military alliances that then converted into more mercenary relationships in the classical period. Such networks subsequently reflected polis based foreign policies and had become an extension of them. Athenian aristocrats often had close associations with elites across the eastern Mediterranean and so could use these connections to facilitate mercenary employment. For example, Iphicrates was related to Thracian kings no doubt enabling the flow of mercenaries from Thrace to Athens and vice versa. Sparta regularly assisted the flow of mercenaries from the Peloponnesian states to its allies abroad, like Dionysius I in Sicily. The Spartans enabled Dionysius to recruit from within the Peloponnese. ${ }^{48}$ We are also told that they sent Peloponnesians, certainly non-Spartiatae, to aid their allies in other wars, most notably to Cyrus the Younger for the Anabasis campaign and to the Phocians in the Third Sacred War. ${ }^{49}$ In the case of the Anabasis campaign, Xenophon explicitly states that Cyrus had requested the Spartan commander Chirisophus to lead the contingent of men the Spartans sent to him from the Peloponnese. Within Greek cities wealthier men also made possible hiring troops and these according to Aeneas also should accommodate mercenaries inside the city at their expense. ${ }^{50}$ Hiring practices, therefore, facilitated by elite connections overseas and traditional relationships fuelled the demand for mercenaries in the classical period.

It is important now to pause and consider then 'Who are mercenaries both generally and more specifically?' Definitions are important here. I think it

46 ARRIAN Anabasis 3.21.4; DIODORUS 17.27.2; CURTIUS 5.8.4.

47 See TRUNDLE (2004: 104-131).

48 DIODORUS 14.44.1-2, 58.1.

49 XENOPHON, Anabasis 1.4.3 and DIODORUS 16.24.2.

50 TRUNDLE (2004: 104-1 17); for example, see AENEAS Tacticus 13.1 and 22.29. 
is very rare to find a genuine mercenary prepared to fight for just anybody and only interested in service for the money. As I noted above ancient Greek mercenary service dovetailed closely with both traditional friendship networks and with aristocratic-state foreign policy. How does this change the way in which we understand mercenary service when we consider mercenary service in antiquity more generally? In short it means that there were levels of reciprocity between employers and employed that changed the dynamic in the choices made regarding employment and hiring practices. The absence of genuine 'condottieri' who might switch sides at a whim or serve any paymaster curtailed the role that the free-market played in Greek mercenary activity. By which I mean, there was no free-market or genuine individual mobility in classical Greek mercenary circles. The processes that drove Greek mercenary service were so embedded in traditions of ritualized-friendships and polis foreign-policy constraints that these determined who served where and for whom they fought. It makes identifying those men in mercenary service as 'mercenaries' obsolete, or at least misleading, and as we have seen above Greek terminology did not identify mercenaries as the type of soldiers of fortune that we might recognize in the present age.

In addition to this point, the types of people who found themselves in mercenary service often reflected, at least in an underlying causal way, the reasons for their hiring. Marco Bettalli recently identified mercenaries as coming from three groups or three types of people. ${ }^{51}$ First, young men seeking fortune and adventure based often on family traditions. This might then explain the presence overseas, especially in archaic contexts, of aristocrats like the brother of Alcaeus named Antimenidas or Arcadian nobles noted in Pindar's praise poetry serving foreign rulers - both of which harkened back to Homeric heroes adventuring on military service overseas. The second group he identifies came from those seeking refuge abroad from their communities - here we might identify the large numbers of Arcadians and Achaeans on the Anabasis campaign and Arcadian mercenary traditions more in the fourth century BCE. Finally, there were numbers of men coming from states which essentially exported surplus populations to service also based on traditions of serving foreigners. The Arcadians escaping the poverty of the central Peloponnese or even perhaps the tyranny of Spartan imperialism may also be in this group.

Of the three groups or types of men seeking mercenary service, the first group, the individuals seeking adventure as young men, are clearly distinct 
from those in the second and third categories of those seeking employment en masse from endemic domestic circumstances of poverty or other hardships. Unfortunately, though, any kind of large scale military service still requires the will and the need of employers to enlist and support foreign servicemen in their armies. As we have stated, clearly, mercenary service is - and was - a demand driven industry and not at all driven by supply. No matter how many wanted to become mercenaries in the Greek world without employment these want to be soldiers remained idle and unemployed. Without employment there are no mercenaries.

So, returning to the question 'Why do people hire mercenaries?', then a key preliminary criterion is: 'Who is doing the hiring and for what purpose?' Tyrants hired mercenaries for very different reasons than democratic states even though both did - and do - in fact hire mercenaries to fight their wars. Tyrants hired men to protect their person and because they distrusted the people over whom they ruled to fight for their interests. Indeed, even in the Greek world tyrants regularly disarmed the local population in order to rule over them. The best example of this is perhaps Peisistratus who disarmed the Athenians through a trick. ${ }^{52}$ Aristotle went so far as to distinguish a king from a tyrant by the existence for the latter of a hired bodyguard of mercenaries (xenoi - literally foreigners), while the former's bodyguard was made up of citizens. ${ }^{53}$ Sicily became a hotbed of mercenary activity when tyranny became well established on the island, especially at Syracuse under Dionysius $1 .{ }^{54}$ Our sources paint a grim picture of the tyrant's use of mercenaries to hold the Syracusan people in slavery. ${ }^{55}$ Dionysius exploited mercenaries further for his wars against Carthage. So much was this the case that Sparta acted practically as a supplier of Peloponnesian mercenaries to Dionysius in the early years of the fourth century BCE. Just as in the case of the Persian Empire mercenaries in the service of one side fueled mercenary service on the other. Thus, the Carthaginians became employers of Greek mercenaries in their wars against the Greeks of eastern Sicily. ${ }^{56}$

Mercenaries then represented markers of power relationships for individual rulers whether these were kings or tyrants. The same can be said of the

52 ARISTOTLE, Ath. Pol. 15.3-5.

53 ARISTOTLE, Politics, $1311 \mathrm{la}$

54 Most recently see BETTALLI (2013: 331-345); for examples see DIODORUS 14.44.1-2, 58.1, 15.17.3.

55 DIODORUS 14.65.2-3; PARKE (1933: 68).

56 PLUTARCH, Timoleon, 30 and DIODORUS, 16.81.4. See TRUNDLE (2004: 74). 
Persian rulers in western Asia. The Satraps and the Persian Kings appear to have hired mainland Greeks over whom neither held physical imperial sway principally because they could not trust their own Greeks in Asia Minor, or other local native groups to fight for them willingly. If they did then that too would have ramifications of the power dynamic between ruler and ruled in specific regions of the Persian Empire. The irony was of course that this meant that large numbers of Greeks from outside of the boundaries of the Empire ended up fighting on either side of conflicts between the King and his rivals, for example in Egypt during Persia's three attempts to subdue the country in the fourth century BCE. In this way, mercenary service could be seen to have developed its own dynamic with each side hiring men because the other side was doing the same. But the salient point to make regarding the wars of the Persian king against his enemies from Cyrus' failed coup to the Great Satraps Revolt remains that hired troops from overseas were the easiest and least politically compromising way to wage wars for control of the western Persian Empire.

Democracies too hired mercenaries. Wars often prove unpopular both with the community at large, but also with those specifically asked to fight in them. Money became the means to offset the need to make citizen soldiers fight in unpopular wars and to secure men for military service in the absence of responsibility of citizen servicemen or responsibilities to those enrolled for service. The role of coinage in mercenary service was central. De Ste Croix noted this point when he suggested that Greek mercenaries were the first example of mass hired labor in history. ${ }^{57}$ Athenian coinage transformed military relationships and in turn created professionals out of military personnel, even citizen soldiers. This occurred first at sea in the Athenian navy, but slowly and surely on land. ${ }^{58}$ The ideology of money in place of voluntary manpower appears clearly in the speeches at the start of the Peloponnesian war in which Pericles details the role of money in hiring men for military service as opposed to citizen militias, especially the juxtaposition of naval with infantry personnel. ${ }^{59}$ Eighty years later Demosthenes outlines a very similar ideology in his plans for military activity in Thrace, hiring men with offers of money for food and payment from plunder. ${ }^{60}$ Jason Crowley recently noticed that Athens was a major employer of mercenaries rather than provider of them based primarily on Athenian ability

57 CROIX (1981: 182).

58 For discussion see TRUNDLE (2010a: 227-252).

59 THUCYDIDES 1.141.5.

60 DEMOSTHENES 4.28-29. 
to pay its citizens and by extension other state's citizens for service. ${ }^{61}$ This was due, as he suggests, to Athens' 'aggressive imperial orientation', but we might add to this Athenian wealth and the proliferation of Athenian coinage. Coinage became the tool that enabled mercenary activity like no other. It turned Athens into a city of mercenary service. Athenian citizens received payment for jury service and even other political posts. By the later fifth century BCE payment for military service had become very common in both naval and land warfare. Thus, not only could Athens pay its citizens to serve the state it could afford to pay non-Athenians too, at least in the fifth century imperial period. The role of the navy was central in this. The navy required two things that land warfare had traditionally not needed or if it did need them it never acknowledged that need. The first of these was enormous numbers of oarsmen drawn from the poorer status group of society - the thetes. These men absolutely required remuneration for their service. Secondly, the ships in the fleet required technical specialists to man the ships as navigators, steersmen, carpenters and other experts with skills that gave seamanship a degree of professionalism previously not seen, and once again perhaps that had never been acknowledged in land warfare. Through the fifth century the Athenian navy became increasingly professional as crews manned Athenian ships for payment in Athenian coin from all over the Aegean. ${ }^{62}$ Indeed, one key inscription shows that in addition to Athenians, Metics and Greeks from within the Athenian naval archê approximately twenty percent of the named crew members were listed as slaves..$^{63}$ Payment was made in coin to all, though of course the slaves' pay would have gone to the master. This clearly illustrates the processes that coinage set in motion in transforming warfare into a more mercenary activity in the Athenian classical world. Coinage, therefore, as a tool and medium of exchange became both the means and the end of empire. Unsurprisingly, in such an environment mercenary interests predominated.

The legacy of the Athenian military system with its focus on coins as the means of waging warfare influenced the subsequent war-making of the fourth century BCE. Thus, the same point as shown for the Athenian Empire can be made regarding Philip II of Macedon in the fourth century and his use of coins. ${ }^{64}$ Philip's coinage flooded the Aegean world thanks to his con-

61 CROWLEY (2012: 208, n. 36).

62 See TRUNDLE (2016: 65-79); THUCYDIDES 1.121.3, 143.1-2, 7.63.3.

63 Insciptiones Graecae 1(3) 1032.

64 See, in general, MARTIN (1985); BORZA (1995: 37-55). 
trol of the mines in the region of his new foundation at Philippi (Pangaeum) and then dominated the Greek world. ${ }^{65}$ In a well-known passage Diodorus comments on how Philip's control of the mines made Philip very wealthy and enabled him to pay soldiers and bribe Greeks alike to further his power abroad. ${ }^{66}$ Like the Athenians before him he became a prolific employer of foreigners both in his military and for his state. He professionalized his Macedonian national army. One Greek commentator noted how Philip had made prostitutes of those Greeks who flocked to him and his court seeking his money. ${ }^{67}$ Coinage acted as both a tangible benefit of military service, but also a symbol of the particular-bond between paymaster and wage-taker. This, of course, like so much in the classical world has Homeric roots to justify the relationship based in military connections and plundered property as the basis of the rewards of service.

Money fuelled the proliferation of mercenary service. Of course, it is conceivable that hiring mercenaries was cheaper than using a state's own citizen soldiers especially in the classical age when states like Athens had already begun to provide their own citizen troops with not only supplies and food for campaigns but also payment for their service. Economics, therefore, should not be overlooked in considering why employers hired mercenaries. In several ways, therefore, it might well have been cheaper to hire mercenaries. Firstly, hiring men for a single campaign might have had little impact on a state's resources, especially if the campaign was successful and yielded plunder in excess of the costs of the war. Furthermore, there was clearly no responsibility for training or equipping men hired from outside of the community. The problem came only when wars did not pay for themselves and men go un-remunerated for their service. We have very few stories from the classical period of states having major problems with their mercenaries. There is nothing in classical Greek history to compare with The Mercenary or Truceless War fought between Carthage and its mercenaries at the end of the First Punic War in 241 BCE. In that war, Carthage came close to destruction. We have noted how lsocrates thought roving bands of displaced Greeks presented a problem for Asia Minor in the fourth century. ${ }^{68}$ There are isolated stories of discharged or unemployed mercenaries causing trouble as they travelled from one place to another. Thucydides' account of the Thracian Dii who arrived too late to travel to Sicily with Dem-

65 See TRUNDLE (2010a: 227-252) for the main points of this argument.

66 DIODORUS 16.8.7.

67 THEOPOMPUS in FGrH 115 225-226.

68 ISOCRATES 6 Archidamus, 68. 
osthenes and who on their return home destroyed the city of Mycalessus in Boeotia speaks volumes for the possible consequences of armed men deprived of employment. ${ }^{69}$ Diodorus preserves a series of stories concerning the survivors of the defeat of Phocis in the Third Sacred War that sees these mercenaries pillaging in the Peloponnese before then seeking employment (and plunder) across the Mediterranean and causing chaos in their wake. ${ }^{70}$ Diodorus follows their movements after their defeat and desertion of Greece in order to highlight their eventual defeat and destruction in slavery or death..$^{71}$ The fact that such stories are relatively uncommon and peripheral to Greek polis warfare suggests a degree of 'order', even in the fourth century. Perhaps this was due to the fact that there was enough employment for mercenaries in the period to alleviate brigandage on a large scale.

We have already noted several times the social basis of some mercenary service. In the Greek-World the basis of much military service that we might style as mercenary lay with ritualized-friendships promulgated on Xenia. Aristocratic connections that supported the status of warriors in a warrior society, and mutual gift giving that was itself a form of remuneration, usually in the form of redistribution of booty, all in turn blurred what look very much like mercenary relationships. In effect, of course this also provided mutual support between elites of different polities and meant that those same elites did not need to rely so heavily on men from within their own communities for military support. This point we have already made with regard to tyranny and imperial control in the Aegean and eastern Mediterranean. Service engenders obligation towards and empowerment of those in service. Hence it was important to exclude certain groups from military service on land as a matter of course like slaves and subjects (unlike at sea where the bearing of arms was not a prerequisite).

Finally, we come to the various military reasons for hiring mercenaries. Mercenaries provided skilled and experienced men to augment the strength of states' armies. They sometimes provided specialists otherwise missing from certain forces. Thus, it was not uncommon for Greek states to hire skilled light infantry, like peltasts, archers and slingers from peripheral regions of the Aegean basin to augment their own heavy infantry arm. ${ }^{72}$ Likewise

69 THUCYDIDES 7.27 and 29 .

70 DIODORUS 16.61.4-16.63.4.

71 DIODORUS 16.63.1-4.

72 On light troops especially see generally van WEES (2004); BEST (1969); TRUNDLE (2010b: 139-160). 
Persian Kings and their satraps required Greek hoplites to provide a heavy infantry wing to support their larger numbers of light troops and cavalry. ${ }^{73}$ This is yet another reason to believe that mercenary service was demand driven. Employers sought out specialists and skilled soldiers. Mercenaries too might have had tactical and strategic abilities not found amongst local populations or civilian militias. Aristotle makes this point alongside a criticism of mercenaries as soldiers in his Nicomachian Ethics. ${ }^{74}$ He praised mercenaries (epikouroi) for their fighting skills and ability to inflict casualties, but he goes on to state that professional soldiers often prove cowards when faced with superior arms or numbers, unlike citizen-militia who would more likely die fighting. Such arguments reveal the depth of Greek idealism regarding citizens as non-specialist, unprofessional soldiers juxtaposed with the realities of mercenaries as quality troops.

Finally, it has recently been suggested to me that none of these technical military considerations applied to hiring Greek mercenaries. Hans van Wees gave a paper in Dublin in June 2016 in which he demonstrated that there were plenty of heavy infantrymen in Near Eastern communities in later Archaic and Classical contexts and so the need of the Assyrians or the Persians to employ Greek hoplites was not necessarily to provide a heavy infantry arm that was otherwise missing from Near Eastern armies. ${ }^{75}$ Indeed, one suggestion might then be that the cause that underpinned hiring Greeks into the armies of the Persian Kings and his Satraps was simply to increase the numbers of men one had at one's disposal for any given conflict. This is an interesting notion and needs more consideration. The very large on-paper numbers of Greek hoplites with Persian forces at key moments in the fourth century might well illustrate this point. For one example, we might note the twenty thousand who fought at Granicus and the thirty thousand at Issus against Alexander the Great. ${ }^{76}$ Rather than a small number of highly specialized and well trained men, our sources thus point to tens of thousands of Greeks abroad throughout the fourth century BCE. Numbers on ancient battlefields mattered. Mercenaries were also expendable even if they remained assets. Mercenaries were still outsiders even if they were connected

73 PLATO, Laws, 3.697e; XENOPHON, Cyropedia 8.8.25; ISOCRATES 4.41. For discussion see also SEIBT (1977: 121-162); BETTALLI (1995: 25); BRIANT (1996: 806-807); and TRUNDLE (2004: 71-74).

74 ARISTOTLE, Nicomachean Ethics 3.8.9.

75 VAN WEES (2016).

76 For accounts of the battle of Granicus see ARRIAN 1.13-16; DIODORUS 17.19-21; PLUTARCH, Alexander 16; for Issus see ARRIAN 2.5-14; DIODORUS 17.32-9; PLUTARCH, Alexander 201; CURTIUS 3.2-13. 
by ties of friendship and alliances as I have argued above. No doubt they gave employers a good deal of flexibility on the battlefield balancing paid professionals against unpaid militia. To understand mercenary employment as just a way of increasing military numbers is overly simplistic, but it would explain, like the several other phenomena highlighted in this discussion, the enormous numbers of troops in Persian service in the period.

To conclude this argument, the employment of mercenaries, or perhaps more accurately paid outsiders, to fight for employers lay centrally with the employer or paymaster (misthodotês) as the Greeks called him. Without this paymaster, no service was possible and no remuneration was forthcoming. The demand driven industry that emerged in the Greek world of the fifth and fourth centuries BCE and that led to an explosion in the numbers of mercenary soldiers rests firmly with the chaos that engulfed the Persian Empire in the west as Egyptian Pharaohs and Satraps sought independence from the Great King. Similarly in the west Sicilian tyrants fought the Carthaginians and each other in several major encounters. This demand continued through the whole century and even increased in momentum from the time of Cyrus the Younger in 401 BCE whose employment of Greeks is well documented to the campaigns of Alexander the Great in his successful, but ultimately destructive invasion of Persia in 334 BCE. After Alexander, professional soldiers continued to abound in the wars of the successors. Those who fought for Alexander's empire continued to need soldiers, especially Greek and Macedonian soldiers to serve in their armies and for their wars against one another. Arguably these successor wars were themselves a high-water mark for mobile and professional military service. But, in the end, these wars marked the end of the process of mercenary mobility and mass mercenary employment that the classical age had witnessed. The stable kingdoms that emerged from these wars created a new kind of military environment in which paid, but more sedentary and long term professional and garrison soldiers replaced the mercenaries of the fourth century BCE. ${ }^{77}$ Mercenaries continued in the service of kings and poleis in the Hellenistic world, but on nothing like the scale seen in the earlier period.

77 For the changed environment of the Hellenistic period see PARKE (1933: 206-226); GRIFFITH (1935: 33-56); AUSTIN (1986: 450-466); BILLOWS (1990: 292-305); BILLOWS (1995: 146 182); FOULON (1995: 211 -218); LAUNEY (1987); CHANIOTIS (2005: 78-101); SEKUNDA (2007: 343-349); and TRUNDLE (2008: 103-116). 


\section{BibLIOGRAPHY}

AYMARD, A., (1967): "Mercenariat et l'histoire grecque". ÍD. (ed.), Etudes d'histoire ancienne. Paris, Presses Universitaires de France, pp. 487-498. AUSTIN, BAKER, P. (1999): "Les mercenaires". PROST, F. (ed.), Armées et Sociétés de la Grece classique. Paris, Editions Errance, pp. 240-255.

BETTALLI, M. (1995): I mercenari nel mondo greco. Dalle origini alla fine del $v$ sec. a. C. Pisa, ETS.

BETTALLI, M. (2013): Mercenari. Il mestiere delle armi nel mondo greco antico. Rome, Carocci Editore.

BILLOWS, R. (1990): Antigonos One-Eyed and the Creation of the Hellenistic State. Berkeley, University of California Press.

BILLOWS, R. (1995): Kings and Colonists: Aspects of Macedonian Imperialism. Leiden, Brill.

BRIANT, P. (ed.) (1996): Dans les Pas des Dix Mille. Toulouse, Actes de la Table ronde internationale.

BROWN, R.B. (1983): "Greeks in Assyria: Some Overlooked Evidence". Classical World, n 77, pp. 300-303.

BURCKHARDT, L. (1996): Soldner und Burger als Soldaten fur Athen: Aspekte der politschen und militarischen rolle Athenische burger im Kriegswesen des 4 jarhunderts v. Chr. Stuttgart, Franz Steiner Verlag.

CARTLEDGE, P. (1987): Agesilaos and the Crisis of Sparta. Baltimore, Johns Hopkins University Press.

CHANIOTIS, A. (2008): War in the Hellenistic World: A Social and Cultural History. London, Wiley-Blackwell.

CHESTERMAN, S. and LEHNARDT, C. (2007): From Mercenaries to Market: The Rise and Regulation of Private Military Companies. Oxford and New York, Oxford University Press.

COOPER, F. A. (1978): The Temple of Apollo at Bassai: A Preliminary Study. London, Garland Publishing Inc.

COOPER, F. A. (1996): The Temple of Apollo at Bassai. Princeton, Princeton University Press.

CROIX, G. E. M. de Ste, (1981): The Class Struggle in the Ancient Greek World. London, Duckworth.

CROWLEY, J. (2013): The Psychology of the Athenian Hoplite. Cambridge, Cambridge University Press.

FIELDS, N. (1994): "Apollo: God of War, Protector of Mercenaries". SHEEDY, K. (ed.), Archaeology in the Peloponnese. Oxford, Oxbow Books, pp. 95-113. 
FIELDS, N. (2001): "Et in Arcadia Ego". Ancient History Bulletin, n 15, pp. 102-38.

FOULON, E. (1995): "Misthophoroi et Xenoi Hellenistiques". Revue des etudes grecques, $\mathrm{n}^{\circ} 108$, pp. $211-218$.

GARRISON, L. (1968): "White Mercenaries on a "Rabbit Hunt". ROBINSON, D. (ed.), The Dirty Wars: Gorilla Action and Other Forms of Unconditional Warfare. New York, Delaconte Press, pp. 131-141.

GATTINONI, F.L. (1994): "I mercenari nella politia ateniesi dell'eta di Alessandro i soldati e ufticali merceari ateniesi al servizio della Persia". Ancient Society, $\mathrm{n}^{\circ} 25$, pp. 33-61.

GOMEZ CASTRO, D. (2012): Relaciones Internacionales Y Mercenariado Griego: Del Final de la Guerra del Peloponneso a la Paz del Rey (404-386 A.C.). Barcelona, Publicaciones y Edicions de la Universitat de Barcelona. GRIFFITH, G.T. (1935): The Mercenaries of the Hellenistic World. Cambridge, Cambridge University Press.

GUARDUCl, M. (1953): "Arcadia in Sicily". La Parola del Passato, n 8 , pp. 209-10.

HANSON, V. D. (1995): The Other Greeks: The Family Farm and the Agrarian Roots of Western Civilisation. Nueva York, The Free Press.

HERMAN, G. (1987): Ritualised Friendship and the Greek City. Cambridge, Cambridge University Press.

HUNT, P. (1998) Slaves, Warfare and Ideology in the Greek Historians. Cambridge, Cambridge University Press.

IAPICHINO, L. (1999): "I Diecimila di Senofonte: techniche di combattimento, equipaggiamento militare e approvvigionamento degli strumenti di Guerra". Rivista Storica dell'Antichità, $\mathrm{n}^{\circ}$ 29, pp. 91-105.

KAPLAN, P. (2002): "The Social Status of the Mercenary in Archaic Greece". GORMAN, V. B. and E. W. Robinson (eds.), Oikistes: Studies in Constitutions, Colonies, and Military Power in the Ancient World. Offered in Honor of A. J. Graham. Leiden Brill, Leiden, pp. 229-243.

KNAPP, R. (2002): "Greek Coinage, Mercenaries, and Ideology". Eulimene, $\mathrm{n}^{\circ}$ 3, pp. 183-196.

KRASILINIKOFF, J.A. (1992): "Aegean Mercenaries in the Fourth to Second Centuries B.C.: A Study in Payment, Plunder and Logistics of Ancient Greek Armies". Classica et Mediaevalia, $n^{\circ}$ 43, pp. 23-36.

KRASILNIKOFF, J. A. (1993): "The Regular Payment of Aegean Mercenaries in the Classical Period". Classica et Mediaevalia, n 44, pp. 77-95.

LANDUCCI, G.F. (1994): "I mercenari nella politia ateniesi dell'eta di Ales- 
sandro i soldati e ufticali mercenari ateniesi al servizio della Persia". Ancient Society, $\mathrm{n}^{\circ} 25.1$, pp. 33-61.

LANE FOX, R. (2004): The Long March: Xenophon and the Ten Thousand. New Haven, Yale University Press.

LAUNEY, M. (1987): Recherches sur les armées hellénistiques. Paris, Editions de Boccard.

LAVELLE, B.M. (1989): "Epikouroi in Thucydides". American Journal of Philology, n 110 , pp. 36-39.

LAVELLE, B.M. (1997): "Epikouros and Epikouroi in Early Greek Literature and History". Greek, Roman and Byzantine Studies, n' 38, pp. 229-262.

McKECHNIE, P. (1989): Outsiders in the Greek Cities in the Fourth Century B.C. London and New York, Routledge.

McKECHNIE, P. (1994): "Greek Mercenary Troops and their Equipment". Historia, n 43 , pp. 297-305.

MARINOVIC, L.P. (1988): Le mercenariat grec au IVe siècle av. n.e. et la crise de la polis. Paris, L'Université de Besançon.

MARTIN, T. R. (1985): Sovereignty and Coinage in Classical Greece. Princeton, Princeton University Press.

MILLER, H. F. (1984): "The Practical and Economic Background to the Greek Mercenary Explosion". Greece and Rome, n 31, pp. 153-160.

MITCHELL, L. G. (1997): Greeks Bearing Gifts: The Public Use of Private Relationships in the Greek World. Cambridge, Cambridge University Press. MORGAN, C. (2001): "Symbolic and Pragmatic Aspects of Warfare in the Greek World of the Eighth Century BC". BEKKER-NIELSEN, T. and L. HANNESTAD (eds.), Historik-filosofiske Skrifter 22: War as a Cultural and Social Force: Essays on Warfare in Antiquity. Copenhagen, Det Kongelige Danske Videnskabernes Selskab, pp. 20-44.

NIELSEN, T. (1999): "The Concept of Arkadia - The People, The Land, and Their Organisation". ÍD. and J. ROY (eds.), Defining Ancient Arkadia: Acts of the Copenhagen Polis Centre, vol 6. Copenhagen, Copenhagen Polis Centre, 16-79.

NUSSBAUM, G. B. (1959): "The Captains in the Army of the Ten Thousand". Classica et Mediaevalia, $\mathrm{n}^{\circ}$ 20, pp. 16-29.

Nussbaum, G. B. (1967): The Ten Thousand: A Study of Social Organisation and Action in Xenophon's Anabasis. Leiden, Brill.

OBER, J. (2015): The Rise and Fall of Classical Greece. Princeton, Princeton University Press.

PARKE, H. W. (1933): Greek Mercenary Soldiers from Earliest Times to the 
Battle of Ipsus. Oxford, Clarendon Press.

PERLMAN, S. (1976-7): "The Ten Thousand: A Chapter in the Military, Social and Economic History of the Fourth Century". Rivista Storicha dell'Antichità, n 6-7, pp. 241-84.

PRITCHARD, D. M. (2010): "The Symbiosis between Democracy and War: The Case of Ancient Athens". PRITCHARD, D. M. (ed.), War, Democracy and Culture in Classical Athens. Cambridge, Cambridge University Press, pp. 1-62.

PRITCHARD, D. (ed.), War, Culture and Democracy in Classical Athens. Cambridge, Cambridge University Press, pp. 111-138.

PRITCHETT, W. K. (1974): The Greek State at War, vol. 2, Berkeley, University of California Press.

RAHE, P. (1982): "The Military Situation in Western Asia on the Eve of Cunaxa". American Journal of Philology, $n^{\circ} 103$, pp. 79-98.

RIDLEY, R. (1979): "The Hoplite as Citizen: Athenian Military Institutions in their Social Context". Antiquité Classique, n 48, pp. 508-548.

ROY, J. (1967): "The Mercenaries of Cyrus". Historia, n 16, pp. 292-323. ROY, J. (1999): "The Economies of Arkadia". NIELSEN, T. H. and ÍD. (eds.), Defining Ancient Arkadia: Acts of the Copenhagen Polis Centre vol. 6, Copenhagen, Copenhagen Polis Centre, pp. 320-381.

SALLARES, R. (1991): The Ecology of the Ancient Greek World. Ithaca, Cornell University Press.

SEELINGER, R. A. (1997): "The Case of Seuthes and Xenophon's Success in the Anabasis: A Conflict of Values". Classical Bulletin, n' 73.1, pp. 23-30. SEIBT, G. (1977): Griechische Soldner im Achaimenidenreich. Bonn, Habelt.

SPENCE, I. (2010): "Cavalry, Democracy and Military Thinking in Classical Athens". STRONK, J. P. (1995): The Ten Thousand in Thrace: An Archaeological and Historical Commentary on Xenophon's Anabasis VI-VII. Amsterdam, J. C. Gieben.

SULLIVAN, B.J. (2011): "Paying Archaic Greek Mercenaries: Views from Egypt and the Near East". Classical Journal, n ${ }^{\circ} 107$, pp. 31-61.

RHODES, P. J. (2006): A History of the Classical Greek World 479-323 BC. London, Blackwell Publiching.

SEKUNDA, N. (2007): "Military Forces: Land Forces". SABIN, P., WEES, H. van, and M. WHITBY (eds.), The Cambridge History of Greek and Roman Warfare vol. 1: Greece, the Hellenistic World and the Rise of Rome. Cambridge, Cambridge University Press, pp. 325-356 
TAGLIAMONTE, G. (1994): I Figli di Marte: Mobilita e Mercenariato Italici in Magna Greci Sicilia. Rome, Archaeologica 15.

THOMAS, G. S. (1984): Mercenary Troops in Modern Africa. London, CO, Westview.

TOD, M. N. (ed.), (1948): A Selection of Greek Historical Inscriptions, Oxford, Oxford University Press.

TOOGOOD, N. (1997): "Athens Aids Eretria: A State's Jurisdiction over its Citizens'

Actions". The Classical Quarterly, n 47, pp. 295-7.

TOURRAIX, A. (1999): "Les mercenaries grecs au service des Achéménides". BRUN, P. (ed.), Guerres et sociétés dans les mondes grecs 490-322. Paris, Editions du Temps, pp. 201-16.

TRUNDLE, M. F. (1998): "Epikouroi, Xenoi and Misthophoroi in the Classical Greek World". War and Society, n' 16, pp. 1-12.

TRUNDLE, M. F. (1999): "Identity and Community Among Greek Mercenaries in the Classical World: 700-323 BCE". Ancient History Bulletin, $n^{\circ}$ 13, pp. 28-38.

TRUNDLE, M. F. (2004): Greek Mercenaries from the Late Archaic Age to Alexander the Great. London and New York, Routledge.

TRUNDLE, M. F (2006): "Money and the Great Man in the Fourth Century BCE: Military Power, Aristocratic Connections and Mercenary Service". LEWIS, S. (ed.), Ancient Tyranny. Edinburgh, University Press Edinburgh, pp. 65-76.

TRUNDLE, M. F. (2010a): "Coinage and the Transformation of Greek Warfare". FAGAN, G. and M. F. TUNDLE (eds.), New Perspectives on Ancient Warfare. Leiden, Brill, pp. 229-252.

TRUNDLE, M. F. (2010b): "Light Troops in Classical Atthens". PRITCHARD D. (ed.), War, Culture and Democracy in Classical Athens. Cambridge, Cambridge University Press, pp. 139-160.

TRUNDLE, M. F. (2013): "Professional Soldiers in Antiquity". TRITLE, L. and CAMPBELL, B. (eds.), The Oxford Handbook of War. Oxford, Oxford University Press, pp. 407-441.

TRUNDLE, M. F. (2016): "Coinage and the Economics of the Athenian Empire". ARMSTRONG, J. (ed.), Circum Mare: Themes in Ancient Warfare. Leiden, Brill, pp. 65-79.

TUPLIN, C. (1987): "Xenophon and the Garrisons of the Achaemenid Empire". Archaeologische Mitteilungen aus Iran, $\mathrm{n}^{\circ} 20$, pp. 167-245. 
TUPLIN, C. (1999): "On the Track of the Ten Thousand". Revue des etudes anciennes, $\mathrm{n}^{\circ}$ 101, pp. 331-366.

WEES, H. van. (2004): Greek Warfare: Myths and Realities. London, Duckworth.

WEES, H. van, (2016): "The Eastern Way of War: hoplites and their nonGreek cousins". Paper Presented in SOUZA, Philip de (organizer), New Approaches to Ancient Greek Warfare, University College Dublin.

WEISKOPFF, M. (1989): The So-Called 'Great Satraps' Revolt' 366-360 B.C.: Concerning Local Instability in the Achaemenid Far West. Stuttgart, Franz Steiner Verlag.

WHITEHEAD, D. (1991): "Who Equipped Mercenary Troops in Classical Greece?". Historia, n 40, pp. 105-113.

YALICHEV, S. (1997): Mercenaries of the Ancient World. London, Constable. 


\title{
LOS SOLDADOS DEL EJÉRCITO ROMANO DURANTE LA ETAPA DEL ALTO IMPERIO. SUS COMPONENTES MÁS BÁSICOS: EL CIUDADANO-SOLDADO (LEGIONARIO) Y EL SOLDADO AUXILIAR
}

\section{THE SOLDIERS OF THE ROMAN ARMY DURING THE STAGE OF THE HIGH EMPIRE. HIS MORE BASIC COMPONENTS: THE CITIZEN-SOLDIER (LEGIONARY) AND THE AUXILIARY SOLDIER}

\author{
Eduardo Pitillas Salañer \\ Universidad de Oviedo
}

\section{RESUMEN}

El ejército romano y sus soldados (legionarios y/o auxiliares) fueron el mejor ejemplo de disciplina y eficacia en combate durante la Antigüedad. Integraron un ejército patriótico, no mercenario, y con profundo sentido del deber. Muchos soldados indígenas, reclutados por todo el Imperio y abundantes en el NW de Hispania, formaron parte de sus fuerzas como tropas auxiliares (auxilia) en alas de caballería y cohortes de infantería, o bien en grupos mixtos (cohortes equitatae). Tales fuerzas auxiliares sirvieron allí donde eran necesarias (límites fronterizos) y sufrieron traslados (dislocaciones) en función de las necesidades militares romanas.

Palabras clave legionario, auxiliar, legión, cohorte, ala.

\section{ABSTRACT}

The Roman army and his soldiers (legionary or auxiliary) were the best example during the antiquity of discipline and efficiency in combat. They integrated a patriotic, albeit not mercenary, army with deep sense of duty. Many indigenous soldiers recruited across the whole Empire, and abundant in the northwest of Roman Spain, served as auxiliary troops (auxilia) in wings of cavalry and cohorts of infantry or mixed groups (cohortes equitatae). Such auxiliary forces served where they were necessary (frontier limits) and they suffered movements (dislocations) depending on such military needs.

Keywords: legionary, auxiliary, legion, cohort, wing. 


\section{RESUM}

Els soldats de l'exèrcit romà durant l'etapa de I'Alt Imperi. Els seus components més bàsics: el ciutadà-soldat (legionari) i el soldat auxiliar

L'exèrcit romà i els seus soldats (legionaris i/o auxiliars) van ser el millor exemple de disciplina i eficàcia en combat durant l'Antiguitat. Van integrar un exèrcit patriòtic, no mercenari, i amb profund sentit del deure. Molts soldats indígenes, reclutats per tot l'Imperi i abundants en el NW d'Hispània, van formar part de les seves forces com a tropes auxiliars (auxilia) en ales de cavalleria i cohorts d'infanteria, o bé en grups mixtes (cohortes equitatae). Tals forces auxiliars van servir allí on foren necessàries (límits fronterers) i van patir trasllats (dislocacions) en funció de les necessitats militars romanes.

Paraules clau: legionari, auxiliar, legió, cohort, ala. 


\section{AsPeCtos Generales del eJÉRCITO ROMANO en la etAPA RePUBLICANA Y ALTO-IMPERIAL}

Es de sobra conocida la fama "de invicto" del ejército romano durante la Antigüedad.' Obviamente, se trata de un cliché basado en el índice de profesionalidad alcanzado por sus integrantes a lo largo del tiempo. ${ }^{2}$ No es comparable el ejército republicano, tremendamente agresivo, que coincide con la etapa de mayor expansión territorial y que causó el asombro de Polibio $^{3}$-historiador griego acogido en el seno familiar de los Escipiones- ${ }^{4}$ de aquel otro de etapa imperial, ya muy profesional, que pretendía mantener asegurados los límites de unas fronteras trazadas hacía tiempo. En el segundo de los casos se trataba de un ejército permanente y de naturaleza básicamente defensiva.

Así, tras la masacre del saltus Teutoburgiensis (9 d. C.), el propio Augusto tuvo que reconocer que, a partir de aquel momento, el límite razonable del Imperio iba a ser el Rin y no el Elba, tal y como se había pretendido en una etapa inmediata, cuando tuvieron lugar las correrías de Druso (I), víctima

1 GARLAN, Y. (2002): La Guerra en la Antigüedad. Madrid, Alderabán Ediciones. CONNOLLY, P. (2016): La guerra en Grecia y Roma. Madrid, Desperta Ferro Ediciones SLNE.

2 WOLFF, C. (2012): L'armée romaine. Une armée modéle?. París, CNRS Éditions.

3 El ejército consular (dos legiones, de 4.200 a 5.000 hombres) [Pol., VI, 19, 9] contaba con el apoyo de los aliados itálicos (socii), especialmente en caballería, dado que esta última (300, luego 120 jinetes) era muy reducida. Los aliados se disponían en línea de batalla a los lados (alas), siendo ésta su ubicación más frecuente. La legión manipular estaba compuesta por treinta manípulos y sesenta centurias (un manípulo equivalía a dos centurias). La palabra legión tenía el significado de "leva" y Roma constituía el "pueblo en armas". En la legión manipular polibiana, en primera línea se situaban los hastati (hastados o portadores de lanza), unos mil doscientos; en segunda línea los principes (otros mil doscientos); en tercera línea los triarii (triarios, los más veteranos, unos seiscientos). Por delante y en grupos menos compactos actuaban los integrantes de la infantería ligera (velites, otros mil doscientos).

4 Sin ir más lejos, Publio Cornelio Escipión, el que emprendiera una exitosa campaña en Hispania con la toma de Cartago Nova (209 a. C.) y su posterior y definitiva victoria en Zama (202 a. C.) frente a Aníbal Barca.

5 Fallece a los treinta días de su infortunada caída: BRINGMANN, K. (2008): Augusto. Barcelona, Herder Editorial, p. 203. 
de un infortunado accidente a caballo (9 a. C.). ${ }^{5}$ Entre esas dos fechas, la expansión en Germania se redujo y se contemplaron las cosas desde una perspectiva más realista: ${ }^{6}$ el permeable limes quedó fijado definitivamente en tierras renanas. Esto hizo posible la existencia de ciudades (civitates) de marcado contraste y contacto cultural como fue el caso de Colonia Agrippiniensis (actual Colonia), lugar no exento de tensiones ${ }^{7}$ entre la población mixta galo-romana y el entorno externo germano (gentes externae, barbaricum...) tal y como afloró en la revuelta de Julio Civil, el caudillo bátavo. ${ }^{8}$ Y es que Germania, donde tantos itálicos e hispanos auxiliares combatieron y donde no pocos perdieron la vida, constituye un escenario de enfrentamiento de singular relevancia.

Sea como fuere cabe indicar que a aquel ejército agresivo de etapa republicana ${ }^{9}$ siguió otro que pretendía mantener lo ya conquistado, ${ }^{10}$ y del que hace una descripción Flavio Josefo ${ }^{11}$ en su marcha hacia Judea. ${ }^{12} \mathrm{De}$ hecho, ambas fuentes literarias, la del historiador griego de Megalópolis -un griego sospechoso a ojos de Roma- y la del judío que en el asedio romano a Jotapata se desentendió y, posiblemente, se desilusionó en su apoyo a los rebeldes, podemos hacernos una idea de cómo se articulaba la estructura de las legiones -en manípulos y cohortes durante la época de Polibio-, o bien cómo desplegaba su fuerza de combate el ejército romano en marcha, en el caso de Flavio Josefo. Todas estas cuestiones escapan a un trabajo como éste, en el que más que fijarnos en aspectos técnicos, necesarios y nada desdeñables por otro lado, nos ceñiremos a destacar los

6 Sobre el sueño de Druso: PITILLAS SALAÑER, E. (2010): "Los límites (¿̇necesarios?) del expansionismo romano en etapa altoimperial: El sueño de Druso". ETF, Serie II, Historia Antigua, t. 23, pp. 231-244.

7 Tac., Hist., IV, 64, 2-3.

8 Aunque con ello salvaba, en cierta medida, su "test" de romanización (en expresión de J.J. Hatt): PITILLAS SALAÑER, E. (2010), Roma. La forja de un imperio. Zaragoza, Libros Pórtico, p. 61 y 71 y ss.

9 AA.VV., (2013; 2015-2016): "La legión romana (I, La República Media y II, la Baja República)". Desperta Ferro, Números Especiales VI y VIII.

10 En época del emperador Claudio se ocupó Britannia, mientras que la Dacia lo fue posteriormente, bajo Trajano. AA.VV., (2016-2017): "La legión romana (III, El primer siglo del imperio)". Desperta Ferro, Número Especial X.

11 HADAS LEBEL, M. (1994): Flavio Josefo. El judío de Roma. Barcelona, Editorial Herder.

12 F. Josefo, Bell. lud., III, 73-97. PITILLAS SALAÑER, E. (2013): La Guerra de los judíos y la destrucción de Jerusalén (66-70 d. C.). Zaragoza, Libros Pórtico, pp. 160-162. 
aspectos más "sociales" del ejército romano. ${ }^{13}$ Y desde este último punto de vista, como en ocasiones ha manifestado Narciso Vicente Santos Yanguas, el ejército romano del siglo $\| \mathrm{d}$. C. debe ser contemplado más como un contingente para la "paz" que como una fuerza armada profesionalizada y que pretendía, desde la época del emperador Adriano, mantener sendas fronteras y territorios dentro de una determinada estabilidad, basada más en la participación e integración ${ }^{14}$ que en el simple y brutal uso de la fuerza. Por ende, la época de los Antoninos fue la más relevante, culta y armoniosa de toda la etapa imperial.

Todo ello lleva también a diferenciar la composición de ese mismo ejército, incluso desde sus orígenes republicanos: la existencia de soldados-ciudadanos que integraban las legiones romanas a las que se añadían, como apoyo y complemento, especialmente en caballería -equites-, los aliados (socii). Así, romanos e itálicos combatieron fuera de sus lugares de origen y sentaron las bases de un extenso imperio, ya en etapa republicana, en torno a aquellas tierras que bordeaban el mare nostrum o internum. Durante la época imperial los aliados, una vez integrados dentro de las estructuras políticas y ciudadanas de la Urbs, fueron sustituidos por tropas auxiliares que se reclutaron en los recién incorporados territorios fronterizos del Imperio. Sobre la cuestión de estos auxilia abordaremos sus mecanismos de integración y promoción social, aspectos interpretativos que se deducen epigráficamente de los estudios prosopográficos de soldados romanos indígenas ${ }^{15}$ que sirvieron, en singular proporción, en cohortes de infantería (cohortes) y alas de caballería (alae), ${ }^{16}$ o bien en grupos mixtos (cohortes

13 Para el caso hispano, por ejemplo: ROLDÁN HERVÁS, J.M. (1974): Hispania y el ejército romano. Contribución a la historia social de la España Antigua. Ediciones Universidad de Salamanca, Salamanca. ÍD. (1989): Ejército y sociedad en la España Romana. Granada, Servicio de Publicaciones de la Universidad de Granada.

14 BRAVO G.-GONZÁLEZ SALINERO, R. (2009): Formas de integración en el mundo romano, Actas del VI Coloquio de las AIER. Madrid, Signifer Libros (para el ejército: p. 97 y ss.).

15 SANTOS YANGUAS, N. (1981): El ejército romano y la romanización de los astures. Oviedo, Asturlibros. ÍD. (1988), El ejército y la romanización de Galicia. Conquista y anexión del Noroeste de la Península Ibérica. Oviedo, Servicio de Publicaciones de la Universidad de Oviedo. Sobre los astures las monografías más recientes en ÍD. (2006): Ejército romano, administración y vida civil en territorio de los astures. Astorga, Ediciones Monte Casino. ÍD., (2010): Militares astures en el ejército romano, Aquila Legionis 13. Madrid, Signifer Libros.

16 O cohortes mixtas (cohortes equitatae). 
equitatae) de tropas auxiliares. Estas, numéricamente, venían a duplicar el montante total legionario: unos 125/150.000 hombres; luego, a ellos habría que añadir en torno a 125/150.000 pertenecientes, por lo tanto, a tales cuerpos auxiliares.

Es necesario también puntualizar, aunque sea simplemente de pasada, que a diferencia de los ejércitos helenísticos durante el periodo republicano, los romanos no recurrieron-salvo contadas excepciones- a soldados mercenarios, ya que el fundamento legionario se apoyó siempre en el soldado-ciudadano, es decir, en un tipo de milicia civil cada vez más profesionalizada y homogeneizada. ${ }^{17}$ Ese ejército, de base censitaria y movilizado sistemáticamente todos los años -básicamente, dos legiones para cada cónsul-, era un buen ejemplo de una fuerza de naturaleza cívico-patriótica.

Los romanos nunca confiaron el grueso de sus tropas a mercenarios a sueldo. Su modelo fue completamente diferente al del ejército cartaginés $y$, obviamente, a todos aquellos que movilizaron los poderosos estados helenísticos dados al gigantismo con la utilización de enormes helépolis ${ }^{18}$ e, incluso, de nutridos grupos de elefantes. ${ }^{19}$ Desde este punto de vista, el ejército romano respondió a un sentido cívico, patriótico y pragmático basado en la disciplina del aprendizaje que le dio una enorme cohesión moral. Este aspecto no era nada desdeñable, pues la cohesión del "frente interno" fue siempre notable, tal y como se mostró en los momentos de máxima dificultad a partir de la derrota de Cannas (Cannae, 2 de agosto 216 a. C.). ${ }^{20}$ Ese frente interno, sólido, no se desmoronó. ${ }^{21}$

De todos los ejércitos de la Antigüedad, el romano fue el más sofisticado y, en suma, el que alcanzó mayor nivel de profesionalización tanto desde el punto de vista de la estructura de mandos como en los aspectos derivados

17 Aunque la vestimenta nunca fue del todo homogénea y uniforme como ocurre en los ejércitos contemporáneos.

18 Torres de asalto artilladas. Vid., SAEZ ABAD, R. (2005): Artillería y poliorcética en el mundo grecorromano, Anejos de Gladius 8. Madrid, CSIC. ÍD. (2009): Los grandes asedios de las legiones romanas. Madrid, Almena Ediciones.

19 Sobre la utilización del animal en la guerra antigua: OLESTI, O., VIDAL, J. y ANTELA, B. (eds.) (2014): Animales y Guerra en el Mundo Antiguo. Zaragoza, Libros Pórtico.

20 LANCEL, S. (1997), Aníbal. Barcelona, Crítica, pp. 134-141. BARREIRO RUBíN, V. (2004): La guerra en el Mundo Antiguo. Madrid, Almena Ediciones, pp. 262-263. BRIZZI, G. (2009): Escipión y Aníbal. La guerra para la salvación de Roma. Madrid, Editorial Ariel, pp. 62-69.

21 Aníbal (Hannibal), desde la mentalidad de un soberano "helenístico", no podía entender que Roma no llegara a un acuerdo o tregua en una guerra que los romanos estaban llevando a cabo con un patriotismo y una ferocidad sin límites. 
de su logística ${ }^{22}$ o del propio armamento. ${ }^{23}$ Estaba integrado por soldados convenientemente alimentados, solteros, y cuya profesión les permitía, cuanto menos, permanecer alejados de una vida menos estable fuera de las legiones y/o cuerpos auxiliares (auxilia). En el caso de los peregrini, que no poseían el estatus de ciudadano romano y estaban encuadrados en cohortes de infantería y alas de caballería, la promoción social parece evidente. En términos generales, el ejército romano que evolucionó notablemente de etapa republicana a la imperial y, dentro de ésta última, entre el alto ${ }^{24}$ y el bajo imperio ${ }^{25}$, con un número de integrantes no demasiado alto, basó su actividad mucho más en la eficacia y en la calidad de sus integrantes que en su número. A partir del reinado del emperador Augusto quedaron establecidos un tipo de armamento y un número de legiones veintiocho, reducidas a veinticinco tras la derrota de Publio Quintilio Varo (Publius Quinctilius Varus) en Germania- que, levemente, aumentaron a lo largo de las dinastías de los siglos I y II d. C. Todos los historiadores muestran su acuerdo en cuanto a su superioridad y eficacia en el campo de batalla, lo que no quiere decir obviamente que no sufriera derrotas.

Así, su efectividad no parece ser simple resultado del azar sino la muestra fehaciente del método $y$, llegado el caso, del buen tino de sus generales, ${ }^{26}$ aunque no todos ellos siempre afortunados. A este respecto hizo mucho la existencia de un cuerpo de oficiales y suboficiales ${ }^{27}$ no formados en academia alguna, que fueron el "nervio" de las legiones y de las unidades au-

22 Sobre la logística y el avituallamiento del ejército romano, vid., por ejemplo: MENÉNDEZ ARGÜÍN, R. A. (2004): Las legiones romanas de Germania (s. II-III): aspectos logísticos. Écija, Editorial Gráficas Sol.

23 Vid., recientemente: BISHOP, M.C. y COULSTON, J.C.N. (2016): Equipamiento militar romano. De las guerras púnicas a la caída de Roma. Madrid, Desperta Ferro Ediciones.

24 GILBERT, F. (2006), Légionnaires et auxiliaires sous le Haut-Empire Romain. París, Éditions Errance.

25 LE BOHEC, Y. (2006), L'armée romaine sous le Bas-Empire. París, Picard.

26 PEREA YÉBENES, S. (ed.) (2004): Res Gestae - Grandes generales romanos - (I). Madrid, Signifer Libros. GOLDSWORTHY, A. (2005): Grandes generales del ejército romano. Campañas, estrategia y tácticas. Barcelona, Editorial Ariel.

27 Si se me permite la expresión, algo arriesgada, en comparación con los ejércitos ya de etapa moderna o, mejor aún, contemporánea, podría considerarse a los "oficiales" por encima del centurión, vid: LE BOHEC, Y. (2004): El ejército romano. Instrumento para la conquista de un imperio. Barcelona, Editorial Ariel, p. 50. 
xiliares. ${ }^{28}$ Me refiero básicamente a los centuriones, ${ }^{29}$ algunos de probada experiencia en el campo de batalla como el primus pilus ${ }^{30}$ o el praefectus castrorum (prefecto del campamento). Los diez centuriones procedentes de la primera centuria de cada cohorte tenían una mayor consideración y formaban los denominados primi ordines. Dentro de los centuriones existían tres categorías (pilus, princeps y hastatus) y dos posiciones en la formación (prior y posterior). De todo ello se deduce que la jerarquía en el mando era fundamental. ${ }^{31}$ El simple ejemplo de los centuriones-ayudados por el optio, y el más capacitado para acceder al centurionado: el optio ad spem ordinis- sirve para mostrar la idea de que las legiones romanas ${ }^{32}$ basaron su eficacia en la organización y estructuración. El grupo más reducido de soldados (ocho en total, denominado contubernium) vivía en un mismo espacio dentro del campamento ${ }^{33}$ y sus integrantes hacían la comida. Entre ellos surgían, llegado el caso, fuertes lazos de solidaridad y amistad (amici) que se extendían a la centuria-ochenta hombres, en etapa altoimperial- $y$, finalmente, a la cohorte -cuatrocientos ochenta hombres; seis centurias-, ${ }^{34}$ unidad táctica muy relevante y operativa.

Todo ello ayuda a comprender que el soldado romano también mantenía fuertes lazos de amistad con sus compañeros de armas (conmilitones), junto a los que luchaba escudo con escudo. Y todo ello al margen, como señalaremos más adelante, de la fidelidad debida al emperador y a los símbolos legionarios. Así pues las legiones y los cuerpos auxiliares constituyen el núcleo de un ejército profesional que basó su eficacia en el duro entrenamiento ya desde los inicios de la leva ${ }^{35}$ y en la práctica continuada del ejército en marcha (agmen), de la castramentación (castra, campamento) y de una logística y unos medios de abastecimiento potenciados, a todas

28 Muy bien considerados por César.

29 Cincuenta y nueve (o sesenta) por legión.

30 Centurión de la primera centuria de la primera cohorte.

31 Este no es el lugar, por fuerza, para establecer la jerarquía completa de una legión: LE BOHEC: El ejército romano, p. 51 y ss.

32 Estudio sobre las legiones: RODRíGUEZ GONZÁLEZ, J. (2001): Historia de las legiones romanas, II vols. Madrid, Signifer Libros.

33 Un vestíbulo para guardar pertrechos (arma) y el dormitorio propiamente tal con literas (popilio). Vid., Sala 5, Centro de Interpretación del León Romano (Casona de Puerta Castillo, León).

34 Ello es válido para nueve cohortes excepto la primera cohorte que tenía 5 centurias dobles (160 hombres por centuria con un total de 800 hombres).

35 Reclutas (tirones). 
luces, por el trazado sistemático de una red viaria que permitía el transporte de alimentos y armas. Algo que fue posible debido a la acción de todo un cuerpo de oficiales, con función logística y administrativa, tales como procuratores, beneficiarii, praefectus castrorum, praefectus fabrum, etc. ${ }^{36}$

La disposición flexible en manípulos y cohortes (legión manipular, posteriormente legión cohortal, o bien organizada en cohortes) pudo ya, desde el siglo II a. C., hacer a la legión superior a la falange macedónica, ${ }^{37}$ aunque exista actualmente un debate acerca de esa supuesta superioridad y, al mismo tiempo respecto al momento preciso en que se crearon dichas cohortes. ${ }^{38}$ Es posible que tanto el manípulo (dos centurias) como la cohorte (seis centurias) se emplearan indistintamente desde la Segunda Guerra Púnica en Hispania, hasta que la segunda acabó por imponerse definitivamente durante la conocida reforma de Mario (107-104 a. C). La victoria de Paulo Emilio en Pidna ${ }^{39}$ sobre Perseo pudo haber sido grosso modo ese punto hipotético de inflexión. Así, frente al demoledor rodillo generado por el largo muro de lanzas de las falanges (la sarissa), ${ }^{40}$ los soldados romanos aprendieron a operar en grupos más reducidos, lo que les permitiría desenvolverse mejor en suelos quebradizos y ondulantes.

En este sentido, los romanos no sólo hacían uso de la fuerza y la determinación como elementos clave de su enfoque militar, sino que además innovaban constantemente respecto a organización y tácticas, cuestión que les condujo a obtener la victoria sobre el conjunto de los reinos helenísticos de la época. Igualmente, esa determinación se manifestaba en el hecho de que emprendían nuevas campañas militares todos los años, en el momento en el que llegaba la primavera. La guerra era declarada siguiendo un ritual establecido por sacerdotes destinados a tal efecto, los feciales, con el objetivo de mostrar que se trataba de una guerra justa (bellum iustum) y que, por ende, contaban con el favor de los dioses.

Campaña tras campaña, Roma fue doblegando a sus principales enemigos en una serie de importantes y cruentas guerras. Primero en la propia Italia,

36 MENÉNDEZ ARGÜÍN, Las legiones romanas de Germania, p. 357 y ss.

37 Liv., XLIV, 36-42.

38 CADIOU, F. (2001): "Les guerres en Hispania ef l'emergence de la cohorte legionnaire dans l'armée romaine sous la république: une revisión critique", Gladius, n² 21, pp. 167-182.

39 GOLDSWORTHY, Grandes generales, p. 79 y ss. LENDON, J.E. (2006): Soldados y fantasmas. Historia de las guerras en Grecia y Roma. Barcelona, Editorial Ariel, p. 257 y ss.

40 QUESADA SANZ, F. (2008): Armas de Grecia y Roma. Madrid, La Esfera de los Libros, p. 127 y ss. 
sabinos, etruscos, volscos y samnitas, tras encarnizadas luchas, tuvieron que reconocer finalmente su autoridad. Su más peligroso enemigo, la talasocracia cartaginesa, acabó sucumbiendo tras tres costosos conflictos, las denominadas guerras púnicas: la Primera entre el 264-241 a.C., la Segunda entre el 218-201 a. C. y la Tercera entre el 149-146 a. C. Mediante ellas, Roma estableció su hegemonía en Occidente. Por lo que respecta a Oriente, tras la victoria frente a Cartago y a lo largo de los siglos II y I a.C. Roma neutralizó a las principales potencias helenísticas derrotando a importantes soberanos como Filipo V, Antíoco III, Perseo y Mitrídatres VI Eupátor. Para Roma, la paz de Apamea (188 a. C. $)^{41}$ fue un momento decisivo en el control de todo aquel escenario al evidenciar quién iba a ejercer un dominio total sobre ambas orillas del Mediterráneo. Para ello, se sirvió de una prominente diplomacia, en gran medida unilateral, que hizo de la potencia itálica el "gendarme" del Mare Nostrum. ${ }^{42}$

A diferencia de los ejércitos mercenarios helenísticos, entre los que también se incluye el cartaginés, el romano constituía una fuerza militar integrada por ciudadanos-soldado. Roma no estuvo a merced de tropas mercenarias donde el retraso en las pagas, la carencia de botín o cualquier otro inconveniente podían echar por tierra una operación militar. El botín estaba perfectamente reglado bajo la autoridad del magistrado encargado de ello por lo que, desde ese punto de vista, cabe pensar que la normativa y la disciplina funcionaban adecuadamente en la mayoría de los casos. De hecho, la disciplina, en algunos casos incluso brutal, marcaba los límites de una libertad estrechamente definida, algo que los soldados romanos sabían desde el momento de su juramento, pues el comandante de cada unidad tenía derecho sobre sus vidas en caso de flagrante indisciplina, traición o cobardía. A ello podían sumarse castigos corporales o la expulsión fuera del campamento (castra).

La participación de los ciudadanos romanos ${ }^{43}$ en las legiones respondía, en origen, a un carácter, marcadamente jerárquico y timocrático. Sin embargo, el hecho de que los ciudadanos-propietarios tuvieran que ser compensados con una ayuda económica (stipendium) cuando luchaban fuera

41 PITILLAS SALAÑER, E. (2015): La diplomacia romana de época republicana (241-27 a. C.). Zaragoza, Libros Pórtico, pp. 55-61.

42 VEYNE, P. (1975): "Y a-t-il eu un impérialisme romain?", MEFRA, n 87, pp. 793-855. ÍD. (2009): El imperio grecorromano. Madrid, Akal.

43 Las legiones no admitían extranjeros (peregrini), ya que para eso estaban los cuerpos auxiliares (auxilia). Y, salvo algún caso muy excepcional y límite, mucho menos aún esclavos. 
de las fronteras romanas hizo que estos perdieran progresivamente el interés por formar parte de las legiones. Así, con el paso del tiempo, dichas legiones tendieron a la profesionalización y a dar entrada a los más necesitados (capite censi), inclinándose a la proletarización ya con Cayo Mario. De este modo el ejército se convirtió en un medio de vida y de promoción social, un puesto de trabajo con una paga segura para ciudadanos de condición social humilde. Lo mismo cabría decir para los extranjeros que formaban parte de los cuerpos auxiliares (auxilia), algo que nos impide olvidar su enorme función social.

El ejército romano de la tardía república (siglo I a. C.) fue adquiriendo progresivamente la fisonomía que tendría durante la etapa de Augusto. ${ }^{44}$ En este sentido, las veintiocho legiones pasarían a ser veinticinco, ${ }^{45} \mathrm{con}$ la consiguiente pérdida de tres ${ }^{46}$ tras la derrota sufrida el 9 d.C. en Teutoburgo a manos del caudillo querusco Arminio, adquiriendo así el número estándar de formaciones que habría en el Imperio al inicio de la Pax Ro-

44 SYME, R. (1989): La revolución romana. Madrid, Taurus Humanidades. Vid., más recientemente: BRINGMANN, Augusto. SOUTHERN, P. (2013): Augusto. Madrid, Editorial Gredos. GOLDSWORTHY, A. (2014): Augusto. De revolucionario a emperador. Madrid, La Esfera de los Libros. PITILLAS SALAÑER, E. (2014): Augusto, el estadista. Ficción de una república restaurada. Zaragoza, Libros Pórtico.

45 En el año 20 d. C., en época ya del emperador Tiberio, la distribución era la siguiente: ocho en Germania (cuatro en Germania inferior y otras cuatro en Germania superior); cuatro en Siria; tres en Panonia; tres en Hispania Citerior; dos en Dalmacia y otras dos en Mesia; dos en Egipto y una más en África Proconsular. Concretamente las legiones eran las siguientes: I Germanica (*), II (**) y III Augusta (***), III Cyrenaica (+), III Gallica (++), IIII Macedonica $\left({ }^{*}+\right)$, IIII Scythica $(\wedge), V$ Alauda $\left({ }^{*}\right)$, V Macedonica $(\wedge)$, VI Ferrata $(++)$, VI Victrix $\left({ }^{*}+\right)$, VII Macedonica $\left({ }^{\wedge}\right)$, VIII Augusta $\left(+^{*}\right)$, VIIII Hispana $\left(+^{*}\right), X$ Fretensis $(++), X$ Gemina $\left({ }^{*}+\right), X I$ Claudia $\left({ }^{\wedge *}\right)$, XII Fulminata $(++), X I I I$ Gemina $\left({ }^{* *}\right), X I I I I$ Gemina $\left({ }^{* *}\right), X V$ Apollinaris $\left({ }^{*}\right)$, XVI Gallica (**), XX Valeria Victrix (*), XXI Rapax (*) y XXII Deiotariana (+). Salvo algunas modificaciones, hacia el $75 \mathrm{~d}$. C., por ejemplo, su número se había elevado a veintinueve: la XVI Gallica pasó a denominarse XVI Flavia y se añadió una de nueva creación: la IIII Flavia. Se alcanza el número de treinta con el emperador Domiciano, al añadirse la I Minervia. Bajo Trajano, también se contabilizan treinta, si bien había desaparecido previamente la $V$ Alauda (¿286 d. C. ?) en la guerra que Domiciano mantuvo contra los dacios; luego le tocó el turno a la XXI Rapax (aniquilada prácticamente en el $92 \mathrm{~d}$. C. contra los sármatas yáziges); ello obligó a rellenar tales huecos con dos de nueva creación: la II Traiana y la XXX Ulpia Victrix. [( $\left.{ }^{*}\right)$ Germania Inferior; $\left({ }^{* *}\right)$ Germania Superior; $\left({ }^{* *}\right)$ África Proconsular; $(+)$ Egipto; $(++)$ Siria; $\left({ }^{*}+\right)$ Hispania Citerior; $(\wedge)$ Mesia; $\left({ }^{\wedge}\right)$ Dalmacia; $\left(+^{*}\right)$ Panonia]. Vid., RODRÍGUEZ GONZÁLEZ, Historia de las legiones romanas, p. 696.

46 Las innominadas XVII, XVIII y XVIIII. 
mana. Estas fuerzas se componían a partes iguales de legiones y unidades auxiliares, no siendo en conjunto excesivamente numerosas ${ }^{47}$ pero estando claramente profesionalizadas, lo que permitió a los distintos emperadores contener a sus enemigos en los límites del Imperio.

Sea como fuere, el hecho de combatir por un salario, ${ }^{48}$ rasgo de la profesionalización del ejército romano, en modo alguno estaba reñido con la fidelidad al emperador, vértice del estado imperial. La lealtad a los emblemas militares (aquila, signa...) ${ }^{49}$ resultaba de naturaleza obligada, a la par que el esprit de corps y el orgullo de pertenencia a una centuria, cohorte o legión, así como a un determinado cuerpo auxiliar. El emperador era, a partir de Augusto, jefe supremo del ejército y a él se tributaba lealtad máxima mediante el juramento a su persona. ${ }^{50}$ Los mandos militares (legati Augusti) dependían de él y los triunfos ${ }^{51}$ eran monopolizados política y propagandísticamente por el emperador, en vez de recaer en sucesivos cónsules como ocurrió durante la etapa republicana.

Por último, la disciplina y profesionalidad permitía "matar sin dejarse matar". Esta idea consistía en la capacidad de las legiones y sus integrantes de controlar el pánico, algo no siempre fácil, y mantener la formación.

47 Finalmente, bajo la dinastía iniciada con Septimio Severo, en el paso del siglo II al III d. C., se aumenta de treinta a treinta y cuatro legiones: las incorporaciones fueron la I, II y III Parthica (con Septimio Severo) y, por último, la IIII Italica (con Severo Alejandro).

48 En época de César (y luego con Augusto) era de 225 denarios anuales para un legionario y la mitad para un auxiliar. Esta cantidad se vería aumentada posteriormente a 300 denarios bajo el emperador Domiciano. Los pretorianos cobraban 750 denarios, que ascendieron a 1.000 con Domiciano.

49 QUESADA SANZ, F. (2007): Estandartes militares en el mundo antiguo, Aquila Legionis 8. Madrid, Signifer Libros.. Sobre la tipología y simbología del aquila: KAVANAGH DE PRADO, E. (2015): Estandartes en la Roma antigua. Tipos, simbologías y función, Anejos de Gladius 16. Madrid, p. 28 y ss; pp. 578-582.

50 Para el juramento militar vid., JIMÉNEZ DE FURUNDARENA, A. (2004): "Control religioso y social en el ejército romano: el sacramentvm", Actas del XXVII Congreso Internacional Girea-Arys I. Jerarquías religiosas y control social en el mundo antiguo, Valladolid, pp. 485-489. Juramento pronunciado en Paflagonia (Asia Menor) por provinciales y ciudadanos romanos: "Juro por Zeus, por la Tierra, por el Sol, por todos los dioses y las diosas y también por el mismo Augusto, que durante toda mi vida seré leal a César Augusto, a sus hijos y descendientes de palabra, de obra y de sentimiento, porque consideraré mis amigos a los que él considere amigos y enemigos a los que él considere enemigos...": BRINGMANN, Augusto, p. 235.

51 BEARD, M. (2009): El triunfo romano. Una historia de Roma a través de la celebración de sus victorias. Barcelona, Crítica. 
En este sentido resultaba clave el papel jugado por los centuriones en sus diferentes posiciones dentro de las cohortes y centurias que conformaban la legión. De hecho, el propio César, que se encargaba de dirigir el planteamiento táctico de la batalla, se veía obligado en ocasiones a reforzar la moral de centuriones y legionarios, evitando así el hundimiento de la línea de combate (acies). Su presencia animaba y daba fuerzas a los legionarios en los momentos críticos del combate, lo que permitía no conceder al enemigo ninguna ventaja táctica producida por el pánico de la tropa-situación en la que podía sobrevenir el desastre- evitando así dar la espalda al enemigo que era, en definitiva, lo peor que se podía hacer. No en vano, la inmensa mayoría de los muertos en batalla en la Antigüedad presentan heridas mortales en la espalda como resultado de la huida, algo que refuerza esta idea de la necesidad de mantener la formación durante el combate. Ello hacía del legionario romano un soldado y no un simple guerrero: el guerrero, sin discutir su capacidad personal en el combate, tiende a luchar individualmente, mientras que el soldado tiene conciencia de que lucha en grupo y de que precisamente por hacerlo así puede superar la acción temeraria e indisciplinada del guerrero. El método y la disciplina, no reñida con el valor y el arrojo, complementan estas últimas facultades. ${ }^{52}$

\section{EL ALISTAMIENTO DEL SOLDADO ROMANO}

A los cuarenta y cinco años, M. Ulpio Trajano, ${ }^{53}$ nacido en Hispania (Hispania Ulterior Baetica) en el año $53 \mathrm{~d}$. C., accedía al trono imperial. El imperio se encontraba en su momento de máximo apogeo. Aún tenía notable fuerza expansiva pero sus límites estaban ya bastante definidos desde el reinado de Augusto, dado que la mayor expansión territorial se había producido en época republicana. A ella había hecho alusión Polibio al afirmar que, en una cincuentena larga de años, Roma se había hecho dueña de todo el Mediterráneo. El ejército había sido el instrumento de esa expansión, gracias entre otras cosas a su organización, su logística, su sistema campamental, su disciplina o la jerarquía de sus mandos. La República había entrado en crisis en el siglo I a. C., cuando la corrupción casi sistémica había hecho mella en una estructura política marcada por violentas luchas de facciones. No obstante, a partir de aquel panorama de inestabilidad Augusto había conseguido afianzar una república con nuevo "rostro" basada en la concentración de poder en manos de su primer

52 Virtus = valor. Cualidad no reñida con el método y la eficacia (Y. Le Bohec).

53 ALVAR, J. y BLÁZQUEZ, J.M. (eds.) (2003): Trajano. Madrid, Ed. Actas. 
ciudadano, el emperador. Ese difícil equilibrio entre pasado republicano y futuro imperial, aún por hacer, estaba dando paso al Principado. Por su parte un ejército menos numeroso pero más profesionalizado que el de la etapa de las guerras civiles iba a ser capaz de dar estabilidad a unas fronteras (Germania, Panonia, Mauritania, Siria...) trazadas con unos "límites" cada vez más definidos.

Los ciudadanos romanos de condición humilde, desde época mariana, comenzaron a entrar en masa en los cuadros del ejército romano. Los aliados (socii) comenzaron a ser sustituidos por soldados reclutados en las fronteras recién incorporadas. En el caso de Hispania entre lusitanos, galaicos y astures, preferentemente. El $56 \%$ del total de las tropas auxiliares fueron movilizadas entre soldados procedentes de la actual Europa occidental, auténtico caladero de nuevos combatientes. ${ }^{54}$ Así, los indígenas no romanos (peregrini) se iban incorporando progresivamente a cohortes y alas, de infantería y caballería respectivamente. Incluso Roma también incorporaba entre las filas de su ejército tropas directamente reclutadas entre los pueblos limítrofes, bajo mandos indígenas propios y con sus propias armas y pertrechos bajo denominación genérica de numeri. Es necesario tener en cuenta que los mejores arqueros y honderos ya fueran palmirenos, ${ }^{55} \mathrm{cre}-$ tenses, o baleáricos se incorporarían, al igual que los jinetes (equites) que integraban las turmae de caballería, ${ }^{56}$ (en este caso procedente del área céltica y al frente de oficiales-decuriones-) como apoyo auxiliar de las legiones. Si los ciudadanos romanos de baja condición social encontraron en la milicia un modo de vida que les aseguraba una paga estable -un trabajador no cualificado podía ganar lo mismo que un soldado legionario pero su trabajo no era estable, y esa "temporalidad" lo hacía menos seguro y atractivo-, los auxiliares no ciudadanos se beneficiaban, aunque de una paga menor, de un empleo estable y de la posibilidad, en el momento de su licenciamiento, de acceder a la condición de ciudadano latina de segundo grado. ${ }^{57}$

Tenemos constancia de la existencia de tres tipos diferentes de reclutas a través de una carta de Plinio el Joven al emperador Trajano a propósito

54 LE BOHEC, El ejército romano, p, 130.

55 Procedentes de Palmira.

56 Escuadrón de unos 32 jinetes.

57 Ciudadanía de segundo grado que obtendrían en honesta misio tras veinticinco años de servicio. Los diplomas militares reflejan ese nuevo estatus junto al reconocimiento de sus uniones matrimoniales (ius conubii). 
de dos esclavos que pretendieron, saltándose las reglas, alistarse en el ejército. Como se trataba de una irregularidad manifiesta, en la respuesta del emperador se constata la existencia de tres procedimientos distintos de reclutamiento:

$\left.1^{\circ}\right)$ El obligatorio o forzoso (reclutas denominados lecti)

$\left.2^{\circ}\right)$ Reclutas sustitutos (vicarii)

$\left.3^{\circ}\right)$ Reclutas voluntarios (voluntarii) que eran la mayoría. ${ }^{58}$

De los tres sistemas el mejor y más deseable era el último. En el caso de los forzosos, se encargarían de llevar a cabo tal sistema de reclutamiento oficiales romanos, autoridades locales, o bien destacamentos que se encargarían de la leva (dilectus). Los sustitutos eran individuos obligados a tal servicio o, llegado el caso, por sus familias como precio a una liberación. ${ }^{59}$ Para alistarse en las legiones no lo podía hacer cualquiera que lo deseara sin más. Se requería de unas condiciones mínimas ${ }^{60}$, entre otras estar en posesión de la ciudadanía romana. Las legiones seguían siendo el núcleo ciudadano del ejército romano, un contingente nacional y patriótico. $\mathrm{Ni}$ los extranjeros ni los esclavos (mucho menos estos últimos), salvo contadas excepciones (caso de una guerra o de unas condiciones en extremo precarias de reclutamiento) podían formar parte de las legiones. Debían permanecer durante los años de servicio solteros, o bien aquellos casados que unilateralmente habían abandonado su anterior unión civil. Debían también superar un examen previo de buena salud e integridad física (no podían estar impedidos por falta del dedo índice o pulgar, por ejemplo). Además, tenían que tener una altura determinada, en torno a 1,70-1,77 metros. Se valoraba igualmente su buena visión. Obviamente tenían que ser hombres y estar dotados de genitales masculinos. Debían tener buen "carácter" y estar exentos de faltas penales graves (pequeños delitos no tendrían importancia). Finalmente necesitaban una "carta de recomendación" en un mundo, como el romano, en el que éste era un medio necesario

58 Y que servirían habitualmente para cubrir las bajas en el ejército.

59 GOLDSWORTHY, A. (2003): El ejército romano. Madrid, Akal, p. 76.

60 MATYSZAK, P. (2010): Legionario. El manual (no oficial) del soldado romano. Madrid, Akal, p. 8 y ss. 
para ascender socialmente. El que recomendaba, que podía ser un simple veterano, se hacía responsable moral del recomendado.

Por último, el recluta tenía que afrontar una entrevista personal tras la cual era aceptado en la fase de prueba (probatio). En ella se examinaban sus condiciones físicas y se comprobaba la veracidad de las pruebas que había presentado durante el proceso previo, al tiempo que se le hacía realizar el juramento militar (sacramentum) en el que cada uno de estos reclutas corroboraba ("idem in me"/"lo mismo digo") una fórmula general. Así, el recluta de etapa alto-imperial se incorporaba a una legión durante veinticinco años. El juramento comportaba, ante los dioses, que el nuevo soldado iba a servir fielmente a su emperador a costa de su propia vida, y en caso de cobardía o traición el comandante al que debía obedecer en todo momento podía castigarle con castigos físicos o, incluso, la muerte. Debía mostrar lealtad y fidelidad a los símbolos y estandartes militares (signa) y, de ese modo, su disciplina y respeto a la jerarquía de mandos harían del mismo el modelo de legionario que el imperio y el emperador precisaban. Los soldados romanos llevaban un pequeño identificador (signaculum), una especie de bolsa colgada al cuello a modo de "chapa" distintiva (tablilla de plomo) en la que figuraban detalles físicos personales (cicatrices, verrugas, por ejemplo, en suma, rasgos físicos muy personales que identificaban al individuo en cuestión). El recluta, tras el juramento de fidelidad, pasaba de la oficina de reclutamiento al cuartel, donde se le daba una cantidad de dinero para los gastos del viaje (viaticum o dieta de desplazamiento ${ }^{61}$ ). En ese momento ya podía considerarse que era un soldado romano, aunque aún tendría que pasar por un duro entrenamiento y por las futuras guerras que le esperaban. El recluta tenía que manejar un latín, cuanto menos, rudimentario. No es posible conocer el grado de alfabetización de los soldados rasos, que no sería muy alto. Éste no era el caso, por ejemplo, de los centuriones preparados para actividades administrativas. Aunque se podía promocionar desde simple legionario a centurión, cabe pensar que muchos de ellos serían designados por su mayor nivel de preparación. Al pasar a la condición de eméritos (veteranos) desempeñarían cargos municipales en núcleos de población importantes. ${ }^{62}$

61 "Longino Longo, portaestandarte de la Primera Cohorte Lusitana, a su centurión Tituleio Longino: He recibido 423 denarios y 20 óbolos; esta suma ha sido depositada por 23 reclutas llegados a esta centuria en el sexto día del mes de Thot (23 de septiembre) del vigesimoprimer año del reinado del noble césar Trajano, nuestro señor" (Papiro procedente de Egipto, $117 \mathrm{~d}$. C.) [tomado de MATYSZAK, Legionario, p. 15].

62 Capitales provinciales y/o conventuales en el caso de Hispania. 
Los auxiliares que integraban cohortes de infantería y alas de caballería, ${ }^{63}$ peor pagados (al cobrar la mitad de un sueldo de legionario), participarían en conflictos de "baja intensidad", pequeñas revueltas y/o alteraciones menores, casos aislados de bandidaje, etc. Ello no quiere decir que no expusieran en todo momento sus vidas, todo lo contrario. Seguramente lo hacían con mayor frecuencia que los legionarios. Además, cuando tenían lugar grandes campañas apoyaban en gran número a las legiones, duplicando sus efectivos, amén de la ayuda de príncipes aliados que contribuían igualmente con sus tropas locales, tal y como ocurrió en la campaña de Tito en Jerusalén. ${ }^{64}$ Este futuro purpurado comandó un ejército compuesto por un núcleo central de cuatro legiones (V Macedonica, X Fretensis, XV Apollinaris y XII Fulminata), al que se le unieron diez cohortes más procedentes de diferentes legiones, que en la práctica suponían una legión más. Del mismo modo, también formaban parte del contingente diez cohortes de tropas auxiliares, seis alas de caballería y tropas de apoyo de los reyes aliados. ${ }^{65}$ Entre los auxilia había cohortes de infantería y alas de caballería de tracios, mauritanos e hispanos (cántabros y lusitanos). ${ }^{66}$ Un total, quizá, de unos 70.000 hombres.

De todo ello se deduce que el soldado auxiliar pudo estar más expuesto a la violencia bélica además de que, por tratarse de cuerpos "manejables" que podían integrar operativos rápidos a base de destacamentos o vexillationes, los traslados o dislocaciones por el Imperio eran frecuentes. Esa movilidad obligaba a este a adaptarse a diferentes escenarios y entornos climáticos, lo que le convertía en un combatiente muy polivalente. ${ }^{67}$ En algún caso, además, el soldado auxiliar, si había sido incorporado tempranamente al cuerpo auxiliar (a los diecisiete años, por ejemplo) podía, tras veinticinco años de servicio, incorporarse a una legión, aunque esto no fuera obviamente lo frecuente. Las cohortes de infantería (pedites) estaban integradas por cuatrocientos ochenta auxiliares. Las alas de caballería

63 Estas últimas muy importantes dado que la legión eran una fuerza de infantería.

64 PITILLAS SALAÑER, La guerra de los judíos, pp. $110-111$.

65 Soaemo de Emesa, Antíoco de Comagene y el judío Agripa (II).

66 GONZÁleZ ECHEGARAY, J. (2005): Pisando tus umbrales Jerusalén. Historia antigua de la ciudad. Estella, Ed. Verbo Divino, p. 324.

67 SADDINGTON, D.B. (2012): "The deployment of auxilia and their use in battle in The Roman Army of the early Principate", Visions d'Occident romain. Hommages à Yan le Bohec, CEROR $40, n^{\circ} 2$, pp. 595-601. 
(alae), si eran quingenarias, por quinientos doce, y en el caso de que fueran miliarias por setecientos sesenta y ocho. El ala quingenaria estaba formada por dieciséis escuadrones (turmae); las miliarias, por treinta y dos. Al frente de cada escuadrón, se situada un oficial (decurión).

\section{La guarnición en Roma-capital (La URBS)}

Junto a las legiones y cuerpos auxiliares diseminados a los largo de las fronteras del Imperio, Roma tenía guarnición propia. Su cifra total rondaría los diez mil hombres. Los soldados armados no circulaban por Roma en etapa republicana. Augusto, siempre respetuoso con la tradición y la legalidad, guardando las formas con las anteriores instituciones republicanas y queriendo mantener las apariencias, aunque establece una guardia pretoriana $^{68}$ la dota de nueve cohortes, una menos que una legión al completo. Sólo sitúa intra muros de la Urbs tres cohortes, y el resto en las afueras de la capital. Además, distribuye aquellas en casas de particulares. Era, a buen seguro, una forma enmascarada de evitar una ruptura total con la tradición republicana.

El origen de la guardia pretoriana estuvo en el cuerpo armado que protegía en campaña al general (imperator), anticipo de esta otra que sitúa Augusto en Roma a comienzos del Principado (27/ 26 a. C.). El término lo toma de los magistrados republicanos (praetores). El praetorium era, por otro lado, la fortaleza legionaria y residencia del comandante o legado de una legión. En el campamento (castra) la via praetoria conducía desde la entrada principal (porta praetoria) hasta el cuartel general, conjunto de edificios denominado principia, situado en la via principalis. ${ }^{69}$ Con el emperador Tiberio se establece el Castra Praetoria en la colina del Viminal (23 d. C.) [Tac., Ann., IV, 2]. Se trata ya de un establecimiento fijo dentro de la ciudad de Roma. Albergaba nueve cohortes pretorianas enumeradas de la $I^{a}$ a la $I X^{a}$ y tres urbanas $X^{a}$ a X $I^{a}$. El campamento se extendía

68 DURRY, M. (1938): Les cohortes pretoriennes. París, Ed. de Boccard. PASSERINI, A. (1939): Le coorti pretorie. Roma, Centro edit. internazionale. MENÉNDEZ ARGÜíN, R.A. (2006): Pretorianos. La guardia imperial de la Antigua Roma. Madrid, Almena Ediciones. RANKOV, B. y HOOK, R. (2009): La guardia pretoriana. Barcelona, RBA Libros. CEÑAL MARTÍNEZ, H. (2009): La guardia pretoriana. Composición, funciones e historia. Oviedo. Tesis doctoral inédita.

69 CAMPOMANES ALVAREDO, E. (2016): Guía del León romano. Un recorrido por el legado romano de la ciudad de León. León, Lobo Sapiens, p. 58 y ss. 
sobre una superficie de 16,72 hectáreas, $440 \times 380$ metros, con un campo de maniobras (campus) destinado a la instrucción. Con tales dimensiones, aunque no existe acuerdo pleno entre los historiadores, se podría pensar que las cohortes pretorianas y urbanas eran quingenarias, es decir, de unos quinientos hombres. Bajo Calígula, su sucesor, el número de cohortes pretorianas aumentó a doce. Con Vitelio alcanza el número de dieciséis, posiblemente miliarias, para retornar a nueve bajo Vespasiano, al comienzo de la dinastía flavia. A diez, quingenarias, se elevaba con Domiciano. Al frente de la guardia pretoriana se situaba el o los dos prefectos del pretorio, nombrados por el propio emperador. Ello no evitó que, como ocurriría con Sejano, bajo Tiberio el jefe de la guardia pretendiera, mediante intrigas, aspirar incluso al trono. Calígula fue el primer emperador asesinado por miembros de la guardia pretoriana y Claudio fue aupado al trono también por ella. A comienzos del año $69 \mathrm{~d}$. C. el emperador Galba fue víctima del golpe perpetrado por Otón, su sucesor, con el apoyo decidido de los pretorianos. Otros caso posterior será el de Publio Helvio Pertinax ${ }^{70}$ también, al igual que Galba, víctima de su severidad y tacañería, al no querer otorgar a los pretorianos una generosa compensación económica (donativum).

El aspecto que singulariza a la guardia pretoriana respecto a las legiones era que, al ser un cuerpo de élite, contaba con una proporción de jinetes muy superior en relación al número de infantes. Quizás cada cohorte contara con unos ciento veinte jinetes y en torno a unos trescientos ochenta infantes. Se trataba, por lo tanto, de cohortes equitatae. Cada una de ellas estaba mandada por un tribuno y cada una de las seis centurias que componían la cohorte por un centurión, ${ }^{71}$ al igual que en las legiones. La caballería pretoriana estaba organizada en escuadrones (turmae) mandados por decuriones. Por su parte, las cohortes urbanas (los urbaniciani) fueron igualmente creadas por Augusto en el año 13 a. C. Su número inicial de tres sufrió cambios. Con Claudio aumentaron a siete para reducirse a cuatro con Vitelio en el $69 \mathrm{~d}$. C. Existían además dos cohortes urbanas fuera de la ciudad, una en Lyon (Lugdunum) y otra en Carthago. En el caso de los vigiles (cohortes de vigilantes) hacían la doble función de bomberos y de vigilancia nocturna. Su número era bastante elevado, un total de siete, posiblemente miliarias. Cada una de ellas cubría la necesidad de dos dis-

70 GARZÓN BLANCO, J.A. (1990): El emperador Publio Helvio Pertinax y la transformación política del año 193. Málaga, Gráficas Dialar.

71 El primer centurión recibía el nombre de trecenarius. 
tritos ya que la capital estaba dividida en catorce. Al frente de los vigiles se situaba un prefecto de rango ecuestre y cada cohorte era mandada por un tribuno.

Finalmente cabe señalar que el emperador era protegido no sólo por miembros de la guardia pretoriana sino por una fuerza específica. Augusto se había servido de un cuerpo de jinetes (Germani corporis custodes). Los Equites Singulares Augusti, 500 ó 1000 hombres, formaron un cuerpo de élite para la defensa personal del emperador, entre ellos trescientos speculatores (Tac., Hist., I, 31, 1). Por lo general mostraban fidelidad al emperador al ser extranjeros y vivir en Roma en un ambiente que no era el suyo. Es posible que tales guardias personales, que dicho sea de paso no pudieron proteger la vida de Calígula, ${ }^{72}$ estuvieran instalados en el mismo campamento (Castra Praetoria) que pretorianos y cohortes urbanas.

\section{Los SOldados aUXILIARES en EL NW De hispania, ESPECIALMENTE galaicos $Y$ ASTURES}

La presencia de auxiliares hispanos en el ejército romano se remonta a la Segunda Guerra Púnica, concretamente con la presencia de celtíberos al servicio de Publio Cornelio Escipión Africano. Con anterioridad habían servido a los ejércitos cartagineses y ese equilibrio de fuerzas se fue decantando, con el tiempo, del lado romano. Mucho tuvo que ver en todo ello la rápida captura de Cartago Nova (209 a. C.), con sus ricos pertrechos y avituallamiento. Igualmente, la habilidad diplomática del personaje al atraerse la voluntad de algunos de los más significativos jefes de guerra indígenas como fue el caso de Edecón y de Indíbil, aunque este último luego le traicionara $y$, por ello, pagara con su vida.

En el sitio de Numancia (Numantia), tras una serie de años de desastrosas campañas, Publio Cornelio Escipión Emiliano, tomando como núcleo inicial una tropa de allegados (cohors amicorum), se sirvió de aliados indígenas en elevada proporción, quizás en torno a los cuarenta mil. De este modo los guerreros arévacos sufrieron un demoledor asedio en el que aunque no se utilizara masivamente la artillería, el cinturón (circumvallatio) que rodeó el enclave indígena fue suficiente como para acabar con una resistencia abocada finalmente al fracaso. En el conflicto civil con los itálicos, en la Citerior Tarraconense, un escuadrón de caballería, la Turma Salluitana re-

72 ROLDÁN, J.M. (2012): Calígula. El autócrata inmaduro. Madrid, La Esfera de los Libros, p. 337 y ss. 
clutada entre la población ibérica de Salduie, obtuvo la ciudadanía de manos de Pompeius Strabo (89 a. C.). ${ }^{73}$

Sirvan estos ejemplos para exponer esa necesidad de los romanos de utilizar tropas indígenas como aliados (socii), ya fueran itálicos o pueblos indígenas -iberos o celtas-, en el caso de Hispania durante el proceso de conquista. En el Norte y NW de Hispania (29-19/16 a. C.) se dio el habitual enfrentamiento entre ejército romano y grupos armados indígenas, que utilizaron el conocimiento que tenían del terreno y el golpe de mano por sorpresa. Astures y cántabros se enfrentaron a Roma hasta que la resistencia tocó a su fin como resultado del agotamiento indígena. La represión terminal de M. Vipsanio Agripa (19 a. C.) lo pone de manifiesto: una guerra de exterminio de la que no se sentiría orgulloso precisamente su protagonista.

Un cierto carácter selectivo haría posible su movilización. Así como los legionarios eran reclutados entre ciudadanos humildes de las ciudades (civitates), que veían en el ejército una salida profesional y una paga segura, por su parte los auxiliares no ciudadanos (peregrini) pudieron haber sido reclutados entre los habitantes de centros urbanos o sus proximidades en vías de alcanzar el estatus municipal. Esta aproximación ha sido destacada hasta una conexión prácticamente total. ${ }^{74}$ Además, la importancia de las provincias romanas occidentales en el reclutamiento de tropas auxiliares fue muy relevante, llegando a alcanzar la ya mencionada cifra de un $56 \%$ del total de este tipo de fuerzas. ${ }^{75}$ Hispania, especialmente el NW, ocupó un lugar destacado.

Al finalizar las guerras astur-cántabras (19/16 a. C.), ${ }^{76}$ bajo Augusto, se configuró en Hispania un auténtico ejército de ocupación. Las legiones $\mathrm{VI}$ Victrix, X Gemina y IIII Macedonica, con el apoyo de tropas auxiliares, se hicieron con el control de ambas regiones: las dos primeras de Galicia-As-

73 ABASCAL, J.M. (2009): "Los auxilia hispanos", Historia Militar de España, n 1, Ediciones del Laberinto, Ministerio Defensa, p. 301. Vid. también: PALAO VICENTE, J.J. (2016-2017): "Las tropas auxiliares hispanas", La legión romana (III, El primer siglo del imperio), Desperta Ferro, Número Especial X, pp. 72-75.

74 "... de la misma manera que en estas últimas apelaban a jóvenes que pertenecían a medios cada vez más humildes, los cuerpos auxiliares, en conjunto, iban eligiendo a cada vez más a ciudadanos romanos": LE BOHEC, El ejército romano, p. 126.

75 LE BOHEC, El ejército romano, p. 130.

76 Existen noticias imprecisas de revueltas posteriores (16 d. C.) [D. Cas., LIV, 20, 3] y en época del emperador Nerón (CIL XI, 395 = ILS, 2648). 
turias y la última de Cantabria. La legio IIII Macedonica (del 20/15 a. C. al $39 / 40 \mathrm{~d}$. C.) estuvo establecida en un cerro amesetado, en el interfluvium de Pisuerga-Burejo, en la localidad palentina de Herrera de Pisuerga. ${ }^{77}$ Las VI Victrix y $X$ Gemina estuvieron localizadas en León, con anterioridad a la VII Gemina, la primera, ${ }^{78}$ y Asturica Augusta (Astorga) y Petavonium (Rosinos de Vidriales,León) la segunda. La IIII Macedonica es la primera que salió de Hispania hacia la frontera del Rin (39-40 d. C.). La X Gemina permaneció hasta el $63 \mathrm{~d}$. C., año en el que fue desplazada a Carnuntum (Panonia) para ocupar el puesto vacante dejado por la XV Apollinaris, trasladada esta última a Alejandría para formar parte del operativo de tropas que intervendrían en Judea. ${ }^{79}$ En el año $68 \mathrm{~d}$. C. regresó a Hispania pero volvió a partir, esta vez ya definitivamente. Así, en los años 69-70 d. C. parece que no quedaba ninguna legión: el emperador Vitelio envió temporalmente a la $I$ Adiutrix y esta última, junto a la $X$ Gemina y también la VI Victrix, salieron todas ellas de Hispania. Entre los años 63 al $68 \mathrm{~d}$. C. sólo estuvo en Hispania la VI Victrix. En el 74 ó 75 d. C. se estableció definitivamente en León la VII Gemina, ${ }^{80}$ legión que tuvo ya un papel destacado no sólo en el control de un territorio pacificado sino también en el apoyo técnico a las explotaciones del oro astur. ${ }^{81}$

Tras la ocupación anteriormente señalada se produciría la leva de tropas, forzada en un primer momento, voluntaria después, el consiguiente adiestramiento de tales voluntarios auxiliares y su traslado a algún lugar de la línea fronteriza: allí donde, en aquellos momentos, resultaban necesarios, como Dalmacia, Panonia o el Rin en Germania. ${ }^{82}$ Es bajo Augusto (27 a. C.) cuando se habría recurrido, por vez primera, a este tipo de auxiliares. Como por entonces había tres legiones estacionadas en Hispania, la $X$

77 MORILLO CERDÁN, Á. (2000): "La legio IIII Macedonica en la península lbérica. El campamento de Herrera de Pisuerga (Palencia)", Les legions de Rome sous le Haute-Empire, II, Actes du Congrés de Lyon, pp. 612-613.

78 Establecida en dos campamentos: uno el 5 a. C. y el otro del 10 al 15 d. C. Vid., CAMPOMANES ALVAREDO, Guía del León romano, pp. 28-30.

79 Junto con la $V$ Macedonica y $X$ Fretensis, núcleo operativo básico del ejército de $T$. Flavius Vespasianus, futuro purpurado.

80 PALAO VICENTE, J.J. (2006): Legio VII Gemina (Pia) Felix. Estudio de una legión romana. Salamanca, Ediciones Universidad de Salamanca, 2006.

81 SANTOS YANGUAS, N. (2011): Asturias, los astures y la minería romana del oro. Oviedo, KRK ediciones.

82 SANTOS YANGUAS, Ejército romano, administración y vida civil..., p. 194. 
Gemina y VI Victrix frente a los astures, y la IIII Macedonica frente a los cántabros, cabe deducir que los auxiliares serían adiestrados en algunos de los campamentos al efecto, como Petavonium (Rosinos de Vidriales, León), Asturica Augusta (Astorga), o bien Herrera de Pisuerga (Palencia). Poco más se puede decir al respecto. El testimonio de Estrabón (III, 4, 20) sirve para hacernos una idea sobre aquel ejército de ocupación y la existencia de tres legados militares, dos de ellos con mando sobre tropas, uno para la vigilancia de los cántabros (IIII Macedonica) y otro frente a los astures (X Gemina y VI Victrix). El tercer legado, en suelo ya totalmente pacificado previamente, en la Tarraconense (y seguramente próximo a la capital provincial, Tarraco), ejercería una función política y administrativa. De este modo las tropas auxiliares vinculadas a las legiones serían las siguientes: las alas II Gallorum, II Tauriana Torquata Victrix civium Romanorum y II Thracum y las cohortes IIII Gallorum y IIII Thracum. ${ }^{83}$

No es mucho lo que se sabe sobre el modo concreto del reclutamiento de auxiliares en el cuadrante noroccidental de Hispania. Son más bien, a lo sumo, simples conjeturas lo que puede hacerse al respecto. Cabe suponer que, con el establecimiento de tales legiones durante el periodo de ocupación posterior a la conquista (29-19/16 a. C.) del Norte y del NW de Hispania, se iniciarían los procesos de reclutamiento entre las poblaciones indígenas, y en el caso de los astures tanto entre los cismontanos como entre los transmontanos que habitaban el territorio de la actual Asturias. Ello habría supuesto además la desactivación de la anterior "resistencia", dado que en un momento determinado jóvenes en edad militar habrían iniciado un paulatino proceso de acercamiento a Roma. Es posible que, en un principio, las levas pudieron haber sido forzadas cuando aún existía rechazo o estaba próximo el final de la conquista, o bien en los primeros momentos de la ocupación, eso que se ha venido a denominar como periodo de la "paz armada" (19/16-15 a. C.-10/20 d. C.). ${ }^{84}$ Cabe suponer que tales jóvenes, aceptada la idea de que ya no era posible continuar en lucha contra Roma, contemplaran la posibilidad de alistarse en el ejército romano, lo que iba a suponer para ellos una salida profesional y un factor evidente de promoción social. Muchos de ellos abandonaron sus lugares

83 SANTOS YANGUAS, N. (2009): "Ejército romano y urbanismo en el territorio de los astures", Gerión, n² 27, p. 371.

84 MORILLO CERDÁN, Á. (2002): "Conquista y estrategia: el ejército romano durante el periodo augústeo y julio-claudio en la región septentrional de la península Ibérica". ÍD. (coord..), Arqueología militar romana en Hispania, Anejos de Glaudius 5. Madrid, p. 77 y ss. 
de origen para no regresar. Así, formaron parte de tropas auxiliares, como cohortes de infantería y alas de caballería, o bien cohortes equitatae. Un alto porcentaje de ellos fallecerían jóvenes, si bien su esperanza de vida era sólo algo más corta que la de la media de la población civil, esto es, por debajo de los cuarenta años. ${ }^{85}$

Se pasaría, por lo tanto, de la leva forzada a la voluntaria ya que se considerarían las ventajas de una paga segura, aunque fuera la mitad de la del legionario, y al finalizar los veinticinco años de servicio, con la honesta missio, la obtención de un diploma en el que se garantizaría el logro de la ciudadanía latina y el reconocimiento de su estado civil como casados (ius conubii), dado que una buena parte de los mismos tendrían ya extraoficialmente pareja. La participación de auxiliares galaicos y astures en el ejército romano es ya temprana, y adquiere entidad en época julio-claudia y flavia posterior (s. I d. C.), según se consolida paralelamente el proceso de integración de las poblaciones indígenas y la consiguiente explotación de las cortas mineras del NW. ${ }^{86}$ Además, conforme dicho territorio vaya siendo organizado y administrado por Roma en función de la ubicación de las tres capitales conventuales -Asturica Augusta, Bracara Augusta y Lucus Augusti-, totalmente operativas en época flavia o incluso antes, podemos observar la existencia de un número importante de militares originarios de estas ciudades, tal y como lo refleja la epigrafía. ${ }^{87}$ Son veintitrés casos en total: nueve de Bracara, siete de Asturica, y otros siete de Lucus Augusti. No faltan soldados, originarios también de tierras del Noroeste, con cognomen específico (Reburrus/Reburrinus-Reburrinius) que, en la mayoría de los casos, pueden -aunque no de forma exclusiva- asignarse a las tierras que nos ocupan. ${ }^{88}$ Sirva como simple ejemplo la participación de los astures en un grado importante: cinco alas y siete cohortes con etnónimo propio (asturum), junto a una de astures y luggones, dos de astures y galaicos y un cuerpo de symmachiarii, una especie de cuerpo indígena asociado

85 PITILLAS SALAÑER, E., (1998-1999): "Milites y edad de fallecimiento. Un intento de aproximación". MHA, n 19-20, pp. 321-341.

86 PITILLAS SALAÑER, E. (1998-1999): "Integración y promoción social de las poblaciones indígenas del noroeste hispánico dentro del esquema organizativo romano: ejército y minería", MHA, n 19-20, pp. 225-244.

87 PITILLAS SALAÑER, E. (2003): "Soldados originarios de las tres capitales conventuales del Noroeste hispánico. Su evidencia epigráfica", Aquila Legionis, n 4, pp. 119-135. Vid., tabla actualizada: PITILLAS SALAÑER, E. (2010): El ejército romano en el Norte y Noroeste de Hispania. Conquista, ocupación e integración de la población indígena. Zaragoza, Libros Pórtico, pp. 97-98. 
y armado con su propia panoplia local, a modo de los numeri. Un oficial destaca en este cuerpo, Gaius Sulpicius Ursulus, ${ }^{89}$ con un cursus honorum en el que pasó de prefecto de los symimachiarios a prefecto de la legio III Augusta, discurriendo por otros empleos jerárquicos intermedios. ${ }^{90}$

En lo que se refiere a los galaicos (callaeci) y a las tropas auxiliares de bracaraugustanos y lucenes, podría suponerse que las futuras capitales conventuales -Lucus Augusti (Lugo) y Bracara Augusta (Braga, Portugal)habrían desempeñado algún tipo de función como centros de reclutamiento con un total de once cohortes correspondientes a los bracares (bracari) y siete a los lucenses. Tales auxiliares (auxilia) fueron enviados en los siglos I y |l d. C. allí donde su presencia se hacía necesaria: Moesia. Dacia, Pannonia, Raetia-Noricum y en menor medida en Mauretania-Tingitana, Britannia, Syria y ludaea. Así, las tropas auxiliares reclutadas entre los galaicos podrían agruparse en entidades étnicas, unas de lucenses ${ }^{91}$ (del conventus Lucensis) y otras de bracares o bracari, en este caso procedentes de Bracara Augusta. Pero el término Lucensium, por ejemplo, puede ir sólo o acompañado del más genérico Callaecorum, tal y como ocurre con la Cohors IV Callaecorumm Lucensium. Los bracaros (bracari), ${ }^{92}$ de la circunscripción del conventus Bracaraugustanus, aparecen con tal apelativo (por ejemplo, la Cohors I Bracaraugustanorum civium Romanorum), lo que no impide que exista una Cohors III Callaecorum Bracaraugustanorum y viene a mostrar, en todo caso, el empleo alternativo del genérico callaeci (o gallaeci). Lo mismo ocurre en dos cohortes en las que se combinan galaicos y astures, las Cohors I y II de Asturum et Callaecorum.

88 PITILLAS SALAÑER, E. (2002): "Soldados procedentes del Noroeste de Hispania con el cognomen Reburrus-Reburrinus". HAnt., n²6, pp. 25-34.

89 G(aio) Sulpicio Ursulo/ praef(ecto) symmachi/ ariorum Asturum/ belli Dacici, c(enturioni) leg(ionis)/ I Minerviae p(iae) f(idelis),/ c(enturioni) coh(ortis) XII urba/nae, c(enturioni) coh(ortis) IIII/ praetoriae, p(rimo) p(ilo)/ leg(ionis) XIIX, praef(ecto)/ leg(ionis) III Aug(ustae)/ G(aius) Sulp(icius) Afr(icanus) pos(suit). (AEAA X, 1934, p. $196=$ A.E. 1935, n 12.)

90 Lápida descubierta en la estación ferroviaria de Ujo, Asturias (23-07-1919): SANTOS YANGUAS, N. (2009): "Gayo Sulpicio Ursulo, primer comandante astur de una legión romana". Aquila Legionis, $\mathrm{n}^{\circ}$ 12, pp. 41-57. Algunos autores han considerado la lápida una falsificación, aunque esto último quizá sea una apreciación un tanto excesiva: JIMÉNEZ DE FURUNDARENA, A. y RODRÍGUEZ GONZÁLEZ, J. (1991): "La lápida de Gayo Sulpicio Úrsulo: ¿una falsificación de época?". HAnt., n 15, pp. 83-90.

91 Entre los lucenses fueron reclutadas cinco cohortes de infantería y una cohorte equitata (Cohors I Lucensium equitata).

92 Entre los bracaros lo fueron ocho cohortes. 
Algo similar podría decirse de Asturica Augusta como centro de reclutamiento en el caso de los astures cismontanos. Salvo alguna excepción ${ }^{93}$ en el que la lápida funeraria indica el lugar de nacimiento, no resulta posible diferenciar si los reclutados eran astures cismontanos (augustanos) o transmontanos, estos últimos de la actual comunidad de Asturias, pero lo lógico es pensar que lo fueran de modo indistinto. El reclutamiento entre los astures $^{94}$ fue importante. En otros colectivos, salvo en el caso de los lusitanos, ${ }^{95}$ el número de cohortes reclutadas fue menor. ${ }^{96}$ No faltaron un importante número de cuerpos auxiliares, un total de cuatro alas y diecisiete cohortes, con el apelativo genérico de Hispanorum. ${ }^{97}$

Una buena parte de los cuerpos auxiliares, especialmente entre galaicos y astures, fueron reclutados al comienzo de la etapa imperial: durante el reinado de Augusto, bajo su sucesor Tiberio, o bien durante los siguientes miembros de la dinastía julio-claudia..$^{98}$ Es entonces cuando se habría dado el gran impulso al reclutamiento de auxiliares procedentes del cuadrante noroccidental de la península lbérica. Una vez estacionados en las fronteras correspondientes, levas posteriores de circunscripción local cubrirían las vacantes, pero el etnónimo (astur o galaico) permanecería en cuerpos que sufrirían frecuentes traslados o dislocaciones. ${ }^{99}$

93 Este es el caso de un astur transmontano, originario del castellum no localizado de Intercatia, el signifer de la $V$ Cohors (Pintaius Pedilici f.) del museo de Bon. Para un análisis de su iconografía: PEREA YÉBENES, S. (1996): "La estela del signifer cohortis Pintaius (CIL XIII 8098). Apuntes iconográficos", MHA, n 17, pp. 255-273.

94 Cuatro alas de caballería, siete cohortes de infantería y dos cohortes más (Asturum et Callaecorum).

95 Seis cohortes en total.

96 Dos entre los cántabros, un ala de caballería entre los vetones, una cohorte entre los vascones, otra entre los várdulos, dos cohortes (una de ellas equitata) entre los celtíberos y un ala entre los arévacos.

97 Una recopilación en: ABASCAL, "Los auxilia hispanos", pp. 301-312.

98 Lo que "parece coincidir con la fase de formación, adiestramiento y estabilización de dichos cuerpos de tropas": SANTOS YANGUAS, Ejército romano, administración y vida civil..., p. 195.

99 Las dislocaciones del ala I Asturum, que a continuación se menciona, fueron: Galia Lugdunense, Dacia (Danubio), Britania, Danubio y Britania entre los siglos I al III d. C. Para todas las alas de astures: SANTOS YANGUAS, Ejército romano, administración y vida civil..., pp. 193235. Para las cohortes astures (pp. 237-283) y para unidades mixtas de astures y galaicos (pp. 285-309). 
Conocemos tres alas de los astures. El ala I (hispanorum) ya aparece recogida en una inscripción funeraria (s. I d. C.) hallada en Cavillonum (act. Chalon, Galia Lugdunense), aunque no se indica su numeración (CIL XIII, $2613=$ ILS, 2509). ${ }^{100}$ Tal ala I habría sido reclutada en época julio-claudia. ${ }^{101}$ El primer documento de un soldado es una inscripción funeraria hallada en Tomi (Dobrudja, Mesia Inferior) que se conserva en el Museo de Bucarest. Se refiere a un veterano que sirvió treinta y dos años en el ejército y falleció a los sesenta y cuatro. Se trata de Tiberio Claudio Saturnino, un individuo de origen galo o hispano reenganchado tras los habituales veinticinco años de servicio. ${ }^{102}$ Sus dedicantes fueron su esposa e hijos. Respecto al ala II, su reclutamiento y formación coincidiría con los años finales del reinado de Augusto o los primeros de Tiberio, y su adiestramiento habría que vincularlo a la Legio $X$ Gemina durante su asentamiento en Asturica, luego capital conventual, o en Petavonium (Rosinos de Vidriales, León), ${ }^{103}$ lo que apunta a esa tarea de reclutamiento e integración realizada por las legiones de postconquista en suelo astur. En Intercissa (Panonia Inferior) se ha encontrado recientemente una inscripción de un jinete zoela (sesquiplicarius) de esta misma ala, Tiberius Claudius [...] onis f. Pintamus ${ }^{104}[\mathrm{AE}$, 1992, $\left.n^{\circ} 1458\right]$, que vivió cincuenta y tres años y habría servido como auxiliar durante los reinados de Claudio y Nerón, y al que dediqué algunos párrafos en un artículo. ${ }^{105} \mathrm{El}$ ala III de los astures fue reclutada entre astures augustanos (o transmontanos) y adiestrados por profesionales de

100 SANTOS YANGUAS, Ejército romano, administración y vida civil..., p. 197.

1010 bien a finales del reinado de Augusto y/o a lo largo del de Tiberio. Su adiestramiento pudo haber tenido lugar en los campamentos de las legiones $X$ Gemina, o bien de la VI Victrix. Una vez formada el ala sería enviada al limes danubiano. Pudo haber sido afincada en la región de Dobrudja, entre Durostorum y Troesmis, lugar donde ha aparecido la lápida del jinete que, a continuación, se menciona: SANTOS YANGUAS, Ejército romano, administración y vida civil..., p. 197.

102 "Ti(berius) Claudius Arrenti f(ilius)/ Quir(ina) Saturninus/ duplic(arius) vet(eranus) alae Astur(um)/ vixit an(nos) LXIIII mil(itavit) an(nos) XXXII/ uxor et liberi f(aciendum) c(uraverunt) $h$ (ic) s(itus) e(st)" [AA 29 (1914) 438]: "Tiberio Claudio Saturnino, hijo de Arrento, de la tribu Quirina, duplicario veterano del ala de los astures, vivió 64 años y militó 32, su esposa y sus hijos se ocuparon de erigirlo. Aquí está enterrado." SANTOS YANGUAS, Ejército romano, administración y vida civil..., p. 196.

103 SANTOS YANGUAS, Ejército romano, administración y vida civil..., p. 209.

$104 \mathrm{~J}$. FITZ (RIU n 1216) y B. LÖRINCZ, ZPE, 93, 1992, 118, n 4. Cfr., SANTOS YANGUAS, Ejército romano, administración y vida civil..., p. 211.

105 PITILLAS SALAÑER, "Soldados auxiliares del ejército romano...", pp. 27 y ss. 
la Legio VI Victrix o de la $X$ Gemina, en la misma época que la anterior. Entre los años 88 y 109 d. C. el ala iría adquiriendo los calificativos de pia fidelis y civium Romanorum, como ocurre con otras unidades auxiliares estacionadas en Mauritania Tingitana. ${ }^{106}$ Otra unidad de caballería astur pudo haber sido una $V$ que aparece en una placa de mármol hallada en el Vaticano, inscripción de fecha muy temprana (15-20 d. C.), lo que obliga a pensar en la existencia de un ala IIII hasta ahora desconocida. ${ }^{107}$ En el caso de las cohortes de astures, los casos serían semejantes a los ya vistos de las alas (alae) anteriormente mencionadas, ya que habrían sido reclutadas en los momentos posteriores a las guerras astur-cántabras y en los campamentos de las legiones mencionadas $-X$ Gemina (Astorga, Rosinos de Vidriales) y VI Victrix (León). Se trata de cuerpos de infantería, en algún caso equitatae, entre los que podemos identificar los siguientes: la cohorte I de los astures, la cohorte I de caballería de los astures, la cohorte II pía fiel de caballería de los astures, la cohorte III de caballería de ciudadanos romanos astures, la cohorte IV de los astures, la cohorte V de los astures y la cohorte VI de los astures. Entre las unidades mixtas de astures y galaicos estaban la cohorte I de astures y galaicos y la cohorte II de caballería de astures y galaicos ${ }^{108}$. Si tenemos en cuenta el total de testimonios epigráficos de oficiales y soldados, tanto legionarios como auxiliares, su número se eleva a setenta entre los astures, desglosados del siguiente modo: quince oficiales y veinte soldados sin graduación, todos ellos legionarios; doce oficiales de tropas auxiliares; diecisiete soldados sin graduación auxiliares; $y$, finalmente, siete más que sirvieron en cohortes pretorianas. ${ }^{109}$ Se conocen un total de once pretorianos procedentes del NW 110 y un total de treinta y seis testimonios epigráficos para todos los pretorianos hispanos hasta el momento recogidos. ${ }^{11}$

106 SANTOS YANGUAS, Ejército romano, administración y vida civil..., p. 223.

107 SANTOS YANGUAS, Ejército romano, administración y vida civil..., p. 234.

108 SANTOS YANGUAS, Ejército romano, administración y vida civil..., pp. 237-315.

109 SANTOS YANGUAS, Militares astures, pp. 83 y ss.; y tablas correspondientes en pp. 105, 124-125, 140, 155-156 y 165.

110 PITILLAS SALAÑER E., (2004): "Soldados originarios del NW de Hispania que sirvieron en las cohortes pretorianas. Su testimonio epigráficos". HAnt., $n^{\circ} 28$, tabla: p. 152. Podrían añadirse otros dos más (CEÑAL MARTíNEZ, La guardia pretoriana).

111 CEÑAl MARTíNEZ, H. (2009): "Soldados hispanos en las cohortes pretorianas", Aquila Legionis, $\mathrm{n}^{\circ} 12, \mathrm{p} .77$. El autor menciona un total de treinta y seis. La procedencia es básicamente de Lusitania (s. I d. C.) y algunos béticos, siendo la mayoría de la Tarraconense (ss. II-III d. C.), como los recogidos del NW. Se ha de constatar que no eran béticos en su mayoría como 
Las cohortes auxiliares, que tanto predicamento militar adquirirían ya con César, ${ }^{12}$ fueron muy utilizadas y el modelo de reclutamiento tendría gran acogida entre este tipo de tropas auxiliares, singularmente entre los astures. Ello pudo ser ciertamente el resultado de la guerra mantenida en el Norte de Hispania contra astures y cántabros. La cohorte I de los astures, por ejemplo, habría sido reclutada en un momento semejante al del ala anteriormente mencionada, en época final de Augusto o a lo largo del reinado de Tiberio. Adiestrada en algún campamento de las legiones correspondientes (X Gemina o VI Victrix), fue enviada al Danubio. Por último, conviene poner de manifiesto una cuestión: a pesar de que se insiste en que las cohortes eran de infantería y las alas de caballería, aun siendo esto último una regla general no se ha de tomar como exclusiva. Existen casos en los que se observa la existencia de grupos mixtos (ya los conocemos en parte por las cohortes equitatae) en los que cuerpos de infantería llevaban jinetes, y alas de caballería infantes. Algunos diplomas, ${ }^{113} \mathrm{sin}$ ir más lejos, lo corroboran: infantes y jinetes que militan en una serie de cohortes, o bien jinetes e infantes que sirven en una serie de alas. Por lo tanto, no es cierto que, de forma exclusiva, las alas se correspondiesen con tropas de caballería y las cohortes con tropas de infantería. ${ }^{114}$

\section{Bibliografía}

AA.VV., (2013; 2015-2016; 2016-2017): La legión romana (I, la República Media; II, la Baja República y III, el primer siglo del Imperio), Desperta Ferro, Números Especiales VI, VIII y X. Ed., SLNE.

ABASCAL J.M. (2009): "Los auxilia hispanos", Historia Militar de España, I, Martín Almagro-Gorbea (coordinador), Ediciones del Laberinto, Ministerio de Defensa.

ALVAR J. - BLÁZQUEZ J.M. [Eds.] (2003): Trajano, Ed., Actas, Madrid.

BARREIRO RUBíN V., (2004): La guerra en el Mundo Antiguo, Almena Ediciones, Madrid.

refiere la única obra publicada por un autor español sobre los pretorianos: MENÉNDEZ ARGÜÍN, Pretorianos, p. 39. De todos ellos, cuatro galaicos. Vid., recientemente: SANTOS YANGUAS, N. (2014): "Militares galaicos en las cohortes pretorianas", ETF, n² 27, pp. 185-195.

112 Quien, dicho sea de paso, prefería legiones más reducidas de unos 3000 hombres y no la habituales de 5000/6000.

113 CIL XVI, 36 = ILS 1998; AE 1985, n 992, pp. 281-282; AE 1962, n 264.

$114 \mathrm{Vid}$, al respecto la opinión de: SANTOS YANGUAS, Ejército romano, administración y vida civil..., p. 250. 
BEARD, M. (2009): El triunfo romano. Una historia de Roma a través de la celebración de sus victorias, Crítica, Barcelona.

BISHOP M.C.- COULSTON J.C.N. (2016): Equipamiento militar romano. De las guerras púnicas a la caída de Roma, Desperta Ferro Ediciones SLNE, Madrid.

BRAVO G.-GONZÁLEZ SALINERO R. (2009): Formas de integración en el mundo romano, Actas del VI Coloquio de la AIER, Signifer Libros, 32, Madrid, (para el ejército: p. 97 y ss).

BRINGMANN K., (2008): Augusto, Herder Editorial, Barcelona.

BRIZZI G., (2009): Escipión y Aníbal. La guerra para la salvación de Roma, Editorial Ariel,

Madrid.

CAMPOMANES ALVAREDO, E. (2016): Guía del León romano. Un recorrido por el legado romano de la ciudad de León, Lobo Sapiens, León.

CADIOU F., (2001), "Les guerres en Hispania et l'emergence de la cohorte legionnaire dans l'armée romaine sous la république: une revisión critique", Gladius 21, pp. 167-182.

CEÑAL MARTíNEZ, H., (2009): La guardia pretoriana. Composición, funciones e historia, Oviedo. Tesis doctoral (no publicada).

—, (2009): "Soldados hispanos en las cohortes pretorianas", Aquila Legionis, 12, pp. 59-80.

CONNOLLY P., (2016): La guerra en Grecia y Roma, Desperta Ferro Ediciones SLNE, Madrid.

DURRY, M. (1938): Les cohortes pretoriennes, Ed. de Boccard, Paris.

GARLAN Y., (2002): La Guerra en la Antigüedad, Alderabán Ediciones, Madrid.

GARZÓN BLANCO J.A., (1990): El emperador Publio Helvio Pertinax y la transformación política del año 193, Gráficas Dialar, Málaga.

GILBERT F., (2006), Légionnaires et auxiliaires sous le Haut-Empire Romain, Éditions Errance, Paris.

GOLDSWORTHY A., (2003): El ejército romano, Ediciones Akal, Madrid. -, (2005): Grandes generales del ejército romano. Campañas, estrategia y tácticas, Editorial Ariel, Barcelona.

—, (2014): Augusto. De revolucionario a emperador, La Esfera de los Libros, Madrid.

GONZÁlEZ ECHEGARAY J., (2005): Pisando tus umbrales Jerusalén. Historia antigua de la ciudad, Ed. Verbo Divino, Estella. 
HADAS LEBEL, M., (1994): Flavio Josefo. El judío de Roma, Editorial Herder, Barcelona.

JIMÉNEZ DE FURUNDARENA A.- RODRíGUEZ GONZÁLEZ J., (1991):"La lápida de Gayo Sulpicio Úrsulo: ¿̇una falsificación de época?, HAnt., XV, pp. 83-90.

JIMÉNEZ DE FURUNDARENA A., (2004): "Control religioso y social en el ejército romano: el sacramentvm", Actas del XXVII Congreso Internacional Girea-Arys I. Jerarquías religiosas y control social en el mundo antiguo, Valladolid, pp. 485-489.

KAVANAGH DE PRADO E., (2015): Estandartes en la Roma antigua. Tipos, simbologías y función, Anejos de Gladius 16, Madrid.

LANCEL S., (1997), Aníbal, Crítica, Barcelona.

LE BOHEC, Y. (2004): El ejército romano. Instrumento para la conquista de un imperio, Editorial Ariel, Barcelona.

-, (2006): L'armée romaine sous le Bas-Empire, Picard, Paris.

LENDON J.E., (2006): Soldados y fantasmas. Historia de las guerras en Grecia y Roma, Editorial Ariel, Barcelona.

MATYSZAK P., (2010): Legionario. El manual (no oficial) del soldado romano, Ediciones Akal, Madrid.

MENÉNDEZ ARGÜÍN, RAÚl A., (2004): Las legiones romanas de Germania (s. II-III): aspectos logísticos, Editorial Gráficas Sol, Écija.

—, (2006): Pretorianos. La guardia imperial de la Antigua Roma, Almena Ediciones, Madrid.

MORILLO CERDÁN Á., (2000): "La legio IIII Macedonica en la península Ibérica. El campamento de Herrera de Pisuerga (Palencia)", Les legions de Rome sous le Haute-Empire, II, Actes du Congrés de Lyon, pp. 612-613.

-, (2002): "Conquista y estrategia: el ejército romano durante el periodo augusteo y julio-claudio en la región septentrional de la península lbérica", ÁNGEL MORILLO CERDÁN (coord.), Arqueología militar romana en Hispania, Anejos de Gladius 5, Madrid, pp. 67-93.

OLESTI O./ VIDAL J./ ANTELA B. [editores] (2014), Animales y Guerra en el Mundo Antiguo, Libros Pórtico, Zaragoza.

PALAO VICENTE J.J., (2006): Legio VII Gemina (Pia) Felix. Estudio de una legión romana, Salamanca, Ediciones Universidad de Salamanca, 2006.

—, (2016-2017): "Las tropas auxiliares hispanas", La legión romana (III, El primer siglo del imperio), Desperta Ferro, Número Especial X, Ed., SLNE, pp. 72-75.

PASSERINI A., (1939): Le coorti pretorie, Centro edit., internazionle, Roma. 
PEREA YÉBENES S. [ed.], (2004), Res Gestae -Grandes generales romanos- (I), Signifer Libros, Madrid.

—, (1996): "La estela del signifer cohortis Pintaius (CIL XIII 8098). Apuntes iconográficos", MHA, XVII, pp. 255-273.

PITILLAS SALAÑER, E., (1998-1999): "Milites y edad de fallecimiento. Un intento de aproximación", MHA, 19-20, pp. 321-341.

—, (1998-1999): "Integración y promoción social de las poblaciones indígenas del noroeste hispánico dentro del esquema organizativo romano: ejército y minería", MHA, 19-20, pp. 225-244.

-, (2002): "Soldados procedentes del Noroeste de Hispania con el cognomen Reburrus-Reburrinus", HAnt., XXVI, pp. 25-34.

-, (2003): "Soldados originarios de las tres capitales conventuales del Noroeste hispánico. Su evidencia epigráfica", Aquila Legionis, 4, pp. 119 135.

—, (2004): "Soldados originarios del NW de Hispania que sirvieron en las cohortes pretorianas. Su testimonio epigráfico", HAnt., XXVIII, pp. 141. 152.

—, (2006): "Soldados auxiliares del ejército romano originarios del NW de Hispania (s. I d. C.)", HAnt., XXX, pp. 21-34.

—, (2010): "Los límites (¿́necesarios?) del expansionismo romano en etapa altoimperial: El sueño de Druso", ETF, Serie II, Historia Antigua, t. 23, pp. 231-244.

-, (2010), Roma. La forja de un imperio, Libros Pórtico, Zaragoza.

-, (2010): El ejército romano en el Norte y Noroeste de Hispania. Conquista, ocupación e integración de la población indígena, Libros Pórtico, Zaragoza.

-, (2013): La Guerra de los judíos y la destrucción de Jerusalén (66-70 d. C.), Libros Pórtico, Zaragoza.

-, (2014): Augusto, el estadista. Ficción de una república restaurada, Libros Pórtico, Zaragoza.

—, (2015): La diplomacia romana de época republicana (241-27 a. C.), Libros Pórtico Zaragoza.

QUESADA SANZ F., (2007): Estandartes militares en el mundo antiguo, Aquila Legionis 8, Madrid.

-, (2008): Armas de Grecia y Roma, La Esfera de los Libros, Madrid.

RANKOV B.-HOOK R. (2009): La guardia pretoriana, RBA Libros, Barcelona. RODRÍGUEZ GONZÁLEZ J., (2001), Historia de las legiones romanas, ॥ vols., Signifer Libros, Madrid. 
ROLDÁN HERVÁS J.M., (1974): Hispania y el ejército romano. Contribución a la historia social de la España Antigua, Ediciones Universidad de Salamanca, Salamanca.

-, (1989): Ejército y sociedad en la España Romana, Servicio de Publicaciones de la Universidad de Granada, Granada.

-, (2012): Calígula. El autócrata inmaduro, La Esfera de los Libros, Madrid.

SADDINGTON D.B. (2012): "The deployment of auxilia and their use in battle in The Roman Army of the early Principate", Visions d'Occident romain. Hommages à Yan le Bohec, CEROR 40, 2, pp. 595-601.

SAEZ ABAD, R. (2005): Artillería y poliorcética en el mundo grecorromano, Anejos de Gladius 8, CSIC, Madrid.

-, (2009): Los grandes asedios de las legiones romanas, Almena Ediciones, Madrid.

SANTOS YANGUAS, N., (1981): El ejército romano y la romanización de los astures, Asturlibros, Oviedo.

-, (1988), El ejército y la romanización de Galicia. Conquista y anexión del Noroeste de la Península Ibérica, Servicio de Publicaciones de la Universidad de Oviedo, Oviedo.

-, (2006): Ejército romano, administración y vida civil en territorio de los astures, Ediciones Monte Casino, Astorga.

-, (2009): "Gayo Sulpicio Ursulo, primer comandante astur de una legión romana", Aquila Legionis 12, pp. 41-57.

-, (2009), "Ejército romano y urbanismo en el territorio de los astures", Gerión, 27, pp. 361-385.

—, (2010): Militares astures en el ejército romano, Aquila Legionis 13, Madrid.

-, (201 1): Asturias, los astures y la minería romana del oro, KRK ediciones, Oviedo.

- (2014): "Militares galaicos en las cohortes pretorianas", ETF, 27, pp. 185-195.

SOUTHERN P., (2013): Augusto, Editorial Gredos, Madrid.

SYME R., (1989): La revolución romana, Taurus Humanidades, Madrid.

VEYNE P., (1975): "Y a-t-il eu un impérialisme romain?", MEFRA, LXXXVII, pp. 793-855. - (2009): El imperio grecorromano, Madrid.

WOLFF C. (2012): L'armée romaine. Une armée modéle?, CNRS Éditions, Paris. 


\title{
WARRIORS AND CIVILIANS IN THE CRUSADE MOVEMENT. MILITARY IDENTITIES AND STATUS IN THE LIBERATION AND DEFENCE OF THE HOLY LAND (1096-1204)
}

\author{
GUERREROS Y CIVILES EN LAS CRUZADAS. \\ IDENTIDADES MILITARES Y ESTATUS EN LA \\ LIBERACIÓN Y DEFENSA DE TIERRA SANTA \\ (1096-1204)
}

Alan V. Murray

University of Leeds

\begin{abstract}
In terms of their social composition, the crusades to Palestine and Syria were unlike any other military campaigns in the Middle Ages or the modern world. The liberation and defence of the Holy Land required primarily the participation of experienced, motivated and well-equipped members of the traditional Western military classes, and the core of each crusade expedition was made up of the retinues of kings, prelates and the higher aristocracy from the countries of Europe which produced the main responses to papal calls to crusade. However, the canonical definition of crusades as penitential pilgrimages meant that most expeditions during the first century of the movement included large numbers of non-combatant men, women and children, which caused significant problems with regard to discipline and logistics. This situation only changed in the later twelfth century with a shift to the use of naval transport rather than the traditional land routes.
\end{abstract}

Keywords: Crusades, knights, military professionalism, civilians, non-combatants.

\section{RESUMEN}

Respecto a su composición social, las cruzadas a Palestina y Siria fueron diferentes a cualquier otra campaña militar medieval o moderna. La liberación y defensa de Tierra Santa requirió fundamentalmente de la participación de miembros experimentados, motivados y bien equipados pertenecientes a las clases militares tradicionales de Occidente. Del mismo modo, el núcleo de cada expedición cruzada se conformó a partir de los séquitos de los reyes, prelados y alta aristocracia de los países europeos en los que más respuestas se produjeron a las llamadas papales. Sin embargo, la definición canónica de las cruzadas como peregrinaciones penitenciales significaba que la mayoría 
de las expediciones acaecidas en el primer siglo del movimiento incluyesen grandes cifras de individuos no combatientes, incluyendo mujeres y niños, los cuales generaron importantes problemas en lo tocante a la disciplina y la logística. Esta situación solo se vio modificada a finales del siglo XII, cuando se produjo un cambio en las rutas de transporte de las terrestres a las marítimas.

Palabras clave: Cruzadas, caballeros, profesionalismo militar, civiles, no combatientes.

\section{RESUM}

\section{Guerrers i civils a les croades: identitats militars i estatus en I'alli- berament i defensa de Terra Santa (1096-1204)}

Respecte a la seva composició social, les croades a Palestina i Síria foren diferents a qualsevol altre campanya militar medieval o moderna. L'alliberament $\mathrm{i}$ defensa de Terra Santa va requerir fonamentalment la participació de membres experimentats, motivats i ben equipats pertanyents a les classes militars tradicionals d'Occident. De la mateixa manera, el nucli de cada expedició es va conformar a partir dels sèquits dels reis, prelats, i alta aristocràcia dels països europeus en els que més respostes es van produir a les crides papals. No obstant això, la definició canònica de les croades com peregrinacions penitencials significava que la majoria de les expedicions esdevingudes en el primer segle del moviment incloguessin grans xifres d'individus no combatents, incloent dones $i$ nens, els quals van generar importants problemes respecte a la disciplina i logística. Aquesta situació es va veure modificada a finals del segle XII, quan es va produir un canvi de rutes de transport de les terrestres a les marítimes.

Paraules clau: Croades, cavallers, professionalisme militar, civils, no combatents. 


\section{Introduction: The Genesis of Crusading}

\subsection{Pope Urban II's Appeal to Knighthood}

And so I Nivello, raised in a nobility of birth which produces in many people an ignobility of mind, for the redemption of my soul and in exchange for a great sum of money given me for this, renounce for ever in favour of St Peter the oppressive behaviour resulting from a certain bad custom, handed on to me not by ancient right but from the time of my father, a man of little weight who harassed the poor with this oppression. Thereafter I constantly maintained it in an atrociously tyrannical manner. I had harshly worn down the land of St Peter, that is to say Emprainville and the places around it, in the way that had become customary, by seizing the goods of the inhabitants there. This was the rough nature of the custom. Whenever the onset of knightly ferocity stirred me up, I used to descend on the aforesaid village, taking with me a troop of my knights and a crowd of my attendants, and against nature I would make over the goods of the men of St Peter for food for my knights. ${ }^{1}$

Thus a French nobleman named Nivello expressed himself in a charter issued in 1096 in favour of the monastery of St Peter at Chartres, in which he stated his intention to join the great expedition proclaimed by Pope Urban II at the council of Clermont in Auvergne in November 1095, which was intended to liberate Jerusalem and the Holy Land from Turkish rule. The wording of the charter, with its judgemental tone, must have been formulated by the monks who undoubtedly wrote it rather than by Nivello himself, but there is no reason to doubt that his contrition for his past misdeeds was genuine; in exchange for an agreement that he and his heirs would cease despoliation of the monastery and its dependents, the monks paid him the sum of 10 pounds towards the expenses of the journey and gave smaller amounts of money to other members of his family. The circumstances described in the charter encapsulate the reasons why in attempting to raise an army for what became 
known as the First Crusade (1096-99), Urban II appealed primarily to the class of knights (milites) and by implication, their noble masters, in a manner which was intended to provide aid for Christianity in the Near East, but also to address fundamental social problems in Western Europe.

Understandably, the study of military aspects of the crusades has been primarily concerned with strategy and tactics, the course and mechanics of battles and sieges, and more recently, logistics. ${ }^{2}$ Other aspects which touch on the character of those Westerners who fought on crusades are motivation and individual (as opposed to institutional) finance. ${ }^{3}$ However, the question of military identities has been less studied, one reason that being that definitions such as "warriors" or "professionals" and "civilians" or "non-combatants" are problematic and often fluid. ${ }^{4}$ This essay will attempt to contribute to the study of military identities by exploring the social dichotomy between military elites and popular elements and the manner in which the balance between the two shifted in the course of 150 years of crusades to the Levant.

2 Bibliography on these topics is extensive. Some of the most fundamental studies are: SMAIL, R.C. (1995): Crusading Warfare, 1097-1 193, 2nd edn. ed. C. MARSHAL. Cambridge, Cambridge University Press; FRANCE, J. (1994): Victory in the East: A Military History of the First Crusade. Cambridge, Cambridge University Press; FRANCE, J. (1999): Western Warfare in the Age of the Crusades, 1000-1300. London, UCL; FRANCE, J. (2005): "Crusading Warfare". NICHOLSON, H. (ed.), Palgrave Advances in the Crusades. Basingstoke, Palgrave Macmillan; FRANCE, J. (2006): "Thinking about Crusader Strategy". CHRISTIE, N. and YAZIGI, M. (eds.), Noble Ideals and Bloody Realities: Warfare in the Middle Ages. Leiden, Brill, pp. 75-96; FRANCE, J. (2011): "Warfare in the Mediterranean Region in the Age of the Crusades, 1095-1291: A Clash of Contrasts". KOSTICK, C. (ed.), The Crusades and the Near East. Abingdon: Routledge, pp. 9-26; PRYOR, J. (1992): Geography, Technology and War: Studies in the Maritime History of the Mediterranean, 649-1571. Cambridge, Cambridge University Press; PRYOR, J. (ed.) (2006); Logistics of Warfare in the Age of the Crusades. Aldershot, Ashgate; TYERMAN, C. (2015): How to Plan a Crusade: Reason and Religious War in the High Middle Ages. London, Allen Lane, 2015. Other key works are cited at appropriate points in the discussion below.

3 CONSTABLE, G. (1982): "The Financing of the Crusades in the Twelfth Century". KEDAR, B.Z., MAYER, H.E. and SMAIL, R.C. (eds.), Outremer: Studies in the History of the Crusading Kingdom of Jerusalem. Jerusalem, Yad Izhak Ben-Zvi Institute, pp. 64-88; RILEY-SMITH, J. (1986): The First Crusade and the Idea of Crusading. London, Athlone; RILEYSSMITH, J. (1995): "Early Crusaders and the Costs of Crusading, 1095-1130". GOODICH, M., MENACHE, S. and SCHEIN, S. (eds.), Cross Cultural Convergences in the Crusader Period. New York, Peter Lang, pp. 237-258; RILEY-SMITH, J. (1997): The First Crusaders, 1095-1131. Cambridge, Cambridge University Press.

4 PORGES, W. (1946): "The Clergy, the Poor and the Non-Combatants on the First Crusade", Speculum, n ${ }^{\circ} 21$, pp. 1-23; KOSTICK, C. (2013): "Courage and Cowardice in the First Crusade, 1096-1099", War in History, n 20, pp. 32-49. 
In what follows the terms "warriors" and "soldiers" are employed to denote people who had received training in fighting techniques and discipline, and who earned their living primarily by military activity. The term "civilians" is used to denote those who did not engage in military activities in the course of their everyday lives, at least up to the point that they joined forces bound for the East. However, it shall become evident that these categories did not remain hard and fast during the course of crusade expeditions, whose character often obscured distinctions which might have been clear cut in other contexts. Further clarification will be given in the course of more detailed discussion.

Urban's call to crusade at Clermont came in response to appeals from the Byzantine emperor, Alexios I Komnenos, who wished to stem the Turkish advance into Syria and Asia Minor after the collapse of Byzantine resistance in the wake of the defeat of his predecessor Romanos IV Diogenes at the hands of the Seljuk sultan Alp Arslan at Manzikert in eastern Anatolia in 1071. Alexios had already employed Western knights in his service, both individually and in regiments, such as a contingent of 500 knights sent by the count of Flanders. These men constituted mercenaries in one of the most generally accepted senses of the word, in that they were soldiers who had left their home country to serve a foreign power for pay. Such a basis for service was quite common in the Byzantine army, which employed Varangians, Slavs, Armenians, Turkic peoples and Westerners (generally known as Franks) alongside native Greeks, and this form of military service was much more similar to modern military practice than the armed forces of contemporary Western Europe, which were largely recruited on the basis of feudo-vassalic obligations. ${ }^{5}$ Evidently Alexios hoped for much greater numbers of such experienced soldiers who would fight alongside the Byzantine army, but the use of mercenaries, in the sense just defined, proved to be practically non-existent in the course of the crusades to the Holy Land. ${ }^{6}$ The Western perspective was different. Pope Urban must have realised that aid for Byzantium probably had only a limited appeal among Western Christians, and so he coupled his call to crusade with the aim of freeing the Holy Land and its Christian population from Turkish rule, thus combining the idea of holy war with pilgrimage to the most sacred sites in the Christian faith.

BIRKENMEIER, J. (2002): The Development of the Komnenian Army, 1081-1180. Leiden, Brill, pp. 77-158.

SHEPARD, J. (1997): "Cross-Purposes: Alexius Comnenus and the First Crusade". PHILLIPS, J. (ed.), The First Crusade: Origins and Impact. Manchester, Manchester University Press, pp. 107. 129. For a recent discussion of mercenaries see: FRANCE, J. (ed.) (2008): Mercenaries and Paid Men: The Mercenary Identity in the Middle Ages. Leiden, Brill. 
The response which it brought forth gave rise to a form of warfare which was completely new in terms of the social makeup of those who volunteered to fight in it.

It is clear from all contemporary accounts of the council of Clermont that in his appeal, Urban was addressing himself to the knightly class of Western Europe. We must remember that at this time the status of knight was not yet imbued with the ideology and ethos of the cultural phenomenon that in retrospect came to be called "chivalry". This new idea of chivalry began to develop in the later twelfth century under the influence of the Arthurian romances of Chrétien de Troyes and his successors as well as religious reformers, so that by the thirteenth century most members of the higher nobility and royal families were happy to be described as knights and undergo knighting ceremonies, even though there was a vast social gulf between a count or duke and a simple knight in possession of a small country estate or serving in a castle garrison. What was happening here was a development of the concept of knighthood, which was being extended far beyond its original meaning. At the time of the council of Clermont, things were very different, however. Knights formed a military and managerial caste in the service of kings, bishops, dukes, counts and lords, who employed them in numbers ranging from dozens (as was probably the case with the Frenchman Nivello) to many hundreds, as in the cases of the princes of the Holy Roman empire and the great vassals of the kings of France. Fighting on horseback, armed with lance and sword and protected by a hauberk (coat of mail), helmet and shield, the knight was the dominant element in Western military forces in the eleventh and twelfth centuries. ${ }^{7}$

Knights served in all manner of conflicts, ranging from small-scale raiding to sieges and major wars. As a social group which exercised a near monopoly of violence, knights also had a propensity to feuding amongst themselves and to despoiling easy targets. In most of these cases it was institutions or groups which rarely had the means to defend themselves (such as monasteries or peasants) that suffered the most. Nivello and his followers clearly had military experience that would make them useful on crusade, but according

7 BUMKE, J. (1982): The Concept of Knighthood in the Middle Ages. New York, AMS Press; FLORI, J. (1998): Chevaliers et chevalerie au Moyen Age. Paris, Hachette. The chronicler Gilbert of Mons gives credible figures for the knightly retinues of princes of the Holy Roman empire in the twelfth century, ranging from 500 each for the duke of Austria and the abbot of Fulda to 1000 or more for the count palatine of the Rhine, the landgrave of Thuringia and the archbishop of Cologne. See Gilbert of Mons, Chronicle of Hainaut, trans. L. NAPRAN (Woodbridge, Boydell Press, 2005), esp. pp. 87-88. 
to his confession, they had regularly plundered the estates and dependents of the monastery of St Peter. It was Pope Urban's idea to channel and divert this destructive and senseless violence towards a more laudable and deserving purpose by recruiting the knights of the West as the principal force in his expedition to recover the Holy Land. As the monk Robert of Rheims phrased it in his account of Urban's speech at Clermont:

"Let those", he [Urban] said, "who are accustomed wantonly to wage private war against the faithful march upon the infidels in a war which should be begun now and be finished in victory. Let those who have long been robbers now be soldiers of Christ. Let those who once fought against brothers and relatives now rightfully fight against barbarians. Let those who have been hirelings for a few pieces of silver now attain an eternal reward. Let those who have been exhausting themselves to the detriment of body and soul now labour for a double glory". ${ }^{8}$

Urban envisaged the participation of a number of clerics to provide religious leadership and spiritual guidance. They included his chosen leader, Adhemar, bishop of Le Puy, and a number of other bishops (especially from southern France). However, he expected the bulk of the forthcoming crusade to be made up of secular lords and their entourages of knights, a combination for which modern scholarship has devised the overarching term armsbearers. In a letter to the monks of Vallombrosa sent on 7 October 1096, Urban stated that he had intended to persuade knights to join the expedition, but that he was concerned that "the wrong kind of person" - meaning priests and monks - wanted to set out with them. ${ }^{9}$ In practice neither Urban's commands nor monastic discipline prevented a number of priests, monks and even nuns joining the expedition, but these came to be vastly outnumbered by lay people from beyond the noble and knightly warrior classes.

For the church, the ideal way to fight for the faith had been to live as a monk, a lifestyle that was ill-suited to the majority of believers. What was new about Urban's plan for the crusade was that anyone could fight for the faith in a real sense. Knights who had been condemned by the church for their violent lifestyles could now deploy their military skills in the service of the faith, and gain spiritual benefits in doing so. However, in practice it proved impossible to restrict participation to knights. Urban proclaimed the expedition as a pilgrimage, an institution which had traditionally been 
open to all classes. As the primary incentive, the Pope offered a remission of sins to all who went to the Holy Sepulchre, the traditional site of Christ's burial, death and Resurrection. The precise nature of this indulgence has been much debated by historians, but the important thing is that thousands of people regarded it as an unrepeatable offer in which they could rid themselves of the consequences of $\sin$ in the afterlife. The prospect of this wonderful spiritual bargain meant that members of all social classes joined up by taking the sign of the cross: men, women and children; old and young; rich and poor; free and unfree; townspeople and peasants; laypeople, clerics and monks. ${ }^{10}$

\subsection{Princes' Crusades and Popular Crusades}

The practicalities of recruitment of crusaders over most of France, the Low Countries, western Germany, northern Italy and the British Isles meant that the large number of crusaders who responded to Urban's appeal formed themselves into over a dozen different contingents which travelled separately to the East, but it is important to recognise that these can be regarded as belonging to two distinctive types of units in terms of their composition and leadership.

The majority of crusaders spent many months preparing for their journey, using the time following the council of Clermont to raise the necessary finance, put their affairs in order, and make contact with potential companions, with the aim of leaving on or near the official departure date of the Feast of the Assumption (15 August 1096). Command in crusade armies was based on social rank rather than military ability, although the nature of Western society meant that most of the great lords who figured as commanders already had experience of warfare. This meant that most crusaders, whether singly or (more probably) in small groups of kinsfolk, acquaintances or fellow workers, coalesced around a number of great lords, whose status meant that their leadership was necessarily accepted by those who aimed to travel with them: Raymond of Saint-Giles, count of Toulouse; Godfrey of Bouillon, duke of Lower Lotharingia; Stephen-Henry, count of Blois, and Hugh, count of Vermandois; Robert II, count of Flanders, and Robert Curthose,

10 KOSTICK, C. (2008): The Social Structure of the First Crusade. Leiden, Brill; MURRAY, A.V. (2012): "Sex, Death and the Problem of Single Women in the Armies of the First Crusade". GERTWAGEN, R. and JEFFREYS, E. (eds.), Shipping, Trade and Crusade in the Medieval Mediterranean: Studies in Honour of John Pryor. Farnham, Ashgate, pp. 255-270. 
duke of Normandy. ${ }^{11}$ The contingents led by these lords are now generally referred to as "princes' crusades". In their composition and recruitment, each of these armies (each generally referred to in the sources by the Latin noun exercitus) can be thought of a series of concentric circles. The central element was the princely household. Beyond this were various lords and knights who were connected with the leader by ties of kinship or vassalage, together with their own dependents, while on the periphery were others whose ties were much looser, being based on regional identity or linguistic affiliation. ${ }^{12}$ This scheme can be illustrated in terms of the composition of the army of Godfrey of Bouillon. At its core were Godfrey himself, his brother Baldwin of Boulogne and Baldwin's wife Godevere, along with household officials of knightly rank, who included a seneschal, a butler, and chamberlain, while Baldwin had a secretary who was probably a cleric. This central element also included a number of Bullonienses, that is, knights who held fiefs in Godfrey's allodial territory of Bouillon in the Ardennes, who included the castellan of Bouillon, one Heribrand. Beyond them were a number of lords from neighbouring areas of Lower Lotharingia and the northern part of the kingdom of France, many of whom were linked to Godfrey and Baldwin by ties of kinship: Warner, count of Grez; Cuno, count of Montaigu, and his sons Gozelo and Lambert; Henry and Godfrey of Esch-sur-la-Sûre; Baldwin of Mons, count of Hainaut; Dudo, lord of Cons-la-Grandville; Peter of Dampierre, count of Astenois, and his brother Rainald, count of Toul; and Baldwin, lord of Bourcq. Each of these lords must have had his own retinue of knights, grooms and other servants. Beyond them was a less easily discernable group of laymen and clerics, many of them from urban environments, who included Adalbero of Luxembourg, archdeacon of Metz, and others from the region, as well as those who joined Godfrey from areas that his army passed through on its journey to the East, such as Reinhold of Helmarshausen in Hesse, or Hartmann, count of Dillingen and Kyburg in Upper Swabia. ${ }^{13}$

11 The Italian-Norman leader Bohemund later led a contingent of Normans and Lombards, but I have argued that his decision to join the crusade was largely opportunistic and occurred only after the contingents from north of the Alps were passing through Italy. See: MURRAY, A.V. (2015): "The Enemy Within: Bohemond, Byzantium and the Subversion of the First Crusade". HURLOCK, K. and OLDFIELD, P. (eds.), Crusading and Pilgrimage in the Norman World. Woodbridge, Boydell \& Brewer, pp. 31-47.

12 MURRAY, A.V. (2011): "National Identity, Language and Conflict in the Crusades to the Holy Land, 1096-1 192". KOSTICK, The Crusades and the Near East, pp. 107-130.

13 MURRAY, A.V. (1992): "The Army of Godfrey of Bouillon, 1096-1099: Structure and Dynamics of a Contingent on the First Crusade". Revue Belge de Philologie et d'Histoire, $n^{\circ} 70, \mathrm{pp}$. 301-329. 
Yet long before the princes' crusades set off, other groups were already on the move which were more popular in composition and less hierarchical in their organisation. Their leadership was not based on status and authority, as in the case of the princes' expeditions, but on the personal charisma and promises of those who led them. The wandering preacher Peter the Hermit attracted numerous followers from central and northern France, primarily though the effectiveness of his preaching, and the priest Gottschalk had a similar response in the Rhineland. Others who responded to appeals were more obviously driven by cupidity. Emicho, count of Flonheim, collected a large number of followers from the central Rhineland, who combined with other crusaders coming from the West to attack and despoil the Jews of Mainz. ${ }^{14}$ These and other similarly organised groups were at one time referred to as "Peasants' Crusades", although this designation has now largely been set aside as misleading. Nevertheless, they seem to have included far fewer members of the noble and knightly classes than the princes' expeditions; indeed, it is scarcely conceivable that members of the higher nobility, who were used to exercising command, would have been willing to accept the leadership of simple priests or preachers such as Peter the Hermit. Peter's army eventually absorbed other groups from the lle-deFrance, northern France and western Germany, and while these included knights such as Walter Sans-Avoir (from Boissy-sans-Avoir near Paris) and others from his kin group, the relative paucity of named individuals in the sources suggests that it predominantly consisted of townspeople, peasants and other country dwellers. ${ }^{15}$

Most of these popular groups, as well as others from northern Italy, were already in motion by the spring of 1096. Since their participants were generally poorer than those of the princes' crusades and had spent little time in preparation, they were obliged to recruit additional members and secure funds and provisions on the move as they marched east, through a combination of appeals to charity, plundering and extortion, particularly through despoliation of the Jewish communities of Germany and Bohemia. The lawlessness and indiscipline which they exhibited resulted in most of them being violently dispersed by German or Hungarian authorities. Only a minority reached Constantinople and crossed into Asia Minor, but after a

14 FLORI, J. (1999): Pierre l'Ermite et la Première Croisade. Paris, Fayard; MÖHRING, H. (1992): "Graf Emicho und die Judenverfolgungen von 1096". Rheinische Vierteliahrsblätter, n 56, pp. 97-111.

15 Albert of Aachen, Historia lerosolimitana: History of the Journey to Jerusalem, ed. and trans. S. B. EDGINGTON (Oxford, Oxford University Press, 2007), pp. 1-5, 8-17, 44-53. 
crushing defeat by the Turks of the sultanate of Rūm in the autumn of 1096, the pitiful survivors had little choice but to attach themselves to the princes' expeditions.

\subsection{Problems of Definition: Professionals and Civilians in the First Crusade}

The diverse contingents which assembled on the Asian shore and marched towards Nicaea in early 1097 numbered in total perhaps some 50,000 60,000 men, women and children. ${ }^{16}$ The vast majority of them (as well as those in subsequent expeditions) were volunteers, in the sense that they had voluntarily taken public vows to travel to Jerusalem, reflected in the sign of the cross worn on their clothing. However, we should remember that in this labour-intensive age not only nobles, but many others of much humbler status could afford to maintain personal servants, who may well have had little choice but to accompany their masters. In terms of their experience of war, participants can be roughly divided into two categories. On the one hand were the armsbearers, that is, members of the nobility and their retinues of mounted knights. Most of these would have needed grooms, while the wealthier ones were probably accompanied by other specialists such as armourers, farriers and falconers, as well as contingents of footsoldiers with varying degrees of protective equipment. On the other hand there were significant numbers of peasants, labourers, artisans, domestic servants, as well as clerics and other religious. These can be classified - for want of a better word - as civilians, meaning that they had no experience of warfare in their lives prior to their participation in a crusade, except perhaps, that some of them may have previously been on the receiving end of knightly violence.

It is difficult to map such categories onto classifications such as professionals, mercenaries or non-combatants, whose definitions have essentially been driven by military experience in the post-medieval world, and in more recent times, by laws and conventions. Since around the late fifteenth or sixteenth centuries, professional soldiers can be defined by a number of characteristics which have by and large been maintained up to the present. At its most basic, this form of professionalism required that its practitioners had to undergo training in using weapons and moving in formation on the battlefield, a circumstance which presupposes the existence of a recognised system of drill and commands. To this we can add the acceptance of a hierarchy of military ranks and uniforms (at least within single units). Several of these features were already present among the landsknechts and Swiss 
pikemen and halberdiers of the later Middle Ages, as well as the Spanish tercios of the sixteenth century, and they continued to be characteristic of modern armies, whether these were primarily formed from volunteers (as in the British and French armies of the eighteenth century) or conscripts, as in the military systems of eighteenth-century Prussia and the national armies of most of continental Europe in the period after the French Revolution.

It is no coincidence that all of these modern examples related primarily to footsoldiers, who required drill and ordered formations to function effectively, but who also needed to be more amenable to such discipline than were cavalrymen. Armies of the late eleventh and twelfth centuries were dominated by mounted knights, but there were few formal methods of training that resembled those of modern forces. The most essential attribute for a knight was to be able to ride a horse from an early age and wield spear, sword and shield while doing so. The effectiveness of the charge depended on maintaining a tight formation with knights riding knee to knee, and although some had the opportunity to practice manoeuvres in tourneys, most knights would have learned to fight in formation through real experience and practice.

The distinction between combatants and civilians which prevailed at the beginning of the First Crusade became progressively blurred by conditions which developed in the course of the long march to Jerusalem. The status of knights depended not only on their military experience and skills, but also on their possession of horses and equipment, which enabled them to fight in an effective manner. Most military conflicts in the West at this time were relatively limited in their objectives and thus restricted in time. By contrast, the duration of the First Crusade - from departure in August 1096 to the capture of Jerusalem in July 1099 - had effects which all but the most seasoned participants would have rarely experienced in campaigning in their home countries. During the crossing of the Anatolian plateau, many horses died either as a result of starvation and thirst or from being slaughtered for food by the equally starving crusaders. During the privation of the siege of Antioch, which lasted through the winter and spring of 1097 . 1098, many crusaders sold their possessions to buy food. Horses, and armour and weapons that had been captured, lost or became unusable were difficult to replace many thousands of kilometres away from home, which affected status as well as the ability to fight. One vivid example can illustrate this phenomenon. During the siege of Nicaea (1097), Hartmann, count of Dillingen and Kyburg, had sufficient spare funds to part finance the construction of a siege engine. Yet within a year he had sold his horse and armour, and was riding an ass and fighting with captured Turkish weapons. He was dependent on Godfrey of Bouillon for a daily ration of food, which 
meant that he was probably no longer able to maintain the retinue that must have originally accompanied him. One of the richest men in southern Germany had been reduced to the status of a simple footsoldier, and many other lords and knights were in the position of dependents of the princes, who were better placed to secure forage and tribute by virtue of their role as field commanders and organisers. ${ }^{17}$

At the same time the requirements placed on civilians meant that many of them were gradually being transformed into soldiers. The crusade army was divided into a number of contingents, each led by one of the princes, which marched separately, and each of these units seems to have organised its own foraging and provisioning. This meant that civilians had little choice but to accept the orders and discipline imposed by those in command. It is difficult to train an adult civilian to fight on horseback, which is why knights learned to ride while still in their youth, but a civilian could be made into an infantry soldier given the requirements of the campaign. The crusaders fought pitched battles against highly mobile Turkish horsemen at Dorylaion (July 1097), Albara (December 1097) and at Antioch (February and June 1098), who were more mobile than the crusader cavalry. However, in most of these cases a significant role was played by the crusader infantry, whose effectiveness increased progressively. Yet a greater amount of time was spent in lengthy sieges of a succession of Muslim-held cities: Nicaea (MayJune 1097), Antioch (October 1097 - June 1098), Ma'arrat al-Numan (November-December 1098), 'Akkar (April-May 1099), and Jerusalem (June-July 1099). In these situations knights had to fight dismounted, and infantrymen had to carry out a wide range of tasks: going on foraging parties, sourcing building materials and constructing ladders and other siege equipment, doing sentry duty and guarding prisoners, and in many cases, taking part in assaults. This all meant that by the summer of 1099, when Jerusalem was finally taken, most of the originally civilian crusaders had probably learned to wield weapons, follow orders and maintain disciple, and keep formation where required. It was this cohesion acquired over several years that enabled the crusader army, despite being much reduced in numbers, to win its final victory over a numerically superior Fātimid army on the coastal plain outside Ascalon in August 1099. ${ }^{18}$

17 Albert of Aachen, Historia lerosolimitana, pp. 332-334; MURRAY, A.V. (2006): "Money and Logistics in the Armies of the First Crusade: Coinage, Bullion, Service and Supply, 1096-99". PRYOR, Logistics of Warfare, pp. 229-249.

18 MURRAY, A.V. (2017): "A Race against Time - A Fight to the Death: Combatants and Civilians in the Siege and Capture of Jerusalem". DOWDALL, A. and HOME, J. (eds.), Civilians under Siege from Sarajevo to Troy. Basingstoke, Palgrave Macmillan, forthcoming. 


\section{The Defence of the Holy Land}

\subsection{The Frankish Hosts}

The majority of crusaders probably returned to the West in the summer of 1099, but those lords and knights who remained went on to constitute the military and administrative classes of the four new principalities established by the crusade: the county of Edessa, the principality of Antioch, the county of Tripoli and the kingdom of Jerusalem, known collectively to Western Christians as Outremer. ${ }^{19}$ It is also likely - although difficult to demonstrate with certainty - that many of those who had fought in the crusade as footsoldiers remained to follow military professions in the new homeland.

The opponents of the Frankish states of Outremer were mostly Turkish (or in the case of Saladin, Kurdish) rulers or warlords. The main element in their military forces were professional mounted soldiers (known as mamlüks or ghülams), recruited mostly from Turks or Kurds, but with small numbers from other ethnic groups; each was normally equipped with a mail coat, spear, sword, shield and the composite bow. This core force was usually augmented by nomadic Türkmen tribesmen, fighting in a similar manner but with less armour, while Turkish leaders who controlled major cities such as Aleppo or Damascus could also deploy militias of footsoldiers drawn from the predominantly Arab urban populations. ${ }^{20}$ By contrast, the Fātimid caliphs of Egypt employed multi-ethnic forces which proved much less effective against the Franks; these were disbanded and replaced by mamlüks when Saladin overthrew the caliphate in 1171 . The key element in Frankish armies was the knights, who were used to deliver a devastating charge, a tactic which the Muslim forces feared and did not try to replicate themselves. The main Turkish tactic was to move close and use archery to wear down the Frankish troops; feigned retreats were also used in the hope of breaking up Frankish formations. This meant that the Franks had to employ large numbers of trained infantry to hold the army's position and protect the knights and their

19 RICHARD, J. (1989): "La noblesse de Terre Sainte (1097-1 187". Arquivos do Centro cultural português, $n^{\circ}$ 26, pp. 321-336; MURRAY, A.V. (1989): "The Origins of the Frankish Nobility of the Kingdom of Jerusalem, 1100-1 $118^{\prime \prime}$. Mediterranean Historical Review, $\mathrm{n}^{\circ}$ 4, pp. 281-300; MURRAY, A.V. (1997): "How Norman was the Principality of Antioch? Prolegomena to a Study of the Origins of the Nobility of a Crusader State". KEATS-ROHAN, K.S.B. (ed.), Family Trees and the Roots of Politics: The Prosopography of Britain and France from the Tenth to the Twelfth Century. Woodbridge, Boydell \& Brewer, pp. 349-359; MURRAY, A.V. (2009): "Norman Settlement in the Latin Kingdom of Jerusalem, 1099-1 131". Archivio Normanno-Svevo, n 1, pp. 61-85.

20 HILLENBRAND, C. (1999): The Crusades: Islamic Perspectives. Edinburgh, Edinburgh University Press, pp. $431-467$. 
valuable warhorses until the point that the charge could be unleashed.

A list detailing the military service of the kingdom of Jerusalem shortly before its great defeat by Saladin at the battle of Hattin in 1187 was preserved in the Livre des Assises, a treatise of laws and customs compiled by John of Ibelin, count of Jaffa (d. 1266). It gives the total service available to the king as some 675 knights and 5025 sergeants. ${ }^{21}$ The sergeants were provided by the bishoprics and the urban communities and were most probably footsoldiers, although some may have served on horseback in lighter equipment than the knights. It is likely that the sergeants were full-time professional soldiers, although we cannot exclude the possibility that they were members of the burgess class who were obliged to perform military service as necessity dictated as a condition of their tenures. Experts have argued that the number of knights given by John of Ibelin was considerably lower than the size of the greatest Frankish armies would suggest, and that his figures represented only the service that lords were obliged to provide to the Crown. Thus the count of Jaffa and the lords of Tiberias and Sidon each owed the service of 100 knights, with smaller lordships providing lesser numbers. In actual fact many lords, especially those who held fiefs in frontier areas, probably enfeoffed greater numbers than their own obligations demanded, ${ }^{22}$ which meant that more soldiers were available than were enumerated in the Livre des Assises. A large number of knights were also maintained directly by the Crown through an institution known as the money-fief (French: fief-rente). These men did not hold landed fiefs, but were remunerated directly in cash out of royal revenues. Palestine was a money economy, and there was generally more coin in circulation than in Western Europe. The money-fiefs in Palestine may have originated as a result of tribute paid by Muslim-held cities to Frankish rulers, who used this income to remunerate many of their vassals. All of the Muslim cities in Palestine were in Frankish hands by 1125 except for Ascalon (which fell in 1153), and from this time most of the money-fiefs were probably paid out of customs revenues accruing to the Crown in the demesne cities of Acre and Tyre, and to a lesser extent, other revenues in territories of Nablus and the city of Jerusalem. ${ }^{23}$

21 EDBURY, P.W. (1997): John of Ibelin and the Kingdom of Jerusalem. Woodbridge, Boydell, pp. $118-154$.

22 EDBURY: John of Ibelin, p. 131; FRANCE, J. (2000): "Crusading Warfare and its Adaptation to Eastern Conditions in the Twelffh Century". Mediterranean Historical Review, n 15, pp. 49-56.

23 MURRAY, A.V. (2008): "The Origin of Money-Fiefs in the Latin Kingdom of Jerusalem". FRANCE, Mercenaries and Paid Men, pp. 275-286. 
The nobles and knights of Outremer formed a hereditary caste of European origin, although there was probably less of a divide between the two groups than in the West; because of a general shortage of manpower several relatively lowly or otherwise obscure knights were able to acquire fairly important lordships, especially in the first few decades after the First Crusade. Another important difference was that in the West the service of vassals to their lords was becoming limited by custom to 40 days in the year, but in Jerusalem service in defence of the kingdom was unlimited, and the same probably applied in the other states. By contrast, when kings such as Amalric (1 163-1 174) campaigned in Egypt, they were obliged to offer their vassals financial inducements to take part in expeditions outside the kingdom.

Much less is known about the forces of the northern states of Antioch, Tripoli and Edessa (especially since the last named had fallen to the Turks by 1150 , leaving few surviving sources). However, one significant difference compared to the kingdom of Jerusalem is that the Franks of Syria made extensive use of native Christians in their armies. Unlike conditions in Palestine, where native Christians had lost their upper classes in the course of Muslim invasions, the Armenians of Upper Mesopotamia and Cilicia and the Greeks of Syria still had a class of nobles, chieftains and warriors, many of whom served the Franks as soldiers and administrators. Thus one Euterpius, described as a 'most worthy knight in physical and mental strife', was killed fighting against the Turks at the battle known as the Field of Blood (Ager Sanguinis) in 1119 . This name is undoubtedly of Greek origin and is unknown among Western populations. ${ }^{24}$ Vassals of the Mazoir lords of Margat, named in a charter of Prince Bohemund III of Antioch dating from 1186, include two men named Amelin and Baldwin who were clearly Franks, but also two Easterners with Greek names, George and Theodore. The fact that they are explicitly described as knights and also given the title dominus clearly indicates that they were part of the Mazoir family's military retinue and were more than simple footsoldiers. ${ }^{25}$ Similarly, the Maronites of the Lebanon mountains had maintained military traditions in centuries of resistance to Muslim invaders, and provided soldiers (notably archers) to the counts of Tripoli. ${ }^{26}$ Both Antioch and Jerusalem employed considerable

24 Walter the Chancellor, Galterii Cancelarii Bella Antiochena, ed. H. HAGENMEYER (Innsbruck, Wagner, 1896), p. 90.

25 RÖHRICHT, R. (ed.), Regesta Regni Hierosolymitani, 2 vols. (Innsbruck, Wagner, 1893-1904), no. 649. Another of this group, Dominus Zacharias, may also have been an Eastern Christian.

26 SALIBI, K.S. (1957): "The Maronites of Lebanon under Frankish and Mamluk Rule (1099-1516)". Arabica, $n^{\circ} 4$, pp. 280-303. 
numbers of light cavalry known as Turcopoles, a name deriving from the Greek точркотоићо . This term was used to denote Turkish mercenaries in Byzantine service, but in Outremer it is unclear whether these were really Turks, or were possibly Eastern Christians fighting in the Turkish manner. ${ }^{27} \mathrm{~A}$ private charter issued in 1180 gives a list of witnesses described as Turcopuli, one of whom is named as Gaifredus Baptizatus. The second element of this name suggests that he had converted to Christianity, and had taken the Western name Gaifredus (Geoffrey) on that occasion. The names Godfrey and Gormund are clearly Western in origin, while the names Peter, John and Andrew were popular among both Western and Eastern Christians. The fact that one is named along with his son indicates that the Turcopoles could also be a hereditary profession, although the evidence of names appearing in this charter suggests that they were a fairly diverse group. ${ }^{28}$

The principalities of Outremer were perennially short of manpower. Even when garrisons in castles and towns had been reduced to an absolute minimum, each state could only put a single host into the field, which was invariably smaller than invading Muslim forces. Commanders were thus often reluctant to risk this army, since if it was defeated - as happened against Saladin at the battle of Hattin in 1187 - there would be no sizeable forces left to combat the Muslims. In order to increase available numbers, rulers and holders of lordships seem to have augmented their vassals by employing knights who served purely for pay. The notorious Rainald of Châtillon, who rose to become prince of Antioch and later lord of Transjordan, and died at the hands of Saladin after being captured at Hattin, first appeared in the Holy Land holding a stipendium (a stipend or salary) from King Baldwin III of Jerusalem (1 145-1 163) at the siege of Ascalon in 1153. Rainald does not seem to have taken a crusade vow, but left France and took service with the king of Jerusalem for regular pay. By most definitions, he was a mercenary. ${ }^{29}$ This category of hired men becomes clearer in a charter issued in 1158 by Amalric, then count of Ascalon and later king of Jerusalem, which was witnessed by three groups of men of knightly rank. They are respective-

27 Walter the Chancellor, Galterii Cancelarii Bella Antiochena, pp. 74, 84, 88; RICHARD, J. (1986): "Les Turcoples au service des royaumes de Jérusalem et de Chypre: Musulmans convertis ou chrétiens orientaux?". Revue des études islamiques, n 54, pp. 259-270.

28 RÖHRICHT, Regesta Regni Hierosolymitani, no. 594: Gaifredus Baptizatus, Durantus Scutifer, Petrus, filius ejus, magister Godofredus, Petrus de Capharset, Petrus Lorgius, Arnulfus, Stephanus Rex, Silvester de Sapharia, Gormundus, Andreas, Bonettus Salvagius, Johannes Sansan.

29 Guillaume de Tyre, Chronique, ed. R.B.C. HUYGENS, Corpus Christianorum Continuatio Mediaevalis 63-63A, 2 vols. (Turnhout, Brepols, 1986), p. 790. 
ly described by Amalric as homines mei, meaning his own vassals in the county of Ascalon; homines regis, that is vassals of his brother Baldwin III; and finally stipendiarii mei, who must thus have been mercenaries serving Amalric for pay, rather than holding fiefs like the homines. ${ }^{30}$

\subsection{The Military Monastic Orders}

It was the requirements of the defence of the Holy Land that brought forth one of the most novel and distinctive types of warrior in European history. In 1119-1120 a number of knights living in Palestine dedicated themselves to the protection of pilgrims travelling between their points of arrival on the coast and the holy sites in and around Jerusalem. By 1129 the Templars, as they became known, had been granted a rule, making them into a religious organisation similar to existing orders of monks, but what was revolutionary was that they were permitted and indeed, expected to fight for the Christian faith. In categorising the knight brethren of the military order it is difficult to apply modern concepts of professionalism. We tend to think of a professional soldier as someone who has made a career of service in the military, and while the Templar (and members of other orders) dedicated his life to the knighthood of Christ by fighting against the enemies of Christianity, he combined this service with the lifestyle of a monk. Traditional monastic orders were organised around the celebration of the liturgy, prayer, contemplation and manual work, a combination which did not necessarily appeal to men from the knightly classes who had been brought up to ride, fight and hunt; membership of the Order of the Temple allowed them to combine a religious vocation with a military lifestyle which would have been familiar to them. Thus Templars profited from their service not in material, but in spiritual terms, yet despite their formal status as monks they were probably the most dedicated form of soldier in medieval Christendom. Indeed, a Templar made a profession at the time of his entry into the order, when he took vows of poverty, chastity and obedience. He was subjected to severe forms of discipline, both on campaign and in everyday life, with punishments for infringements of vows as well as for actions that threatened the cohesion of the order's units in wartime. The fact that this quite innovative organisational form was accepted by the papacy and the wider church owed a great deal to the support of the influential Cistercian theologian Bernard of Clairvaux, notably in his treatise written in its support, De laude novae militiae (In Praise of New Knighthood). What Bernard meant by "new knighthood"

30 MAYER, H.E. (ed.), Die Urkunden der lateinischen Könige von Jerusalem, 4 vols. (Hannover, Hahnsche Buchhandlung, 2010), 1, no. 298. 
was a pure form of knightly life in the service of the faith, in contrast to what he perceived as the older, sinful and destructive lifestyle of secular knights. It could thus be said that the development of the military monastic order was a logical consequence of the vision of Christian knighthood proclaimed by Urban II at the council of Clermont. ${ }^{31}$

The appeal of this new institution can be seen from the fact that new orders sprang up on the Templar model in Outremer, Iberia and the Baltic region. Meanwhile the Order of the Hospital, originally a purely charitable and medical organisation, had by the 1160 s restructured itself to become a military order, while retaining its original hospitaller functions. A similar development occurred with the Order of St Mary of the Germans, founded as a hospitaller organisation during the Third Crusade, but which soon become a military order in which knight brethren were the dominant element. The first master of the Templars, a knight from Champagne named Hugh de Payns, came to Palestine some time after the First Crusade (probably in 1104) and indeed Templars, Hospitallers and Teutonic Knights rarely took part in large crusade expeditions. ${ }^{32}$ Rather, they usually entered their respective orders in Western Europe, and later travelled to the East by ship, where they were assigned postings. In the twelfth century the Templars and Hospitallers maintained significant numbers of knight brethren and sergeants who regularly fought alongside the forces of the secular rulers, but they made a wider contribution to the defence of Outremer. Since they derived revenues from their extensive estates in the West, they were able to finance the maintenance and construction of castles, especially in frontier areas. They also purchased fiefs and castles from secular nobles, many of whom had become impoverished as a result of having to pay ransoms, which meant that the orders acquired vassals of their own, who were obliged to perform military service. They also employed Turcopoles, who were under the command of a desig-

31 FOREY, A.J. (1985): "The Emergence of the Military Order in the Twelfth Century". Journal of Ecclesiastical History, n 36, pp. 175-195; BARBER, M. (1994): The New Knighthood: A History of the Order of the Temple. Cambridge, Cambridge University Press, pp. 1-37; CERRINI, S. (2001): "Le fondateur de l'ordre du Temple à ses frères: Hugues de Payns et le Sermo Christi militibus". BALARD, M., KEDAR, B.Z, and RILEY-SMITH, J. (eds), Dei gesta per Francos: Etudes sur les croisades dédiés à Jean Richard. Aldershot, Ashgate, pp. 99-1 10.

32 A notable exception was the Second Crusade, when a contingent of Templars accompanied the army of King Lovis VII of France (see Section 3.1 below). 
nated high officer called the turcopolier. ${ }^{33}$ When King Amalric of Jerusalem planned the invasion and annexation of Egypt in 1168-1171, the Hospitallers agreed to provide 500 knights and 500 Turcopoles in exchange for major territorial concessions in the Nile Delta and revenues elsewhere in Egypt. ${ }^{34}$ It is unlikely that the order could garrison its castles and undertake campaigns of this magnitude using only its own knight brethren, sergeants and Turcopoles, and there is considerable evidence that both Hospitallers and Templars employed different sorts of soldier who were not members of the orders. Some were mercenaries: knights, sergeants and even Turcopoles who were hired from outside. These contrasted with the volunteers known as milites ad terminum, recruited from lords and knights from the West who served for a limited period at their own expense. It is possible that these men arrived in the East in the periods between major crusade expeditions, and regarded service with one of the orders as the most promising opportunity to gain experience of combat against the Muslims. ${ }^{35}$

\section{The later Crusades}

\subsection{The Second Crusade (1147-1149)}

Thus, from the middle third of the twelfth century until the late thirteenth, the crusades were fought by several distinct categories of soldier: crusaders, that is volunteers from Western Europe who had taken vows to defend or liberate the Holy Land; the lords, knights, sergeants and Turcopoles in the

33 BARBER, The New Knighthood, pp. 166, 189; NICHOLSON, H. (2001): The Knights Hospitaller. Woodbridge, Boydell Press, pp. 21-23; FOREY, A.J. (1984): "The Militarisation of the Hospital of St John". Studia Monastica, n 26, pp. 75-89; RILEY-SMITH, J. (2012): The Knights Hospitaller in the Levant, c. 1070-1309. Basingstoke, Palgrave Macmillan, pp. 27-51; BURGTORF, J. (2006): "The Military Orders in the Crusader Principality of Antioch". CIGGAAR, K. and METCALF, M. (eds), East and West in the Medieval Mediterranean, I: Antioch from the Byzantine Reconquest until the End of the Crusader Principality. Leuven, Uitgeverij Peeters, pp. 217-246.

34 MURRAY, A.V. (2016): "The Grand Designs of Gilbert of Assailly: The Order of the Hospital in the Projected Conquest of Egypt by King Amalric of Jerusalem (1 168-1 169)". Ordines Militares: Yearbook for the Study of the Military Orders, n²0, pp. 7-24; MURRAY, A.V. (2016): "The Place of Egypt in the Military Strategy of the Crusades, 1099-1221". MYLOD, E.J., PERRY, G., SMITH, T.W. and VANDEBURIE, J. (eds.), The Fifth Crusade in Context: The Crusading Movement in the Early Thirteenth Century. Abingdon, Routledge, pp. 117-134.

35 FOREY, A.J. (2008): "Milites ad terminum in the Service of the Military Orders during the Twelfth and Thirteenth Centuries". UPTON-WARD, J. (ed.), The Military Orders, 4: On Land and by Sea. Aldershot, Ashgate, pp. 5-1 1; FOREY, A.J. (2016): "Paid Troops in the Service of the Military Orders during the Twelfth and Thirteenth Centuries". BOAS, A. (ed.), The Crusader World. London, Routledge, pp. 84-97. 
Frankish principalities of Outremer; the warrior monks and their service personnel in the military monastic orders; and mercenaries, who might have served any one of the other three groups who were wealthy enough to hire them. The involvement of each group varied considerably over time, and the character of crusades in particular began to change quite fundamentally from the later twelfth century onwards. Numerous land and sea expeditions continued to arrive in the East in the period between 1099 and 1147. The crusades of $1101,1122-1124$ and 1129 brought smaller numbers than in 1096-1099, and once they had arrived in Outremer they fought alongside seasoned local Frankish forces, who by this time had considerable experience in fighting their Turkish and Egyptian opponents. It was only with the so-called Second Crusade (1147-1149) that numbers of crusaders were comparable to those in Pope Urban's expedition.

While a combined force from northern Germany, the Low Countries and England sailed via Iberia, the main armies travelled by land, led Conrad III, king of Germany, and Louis VII, king of France. These two expeditions were bedevilled by problems similar to those which had been evident in the First Crusade, which were already evident in the period of preaching and recruitment. In 1146 a French Cistercian named Ralph inspired large numbers in the Rhineland, but their energies were largely directed into attacks on Jewish communities. He was eventually persuaded to desist and return to his monastery by Bernard of Clairvaux, who preached in a more moderate manner throughout south-western Germany, but it was noticeable that while large numbers of common people took the cross, those who were better off and experienced in warfare held back. When King Conrad took the cross at Easter 1147 in Würzburg along with numerous bishops, counts and nobles, large numbers of brigands and thieves turned up. This was not surprising. Bernard's preaching emphasised that sinners and criminals could redeem themselves by fighting for the cross, while a famine in 1146 meant that many peasants and agricultural labourers joined up in the hope of better prospects. Conor Kostick has convincingly argued that Conrad's army contained a large popular element which caused major problems during the passage through Byzantine territory with indiscriminate violence, looting and attacks on local populations, and ultimately forced Conrad to abandon his advance on the Anatolian plateau. ${ }^{36}$ This element was not only indisci-

36 PHILLIPS, J. (2007): The Second Crusade: Extending the Frontiers of Christendom. New Haven, Yale University Press, pp. 80-103; KOSTICK, C. (2010): "Social Unrest and the Failure of Conrad III's March through Anatolia, $1147^{\prime \prime}$. German History, n 28, pp. 125-142. 
plined; it had little real fighting experience. One of several sources which describe these events, the Annals of Pöhlde, describes the passage through Turkish-held territory, reporting that "the pedites were worn out by starvation and ignorant of wars". The Latin term pedites is normally translated as "footsoldiers", in distinction to mounted knights (milites), but this meaning makes little sense in this context; rather, pedites here is more likely to mean the large number of common people who were travelling on foot but had no military experience. ${ }^{37}$ Most of these refused to co-operate with the crusade leadership and became separated from the main force of knights. On 26 October 1147 they were overwhelmed by the army of Mas'ud, sultan of Rūm, and Conrad had little choice but to lead the survivors back to Constantinople.

We know less about the composition of the French army, but descriptions given by the chronicler suggest something similar. Unusually, Louis was accompanied by a contingent of Templars under their master, Everard of Barres, who acted as guides and divisional commanders during the crossing of Anatolia. Despite the support of such disciplined warriors, discipline left much to be desired. As Louis led his troops over the Kadmos mountain in southern Anatolia, a mass of common people lagged behind and began to be picked off by Turkish horse archers. Louis led his vanguard back to go to their aid, but the commoners, described as a "mob" (turba), failed to maintain resistance and fled, exposing themselves and the king's own troops to destruction. After this disaster Louis complained bitterly about the "unarmed mob" (inermem turbam) which had slowed down the passage and made food expensive. However, their numbers were swelled by those whom the chronicler Odo of Deuil neatly describes as "those whom nature or fortune had made into footsoldiers" (Illi ... quos natura fecerat pedites vel fortuna), explaining that many of the nobles were marching not with the cavalry, but among the mob in "an unaccustomed manner" (multi enim nobiles rebus preditis vel expensis more insolito ibant in turba). The combination of Turkish attacks and privation meant that many horses died of hunger, were killed in fighting, or were slaughtered for food, and many who had lost their mounts threw away much of their equipment rather carry it in foot. ${ }^{38}$ When the army reached the coast, those who could afford it were desperate to buy fresh horses, as this would have most readily restored their fighting

37 'Annales Palidenses', in Monumenta Germaniae Historica: Scriptores, n 16 (1869), pp. 82-83: pedites inedia fatigati nec bellorum gnari ideoque minus cauti periculorum.

38 Odo of Deuil, De profectione Ludovici VIl in orientem, ed. and trans. V.G. BERRY (New York, Columbia University Press, 1948), pp. 114-135 (here 124, 130). English translations by the present author. 
ability, but mounts were practically unobtainable. According to Odo, the French barons lamented to their king, saying "since they have cast their arms aside, all of the common knights in your army have been reduced to foot soldiers ... and the same fate has befallen many of the more noble ones". ${ }^{39}$ This entire dialogue is clearly a literary construction, but it encapsulates how the status of knights and nobles could be reduced to the level of commoners through the loss of horses and equipment, in much the same way as had occurred during the expeditions of 1096-1099. The military defeats suffered by both German and French armies in Asia Minor not only reduced the numbers that they were able to bring to the Holy Land; they also meant that these disparate forces were never able to develop the type of cohesion that was achieved by the First Crusade armies as they marched south from Antioch.

\subsection{From Land Campaigns to Sea Voyages}

After 1149 there was a significant change in the composition of crusade expeditions. By and large, crusade expeditions came to comprise a far higher proportion of crusaders who could be regarded as professionals, that is nobles, knights and footsoldiers and support personnel such as grooms or squires. The leadership were keen to exclude the indigent, who would put a strain on financial and alimentary resources and had little fighting ability, as previous experience had shown. It was never possible to exclude civilians entirely. For one thing, clerics were invariably present to act as advisors to secular leaders and also to provide for the spiritual welfare of the troops. Some women were allowed to participate carry out duties such as laundry and delousing. ${ }^{40}$ However, those expeditions which actually reached the East did not contain anything like the large popular elements that were found in 1096 and 1147. When preaching did produce a large response from the common people, these usually combined into disorganised and undisciplined mobs which were shunned by knights and nobles, as was the case with the so-called Pastores who received considerable popular support in France and western Germany in 1251 and 1320.

There were two main organisational and logistic factors which helped bring about this change. The first was the introduction of dedicated crusade taxation. Between 1166 and 1199 the kings of France and England and the

39 Odo of Deuil, De profectione Ludovici VII in orientem, p. 130: Omnes vestri exercitus gregarii milites his diebus armis proiectis pedites sunt effecti, et cum eis de nobilioribus multi. English translation by Berry (p. 131).

40 TYERMAN, How to Plan a Crusade, p. 249. 
popes declared various taxes on incomes and property which were to be used for the defence or liberation of the Holy Land. Collection methods varied, but in general the proceeds went to kings or other nobles who were in the process of organising crusades. This meant that they were able to divert funds to their own followers and others whose skills and equipment would be of the greatest use on campaign.

An equally important matter was a shift towards seaborne expeditions. Up to the time of the Third Crusade (1 189-1 192) some smaller expeditions had travelled to Palestine by sea, but larger armies (which we could define as those numbering thousands) all took overland routes, proceeding either down the Italian peninsula with a short crossing of the Adriatic to link with the Byzantine road system, or along the Danube and through the Balkans. From Constantinople various routes were available through Asia Minor, although as the examples from the Second Crusade show, these all carried the risk of privation and attacks from the Turkish powers of Anatolia and nomadic Türkmen tribesmen. ${ }^{41} \mathrm{~A}$ turning point came about at the time of the Third Crusade (1 189-1 192), called in response to the defeat of King Guy of Jerusalem by Saladin at Hattin and the subsequent loss of Jerusalem and most of the Holy land in 1187 . Frederick Barbarossa, Holy Roman emperor, assembled an army at Regensburg and marched along the traditional route through the Balkans. This had a logistic advantage in that much of the army's baggage could by transported by boat on the Danube as far as Byzantine territory. Frederick may also have been influenced by his own experience, having accompanied his uncle Conrad III by land in the Second Crusade. However, the armies of Richard the Lionheart of England and Philip Augustus of France covered the greater part of their journeys by sea, and all subsequent expeditions to the Levant were carried on fleets. This shift was brought about by technological possibilities as well as logistical necessity. Developments in shipbuilding and navigation made it possibly to transport horses over long distances by sea, something which had been quite impractical around $1100.4^{42}$ The transport of knights and their horses meant

41 MURRAY, A.V. (2012): "Roads, Bridges and Shipping in the Passage of Crusade Armies by Overland Routes to the Bosporus, 1096-1 190". BLASCHITZ, G., HOLZNER-TOBISCH, K., and KÜHTREIBER, Th. (eds.), Die Vielschichtigkeit der Straßen: Kontinuität und Wandel in Mittelalter und früher Neuzeit. Wien, Verlag der Österreichischen Akademie der Wissenschaften, pp. 183207.

42 PRYOR, J.H. (1982): "Transportation of Horses by Sea during the Era of the Crusades: Eighth Century to 1285 A.D.". Mariner's Mirror, n 68, pp. 9-27, 103-125; PRYOR, J.H. (2015): "A Medieval Mediterranean Maritime Revolution: Crusading by Sea, ca. 1096-1204". CARLSON, D.N., LEIDWANGER, J., and KAMPBELL, S.M. (eds.), Maritime Studies in the Wake of the Byzantine Shipwreck at Yassıada, Turkey. College Station, Texas A\&M University Press, pp. 174-188. 
that large quantities of equipment could also be carried. Thus Richard the Lionheart arranged for many thousands of horseshoes to be supplied to his troops; it would have been difficult to carry these by land, but the capacity of his ships made it possible..$^{43}$ All of these factors combined to produce the conditions for a more professional army. The final consideration was that with ships under the command of royal officers it was now possible to physically prevent undesirables from taking part.

The dimensions of such organisational changes can be seen in the logistic arrangements contracted for the Fourth Crusade (1201-1204). While previous expeditions had been directed to the Holy Land, the leaders who planned the crusade in the years 1199-1201 decided to make a major attack against Egypt, the centre of the power of the Ayyūbid dynasty (Saladin's successors). The aim was to strike a major blow which would force the Ayyūbid sultan to surrender Jerusalem and other territories in a negotiated peace. Representatives of the crusade leadership negotiated a treaty with the republic of Venice, whose doge and counsellors agreed to provide transport for the entire crusade army and to supplement this with additional ships and naval forces. The treaty specified that transport would be provided for 4500 "well-armed knights" (milites bene armatos) and the same number of horses, 9000 squires (scutiferos), and 20,000 "well-armed foot soldiers" (pedites bene armatos). ${ }^{44}$ These Latin descriptions correspond to the French terms used in the account of the treaty given by the French chronicler Villehardouin: chevaliers, escuiers, and serjanz a pié. ${ }^{45}$ These categories suggest a completely professional army. Since each knight was allowed two scutiferi or escuiers, it is tempting to assume that one was in charge of the knight's horse while the other was to look after his equipment and help him arm. The term pedites bene armatos or serianz a pié undoubtedly meant that these were expected to be experienced soldiers with good quality equipment, corresponding to the foot sergeants employed in the armies of Outremer and the military orders, rather than simply untrained pilgrims on foot. They included specialists such as crossbowmen, who fought well at

43 TYERMAN, How to Plan a Crusade, pp. 263-265.

44 Urkunden zur älteren Handels- und Staatsgeschichte der Republik Venedig: mit besonderer Beziehung auf Byzanz und die Levante vom neunten bis zum Ausgang des fünfzehnten Jahrhunderts, ed. G.L.F. TAFEL and G. THOMAS, 3 vols (Wien, Hof- und Staatsdruckerei, 1856-1857), vol. 1, pp. 365-366.

45 Villehardouin, La Conquête de Constantinople, ed. and trans. E. FARAL, 2 vols (Paris, Les Belles Lettres, 1961), vol. 1, pp. 22-25. 
Constantinople, but overall the crusaders who assembled at Venice were far short of the numbers agreed in the treaty, and many were not of the quality envisaged in it. Robert of Clari, a French crusader, describes a category he calls the "common people" (menue gent) who nevertheless had to fight. In the first assault on Constantinople (July 1203), the commanders ordered up all the grooms and cooks in the army and kitted them out with improvised arms and armour; despite the inferior quality of this equipment, they were encouraged that these temporary soldiers were so "ugly and hideous that the common foot soldiers of the emperor, who were in front of the walls, had great fear and terror when they saw them". ${ }^{46}$ Clari also tells of clerics who took part in the fighting. A priest, Aleaumes de Clari, had either come with, or acquired a horse and hauberk; since he had fought like a knight, he argued that he was entitled to a knight's share in the booty after the final assault in April 1204. ${ }^{47}$

The failure of the crusade occurred because insufficient numbers arrived at Venice by the agreed departure date. Since the reduced army could not raise the agreed costs of transport, it had no choice but to follow Venetian direction, a decision which ultimately led to the diversion of the crusade to Constantinople. However, the process of planning and recruitment show that a century after Pope Urban's appeal, the business of crusading was expected to succeed only with personnel who could be described as professionals.

\section{Conclusions}

The idealistic intentions of the papacy to liberate (and later to defend) the Holy Land would require the whole-hearted participation of the traditional military classes of Western Europe. This was why at the Council of Clermont Pope Urban II appealed to the class of knights. Yet the definition of the crusade as a pilgrimage, with unheard of spiritual rewards, meant that all sections of the population were encouraged to take part, most of whom had

46 Robert de Clari, La Conquête de Constantinople, ed. P. LAUER (Paris, Honoré Champion, 1974), p. 46: Et aprés prist on tous les garchons qui les chevax gardoient, et tous les cuisiniers qui armes peurent porter; si les fist on trestous armer et de keutes pointes et de peniax et de pos de coivre et de poletes et de pestiaux, si k'il estoient si lait et si hideus qie le menue gent a pié l'empereur, qui estoient par dehors les murs, en eurent grant peur et grant hisde, quant ils les virent. Translation from: Robert of Clari, The Conquest of Constantinople (New York, Columbia University Press, 1936), p. 72.

47 Robert de Clari, La Conquête de Constantinople, p. 96. 
little military skill or experience, and often insufficient funds or equipment to function effectively through the rigours of the journey. The dichotomy between military professionals and elites on the one hand, and popular elements on the other constituted the main factor which threatened the success of crusading during this period, even more than political rivalries based on national or feudo-vassalic allegiances. This situation only began to change from 1189 onwards. The shift away from land-based to seaborne expeditions, although undertaken primarily for logistical reasons, allowed the organisers to exclude popular elements in favour of trained professional soldiers. However, the concentration on professionalism brought about a necessity for upfront funding on a hitherto unimagined scale, which produced unforecast problems in the crusade originally intended to be directed against Egypt in 1201.

\section{BibLIOGRAPHY}

\section{Sources}

Albert of Aachen, Historia lerosolimitana: History of the Journey to Jerusalem, ed. and trans. S. B. EDGINGTON (Oxford: Oxford University Press, 2007).

'Annales Palidenses', in Monumenta Germaniae Historica: Scriptores 16 (1869), pp. 48-98.

Chronicles of the First Crusade, 1096-1099, ed. C. TYERMAN (London, Penguin, 2004).

Gilbert of Mons, Chronicle of Hainaut, trans. L. NAPRAN (Woodbridge, Boydell Press, 2005).

Guillaume de Tyre, Chronique, ed. R.B.C. HUYGENS, Corpus Christianorum Continuatio Mediaevalis 63-63A, 2 vols (Turnhout: Brepols, 1986), p. 790.

MAYER, H.E. (ed.), Die Urkunden der lateinischen Könige von Jerusalem, 4 vols (Hannover: Hahnsche Buchhandlung, 2010), 1, no. 298.

Odo of Deuil, De profectione Ludovici VII in orientem, ed. and trans. V.G. BERRY (New York, Columbia University Press, 1948).

Robert de Clari, La Conquête de Constantinople, ed. P. LAUER (Paris, Honoré Champion, 1974).

Robert of Clari, The Conquest of Constantinople (New York: Columbia University Press, 1936).

RÖHRICHT, R. (ed.), Regesta Regni Hierosolymitani, 2 vols (Innsbruck: Wagner, 1893-1904), 
Urkunden zur älteren Handels- und Staatsgeschichte der Republik Venedig: mit besonderer Beziehung auf Byzanz und die Levante vom neunten bis zum Ausgang des fünfzehnten Jahrhunderts, ed. G.L.F. TAFEL and G. THOMAS, 3 vols (Wien: Hof- und Staatsdruckerei, 1856-1857).

Villehardouin, La Conquête de Constantinople, ed. and trans. E. FARAL, 2 vols (Paris: Les Belles Lettres, 1961).

Walter the Chancellor, Galterii Cancelarii Bella Antiochena, ed. H. HAGENMEYER (Innsbruck: Wagner, 1896).

\section{Literature}

BARBER, M. (1994), The New Knighthood: A History of the Order of the Temple. Cambridge, Cambridge University Press.

BIRKENMEIER, J. (2002): The Development of the Komnenian Army, 1081 1 180. Leiden, Brill, pp. 77-158

BUMKE, Joachim (1982): The Concept of Knighthood in the Middle Ages. New York, AMS Press.

BURGTORF, J. (2006): "The Military Orders in the Crusader Principality of Antioch". In: CIGGAAR, K. and METCALF, M. (eds), East and West in the Medieval Mediterranean, I: Antioch from the Byzantine Reconquest until the End of the Crusader Principality. Leuven, Uitgeverij Peeters, pp. 217-246.

CERRINI, S. (2001): "Le fondateur de l'ordre du Temple à ses frères: Hugues de Payns et le Sermo Christi militibus". In: BALARD, M., KEDAR, B.Z, and RILEY-SMITH, J. (eds), Dei gesta per Francos: Etudes sur les croisades dédiés à Jean Richard. Aldershot, Ashgate, pp. 99-110.

CONSTABLE, G. (1982): "The Financing of the Crusades in the Twelfth Century". In: KEDAR, B.Z., MAYER, H.E. and SMAIL, R.C. (eds), Outremer: Studies in the History of the Crusading Kingdom of Jerusalem. Jerusalem, Yad Izhak Ben-Zvi Institute, pp. 64-88

EDBURY, P.W. (1997): John of Ibelin and the Kingdom of Jerusalem. Woodbridge, Boydell.

FLORI, J. (1998): Chevaliers et chevalerie au Moyen Age, Paris, Hachette. FLORI, J. (1999): Pierre l'Ermite et la Première Croisade. Paris, Fayard.

FOREY, A.J. (1984): "The Militarisation of the Hospital of St John", Studia Monastica $\mathrm{n}^{\circ} 26$, pp. 75-89.

FOREY, A.J. (1985): "The Emergence of the Military Order in the Twelfth Century", Journal of Ecclesiastical History n ${ }^{\circ} 36, \mathrm{pp}$. 175-195.

FOREY, A.J. (2008): "Milites ad terminum in the Service of the Military Orders during the Twelfth and Thirteenth Centuries". In: UPTON-WARD, J. 
(ed.), The Military Orders, 4: On Land and by Sea. Aldershot, Ashgate, pp. 5-11.

FOREY, A.J. (2016): "Paid Troops in the Service of the Military Orders during the Twelfth and Thirteenth Centuries". In: BOAS, A., The Crusader World. London: Routledge, pp. 84-97.

FRANCE, J. (1994): Victory in the East: A Military History of the First Crusade. Cambridge, Cambridge University Press.

FRANCE, J. (1999): Western Warfare in the Age of the Crusades, 10001300. London, UCL.

FRANCE, J. (2000): "Crusading Warfare and its Adaptation to Eastern Conditions in the Twelfth Century". Mediterranean Historical Review $n^{\circ} 15$, pp. 49-56.

FRANCE, J. (2005): "Crusading Warfare". In: NICHOLSON, H. (ed.) Palgrave Advances in the Crusades. Basingstoke, Palgrave Macmillan

FRANCE, J. (2006): "Thinking about Crusader Strategy". In: CHRISTIE, N. and YAZIGI, M. (eds.), Noble Ideals and Bloody Realities: Warfare in the Middle Ages. Leiden, Brill, pp. 75-96

FRANCE, J. (2011): "Warfare in the Mediterranean Region in the Age of the Crusades, 1095-1291: A Clash of Contrasts". In: KOSTICK, C. (ed.), The Crusades and the Near East. Abingdon: Routledge, pp. 9-26

FRANCE, J. (ed.) (2008), Mercenaries and Paid Men: The Mercenary Identity in the Middle Ages, Leiden: Brill.

HILLENBRAND, C. (1999): The Crusades: Islamic Perspectives. Edinburgh, Edinburgh University Press.

KOSTICK, C. (2008): The Social Structure of the First Crusade, Leiden, Brill. KOSTICK, C. (2010): "Social Unrest and the Failure of Conrad III's March through Anatolia, 1147", German History n 28, pp. 125-142.

KOSTICK, C. (2013): "Courage and Cowardice in the First Crusade, 10961099", War in History n 20, pp. 32-49

MÖHRING, H. (1992): Graf Emicho und die Judenverfolgungen von 1096", Rheinische Vierteljahrsblätter n 56, pp. 97-111.

MURRAY, A.V. (2009): "Norman Settlement in the Latin Kingdom of Jerusalem, 1099-1 131", Archivio Normanno-Svevo n 1 for 2008 (2009), 61-85.

MURRAY, A.V. (1992): "The Army of Godfrey of Bouillon, 1096-1099: Structure and Dynamics of a Contingent on the First Crusade", Revue Belge de Philologie et d'Histoire $\mathrm{n}^{\circ}$ 70, pp. 301-29.

MURRAY, A.V. (2006): "Money and Logistics in the Armies of the First Cru- 
sade: Coinage, Bullion, Service and Supply, 1096-99". In: PRYOR, J. H. (ed.), Logistics of Warfare in the Age of the Crusades. Aldershot, Ashgate, pp. 229-49.

MURRAY, A.V. (2008): "The Origin of Money-Fiefs in the Latin Kingdom of Jerusalem". In: FRANCE, J. (ed.), Mercenaries and Paid Men: The Mercenary Identity in the Middle Ages. Leiden, Brill, pp. 275-286.

MURRAY, A.V. (2012): "Roads, Bridges and Shipping in the Passage of Crusade Armies by Overland Routes to the Bosporus, 1096-1190". In: BLASCHITZ, G., HOLZNER-TOBISCH, K., and KÜHTREIBER, Th. (eds.), Die Vielschichtigkeit der Straßen: Kontinuität und Wandel in Mittelalter und früher Neuzeit. Wien, Verlag der Österreichischen Akademie der Wissenschaften, pp. 183-207.

MURRAY, A.V. (2012): "Sex, Death and the Problem of Single Women in the Armies of the First Crusade'. In: GERTWAGEN, R. and JEFFREYS, E. (eds.), Shipping, Trade and Crusade in the Medieval Mediterranean: Studies in Honour of John Pryor. Farnham, Ashgate, pp. 255-270.

MURRAY, A.V. (2014): "The Siege and Capture of Jerusalem in Western Narrative Sources of the First Crusade". In: EDGINGTON, S., and GARCÍA-GUIJARRO, L. (eds.), Jerusalem the Golden: The Origins and Impact of the First Crusade. Turnhout, Brepols, pp. 191-215.

MURRAY, A.V. (2015): "The Enemy Within: Bohemond, Byzantium and the Subversion of the First Crusade". In: HURLOCK, K. and OLDFIELD, P. (eds.), Crusading and Pilgrimage in the Norman World. Woodbridge, Boydell \& Brewer, pp. $31-47$.

MURRAY, A.V. (2016): "The Grand Designs of Gilbert of Assailly: The Order of the Hospital in the Projected Conquest of Egypt by King Amalric of Jerusalem (1 168-1 169)", Ordines Militares: Yearbook for the Study of the Military Orders 20, pp. 7-24.

MURRAY, A.V. (2016): "The Place of Egypt in the Military Strategy of the Crusades, 1099-1221". In: MYLOD, E.J., PERRY, G., SMITH, T.W. and VANDEBURIE, J. (eds.), The Fifth Crusade in Context: The Crusading Movement in the Early Thirteenth Century, Abingdon, Routledge, pp. 117-134.

MURRAY, A.V. (2017): "A Race against Time - A Fight to the Death: Combatants and Civilians in the Siege and Capture of Jerusalem". In: DOWDALL, A. and HOME, J. (eds.) Civilians under Siege from Sarajevo to Troy, Basingstoke, Palgrave Macmillan, forthcoming.

NICHOLSON, H. (2001): The Knights Hospitaller, Woodbridge, Boydell Press. PHILLIPS, J. (2007): The Second Crusade: Extending the Frontiers of Christendom. New Haven, Yale University Press, pp. 80-103. 
PORGES, W. (1946), "The Clergy, the Poor and the Non-Combatants on the First Crusade", Speculum n ${ }^{\circ} 21$, pp. 1-23.

PRYOR, J. (1992): Geography, Technology and War: Studies in the Maritime History of the Mediterranean, 649-1571. Cambridge, Cambridge University Press.

PRYOR, J. (ed.) (2006); Logistics of Warfare in the Age of the Crusades. Aldershot, Ashgate.

PRYOR, J.H. (1982): "Transportation of Horses by Sea during the Era of the Crusades: Eighth Century to 1285 A.D.", Mariner's Mirror n ${ }^{\circ}$ 68, pp. 9-27, 103-125.

PRYOR, J.H. (2015): "A Medieval Mediterranean Maritime Revolution: Crusading by Sea, ca. 1096-1204". In: CARLSON, D.N., LEIDWANGER, J., and KAMPBELL, S.M. (eds.), Maritime Studies in the Wake of the Byzantine Shipwreck at Yassıada, Turkey. College Station, Texas A\&M University Press, pp. 174-188.

RICHARD, J. (1986): "Les Turcoples au service des royaumes de Jérusalem et de Chypre: Musulmans convertis ou chrétiens orientaux?", Revue des études islamiques $\mathrm{n}^{\circ}$ 54, pp. 259-270.

RICHARD, J. (1989): "La noblesse de Terre Sainte (1097-1 187", Arquivos do Centro cultural português $n^{\circ} 26$, pp. 321-336

RILEY-SMITH, J. (1967): The Knights Hospitaller in the Levant, c. 10701309, Basingstoke, Palgrave Macmillan, pp. 27-51

RILEY-SMITH, J. (1986): The First Crusade and the Idea of Crusading. London, Athlone.

RILEY-SMITH, J. (1995): "Early Crusaders and the Costs of Crusading, 1095-1 130". In: GOODICH, M., MENACHE, S. and SCHEIN, S. (eds.). Cross Cultural Convergences in the Crusader Period. New York, Peter Lang, pp. 237-258.

RILEY-SMITH, J. (1997): The First Crusaders, 1095-1 131. Cambridge, Cambridge University Press.

SALIBI, K.S. (1957): "The Maronites of Lebanon under Frankish and Mamluk Rule (1099-1516)", Arabica n 4, pp. 280-303.

SHEPARD, J. (1997): "Cross-Purposes: Alexius Comnenus and the First Crusade". In: PHILLIPS, J. (ed.): The First Crusade: Origins and Impact, Manchester, Manchester University Press, pp. 107-129.

SMAIL, R.C. (1995): Crusading Warfare, 1097-1193, 2nd edn. ed. C. MARSHAL. Cambridge, Cambridge University Press.

TYERMAN, C. (2015): How to Plan a Crusade: Reason and Religious War in the High Middle Ages, London, Allen Lane. 


\title{
THE FLORENTINE ARMY IN THE AGE OF THE COMPANIES OF ADVENTURE
}

\section{EL EJÉRCITO DE FLORENCIA EN LA ÉPOCA DE LAS COMPAÑÍAS DE MERCENARIOS}

William Caferro

Vanderbilt University

\begin{abstract}
The essay explores the recruitment and composition of the Florentine army in the fourteenth century. It stresses the importance of native troops and continuity of service among mercenaries in an era associated with free companies and organizational chaos. The Florentine army was, in contrast to the current literature, not an ad hoc and temporary entity but the product of careful consideration and coordination.
\end{abstract}

Keywords: Companies of Adventure, Continuity, Native Infantry, Rural Lords, Lance Unit.

\section{RESUMEN}

Este artículo explora el reclutamiento y composición del ejército florentino en el siglo XIV. Subraya la importancia del uso de tropas nativas y de la continuidad del servicio entre los mercenarios, en una era asociada a las compañías "libres" de mercenarios y al caos organizativo. El ejército florentino fue, en contraste con la literatura actual, no una entidad temporal y creada ad hoc para un momento concreto, sino el producto de una cuidadosa preparación y coordinación.

Palabras clave: compañías mercenarias, continuidad, infantería nativa, señores rurales, lanza. 


\section{RESUM}

\section{L'exèrcit de Florència al temps de les companyies de mercenaris}

Aquest article explora el reclutament i composició de l'exèrcit florentí al segle XIV. Subratlla la importància de l'ús de tropes natives i de la continuïtat del servei entre els mercenaris, en una era associada a les companyies "lliures" de mercenaris i al caos organitzatiu. L'exèrcit florentí va ser, en contrast amb la literatura actual, no una entitat temporal i creada ad hoc per a un moment concret, sinó el producte d'una acurada preparació i coordinació.

Paraules clau: companyies mercenàries, continuïtat, infanteria nativa, senyors rurals, llança. 
The recruitment and composition of armies in fourteenth century ltaly are among the most vexing and misunderstood aspects of medieval warfare. Such scholarship as there has been emphasizes the reliance of states on mercenary troops and the advent in the trecento of compagnie di venturacompanies of adventure-, bands of mercenaries from ltaly and elsewhere in Europe, who overwhelmed the native component of armies and undertook raids in times of peace. The companies have served as the symbol of the loss of communal fighting spirit and with it the moral degeneracy of Italian states. What has been forgotten in this construct is the realities of warfare and the actual nature of Italian armies. How were soldiers recruited, what did armies look like and how were they deployed in the field?

The current scholarly consensus speaks of a "devolution" of military organization. In the thirteenth century, states relied primarily on native forces, reflecting a vigorous "communal martial spirit." In the fourteenth century, states came to rely more on mercenaries, arrayed often in pre-formed bands. By the fifteenth century, the bands became replaced by powerful individual condottieri, who in several well-known cases took over the states they served. 'This last phase is a main theme of Jacob Burckhardt's seminal Civilization of the Renaissance in Italy. Burckhardt saw in the condottieri the type of calculated self-interest and "unbridled egotism" that was representative of the Renaissance as a whole.

1 RICOTTI, E. (1844): Storia delle compagnie di ventura in Italia, vol. 2. Turin, Unione Ed.; CANESTRINI, G. (1851): "Documenti per servire della milizia italiana del secolo XIII al XVI". Archivio Storico Italiano, ser. 1, 15, XI- CXXVI; SCHÄFER, K. H. (1911): Deutsche Ritter und Edelknechte in Italien wahrend des 14. Jahrhunderts, vol. 1. Paderborn, Paderborn Schöningh; MALLETT, M. (1974): Mercenaries and Their Masters: warfare in Renaissance Italy. Totowa, NJ, Rowman and Littlefield. The scholarly terms of discussion are outlined in CAFERRO, W. (1998): Mercenary Companies and the Decline of Siena. Baltimore, Johns Hopkins, pp. XIV-XV, 1-14; GRILLO, P. (2008): Cavalieri e popoli in armi: Le istitutioni military nell'Italia medieval. Bari, Editori Laterza. 
This portrait of Italian warfare bears the stamp of Niccolò Machiavelli, who depicted "lazy" "useless" mercenaries as the ruination of Italy and blamed them and the states who hired them for the foreign subjugation of the peninsula in the fifteenth century. The present essay examines the Florentine army during the era of the companies of adventure. The period was chosen because the Florentine army has been judged by scholars as "retrograde" and "backward" even with respect its counterparts in Venice and Milan. Florence stands accused not only of relying on mercenaries, but of hiring men on short-term contracts and dismissing them wholescale from service at the end of "the campaigning season." Florence did this while Venice and Milan began hiring its mercenaries on longer-term contracts, promoting continuity in the ranks, and more generally encouraging permanent forces that remained under contract even in times of peace. ${ }^{2}$ Florentine forces were ad hoc.

The dated scholarly consensus requires revision. Indeed, close archival study reveals (unsurprisingly) that Florence devoted much attention to its army. It relied on mercenaries, but it chose the men with care and maintained longterm relationships with them despite short-term contracts. Florentine officials recruited mercenaries alongside rural feudal lords, who played an important and often overlooked role in warfare. In addition, Florence maintained a substantial infantry force, much of which was recruited from its contado and subject communes and was far more professionalized than has been portrayed. Finally, any evaluation of Florence's army must be understood in terms of the city-leagues or taglie that the city joined during this era. The leagues were enacted by participants (often neighboring cities) to provide a share (taglia) of troops for joint armies for the purposes of mutual protection in times of external threat. They were so frequent that it is difficult to find a single year for which Florence was not involved in one. Thus, it was the case, to paraphrase Daniel Waley for the first years of the trecento, that the Florentine army was as much an expression of "regional military policy" as it was an expression of the city's own civic power.

\section{I}

Discussions about the Florentine army usually begin in the year 1250 , when the city issued a code governing its composition. The code was the work of Florence's first popular government, the so-called primo popolo. Giuseppe

2 CAFERRO, W. (2008): "Continuity, Long-Term Service and Permanent Forces: A Reassessment of the Florentine Army in the Fourteenth Century". The Journal of Modern History, n ${ }^{\circ} 80, \mathrm{pp}$. 219-220. 
Canestrini published the document in the nineteenth century and stressed how it reflected the "native nature" of the Florentine army. ${ }^{3}$ It revealed a Florentine army arranged in twenty compagnie recruited from the popolo of the city and leghe recruited from 96 pievi in the contado. A pieve consisted of a single town or several communities. All compagnie and leghe were led by captains, whose brigades were variable in size. Men between the ages of 15 and 70 who resided in the city (cittadini) and contado (contadini) were eligible to serve in the army. Magnates and Ghibellines (often the same) were expressly forbidden from participating because their loyalties were suspect. ${ }^{4}$ In times of civic unrest, the army assumed police functions. It protected government buildings and arrested exiles and other malfatori, who caused trouble. In times of war, the compagnie formed the cavalry core of the army. The vanguard of the army consisted of the so-called feditori, the striking force, followed by the infantry, who stood behind the cavalry. The route of armies out of Florence to the battlefield was carefully planned in conjunction with astrologers. Local shops were closed, city bells rang and the carroccio, a wheeled cart that was the symbol of the city, went forward under heavy guard.

Daniel Waley has questioned the degree to which the military code of 1250 reflected the true nature of Florentine forces. Waley sees it as part of a general institutional reorganization that involved also the transfer of the internal police duties of the force to civic officials. Nevertheless, the importance of native troops in the Florentine army is clear. The famous libro di Montaperti gives important detail about an actual Florentine army deployed in the eponymous battle of 1260. Native Florentine cavalry numbered nearly 1400 men. The mercenary cavalry consisted of only 200 men, recruited primarily from the nearby Emilia and Romagna regions, just north of Florence. The infantry, believed to be more than 16,000 men, was recruited from the Florentine contado. ${ }^{5}$ Waley saw little trace of the deployment of urban compagnie in the battle and in subsequent armies.

4 NALDINI, L. (1920): "La 'tallia militum societatis tallie Tuscie' nella seconda metà del sec. XIII". Archivio Storico Italiano, LXXVIII, pp. 78-79.

5 WALEY, D. (1968): "The Army of the Florentine Republic from the Twelfth to the Fourteenth Century". RUBINSTEIN, N. (ed.), Florentine Studies. Evanston, Northwestern University Press, pp. 76-78. 
The army at Montaperti was nevertheless an overwhelmingly Florentine one, and its calamitous defeat at the hands of Siena and its Ghibelline allies, who relied on German mercenary cavalrymen, gave impetus to change. After the battle, Florence began systematically to recruit mercenaries. This was aided by involvement in a series of Guelf Tuscan leagues, headed by the king of France's brother, Charles of Anjou, who became ruler of Naples and the kingdom of Sicily in 1266. Participation brought numerous French and Provencal mercenaries into Florentine service, including the distinguished captain Amauri of Narbonne.

For all the discussion of Montaperti as a turning point in Florentine military organization, the limited evidence also suggests that Florence continued to rely on native troops through the end of the thirteenth and beginning of the fourteenth century. A careful analysis by Cesare Paoli of the Florentine army assembled to fight against neighboring Pistoia in May of 1302 shows that the force consisted almost wholly of native cavalry and infantry. ${ }^{6}$ The composition of the army is listed in table 1.

Table 1. Composition of the Florentine Army, 1302

497 Cavalrymen from the city

117 Crossbowmen from outside the city

644 Crossbowmen and shield bearers from Florence

3,961 Infantrymen from the contado and Florentine state

1058 Non-Florentine infantrymen

972 Guastatori (Destroyers)

The native element was clearly significant, and the army also had a considerable number of infantrymen. The latter owed to the fact that the campaign against Pistoia involved besieging the city, which required infantrymen as well as contingents of guastatori or destroyers, who set fires, dug ditches and mined below fortifications. The guastatori were often country rustics

6 PAOLI, C. (1867): "Rendiconto e approvazione di spese occorse nell'esercito fiorentine conto Pistoia nel Maggio MCCCII". Archivio Storico Italiano, ser. 3 vol. 6, p. 7. 
with little training. But their contribution to war, especially during sieges, was important. ${ }^{7}$

Paoli suggests that the army of 1302 also contained mercenaries who do not appear on the Florentine payroll, but most likely were supplied to the city by its allies. The judgment underscores a basic problem in evaluating armies of this and all periods: it is difficult to isolate a precise "Florentine army" from the bands of auxiliaries and additional troops sent by allies. Likewise, Florence's participation in city-leagues (taglie), which required each adherent to provide a share of the troops for a joint army, further obscures the line between what was specifically Florentine and what was not. The leagues were joined more frequently after Montaperti and the arrival in Italy of Charles of Anjou. Charles became the guiding force behind the Guelf cause and a champion of leagues, which continued after he died in $1285 . .^{8}$ In his pioneering essay on the league (taglia) of 1281, Lamberto Naldini argued that the alliance, and those that immediately followed, gave impetus to the formation of a regional Tuscan economy, and, inasmuch participants recruited professional soldiers who stayed on the payroll over the long run, encouraged the dependence on mercenaries, which came at the expense of the "old feudal class" of native soldiers. " Daniel Waley has claimed that the leagues were so important to Florentine military organization that the local army can only be understood in regional "Guelf" rather civic terms.

Waley is nevertheless too quick to dismiss the significance of the "Guelf" political label, just as Naldini is too hasty to announce the end of the feudal class. Florentine armies of the early trecento and subsequent years always contained soldiers from the feudal class of rural magnates who inhabited the Italian countryside. Moreover, however amorphous the label Guelf may appear to modern scholars, it had real meaning in its historical context. All Italian soldiers hired by Florence were specifically required to be "faithful Guelfs," a stipulation written into their contracts. In addition, it is important to stress that Italian military and political history on the peninsula was not driven solely by the actions of major states such as Florence, Venice, Pisa,

7 BIANCHI, S. A. (1995): "Gli eserciti delle signorie venete del Trecento fra continuità e trasformazione". CASTAGNETTI, A. and VARANINI, G.M. (eds.), Il Veneto nel medioevo. Verona, Banca Popolare di Verona, p. 176.

8 WALEY, "The Army of the Florentine Republic", p. 80.

9 NALDINI, "La 'tallia militum societatis tallie Tuscie'", p. 77. 
Genoa and others. There were, throughout Italy, many independent feudatories that pursued their own interests, alternately siding with their neighbors and against them. They chose sides in Guelf and Ghibelline rivalries and when they were not themselves at war, they hired themselves out to fight wars for others. The captains of the Guelf leagues included independent rural lords such as Ranuccio Farnese, from southern Tuscany, and Aghinolfo of Romena, from the mountains in the Casentino north of Florence. Meanwhile, Florence routinely recruited horsemen from Umbria, the Marches of Ancona and the Romagna. The service of members of lordly clans of these regions was remarkably enduring. The counts of Sarteanno in southern Tuscany, for example, worked both for and against Florence throughout the thirteenth and fourteenth century, as did members of the Tarlati clan from near Arezzo. The image of local lords turned into the great condottiere famously outlined by Jacob Burckhardt for the fiffeenth century had its roots in the fourteenth.

Florence's wars against Castruccio Castracane, the powerful lord of Lucca, in the 1320s have been viewed by scholars as a point of no return in the transformation of communal armies. Castruccio posed a grave threat to Florence and the battles against him were especially bitter and protracted. Castruccio's military might owed in large part to the support of the German emperor Ludwig of Bavaria, who supplied Castruccio with German mercenaries for his cavalry. The men were effective at Altopascio in 1325, where Florence suffered a stunning defeat. After Altopascio, Florence began to recruit German cavalrymen in significant numbers. They replaced the largely French and Catalan mercenaries that the city had employed during the years that Charles of Anjou was active in Italy. They had been ineffective and untrustworthy at Altopascio. ${ }^{10}$

The aftermath of the battle of Altopascio represented the start of the so-called era of the companies of adventure (compagnie di ventura), who would play an important part in political and military affairs on the Italian peninsula until the end of the trecento. In 1337 Florentine issued a new code governing its army and reordering the office of the condotta that hired troops. The code coincided with the start of yet another war, this time against the della Scala lords of Verona. Florence sought an alliance with Venice, whose interests were similarly threatened by the expansionist Scala state. The terms

10 WALEY: "The Army of the Florentine Republic", p. 106; CANESTRINI, "Documenti", p. xxVI. 
were generally unfavorable to the Florentines, who sent money north to help the Venetians repel the Scala. But Venice did little to help Florence with the Scala threat in Tuscany, which centered on the nearby city of Lucca.

C. C. Bayley interpreted the terms of the military code of 1337 as evidence of the "infiltration" of the "mercenary element" into Florentine armies. ${ }^{11}$ The point is, however, overstated. The code, which was the work of a committee of prominent citizens (Francesco Bilioti, Filippo Duccio Magalotti, Tommaso Dietiauti, Luca Gerini delle Strozzi, Benincasa Falchi and Aldobrando Lapi Tanaglie), encouraged the use of mercenaries, notably ultramontane soldiers (those from beyond the Alps), but native elements also remained. ${ }^{12}$ City officials were permitted to hire 800 cavalrymen and 1000 infantrymen directly through the office of the condotta, but all additional hires needed the consent of the priori, gonfalonieri and twelve buonuomini, who formed the executive branch of the government. ${ }^{13}$ The hire of Florentine citizens, contadini and Italian soldiers required the specific approval of these same officials. No more than fifteen Italian cavalrymen were allowed to serve in units of twenty to fifty men. Ultramontane cavalry units consisted of 20 men. Soldiers received their pay at the beginning of each month. Foreign soldiers required a mallevedore to serve as surety for their service in case of fraud. All cavalry captains had to maintain a horse worth 50 florins, while cavalrymen needed to have horses worth 30 florins.

The code also contained important guidelines on how soldiers had to arm themselves for war and the penalties for failing to pass musted. Cavalry captains supplied their own horse, armor and weapons. These included a breastplate with iron sleeves, a steel helmet, a shield, lance and dagger. Failure to pass muster was punished by a fine. To this end, officials carefully listed the names of the troops and their equiptment. Muster was held two days after the payment of wages. Fines were deducted directly from soldiers' pay.

Florence arranged its armies primarily in banner units, described in the code as consisting of twenty to twenty-five men. This included both cavalry and infantry units, the basic divisions of the army. Florence hired men on contracts (condotte) ranging from four to six months long. The code says explicitly that troops could not serve for more than six months without additional approval. C. C. Bayley says that Florence's preference for short-term

11 BAYLEY, C. C. (1961): War and Society in Renaissance Florence: The De Militia of Leonardo Bruni. Toronto, University of Toronto Press, p. 15.

12 CANESTRINI, "Documenti", p. 498.

13 CANESTRINI, “Documenti”, pp. 498, 501-502. 
contracts was based on the "fading assumption" that "war was brief."14 But this is not true. Florentine public officials chose short term contracts to avoid nepotism and circulate new people into these important jobs. This was true of civic jobs as well as military ones. The priori of the Signoria, the chief executives of the city, served two-month terms, members of the advisory councils, the twelve buonuomini and sixteen gonfalonieri, held office for three and four months, respectively. The podestà, who helped maintain internal peace and defend against external enemies, served on a six-month contract. In the case of the army, the short-term contracts were related to quality and control, allowing city officials to routinely reassess its force and dismiss those soldiers who were lacking.

Further proof of this is the evidence that those soldiers who served well were often rehired, despite their short-term contracts. Some men worked for Florence for long periods of time, including the restless and so-called "faithless" mercenaries. The German captain Gottfried Roher was, for example, hired by Florence in 1334 on a six-month contract. He remained in Florentine employ on similar contracts without interruption until 1354. In that year, he joined the famous free company of the Provencal adventurer Fra Moriale, which extorted a large bribe from Florence and other cities.

Throughout the fourteenth century, Florence often rehired the same mercenary cavalry captains. The length of service stipulated in their contracts did not determine how long they actually served the city. The Italian mercenary captain Nino di Dini degli Obizzi, a Guelf exile of Lucca, worked for Florence for a full sixteen years from 1347 to 1362. The German captains Edvard Bingher, Hans Dornich, and Heinrich Paer worked for Florence for at least a decade, always on four- to six-month contracts. Wilhelm Belmont stayed in the city's employ for twelve consecutive years from 1343 to $1354 .{ }^{15}$

Germans were the most numerous of the mercenaries in Florentine employ through the middle of the trecento. But the trend toward long-term employment on short-term contracts cut across national lines. Hungarian mercenaries, whose numbers, like those of the English, were small, also worked for Florence for extended periods. Georgio Gregori, a Hungarian horseman, was on the payroll for thirteen consecutive years, on four-month contracts.

14 BAYLEY, War and Society in Renaissance Florence, p. 9.

15 Archivio di Stato di Firenze (ASF), camarlinghi uscita, 80, fols. 1r-32r compared with Provvisioni, registri, 26, fol. 149v; Miscellanea Repubblicana, 119, fols. $11 \mathrm{r}-12 \mathrm{v}, 35 \mathrm{r}, 44 \mathrm{r}$; 120, fols. 2r, 12v, 18r; camarlinghi uscita, 6, fols. 1r-17v; 7, fol. 176r; scrivano di camera uscita, 1 , fols. 17r-25r. 
Another Hungarian, Bachone di Giovanni, served for eleven consecutive years, from 1360 to 1370, also on four-month contracts. The English captain Oschino Archer worked for Florence for seven consecutive years. Johnny Liverpool served the city for eight consecutive years on four, five and six-month contracts.

The career of the German captain Burchardt da Toro is especially noteworthy. He appears to have been hired by Florence in 1341, for the army sent against Pisa. He remained in Florentine employ through the rest of the decade and was part of the feditori contingent that took on the Ubaldini clan in 1350. A year later, when the Milanese threatened the Florentine state, Burchardt was put in charge of all Florentine forces. His army guarded the northern passes into the Florentine state in the Mugello and took part in the heroic defense of the town of Scarperia, for which he received bonus pay. He was subsequently used as an ambassador and appears to have integrated himself into Florentine society.

The evidence makes clear that at the same time that Florence began to rely more on mercenaries, particularly foreign born ones, it also attempted to maintain a continuity of personnel. The city built its forces around a core of seasoned professionals. The portrait contradicts the current scholarly view that stresses the ad hoc and backward nature of Florentine forces. But there is no reason to assume that Florence, even in the era of mercenary companies, did not give careful thought to their army, which was so frequently in the field.

Indeed, a careful examination of Florentine budgets shows that of the forty mercenary captains listed as serving in the army against Milan in May/June 1351, twenty-two (55 percent) had previously worked for Florence, several for nearly a decade. The leadership of Florentine forces in September/ October 1369, on the eve of the battle of Cascina, consisted of ninety-four mercenary captains, sixty-three of whom (67 percent) had already worked for Florence for at least four years. The army deployed to fight the papacy in September/October 1376 contained forty-five mercenary captains, of whom thirty-three (73 percent) had worked previously for Florence, most for at least five years. ${ }^{16}$

A more difficult task is assessing the role of infantry in Florentine armies. As we have seen, the number of such men was large in the late thirteenth and early fourteenth century. Nevertheless, the chronicle sources, which often give precise (albeit suspect) figures for the cavalry, frequently describe 
the infantry as a "mass of men." The generic rendering is likely related to the lack of status of the men. But even so, we must take care not to make rash judgments. Indeed, Florentine budgets (beginning from 1343) suggest that Florence took care assembling its contingents of crossbowmen, shield bearers and mixed bands that contained both. The budgets provide the provenience of the captains of these units and show that many, like their predecessors of the earlier years, came from the Florentine contado, distretto and subject lands. The wealth of documents that survive for Florence's conflict with the Ubaldini clan in 1350 show that the army sent by the city to the Apennine mountains in the Mugello region was composed of infantry captains from that area, and from mountain villages in the Garfagnana near Lucca and the mountains near above Pistoia. Florentine officials, in short, consciously recruited men adapted to the type of warfare (in the mountains) that it intended to wage. ${ }^{17}$

Similarly, there is evidence among infantrymen of long-term service despite short term contracts. The shield bearer captain Francesco Bartoli from Florence, known by the nickname "Malamama" (or "bad mother"), began working for communal armies in 1349 and continued to work for Florence until 1353. He appears again in the records from 1359 to 1370 . The infantry captain Ottolino Casoli from Prato worked for the city continuously from 1362 to 1378, while luntino Giuntini from Sarzana worked as a captain of crossbowmen units from 1365 to $1379 .{ }^{18}$

There are many additional examples and much more work needs to be done and can be done with close inspection of extant budgets. But the evidence suggests that even the infantry, whose value is traditionally undervalued by scholars, was arranged with care and there was a measure of continuity in the ranks. The notion is not far-fetched, as the geography of Tuscany, with its many hills, necessitated siege rather than war of maneuver in the field.

It is important to note that the continuity in Florentine armies occurred over diverse communal regimes and numerous wars. Gottfried Roher fought against the Scala at Lucca in 1338, against Pisa in 1341 and against Milan from 1351-1353. In the meantime, he survived the shift of government from the popolo to the duke of Athens in 1343 and the expulsion of the duke shortly thereafter.

17 CAFERRO, W. (2013): "Petrarch's War: Florentine Wages at the Time of the Black Death". Speculum, n 88/1, pp. 144-165.

18 CAFERRO, "Continuity, Long-Term Service and Permanent Forces", pp. 233-234. 


\section{II}

The example of the Florentine army that fought against the Pisans in 1341 reveals the increased influence of mercenary soldiers. The main striking force was now made up of 2,000 mercenaries, captained by an Italian knight, Matteo de Pontecarali. The citizen cavalry numbered no more than 40 men, although it included members of the leading families of the city. The lack of a native element caught the attention of the chronicler Giovanni Villani, who questioned the wisdom of city officials for putting the fate of the commune in the hands of outsiders. The complaint must be understood, however, in terms of Villani's bitterness at the eventual defeat of the Florentine force. ${ }^{19}$ Villani's main objection was that the army had too many knights in it, such that the captain general had difficulty coordinating the men, who did not listen to him. Nevertheless, the army was arrayed in much the same way that it was when it took the field in 1337. The basic fighting unit remained the "banner," consisting of twenty to twenty-five men. It was used both by the cavalry and infantry. The cavalry striking force or feditori was, as in the past, at the vanguard of the army, with the infantry behind it. Important and basic changes were nevertheless beginning to occur in Florentine armies. A turning point for Florence and all of Italy occurred with the arrival of the English White Company on the peninsula in 1361. The famous Company crossed the Alps from France to participate in war in the Piedmont region in the employ of the Marquis of Montferrat. The band, made up primarily of Englishmen but commanded by a German, created a sensation, owing to its cruel efficiency in battle. In the summer of 1363, with the help of the Visconti of Milan, the band took up employ with Pisa, which was at war with Florence. During the transfer, the band's most notable member, John Hawkwood, took over leadership of the company and with it the Pisan army. Under his command, Pisan forces gained the momentum in a war that had been a tedious and all-too-familiar contest of maneuver since it began in 1362. Florence responded to the White Company by hiring large bands of the German mercenaries, including those led by the southern German nobles Johann and Rudolf Hapsburg.

The conflict marked the start of a new era in the reliance on mercenaries for Florence. The city now routinely sought the service of large organized companies of men rather than only small units. It is important to stress this point, which suggests that the reliance on "companies" of mercenary men 
was not the result of a natural evolution or, better, "devolution" of mercenary service, as scholars have long suggested, but more the result of happenstance and the concurrence of the Hundred Years War in France, which created such bands. Hawkwood and the Pisan army penetrated to the walls of Florence in 1364. The city saved itself by bribing the English company, as well as a German band captained by another notable mercenary, Hannekin Baumgarten. Hawkwood gained a reputation for honesty by being among the few soldiers who turned down the Florentines. He remained at the head of Pisan forces.

After the war, Florence recruited large bands of mercenaries and frequently sought the services of John Hawkwood, who had emerged as the best commander of his generation. It is important to note, however, that Florence continued to hire small bands of mercenaries and to build its army from a small cadre of faithful, battle proven soldiers. It also continued to hire rural lords and exiles from enemy cities in its armies. They provided vital reconnaissance, regardless of their qualities as men at arms.

Changes in the organization of the Florentine army come into fuller view when the city fought its next major opponent, Milan, in 1369. As happened in 1337, Florentine officials issued a code governing its army at the outset of conflict. The code is notable for its stark difference from the earlier one. It included specific rules regarding a wide array of mercenary cavalrymen, including those of English, German, Burgundian, Italian and Hungarian background. The code of 1337 speaks only a generic terms of "mercenaries."

A close reading of the code of 1369 makes clear the primacy of English mercenaries above all others. They were the most desirable soldiers. Their contingents included the famed longbow archers that had performed so well in France. But the overall number of archers remained small in Italy, and they do not appear to have had a major impact in battles. The effect of the English is most apparent in the change from the use of banners as the basic cavalry unit to lances. The lance consisted of three men: a knight, a squire and a page, each with his own mount. The page was typically a young man or apprentice who rode a pony. ${ }^{20}$ According to the Florentine chronicler Filippo Villani, "it was the English who introduced this formation into Italy. ${ }^{21}$ The Florentine infantry does not appear to have undergone a

20 CAFERRO, W, (2006): John Hawkwood: An English Mercenary in Fourteenth Century Italy. Baltimore, Johns Hopkins, p. 88.

21 VILLANI, Filippo (1980): Cronica di Matteo e Filippo Villani, vol. 5. Rome, Multigrafica, p. 258; CAFERRO, John Hawkwood, p. 88. 
similar transformation. The banner remained the standard unit among crossbowmen and shield bearers.

Much has been written about the lance. Geoffrey Chaucer's "worthy knight" in the prologue to the Canterbury Tales belonged to a lance unit. In the battles of the Hundred Years War, the formation has been seen as facilitating the dismounting of cavalry that contributed to England's great victories against French armies at Crecy and Poitiers. In Italy, the lance became the standard unit of organization for cavalry throughout the peninsula. The historian Stephan Seltzer has traced the shift from banners to lances in the armies of Perugia, Venice and the papacy in 1367/68 and in the armies of Milan and Modena in 1370. ${ }^{22}$ Thus whether inspired directly by the English or by the actions of other states, Florence's change to lances coincided with broader military developments.

The precise meaning of the shift to lances is nevertheless not entirely clear. Was the change primarily an administrative one or did it have tactical military meaning in its Italian context? Stephan Selzer emphasizes the latter, arguing that the lance encouraged in Italy the type of "dismounting" technique used by the English cavalry in the Hundred Years War. ${ }^{23}$ Paolo Grillo has more recently affirmed Selzer's judgment, seeing the use of the lance as evidence of English influence on the methods of Italian war. ${ }^{24}$ The difficulty with the interpretation, however, is that it is not entirely clear how the banner unit that preceded the lance was deployed in the field, nor is it clear how many horses a captain had and how many ancillary personnel. The evidence relating to military practice in the field suggests that Florence rarely confronted an opponent directly, as occurred up north at the battles of Crecy and Poitiers.

In any case, the shift by Florence to lances in 1369 appears to have occurred by degrees, and prior to Florence's active engagement with an enemy. In December 1367, the city hired its first lance unit. On 8 December 1367, after two years of service at the head of a banner unit of cavalrymen, the English soldier Oschino Archer shifted to command a single "lance" unit. On that same day, Florence hired three additional Englishmen, William Bocoste, Edward Bertum and John of London, each at the head of a lance unit. ${ }^{25}$ Two days later, Florence hired fourteen more English captains

22 SELZER, S. (2001): Deutsche Söldner im Italien des Trecento. Tubingen, Niemeyer, pp. 56-57; CAFERRO, John Hawkwood, p. 88.

23 SELZER, Deutsche Söldner im Italien des Trecento, pp. 56-57.

24 GRILLO, Cavalieri e popoli in armi, p. 154.

25 ASF, Scrivano di camera uscita, 32 fols. 22v-23r. 
in lance units, and then (11 December) eleven English captains, again in charge of single lance units. ${ }^{26}$ At the same time, however, the prominent English captain Richard Romsey continued in Florentine employ in charge of sixteen banners of cavalrymen, as did Thomas Corensie and John Aguillant, all of whom were hired in December 1367. ${ }^{27}$ Romsey continued to captain banner units into $1368 .^{28}$

The hires reflect a general military build-up in Florence that winter owing to the growing hostilities with Pisa and Milan and worries about the possible descent into Italy of the Holy Roman Emperor Charles IV. There was likewise civic discord in nearby San Miniato al Tedesco, a Florentine satellite on the border with Pisa. Florence continued to hire banner units, but the preeminence of the lance unit became clear. In 1368, captains of multilance units appear in Florentine service. The men were not only English, but also German, Italian, Burgundian and Gascon. Indeed, the Burgundians in Florentine employ appear to have been arrayed in lance units as early as the English, and just afterward. The largest lance unit in Florentine employ at the beginning of 1368 was a Burgundian one, led by Stefano di Santo Giovanni, who commanded 12 lances. ${ }^{29}$ Italian mercenaries, on the other hand, seem to have been slow in adopting the new unit, remaining mostly in banner contingents. ${ }^{30}$

The change to lances did not involve Hungarian cavalrymen at all. They became increasingly important to communal armies at this time. But unlike their German, Italian and English counterparts, Hungarian cavalrymen were also bowmen, who shot arrows from their mounts. They were arranged in their own units, usually consisting of twelve to fourteen men. It is unclear how the Hungarian units were integrated into the overall army.

The documents in the Florentine state archive trace a significant military buildup in in the spring and summer of 1368. The advent of Charles IV in Italy in May 1368 caused confusion and fear throughout northern and central Italy. When Charles entered Tuscany in September 1368, San Miniato rose up in rebellion against Florentine rule. ${ }^{31}$ In the meantime. Milanese

26 ASF, Scrivano di camera uscita, 32 fols. $23 \mathrm{v}-25 \mathrm{v}$

27 ASF, Scrivano di camera uscita, 32 fols. 30r-v

28 ASF, Scrivano di camera uscita, 36 fol. $23 \mathrm{r}$

29 ASF, Scrivano di camera uscita, 37 fols. 40r, 42r

30 ASF, Scrivano di camera uscita, 32 fols. 22r, 33v

31 STEFANI, M. di C. (1903): "Cronaca fiorentina". RIDOLICO, N. (ed.), Rerum Italicarum Scriptores, vol. 30, Part I. Cittò di Castello, S. Lapi, pp. 269-270. 
armies moved into Umbria by early 1369, trying to exploit unrest between Perugia and the papacy -the latter a long-time enemy of Milan..$^{32}$ The presence of Milan in Umbria frightened Florentine officials, who allied with Pope Urban V in November 1369.

As military conflict became inevitable. Florence's army continued to morph into a lance-based cavalry force. By 1369, all of its English cavalrymen were arranged in lance units, as were Breton, Gascon and German captains in communal service. Only ltalian captains remained in banner units. ${ }^{33}$ Oschino Archer now captained 12 lances. ${ }^{34}$ The Florentine politician Giovanni Corsi suggested that the city augment the army with "as many Englishmen as possible." ${ }^{35}$ To this end, Florence tried to recruit John Hawkwood, who was captain of the Milanese army. Hawkwood was not interested. The city tried to woo members of his army, but also with little success. ${ }^{36}$ The city hired instead more German, Gascon and Hungarian mercenaries. ${ }^{37}$

This "new" style Florentine army with its multinational collection of mercenaries engaged in battle with its Milanese counterpart near the town of Cascina (near Pisa) at the beginning of December 1369. The Florentine diarist Donato Velluti estimated that the Florentine army had approximately 3,000 horses and 3,000 infantrymen, including contingents sent by Pope Urban V. ${ }^{38}$ Velluti estimated that the opposing army had between 3,000 and 2,000 horses, while an anonymous Pisan chronicler put the number at 1,200 horses. ${ }^{39}$ Neither writer mentions whether the enemy cavalry was arrayed in lances, nor do they give any details about the infantry.

The Florentine force suffered a decisive defeat at Cascina. ${ }^{40}$ Velluti lamented that "almost all of our people" were taken, including the captain of war, Giovanni Malatacca, who was also wounded in the battle. ${ }^{41}$ Florence's

32 CAFERRO, John Hawkwood, pp. 136-137.

33 ASF, Scrivano di camera uscita, 38 fols. 17r-26r; Scrivano di camera uscita, 42 fols. 20r-37r

34 ASF, Camera del comune, camarlinghi uscita, 189 fol. 39r

35 ASF, Consulte e pratiche 10 fol $5 \mathrm{r}$

36 ASF, Scrivano di camera uscita, 44 fol. $21 \mathrm{r}$

37 ASF, Scrivano di camera uscita, 43 fol. $35 \mathrm{r}$

38 La cronica domestica di Messer Donato Velluti, edited by Isidoro del Lungo and Guglielmo Volpi Florence, 1914, p. 282.

39 "Chronica di Pisa," edited by L. A. Muratori, in Rerum Italicarum Scriptores, vol 15 (Milan, 1729), cols. 1055-1056.

40 CAFERRO, John Hawkwood, pp. 138-139.

41 La cronica domestica di Messer Donato Velluti, pp. 285-286. 
deployment of lances did not prove effective. It is in any case difficult to determine how the unit may have affected either side. The contemporary accounts of the battle of Cascina indicate that the Florentine army took the offensive, and Hawkwood a defensive stance. The most detailed account is that of Ranieri Sardo, a Pisan merchant, ambassador and government official, who may have stood closest to the action. According to Sardo, the Florentine army moved forward in good order, in three lines (schiere) toward Hawkwood's force, which had descended on foot and waited for them. The Florentine cavalry likewise dismounted from their horses and the initial battle took place on foot. ${ }^{42}$ Sardo makes no mention, however, of the presence of the lance units in either army -even if the dismounting technique may seem to serve as evidence of it. The Florentine accounts blame the captain Giovanni Malatacca for moving forward in poor order and getting drunk before the offensive to gain courage. According to Hawkwood's nineteenth century biographer, John Temple-Leader, the battle was precisely an example of the superior tactical skill of Hawkwood, who after dismounting his cavalry from their horses executed a flanking maneuver that succeeded in surrounding the enemy, whose mounts got stuck in the soft mud near the banks of the Arno River. ${ }^{43}$ The resemblance to Poitiers and English actions in France is palpable and suggests that the victory relied on English methods of which we may suppose that the lance formation was a component.

But Temple-Leader's romanticized account, which exalts the skill of his hero, does not correspond to the accounts of contemporary writers. Ranieri Sardo paints a far more chaotic scene, in which Hawkwood's army defended its position by tossing rocks from local fortifications at the heads of the Florentine horses to impede their advance. It was this action that caused the Florentine cavalry to dismount. Moreover, Hawkwood's great "flanking maneuver" is more implied than stated in Sardo's account which notes that the Florentine army had attempted a flanking maneuver first, with 800 cavalrymen, but failed placing the entire force in jeopardy.

Whatever the details at Cascina and the role of lance units, it is clear that the encounter increased Florence recourse to lances. Just after the defeat, Florentine officials rebuilt their army, hiring more lance units, now much

42 "Cronaca di Pisa di Ranieri Sardo" in Fonti per la Storia D'ltalia, edited by Ottavio Banti (Rome, 1963), pp. 193-195.

43 TEMPLE-LEADER, J. (1889): Sir John Hawkwood: Story of a Condottiere. London, Fisher Unwin, pp. 65-67. 
larger in size. The city recruited the German captains Oswald Buvolar and Konrad Chonz with 177 lances each, and Konrad Weitingen with 170 lances. ${ }^{44}$ Fortunately for the city, Hawkwood and his Milanese force unexpectedly retreated from Tuscany after the victory, looting the environs of Pisa as they rode back north to Lombardy. The next time Florence sent its army into the field, five years later during the War of Eight Saints against the pope, the cavalry consisted exclusively of lance units. ${ }^{45}$ But Florence, unlike after the battle of Cascina, relied mostly on small contingents, eschewing big units like those of Konrad Weitingen for fear of their effect on forces should they desert. ${ }^{46}$

\section{III}

The preeminence of the lance units reflects the influence of English soldiers in Italy in the middle of the fourteenth century. But the formation should not be taken as evidence of a heightened importance of cavalry in Florentine warfare during the period. Indeed, it is important to stress that infantry remained a critical part of communal armies. Their role needs to be underlined owing to the lack of attention they have received from modern scholars. This echoes in part the silences of contemporary chroniclers, who tend to stress the deeds of cavalrymen, the most conspicuous element of the army, while speaking in more general terms about the infantry. It is not uncommon for chronicles to give the precise names of cavalrymen, while at the same time referring to the infantry, invariably the largest part of the army, as a "mass of men." The tendency is based more on medieval class distinction than on overall importance to the army. Class distinctions were a fundamental part of medieval society.

And that infantry remained essential is clear from the undeniable fact that the most common type of engagement in which the Florentines were involved were sieges, for which infantrymen were the critical component. Violent encounters between knights on horseback occurred and drew the attention of contemporary writers. Sieges were usually tedious and it was dull. Indeed, any careful examination of contemporary sources shows that

44 ASF, Provvisioni registri, 57 fol. 166v; Scrivano di camera uscita, 44 fols. 30v-31v, $41 \mathrm{r}$, 167r-167v; Scrivano di camera uscita, 47 fols. $22 \mathrm{r}-32$.

45 CAFERRO, John Hawkwood, p. 169.

46 CAFERRO, "Continuity, Long-Term Service and Permanent Forces," pp. 29-33. 
the Florentines were very reluctant to engage in open battle. The risk was too great, as was the potential expense (in assembling a wholly new army). The wars of trecento ltaly were primarily wars of attrition in which enemies attempted to bleed opponents dry economically. Siege warfare also corresponded to the geography of Florence, protected to the north by Apennines in the Mugello and Casentino regions, and to the south by the Chianti hills. When Florence took on rural magnate families at the borders of the Romagna (a perennial enemy) the siege was the standard method of warfare. This was true also of war with Siena, Florence's great rival to the south. The bitter fighting between the two sides in 1390-92 was in the manner of a series of sieges to border towns. In such battles trebuchets and canons played a significant and still to be studied role. It is noteworthy that John Hawkwood, the greatest captain of the era, made his reputation for his victories in the field in the flat plains of Lombardy, which could accommodate prototypical pitched battles. But Hawkwood fought few such battles in Lombardy and when so engaged did not often fare well.

It is similarly important to stress that while Florentine forces evolved in the Fourteenth century, the continuities remained substantial. Whether in recruiting cavalrymen or infantrymen, Florence was steadfast in its practice of retaining effective soldiers in its employ over the long term, and building its army around a small cadre of such men. Florentine officials also hired soldiers from rural magnate clans, with familiar surnames such as Orsini, Farnese, Savelli -clans that appear just as frequently in thirteenth and fifteenth century documents. Enemy exiles also routinely found a place in Florentine armies. During Florence's war with Milan and Siena in 1392, city officials gave four prominent Sienese traitors -Orlando, Jacopo, and Naddo Malavolti and Bertoccio Tolomei- lifetime contracts for military service, permitting them to remain "as long as they wished." The most egregious instance of continuity is the great English captain John Hawkwood himself. Hawkwood was in great demand among all states, from the north to south of the peninsula. But it was ultimately Florence, by the late 1380s, who was able to keep him consistently in their employ, assuring their survival against the growing threat of Milan.

Finally, it is essential to view the Florentine army in terms of the frequent city leagues (taglie) of the era. Just as Daniel Waley noted for the late thirteenth and early fourteenth century, it is difficult to separate specifically Florentine army from those of the leagues that the city joined. The association required participating communes to pledge soldiers for a joint force. Unlike the earlier leagues, however, the ones of the mid and later trecento were often aimed at defense against marauding mercenary companies, in addition to hegemonic city states and rulers. Scholars have thus tended to view the 
leagues cynically, as ineffective in their stated aims and ultimately used by participants as a means of diplomacy aimed at manipulating and exploiting others. Giangaleazzo Visconti of Milan stands particularly accused of such deeds, using leagues as a veritable diplomatic weapon to isolate and weaken opponents. But the leagues were important to understanding civic armies. To quote Daniel Waley again, they reveal, like the earlier incarnation, a Florence army that was not entirely an expression of civic pride, but reflected also regional military priorities. The point is crucial because Florence joined many leagues in this period. The archival evidence shows that Florence participated taglie in 1336, 1344, 1347, 1349, 1351, 1354, $1356,1357,1358,1359,1361,1366,1369,1370,1371,1379,1380$, $1381,1384,1385,1389 / 90,1392,1396$ and 1398. The list is merely a guideline. The leagues were constantly being renegotiated and changed, so that it is difficult to know exactly where one ended and another began.

The leagues, like much of Florentine and Italian military history, require more study. But from the limited perspective of Florentine armies -the purpose of this essay- they meant that Florence continually had men at arms on the payroll and with that a species of standing army, albeit not strictly a civic one. When Florence fought Milan in 1351, its effort must be understood in terms of a league it made with Perugia and Siena for a joint army of 2,000 cavalrymen, for which Florence provided 1040 men, Perugia provided 575 men and Siena provided 375 men. The three cities also supplied 1000 crossbowmen, each according to the same proportion as the cavalrymen. ${ }^{47} \mathrm{After}$ the defeat of Florentine forces in 1369, the city immediately sought out an alliance and finally arranged one in October 1371 for a joint force of 2000 lances and 4,000 infantrymen (for four years) with the papacy, Pisa, Siena and Arezzo. ${ }^{48}$ The war with Milan was over, but Florence remained at arms, its force integrated with that of allies. The evidence not only makes clear the permanence of the Florence's army, but the deeply integrated nature of Italian military organization in trecento Italy.

\section{BIBLIOGRAPHY}

BAYLEY. C. C (1961): War and Society in Renaissance Florence: The De Militia of Leonardo Bruni. Toronto. University of Toronto Press.

BIANCHI, Silvana Anna (1995): "Gli eserciti delle signorie venete del Trecento fra continuità e trasformazione," in I/ Veneto nel medioevo, edited by Andrea Castagnetti and Gian Maria Varanini. Verona.

47 CANESTRINI: "Documenti," p. XVLIII-XLVIIX

48 Archivio di Stato di Siena (ASS), Capitoli 78 fols $1 \mathrm{r}-3 \mathrm{v}$ 
CANESTRINI, Giuseppe (1851): "Documenti per servire della milizia italiana del secolo XIII al XVI," Archivio Storico Italiano, ser. 1, 15.

CAFERRO, William (2006): John Hawkwood, An English Mercenary in Fourteenth Century ltaly Baltimore, Johns Hopkins Press.

CAFERRO, William (2008): "Continuity, Long-Term Service and Permanent Forces: A Reassessment of the Florentine Army in the Fourteenth Century." The Journal of Modern History 80, pp. 219-251.

CAFERRO, William (2008): "Warfare and Economy of Renaissance Italy, 1350-1450," Journal of Interdisciplinary History 39, pp. 167-209.

CAFERRO, William (2013): Edward Despenser, The Green Knight and the Lance Formation: Englishmen in Florentine Military Service," in The Hundred Years War, part III, edited by L. J. Andrew Villalon and Donald Kagay. Leiden. Brill, pp. 85-104.

CAFERRO, William (2013): Petrarch's War: Florentine Wages at the Time of the Black Death" Speculum 88.1 January, pp. 144-165.

CONTAMINE, Philippe (1980): War in the Middle Ages. Translated by Michael Jones. Oxford. Blackwell Publishing.

HALE, John (1986): War and Society in Renaissance Europe. Baltimore: Johns Hopkins Press.

GREEN, Louis (1986): Castruccio Castracani: A Study on the Origins of a Fourteenth-Century Italian Despotism. Oxford, University Press.

GRILLO, Paolo (2008): Cavalieri e popoli in armi: Le istitutioni military nell'Italia medievale. Bari. Editori Laterza.

MALLETT, Michael (1974): Mercenaries and their Masters. Totowa. New Jersey: Rowman and Littlefield.

Paoli, C. (1867): "Rendiconto e approvazioni di spese occorse nell'esercito fiorentino contro Pistoia nel Maggio 1302." Archivio Storico Italiano 6, pp. 3-16.

PIERI, Piero (1933): "Alcune questioni sopra fanterie in Italia nel periodo comunale." Rivista storica italiana, pp. 561-614.

PIERI, Piero (1952): Rinascimento e la crisi militare italiana. Turin. Einaudi. RICOTTI, Ercole (1844): Storia delle compagnie di ventura in Italia. Turin. Pomba.

SELZER, Stephan (2001): Deutsche Soldner im Italien des Trecento. Tubingen. Niemeyer.

WALEY, Daniel (1968): "The Army of the Florentine Republic from the Twelfth to the Fourteenth Century." In Florentine Studies, edited by Nicolai Rubinstein, 70-108. London. Faber and Faber. 


\title{
EL PRIMER MODELO DE RECLUTAMIENTO FORZOSO EN ESPAÑA DURANTE LA EDAD MODERNA: LAS LEVAS PARA LOS PRESIDIOS (1634-1642)'
}

\section{THE FIRST MODEL OF FORCED RECRUITMENT IN SPAIN DURING THE EARLY MODERN PERIOD: THE LEVIES FOR THE PRESIDIOS (1634-1642)}

Antonio José Rodríguez Hernández

UNED

\section{RESUMEN}

A mediados del siglo XVII aparecen en España nuevos modelos alternativos de reclutamiento basados en la coerción. Los primeros fueron los diversos repartimientos de soldados realizados en Castilla tras la propuesta del conde-duque de Olivares de llenar los presidios, que contaron con aprobación de las Cortes. Estas levas establecían nuevas fórmulas de reclutamiento forzoso que servirán de base de otras posteriores. Este texto repasa la gestión del reclutamiento, utilizando fuentes originales. Para disponer de mayor perspectiva usaremos tanto la documentación producida directamente por la administración militar, como la de carácter local custodiada en archivos municipales.

Palabras clave: Reclutamiento, Presidios, conscripción, deserción y control social.

\begin{abstract}
In the middle of the 17th century, new alternative models of recruitment based on conscription arose in Spain. The first ones were the diverse quotas of soldiers realized in Castile after the proposal of the count-duke of Olivares to of fill the Presidios, which received the necessary approval of the courts of Castile. These levies established new prescription of forced recruitment that would be used as base to others enlistments. This paper addresses the management of that recruitment, using documentary sources. To have a wider perspective we will use both documents produced by the military administration and local material accumulated in municipal archives.
\end{abstract}

Keywords: Recruitment, Presidios, conscription, desertion, and social control.

1 Trabajo integrado en el proyecto de investigación Guerra, ejército y poder en la lucha por la conservación de la monarquía de Carlos II (HAR2016-80673-P). Abreviaturas: Archivo General de Simancas (AGS): Guerra Antigua (GA), Estado (E), Contaduría Mayor de Cuentas $(C M C)$, Secretarías Provinciales (SP); Biblioteca Nacional (BN); Archivo Municipal de Burgos (AMBurgos); Archivo Municipal de Ponferrada (AMPonferrada); Archivo Municipal de Morón de la Frontera (AMMorón); Archivo Municipal de Marchena (AMMarchena); Legajo (Leg.), Libro de Actas (LA), manuscrito (ms.), folio (f.). 


\title{
RESUM
}

\section{El primer model de reclutament forçós a Espanya durant l'Edat Moderna: les lleves per als Presidis (1634-1642)}

\begin{abstract}
A mitjans del segle XVII apareixen a Espanya nous models alternatius de reclutament basats en la coerció. Els primers van ser els diversos repartiments de soldats realitzats a Castella després de la proposta del comte-duc d'Olivares d'omplir els presidis, que van comptar amb aprovació de les Corts. Aquestes lleves establien noves fórmules de reclutament forçós que serviran de base d'altres posteriors. Aquest text repassa la gestió del reclutament, utilitzant fonts originals. Per disposar de major perspectiva utilitzarem tant la documentació produïda directament per l'administració militar, com la de caràcter local custodiada en arxius municipals.
\end{abstract}

Paraules clau: Reclutament, Presidis, conscripció, deserció i control social. 
Las guerras de Italia enseñaron a los españoles a apostar por la calidad frente a la cantidad -manteniendo y disciplinando a sus soldados más allá del final de los conflictos bélicos-, creando un sistema militar en el que los profesionales eran la clave. ${ }^{2}$ La decisión española de mantener una infantería profesional con carácter autóctono, contrasta con la política de los monarcas franceses, que preferían mantener a sus súbditos -con la excepción de la nobleza-, alejados de la profesión militar, y apostaron por el mercenariado suizo, gascón o alemán. ${ }^{3}$ Realidad interpretada como la preferencia de España por un mercenariado autóctono, los soldados de los Tercios. Pero ver a éstos como unos mercenarios parece una interpretación algo simplista. Los soldados españoles de los Tercios eran voluntarios de cualquier origen social que pretendían ganarse la vida, adquirir honor y reputación, o ascender socialmente. ${ }^{4}$ Posibilidades que durante mucho tiempo el ejército ofreció, por lo que no faltaron los voluntarios, manteniendo éste una estructura profesional, en la que los ascensos y remuneraciones -regulados por las Ordenanzas Militares ${ }^{5}$ - eran acordes al valor y la experiencia. Soldados, que ante la clara voluntad de los reyes convirtieron el oficio de las armas en su forma de vida. Para ello, cuando se alistaban, firmaban un compromiso que los ataba al ejército hasta que murieran o fueran licenciados. ${ }^{6}$

2 RODRÍGUEZ HERNÁNDEZ, A.J. (2013): "Los hombres y la Guerra". En RIBOT, L.(Coord.): Historia Militar de España. Tomo III. Edad Moderna II. Escenario Europeo. Madrid, Ministerio de Defensa y Real Academia de la Historia, pp. 187-222.

3 POTTER, D. (2008): Renaissance France at War Armies, Culture and Society, 1480-1560. Woodbridge, Boydell, pp. 95-123.

4 THOMPSON, I.A.A. (2003): "El soldado del Imperio: Una aproximación al perfil del recluta español en el Siglo de Oro". Manuscrits, n²1, pp. 17-38.

5 Ordenanzas Militares de 1632, AGS, SP, Leg. 1.431.

6 RODRÍGUEZ HERNÁNDEZ, A.J. (2011): Los Tambores de Marte. El Reclutamiento en Castilla durante la segunda mitad del Siglo XVII (1648-1700). Valladolid, Universidad de Valladolid, pp. 87 y ss. 
La monarquía concentró sus recursos en la captación de profesionales que sólo debían rendir cuentas ante el rey y el Consejo de Guerra, siendo una de las pocas potencias que pudo construir un sólido y avanzado modelo de reclutamiento, centralizado y controlado directamente por la administración; ${ }^{7}$ en un tiempo en el que el método más usado era el indirecto, mediante la acción de los particulares: nobles, asentistas o mercenarios. Un modelo, conocido como sistema administrativo, ${ }^{8}$ que regulaba la elección de los oficiales que ejecutarían el reclutamiento -a los que se exigía varios años de servicio antes de acceder al cargo-, establecía de manera precisa los partidos de reclutamiento y el número de hombres, ${ }^{9}$ los pagos y tránsitos de las tropas. ${ }^{10}$ Todo ello pagado y organizado directamente por las autoridades militares ${ }^{11}$, siendo los capitanes los encargados directos de alistar sus compañías, sin que fuera necesario la intervención de las autoridades locales, y sin que éstas debieran obligar a nadie a alistarse. Su contribución era asegurar unos alojamientos adecuados y que los hombres pudieran encontrar los productos que necesitaban a unos precios apropiados de mercado, pudiendo ser lo primero bastante conflictivo. ${ }^{12}$ Así no se presionaba a los municipios, al recaer todas las responsabilidades en los capitanes y el Consejo de Guerra.

El principal problema del sistema era que todo dependía de la capacidad de encontrar voluntarios, algo cada vez más complicado, especialmente a partir de 1580, cuando los efectos de la crisis demográfica se hicieron patentes, haciendo que las compañías estuvieran lejos de completarse. ${ }^{13}$ Los

7 TALLETT, F. (1995): War and society in Early-Modern Europe, 1495-1715. Londres, Routledge, p. 73.

8 Sobre este sistema: THOMPSON, I.A.A. (1981): Guerra y decadencia. Gobierno y administración en la España de los Austrias, 1560-1620. Barcelona, Crítica, pp.129-180; PARKER, G. (1985): El Ejército de Flandes y el Camino Español 1567-1659. Madrid, Alianza, pp. 71-73; QUATREFAGES, R. (1983): Los Tercios. Madrid: Ed. Ejército, pp.423 y ss; MARTíNEZ RUIZ, E. (2008): Los Soldados del Rey. Los ejércitos de la Monarquía Hispánica (1480-1700). Madrid, Actas, pp.901-904.

9 Elección de capitanes, 27/4/1613. AGS, GA, Libro 96 f. 97.

10 Nombramiento como comisario e instrucciones a Francisco de Oviedo, Valladolid, 25/4/1604 AGS, GA, Libro 96 f.31.

11 Instrucción Real, Lisboa, 12/9/1619. AGS, GA, Leg. 839.

12 RODRÍGUEZ HERNÁNDEZ, A.J. (2014): "Milites Vs. Civitas: Análisis de los conflictos producidos por el reclutamiento de soldados voluntarios en las ciudades castellanas durante la segunda mitad del siglo XVII". Chronica Nova. Historia Moderna, n40, pp.77-105.

13 THOMPSON: Guerra y Decadencia..., p. 131 y ss. 
capitanes tenían instrucciones de reclutar hasta cierta cantidad de soldados -número fijado desde mediados del reinado de Felipe II en 250, cifra que se mantuvo hasta las primeras décadas del siglo XVII-, algo que no siempre se cumplía ante la falta de voluntarios, imponiéndose un límite hacia arriba pero no un número mínimo. La media real de soldados alistados en las compañías era mucho más baja: 123 hombres en 1594; cifra que bajó hasta los 105-107 en las primeras dos décadas del XVII. ${ }^{14}$ La brusca bajada en la eficacia del reclutamiento hará que desde 1624 el Consejo de Guerra reconozca que bastaban 100 hombres para formar una compañía ${ }^{15}$, si bien las ordenanzas militares de 1632 seguían indicando que las compañías en España debían tener 250 efectivos. ${ }^{16} \mathrm{El}$ reclutamiento administrativo necesitaba voluntarios -y su número siempre fluctuaba respecto a las condiciones de vida, las cosechas, la demografía, las plagas o las epidemias-, sin que se supiera a ciencia cierta cuántos hombres se podrían reunir cada año.

Estaba claro que era imposible que un país tan pequeño como España pudiera satisfacer la demanda de soldados impuesta por una monarquía global. Durante la década de 1630 esto se hizo más evidente, ante la crisis del modelo, que no llegaba a reunir los suficientes hombres. Los soldados españoles se habían convertido en un bien escaso que había que reservar para las operaciones más importantes y destacadas, y defender las zonas más sensibles, al ser las tropas de mayor confianza. ${ }^{17}$ No es de extrañar que durante las primeras operaciones militares de la Guerra de los Treinta años en el Sacro Imperio Germánico no hubiera ninguna unidad española integrada en el ejército de más de 9.000 hombres que formó España para apoyar al bando católico, y que se hizo con la victoria en Montaña Blanca (1620). La monarquía mandó soldados valones e italianos, y reclutó alemanes. Pero, aunque hubo oficiales españoles, ninguna unidad estaba compuesta por éstos. ${ }^{18}$ Hasta el envío a Alsacia del duque de Feria en 1633 no hubo tercios españoles combatiendo en Alemania. Algo que se produjo

14 THOMPSON: Guerra y Decadencia..., pp. 131-132; y RODRÍGUEZ HERNÁNDEZ: "Los hombres y la Guerra...", pp. 202-204.

15 Memoria de los distritos, Madrid, 5/7/1624. AGS, GA, Libro 96.

16 Ordenanzas Militares de 1632, AGS, SP, Leg. 1.431.

17 Consejo de Estado, 14/5/1634. AGS, E, Leg. 2.048 f. 45.

18 GUTHRIE, W.P. (2002): Battles of the Thirty Years War: From White Mountain to Nordlingen 1618-1635. Westport, Greenwood Publishing, pp. 61-62. PALAU CUÑAT, J. (1994): "La batalla de Weissenberg (Montaña Blanca), 1620". Dragona, n4, pp. 12-13. Cuentas de Hurtuño de Ugarte, 1617-22. AGS, CMC $3^{a}$ época, Leg. 706. 
debido a su vital objetivo: allanar el camino a la futura expedición militar del Cardenal Infante hacía Flandes. ${ }^{19}$

Ante la crisis del modelo tradicional voluntario se necesitaba otro alternativo, dándose los primeros pasos hacia la descentralización del sistema. Una política que destacará por ser errática, y que primero se centró en extender el reclutamiento indirecto, apelando a intermediarios -ya fueran asentistas $^{20}$ o nobles, siendo la respuesta de los últimos bastante tibia ${ }^{21}-$, que reunían hombres a cambio de dinero u otras contraprestaciones, entrando en juego la venalidad. ${ }^{22}$ Ellos se encargarían de sustituir momentáneamente a los capitanes profesionales que desde hacía más de 100 años se encargaban de reclutar voluntarios, teniendo como principal misión enviar tropas a los ejércitos europeos de la monarquía.

Rápidamente quedó patente que esto no era suficiente, por lo que al mismo tiempo se intentó recuperar las antiguas obligaciones militares de los municipios, y que éstos se encargaran de reunir los hombres suficientes

19 Consejo de Estado, 24/5 y 27/10/1633. AGS, E, Leg. 2.334.

20 Sobre los asientos: RIBOT, L. (2000): "Types of Armies: Early Modern Spain". En CONTAMINE, P.(Coord.), War and competition between States. Oxford, Oxford University Press, pp. 52-55. ANDÚJAR CASTILLO, F. (2006): "Empresarios de la guerra y asentistas de soldados en el siglo XVII". En GARCÍA HERNÁN, E. y MAFFI, D. (Eds.), Guerra y sociedad en la Monarquía Hispánica: Política, Estrategia y Cultura en la Europa Moderna (1500-1700). Madrid, Laberinto, Vol. II, pp. 375-394. RODRÍGUEZ HERNÁNDEZ, A.J. (2007): "Patentes por soldados. Reclutamiento y venalidad en el ejército durante la segunda mitad del siglo XVII". Chronica Nova, n³3, pp. 37-56.

21 Junta de Ejecución, 11/11/1634. Sumario de lo que han respondido algunos prelados y títulos, AGS, GA, Leg. 1.099. Coronelías de a pie y de a caballo de la Junta del Arzobispo de Granada, 2/6/1635, AGS, GA, Leg. 1.258. Conde de CLONARD (1862), Historia Orgánica de la Armas de Infantería y Caballería. Madrid, t. IV, pp. 409-410; MACKAY, R. (2007): Los Límites de la autoridad real. Resistencia y obediencia en la Castilla del siglo XVII. Valladolid, Junta de Castilla y León, pp. 120-134. THOMPSON, I.A.A. (1986): "El reinado de Felipe IV", en ANDRÉS GALLEGO, J. (coord.), Historia General de España y América. Madrid, Rialp, t. VIII, p. 459.

22 JIMÉNEZ MORENO, A. (2009): “Honores a cambio de soldados, la concesión de hábitos de las Órdenes Militares en una coyuntura crítica: la Junta de Hábitos (1635-1642)". En SORIA MESA, E. y DELGADO BARRADO, J.M. (eds.), Las élites en la época moderna: la monarquía española, vol. 3, Economía y poder. Córdoba, Universidad de Córdoba, pp. 155-171. RODRÍGUEZ HERNÁNDEZ, A.J. (2012): "Servir al rey con hombres. Recompensas concedidas a élites y representantes del rey por su colaboración en el reclutamiento (1630-1700)". En ESTEBAN ESTRÍNGANA A. (ed.), Servir al rey en la Monarquía de los Austrias. Medios, fines y logros del servicio al soberano en los siglos XVI y XVII. Madrid, Sílex, pp. 415-443. 
para asegurar la defensa peninsular, aumentando la coerción. La fallida Unión de Armas había intentado sin éxito asegurar a la monarquía unos contingentes mínimos para afrontar sus empresas militares. Tras abandonar el proyecto, el conde-duque de Olivares intentará desarrollar un modelo alternativo que sólo afectará a Castilla, consiguiendo que las Cortes aprueben en 1634 la primera recluta forzosa que tendría como objetivo que los presidios mantuvieran sus dotaciones, para que así el reino estuviera bien defendido; ${ }^{23}$ cuestión sobre la que profundizaremos en este trabajo ante su importancia para los sistemas de reclutamiento venideros, ya que desde entonces los municipios cobrarán una importancia capital en el reclutamiento de sus naturales, la cual se mantendrá a lo largo de todo el siglo a pesar de los continuos cambios. ${ }^{24}$

\section{La primera leVA de los presidios (1634-35)}

\subsection{La propuesta al reino de 1634}

Aprovechando las quejas vertidas en el Consejo de Castilla en 1631 en base a las molestias y cargas que representaban para muchos pueblos los alojamientos y tránsitos de tropas que se reclutaban, el Valido hábilmente introdujo la idea de que si los presidios mantenían sus dotaciones -y una consignación económica periódica y suficiente-, dejaría de ser necesario que se realizaran levas, ya que los voluntarios fluirían directamente al ser las pagas puntuales. ${ }^{25}$ Durante la década de 1630 Olivares consiguió mejorar la financiación del dispositivo defensivo peninsular: los presidios. ${ }^{26}$ Un conjunto de guarniciones permanentes de infantería repartidas por las fronteras terrestres y marítimas. Éstas se encontraban en la frontera pirenaica -en los lugares y pasos más sensibles-, en las zonas costeras de mayor importancia, tanto en la península -incluida Portugal- como en las islas

23 THOMPSON, I.A.A. (1990): "Aspectos de la organización naval y militar durante el ministerio de Olivares". En ELLIOTT, J.H. y GARCÍA SANZ, A. (coords.), La España del Conde Duque de Olivares. Valladolid, pp. 251-258; MACKAY, Los límites..., pp. 57-70. RODRÍGUEZ HERNÁNDEZ, A.J. (2012): "Las Cortes de Castilla y la leva para los Presidios: La gestión de la primera recluta obligatoria de los Austrias". En PÉREZ ÁlVAREZ, M.J., RUBIO PÉREZ, L.M. y MARTíN GARCÍA, A. (eds.), Campo y campesinos en la España Moderna. Culturas políticas en el mundo hispano. León, Fundación Española de Historia Moderna, pp. 1731-1744.

24 RODRÍGUEZ HERNÁNDEZ: Los Tambores de Marte..., pp. 145-196.

25 ELLIOTT, J.H. y DE LA PEÑA, J.F. (1981): Memoriales y cartas del Conde Duque de Olivares. Tomo II. Política interior: 1628 a 1645. Madrid, Alfaguara, pp. 104-105.

26 Decreto de su majestad, Madrid, 22/6/1631. AGS, GA, Leg. 1.037. 
atlánticas y mediterráneas, y el Norte de África. Unas guarniciones que tenían una dotación teórica de 18.000 plazas. ${ }^{27}$

La medida tardó en cuajar ante los problemas de financiación que supondría su implantación, y la apurada situación financiera, como advirtieron las Cortes de 1632. ${ }^{28}$ Sin embargo, al tener claro que estallaría una nueva guerra con Francia, se debía mejorar la defensa fronteriza que los presidios representaban, al ser el único cuerpo de infantería profesional que había en España más allá del tercio de la Armada destacado en Andalucía. ${ }^{29}$ A comienzos de 1634 Olivares propuso la forma de "llenar los Presidios", debatiéndose posteriormente el tema en las Cortes ${ }^{30}$ y en los Consejos de Estado y Guerra. ${ }^{31}$ La propuesta pretendía atender tanto al mantenimiento -asegurando un asiento anual por valor de 270 millones de maravedíes con Octavio Centurión- como la completa dotación de los presidios. Para que estas guarniciones fueran más atractivas se proponían medidas para mejorar la vida de los soldados, asegurar su paga puntual, posibilidades de ascenso, premios y movilidad, especialmente para los que defendían los presidios norteafricanos. La medida de llenar los Presidios se vendía como un gran beneficio para Castilla, que estaría mejor defendida y se vería libre de otras levas. Para ello, el reino -por provincias, y según sus vecindarios-, debía poner en los Presidios la gente que faltaba para cubrir su dotación, quedando su mantenimiento económico en manos de los Millones y otros ingresos. Las provincias tendrían libertad para realizar la recluta, no sobrecargándose los lugares pequeños y de poca vecindad. Para animar la colaboración de las ciudades, se las prometía que podrían echar mano de los muchos desocupados y vagabundos que había, a los que se persuadiría para alistarse. En ningún caso el reclutamiento se efec-

27 Relación de la gente que conforme al nuevo pie que ha de haber en los Presidios, 5/2/1634 Relación de la gente que ha de haber en los presidios conforme al nuevo pie de que queda bajado, Madrid, 7/2/1634. AGS, GA, Legs. 1.095 y 1.038. Para una visión general: CONTRERAS GAY, J. (1998): "Consideraciones generales sobre la defensa de la Península entre 1580 y 1640". En Mediterráneo: hechos de relevancia histórico-militar y sus repercusiones en España: V Jornadas Nacionales de Historia Militar. Sevilla: Universidad de Sevilla, pp. 647. 664.

28 Consejo de Guerra, 25 de agosto 1632. Cédula Real, 27/7/1632. AGS, GA, Leg. 1.098. También: Actas de las Cortes de Castilla, Vol. LI, p. 33 y ss.

29 Consejo de Guerra, 27/1/1634. AGS, GA, Leg. 1.098.

30 MACKAY, Los límites..., pp. 57-70. Acuerdo que el reino hizo en 25/2/1634. AGS, GA, Leg. 1.095.

31 Consejo pleno de Estado y Guerra, 3/3/1634. AGS, GA, Leg. 1.095. 
tuaría mediante la fórmula habitual, y no se permitiría que las tropas marcharan con banderas y cajas. Así las ciudades no se verían sobresaltadas, y se evitarían daños y problemas. Incluso se establecían castigos para los futuros desertores, que debían ser capturados si volvían a sus hogares, y evitar así nuevas levas para cubrir las bajas. ${ }^{32}$

El acuerdo, aceptado por el reino en las Cortes de febrero de 1634, ponía las bases del servicio. ${ }^{33}$ El reino se encargaría de que los presidios mantuvieran su dotación de unos 18.000 hombres, repartiéndose los 12.000 hombres que faltaban entre todas las provincias por cupos. Los gastos de reclutamiento y mantenimiento de las tropas correrían a cargo del rey, por lo que a cada provincia se enviaría el dinero necesario. Según el acuerdo, el reino debía suplir las bajas cuando se debieran a la muerte o fuga de los soldados. Sólo se excusaba el reemplazo en caso de que el rey enviara a éstos a combatir a otras partes. Con este servicio el reino conseguía evitar las vejaciones que provocaban las levas, anulándose todas las que estaban teniendo lugar. El servicio duraría seis años. El último punto de las condiciones ofrecidas era para los consejeros el más polémico, ya que determinaba que si no era posible encontrar voluntarios los pueblos podrían acudir al sorteo o quintar, lo cual suponía una fórmula obligatoria de reclutamiento, que quedaba justificada debido a que las tropas no servirían fuera de España, y que el reclutamiento era para defender el reino. ${ }^{34}$

La recluta se efectuó según unos cupos basados en la población teórica de cada una de las 17 provincias en las que se dividió Castilla, las cuales supuestamente tenían 1.015 .000 vecinos; ${ }^{35}$ cifra ponderada y redondeada que era algo inferior a otros recuentos demográficos del periodo. ${ }^{36}$ En total se sacarían 12.000 soldados, quedando al margen las Provincias Vascas, Canarias y los lugares que estuvieran a menos de ocho leguas de un Presidio; si bien esto último no se cumplió. Los vecindarios se corrigieron continuamente ante su falta de fiabilidad, aunque de media se debía sacar un

32 Proposición para llenar los Presidios y conservarlos, s/f. AGS, GA, Leg. 1.095.

33 Acuerdo que el reino hizo en 25/2/1634. Papel del reino sobre llenar los Presidios, 2/3/1634. AGS, GA, Leg. 1.095.

34 Consejo pleno de Estado y Guerra, 3/3/1634. Acuerdo que el reino hizo en 25/2/1634. Forma que las provincias han de guardar en juntar la infantería, conducirla, y los privilegios concedidos, s/f. AGS, GA, Leg. 1.095.

35 Relación de la vecindad que hay en las provincias del reino, s/f. AGS, GA, Leg. 1.095.

36 ELLIOTT, J.H. (2004): El conde-duque de Olivares. Barcelona: Crítica, p.562. DOMINGUEZ ORTIZ, A. (1963): La Sociedad Española en el Siglo XVII. Madrid, CSIC, t. 1, pp. $110-112$. 
soldado por cada 85 vecinos. ${ }^{37}$ Los cupos fueron más o menos respetados y aceptados, debatiéndose en las diferentes ciudades con voto en cortes la cuestión durante los meses siguientes. ${ }^{38}$

\subsection{Los resultados}

Los cupos no se cubrieron de manera significativa hasta mediados de 1635. Numerosos informes revelan las continuas llegadas, si bien las cuentas no están completas, y no siempre los secretarios pudieron incluir a todos los hombres enviados ante la magnitud de la operación, ya que además debían intentar cruzar la información entre las cartas y testimonios que enviaban los corregidores y los informes administrativos llegados desde los presidios, más precisos y concluyentes. En marzo se contabilizaba la llegada de 6.018 hombres. ${ }^{39}$ A comienzos de abril eran 7.523, aunque ya habían huido 1.543. ${ }^{40}$ Según los informes finales faltaron por entregar 2.064 soldados, bien porque las autoridades no los alistaron, bien porque huyeron por el camino o se despidieron a su llegada al ser inútiles para el servicio. ${ }^{41}$

A lo largo del mes de abril -un año después de su comienzo- se realizó un informe muy preciso de cómo estaban cumpliendo los diversos partidos. Los principales problemas estaban en las circunscripciones más grandes. Sevilla no había entregado muchos hombres debido a la poca implicación de algunos corregidores. De hecho, las órdenes no llegaron hasta el verano a algunos territorios de la nobleza, como la villa de Morón de la Frontera. ${ }^{42}$ Madrid también había sido problemática, pero pactó el cumplimiento del cupo en base a poder reclutar voluntarios, acordándose con los gremios la entrega 200 hombres. Pero a esas alturas el principal escollo era el alto grado de fugas, tanto antes como después de llegar a su destino. Aunque Murcia había reunido los hombres pedidos y los había enviado a

37 Relación de los 12.000 hombres que ha de dar el reino, s/f. AGS, GA, Leg. 1.038. Relación de la gente que está repartida a todas las ciudades y cabezas de partidos, $s / f$. Repartimiento de los infantes que se han de levantar para los Presidios, s/f. AGS, GA, Leg. 1.095.

38 Acuerdos del cabildo de Burgos, marzo y abril 1634. AMBurgos, LA de 1634 f.24 y ss.

39 Junta o comisión del conde de Castrillo, Madrid, 18/3/1635. AGS, GA, Leg. 1.121

40 Notas sobre los informes realizados en marzo y abril de 1635. AGS, GA, Leg. 1.132.

41 Notas sobre lo que falta por entregar del primer repartimiento, 4/12/1636. AGS, GA, Leg. 1.194. Carta de Matías Fernández Zorrilla, Madrid, 21/4/1635. AGS, GA, Leg. 1.121.

42 Cédula de García Sarmiento de Sotomayor, Asistente de Sevilla, Sevilla, 18/7/1635. AMMorón, Leg. 649. 
la frontera valenciana, una noche -estando en el castillo de Játiva-, buena parte de ellos se fugaron ante la falta de dinero para su socorro. ${ }^{43}$

Empero, el grado de cumplimiento y aceptación fue alto, y durante la primavera de 1635 muchos de los corregidores remisos comenzaron a despachar las tropas que faltaban. El territorio menos dispuesto a cumplir era Granada, que se quejaba de que debía acudir a sus costas para defenderlas, y contribuir económicamente socorriendo a las guarniciones profesionales presentes, por lo que en junio de 1635 sólo había entregado en Málaga 275 hombres, lejos de los 1.320 asignados. La cuestión que más empañaba el servicio estaba siendo las fugas, que en Cádiz habían sido exorbitadas. Desde algunos sectores se achacaba el problema a la falta de camas, pero la principal dificultad estaba en la falta de un socorro adecuado para los bisoños y la carestía creada artificialmente ante la llegada de muchos hombres en poco tiempo. ${ }^{44}$ Durante el verano siguieron llegando tropas a cuenta de los que todavía no se habían remitido. Incluso algunos partidos empezaron de forma esporádica a cubrir las bajas de los hombres entregados meses atrás. Las provincias de Córdoba y Jaén dieron otros 387 hombres para cubrir parte de los 1.400 que hasta el momento habían huido. ${ }^{45}$ Los envíos a Cataluña fueron algo más tardíos, aumentando poco a poco el número. ${ }^{46}$ En noviembre se habían entregado 1.253, y a Toledo y Cuenca sólo les faltaban por entregar 16 y 20 hombres respectivamente; aunque Murcia debía reponer los 187 que se habían fugado de camino. ${ }^{47}$ En muy poco tiempo los corregidores escribieron indicando que los soldados empezaban a volver sin licencia, por lo que se debieron tomar medidas. Se persiguió a los fugados, y se remitieron listados a los lugares por los que servían para que fueran apresados si volvían. ${ }^{48}$ También se ordenó

43 Relación de los 12.000 hombres que se ha de conducir, Madrid, 19/4/1635. AGS, GA, Leg. 1.121 .

44 Relación de lo que ha obrado el cuerpo de la junta que está a cargo del conde de Castrillo, Madrid, 29/6/1635. AGS, GA, Leg. 1.144.

45 Relación de la gente que ha llegado, Cádiz, 31/7/1635. Carta de Juan de Castro y Castilla, Cádiz, 5/8/1635. AGS, GA, Leg. 1.147.

46 Relación de la gente que a la fecha se ha entregado, Barcelona, 13/4/1635. AGS, GA, Leg. 1.146.

47 Relación de los soldados que están en las atarazanas de Barcelona, 11/8/1635. Informes de los soldados repartidos; los entregados en Barcelona; y los que faltan de Conducir, 7/11/1635. AGS, GA, Leg. 1.132.

48 Carta del gobernador de Llerena, 22/9/1635. Carta de la princesa Margarita, Gobernadora de Portugal, Lisboa, 19/2/1635. AGS, GA, Legs. 1.140 y 1.145. 
a los corregidores que capturaran en sus distritos a todos los soldados que hubiera sin licencia -aunque no vinieran de los presidios-, medida que por primera vez se tomaba en España, la cual pretendía dificultar que pudieran volver a sus hogares. ${ }^{49}$

La calidad de los reclutados era mala y muchos ministros reconocían que la mayoría eran jornaleros apresados, que incluso estaban casados y tenían hijos. ${ }^{50}$ Algunos oficiales no aceptaron a parte de las tropas, y desde Cádiz se avisó que no se habían recibido 50 por considerarlos mendigantes que venían sin espadas y que no parecían de provecho para la infantería. ${ }^{51}$ La leva no fue fácil, y algunos municipios prendían hasta 40 hombres para cumplir con un único soldado. Tampoco los comisarios que conducían las tropas salían indemnes de las críticas, ya que se decía que en el tránsito muchos liberaban a los soldados a cambio de dinero, poniendo a otros en su lugar, estando al orden del día los fraudes. A pesar de que las tropas solían hacer su viaje acompañados por guardas, y con esposas y grilletes -siendo incluso maltratados, como si fueran prisioneros-, hubo casos en los que sujetos armados se concentraron para liberar a los reclutas. Además, los municipios entregaban hombres que no siempre cumplían las condiciones mínimas de un recluta medio, de ahí que algunos oficiales expresaran que en estas levas sólo venían "viejos, ciegos, mancos y tullidos". ${ }^{2}$ La llegada de esa gran cantidad de gente inútil acrecentaba los gastos y la necesidad de los hospitales militares. Cuestión que se agravaba debido a que los pueblos enviaban a los soldados descalzos y sin vestuario adecuado para aguantar el invierno, teniendo los reclutas un aspecto lamentable. Pocos perseverarían en el oficio militar, y los que podían, y reunían el dinero necesario, intentaban comprar su libertad a sus capitanes. No es de extrañar que el Consejo de Guerra criticara abiertamente la leva ante el gasto realizado, al ser un esfuerzo inútil. Incluso se afirmó que el reclutamiento había generado más daños que soluciones, pues las levas involuntarias no funcionaban y no servían para el objetivo marcado de llenar los presidios. Lo que se necesitaba realmente era voluntarios; cuestión que quedaría en saco roto ante la renovación del servicio. ${ }^{53}$

49 Cartas de los corregidores de Anquera, Madrigal, Murcia y Guadix, 11, 14, 17 y 30/4/1635. AGS, GA, Leg. 1.146.

50 Carta de Juan de Castro y Castilla, Cádiz, 5/8/1635. AGS, GA, Leg. 1.147.

51 Carta de Juan de Velasco, Cádiz, 18/3/1635. AGS, GA, Leg. 1.145.

52 Carta de Juan de Velasco, Cádiz, 18/6/1634. AGS, GA, Leg. 1.124.

53 Consejo de Guerra, 18 y $31 / 5,5$ y 14/7, 8 y 18/8 y 27/10/1635. AGS, GA, Leg. 1.124. 
Tabla 1: Resultados de la leva de los Presidios por partidos (abril 1635)

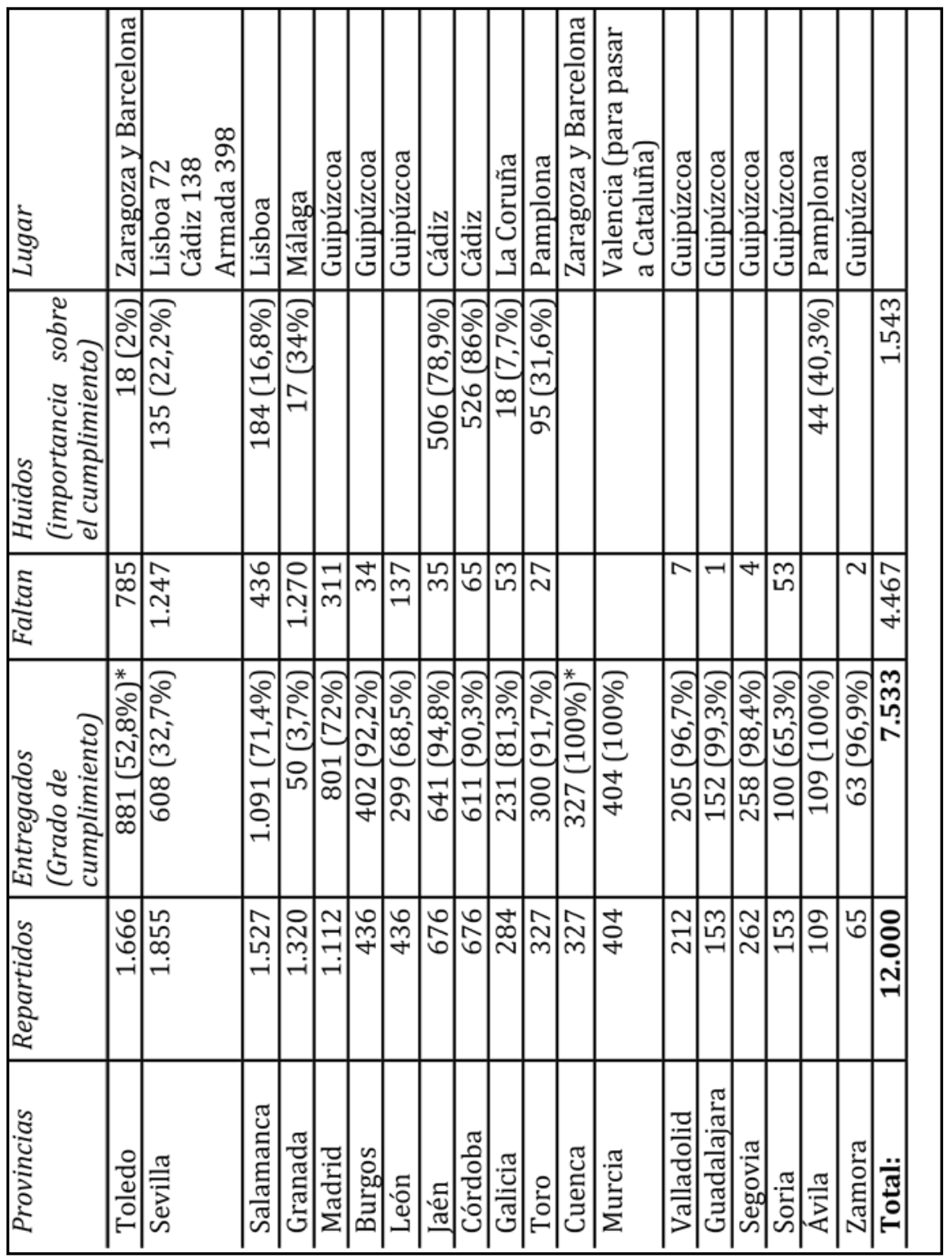

Fuente: AGS, GA, Legs. $1.121,1.132$ y 1.145. (*)=En noviembre se informaba que Toledo había entregado 1.001 hombres en Cataluña y otros 649 en Aragón, por lo que sólo quedaban por entregar 16. Cuenca había remitido 197 a Cataluña y 110 a Aragón, faltando 20. 


\subsection{La llegada a los presidios}

El aumento del número de bisoños en los presidios acrecentó los problemas estructurales de éstos, ya que no se había previsto su llegada y no se había aumentado su dotación económica. Los soldados sobrevivían en unas condiciones lamentables, con incomodidades y hacinados. ${ }^{54}$ Faltaban alojamientos adecuados ante el incremento de las dotaciones -incluso algunos soldados debieron dormir al raso ante la escasez de lugares apropiados-, y la carencia de camas y ropa de abrigo fue difícil de solucionar conforme llegaba el invierno. Muchos presidios como Cádiz o Pamplona compraron camas -365 y 289 respectivamente-, pero los fondos para costearlas fueron insuficientes, y aunque los soldados dormían de dos en dos, se calculaba que cada una costaba 166 reales y medio. ${ }^{55}$ Los nuevos soldados procedían de las capas sociales más pobres, por lo que no tenían medios para proporcionarse un vestuario adecuado y pasaban frío. Cuestión que se agravaría cuando en algunos presidios, como en Cádiz, la falta de consignaciones económicas periódicas y el incremento del coste de pan hizo que parte de las tropas no pudieran procurarse diariamente este alimento básico. Por ello las autoridades militares insistieron en dar a cada soldado al menos un socorro diario de 1 real de vellón y pan de munición. La precaria situación de los nuevos soldados impulsó a muchos a fugarse, a pesar de que si eran capturados se les condenaba a recibir azotes y a pasar entre 4 y 6 años en las galeras; penas que recibieron los 15 fugitivos apresados entre agosto y diciembre de 1635. Pero no parece que esa medida draconiana evitase de manera significativa las fugas ante la desesperación de muchos soldados, que no sólo eran forzados a alistarse, sino que además no recibían lo necesario para subsistir. ${ }^{56}$

A pesar de los esfuerzos, el mayor problema siguió siendo la poca continuidad de los soldados, ya que muchos desertaron cuando se presentó la

54 Consejo de Guerra, 14/6/1634. AGS, GA, Leg. 1.096.

55 Consejo de Guerra, 15 y 26/6, y 1/8/1635. AGS, GA, Leg. 1.120. Relación del estado del alojamiento, Pamplona, 28/6/1635. Relación de lo que costará cada cama, s/f. AGS, GA, Leg. 1.133. Cartas de Leonardo de Sorca Camargo y Francisco Lario de Losada, Cádiz, 3/6 y $30 / 11 / 1635$. AGS, GA, Leg. 1.148.

56 Consejo de Guerra, 28/8, 2/9 y 28/11/1635. Junta que se hace en la posada del conde de Castrillo, 21/8/1635. AGS, GA, Leg. 1.121. Orden al marqués de Monesterio, asentista de los presidios, Madrid, 23/10/1635. AGS, GA, Leg. 1.123. Carta de Juan de Velasco, Cádiz, 5/12/1635. AGS, GA, Leg. 1.140. 
oportunidad. ${ }^{57}$ En Cádiz entraron hasta mediados del mes de junio 1.168 soldados de los partidos de Jaén, Córdoba y Sevilla. En menos de tres meses sólo quedaban 279 , uno de cada cuatro. ${ }^{58}$ De poco servía el esfuerzo si no se mejoraba la situación en los Presidios, que no podían estar herméticamente cerrados, por lo que consecuentemente los forzados intentaban volver a sus casas. Según otro informe, hasta el verano de 1635 habían llegado a Cádiz 2.033 hombres de Jaén, Córdoba y Sevilla, de los que 156 no fueron admitidos en un primer momento por ser inútiles para el servicio, recibiéndose al sueldo 1.877. De ellos, a finales de julio -tres meses después de que llegara la primera tropa- 1.563 habían huido, 14 habían muerto o habían sido despedidos y 300 seguían en servicio en el presidio. Sólo un $15 \%$ había perseverado en el oficio militar. ${ }^{59}$

A pesar de lo ocurrido en Cádiz, debido a la improvisación, el balance en otros presidios fue más positivo. En Fuenterrabía y San Sebastián la llegada fue significativa. En febrero de 1634 había sólo 548 soldados, a principios de agosto dicha cifra se había triplicado y llegaba a los 1.620 hombres. ${ }^{60}$ También en Aragón los nuevos reclutas contribuyeron notablemente a aumentar su dotación. Entre finales de junio de 1634 y finales de agosto del año siguiente habían llegado 722, muriendo y fugándose 190 (el 26\%). Un balance basta positivo. Incluso los oficiales del sueldo justificaban el nivel de fugas debido a que no había hospital, faltaban medicinas, médicos y camas. Buena parte de los hombres debían dormir en el suelo, ya que, aunque se proveyó dinero para 265 camas, el precio era más elevado y no se habían podido enviar. ${ }^{61}$ De hecho -a pesar de las fugas y de que 300 de ellos fueran enviados a la frontera navarra para participar en la invasión que se realizaba en Francia-, a mediados de 1637 quedaban aún 53 soldados de estas tropas, cerca del $25 \%$ del total de los hombres presentes. ${ }^{62}$

57 Memoria de los oficiales reales de Cádiz, 17/12/1634. AGS, GA, Leg. 1.115.

58 Relación de la infantería bisoña, Cádiz, 15/7/1634. AGS, GA, Leg. 1.095.

59 Relación de la gente que ha llegado, Cádiz, 31/7/1635. AGS, GA, Leg. 1.147.

60 Relación del número de gente, Madrid, 9/12/1634. AGS, GA, Leg. 1.096.

61 Carta de los oficiales al sueldo de Zaragoza, 28/8/1635. Relación particular de la gente que ha venido de Castilla, Zaragoza, 28/8/1635. AGS, GA, Leg. 1.147.

62 Relación de los soldados efectivos, Zaragoza, 31/3/1637. Muestra de los presidios, 31/3/1637. Carta de Juan Sáez de Arriaga, Zaragoza, 31/3/1637. AGS, GA, Leg. 1.195. 
Tabla 2: Hombres entregados en los presidios durante 1635:

\begin{tabular}{|c|c|c|c|c|}
\hline Presidio de Entrega & $\begin{array}{ll}\begin{array}{l}\text { Fecha del } \\
\text { informe }\end{array} & \\
\end{array}$ & Entregados & $\begin{array}{l}\text { Fugados, } \\
\text { despedidos }\end{array}$ & $\begin{array}{ll}\text { muertos } & o \\
\end{array}$ \\
\hline Cádiz & mayo & 1.388 & & $1.221(87,9 \%)$ \\
\hline Cataluña & febrero & $\begin{array}{r}635 \\
\text { noviembre; } 1.253 \\
\end{array}$ & & $92(14,4 \%)$ \\
\hline Aragón & agosto & $\begin{array}{r}722 \\
\text { noviembre; } 759\end{array}$ & & $190(26,3 \%)$ \\
\hline Navarra & marzo & 407 & & $147(36,1 \%)$ \\
\hline Guipúzcoa & marzo & 1.733 & & $521(30 \%)$ \\
\hline Galicia & marzo & 236 & & $34(14,4 \%)$ \\
\hline Portugal & febrero & 1.163 & & $184(15,8 \%)$ \\
\hline Peñón Vélez de la Gomera & abril & 21 & & \\
\hline Armada & febrero & 398 & & \\
\hline Total: & & 6.703 & & $2.389(35,6 \%)$ \\
\hline
\end{tabular}

Fuente: AGS, GA, Legs. 1.121, 1.132, 1.144 y 1.147.

\section{La CONTINUIDAD DEL SERVICIO Y SU GESTIÓN 1635-1642}

El servicio de los presidios continuó durante ocho años, ajustándose distintos repartimientos. Unos estaban justificados por los incumplimientos del reino y las excesivas fugas de soldados; mientras que otros se realizaron para atender al mantenimiento de las dotaciones teóricas de los presidios. La gestión de la mayoría de ellos fue muy parecida. En total se realizaron al menos seis repartimientos que pretendían reunir 42.727 hombres, estando la cifra muy cerca de los 44.000 que Olivares demandó a Castilla y las Indias dentro de su Unión de Armas. ${ }^{63}$

Cualquier reparto era complicado, no sólo por lo difícil que era alcanzar el cupo asignado, sino también por el hecho de que las propias comunidades debían gestionar el reclutamiento y transporte de las tropas. Hasta el reparto de 1639, los costes fueron asumidos por las arcas locales. Desde los comienzos del servicio se insistió en que los hombres se llevaran "con prisiones y guardias", lo que aumentaba los costes. Cada comisario, alguacil armado o guardia debía ser pagado durante los días que le llevara su ocupación. Esto generaba unos costes excesivos, ya que había pueblos que debían enviar uno o dos soldados a cientos de kilómetros de distancia, 
y los comisarios debían ser pagados tanto durante el viaje de ida como el de vuelta, al no concentrarse las tropas en las capitales de partido; 64 algo que tras la experiencia se remediaría años después para ahorrar costes.

Otro problema era que todas estas demandas de soldados, y el dinero necesario para conducirlos, llegaban en un momento en el que comenzaban a proliferar otras demandas de carácter militar. Una escalada de peticiones que empezaban a colapsar las arcas de muchos municipios. En 1639 Marchena tuvo que entregar 25 soldados para los presidios, y pagar 200 reales de vellón por cada soldado; todo a cargo de los bienes de propios del concejo, pese a su lamentable estado. La ciudad cumplió, pero la petición llegaba en un momento de enormes obligaciones, ante las demoras del pago de los Millones, y la petición extraordinaria de enviar grano para el ejército. La cuestión económica sólo se pudo solucionar al permitirse imponer nuevos arbitrios sobre el consumo: 2 maravedíes por cada libra de aceite, otros 2 por cada libra de carne y tocino que se consumiera en la villa, y un real por cada cabeza de ganado vendida. Nuevos impuestos que encarecerían el nivel de vida de la población. ${ }^{65}$

En ocasiones se generaron diversos problemas a la hora de repartir los cupos entre las cabezas de provincia y sus jurisdicciones. ${ }^{66}$ Se solían usar parámetros poco claros para dividir el esfuerzo humano, los cuales se decidían en las cabezas de las provincias y no por el Consejo de Guerra. En muchos casos las proporciones no eran nada equitativas, y se sobrecargaba a algunos lugares frente a otros, siendo los aportes de las grandes ciudades con voto en cortes algo moderadas en relación al resto. Los problemas y quejas sobre los cupos repartidos internamente incidían en el grado de cumplimiento. En el repartimiento ajustado en 1640, el Reino de Sevilla debía aportar 1.266 hombres, pero sólo había podido remitir 993 ante la negativa de muchas jurisdicciones a cubrir el cupo, además de que los señores -especialmente cuyos estados estaban colindantes con la frontera portuguesa- se negaban a contribuir, aludiendo a sus privilegios y a la

64 Cédula Real refrendada por el Asistente de Sevilla, Sevilla, 12/1/1636. AMMarchena, Libro Registro de Órdenes 69. Acuerdos del 2/1 y 21/7/1636. AMPonferrada, Leg. 5, LA n 3 fs. 366 y 387.

65 Acuerdos del 25/1, 18/2, 17/3 y 17/4/ 1639. Copia de las órdenes, Sevilla, 24/1/1639. AMMarchena, LA n 7 fs. 3, 5, 10, 17 y 32. Relación de la gente que se ha recibido, Cádiz, 19/5/1639. AGS, GA, Leg. 1.261.

66 ARTAZA, M.M. (1998): Rey, Reino y Representación. La Junta General del Reino de Galicia (1599-1834). Madrid, CSIC, pp. 270-272. 
defensa del territorio. ${ }^{67}$ Estas cuestiones también resucitaban viejas desavenencias locales. En 1634 a la villa de Ponferrada la tocó contribuir inicialmente con 16 soldados de los 437 que debía aportar León; pero un mes después se le incrementó el número en otros 3 , tras rehacerse los cómputos debido a que se debió rebajar el número a algunas localidades pequeñas. La villa cumplió, pero en marzo del año siguiente desde León llegaron distintas instancias para que entregara dos hombres que supuestamente faltaban. Los informes eran erróneos y Ponferrada sólo debía entregar un soldado más en sustitución de uno que había muerto por el camino. La villa cumplió, a pesar de que las indagaciones molestaron profundamente al cabildo y reavivaron sus desavenencias con la capital leonesa. ${ }^{68}$

Dentro del sistema, uno de los grandes cambios fue la leva ajustada en 1639, que se conocería como la leva del uno por ciento, la cual -al contrario de lo ocurrido anteriormente- estuvo gestionada por la Junta de Coronelías. ${ }^{69}$ En esta ocasión los cupos fueron más imprecisos, a pesar de que las órdenes indicaban claramente que se debía alistar a uno de cada 100 vecinos, pudiéndose excusar las localidades que no llegaban a los 50 , excluyéndose del cómputo de la vecindad las viudas, los clérigos y los soldados de milicias. ${ }^{70}$ La formulación de la leva era mucho más novedosa y atípica que las anteriores, ante la generalización de la misma y la aparición de algunas excepciones, modelándose las aportaciones a lo largo de varios meses. Como novedad algunos partidos de Castilla la Vieja -como Burgos, Palencia o Valladolid- fueron exceptuados debido a su implicación en el reclutamiento de milicias, y el alojamiento de tropas que habían defendido la frontera de Fuenterrabía. Pero la gestión se extendió espacialmente y se dejaba en manos de los corregidores, que debían hacer frente a cupos menores que en las levas pasadas, aunque eran más los agentes implicados. Se intentó de manera particular que los territorios de las órdenes militares contribuyeran separadamente para que cubrieran en-

67 Cédula de García Sarmiento, Asistente de Sevilla, Sevilla, 10/4/1641. AMMarchena, Libro de Registro de Órdenes 69. Cuentas de Fernando de Madrid sobre los gastos de levantar y conducir 1.266 infantes al presidio de Cádiz, 1639. AGS, CMC $3^{a}$ época, Leg. 1.935 f. 6. Relación de los 8.042 soldados con que sirve el Reino, 11/9/1641. AGS, GA, Leg. 1.387.

68 Acuerdos del $28 / 4,5$ y $27 / 5$ y $24 / 7 / 1634$. Acuerdos del 26/3 y 30/5/1635. AMPonferrada, Legajo 5, LA n 3 fs. 276,279, 282, 292, 325 y 339.

69 Junta de Coroneles, 17/1/1639. AGS, GA, Leg. 1.261.

70 Junta de Coroneles, 10/7/1639. Cédula Real, 1/7/1639. AGS, GA, Leg. 1.258. Listado de los corregidores que participan, s/f. AGS, GA, Leg. 1.277. 
teramente los cupos, generándose quejas y el solapamiento de partidos. ${ }^{71}$ Otra novedad importante fue que con cierto éxito $-y$ fuera de los cupos establecidos en Castilla- se extendió el reclutamiento por la Corona de Aragón. Entre Valencia, Aragón ${ }^{72}$ y Mallorca se reunieron 1.140 soldados, si bien no se tuvieron en cuenta los vecindarios, sino que se establecieron cupos, y al contrario de lo que sucedía en Castilla las tropas se estructuraban en compañías, dirigidas por sus propios capitanes. ${ }^{73}$

El servicio en Castilla se efectuó de manera diferente, y algunos corregidores realizaron nuevos padrones para contabilizar su población. ${ }^{74}$ Pero no se configuró un vecindario general, sino que la mayoría de los corregidores realizaron estimaciones poblacionales y establecieron un cupo. ${ }^{75}$ Algo especialmente evidente para el caso de grandes ciudades como Sevilla o Madrid, en las que nunca se tuvo en cuenta los vecinos reales. Madrid debía contribuir con 400 hombres, a lo que puso enormes pegas. La ciudad intentó contribuir con dinero y se quejó del importante número de milicianos, de genoveses y otros extranjeros que vivían en la capital, y que por lo tanto estaban exentos. De hecho, a duras penas remitió 358 hombres. ${ }^{76}$ Los cupos se cumplieron, e incluso se sobrepasaron, ${ }^{77}$ aunque no siempre los señores remitieron los soldados asignados. ${ }^{78}$ Los corregidores lograron sus objetivos gracias a que utilizaron su poder, ya que se les autorizó el uso

71 Junta de Coroneles, 17/1, 11 y 22/3 y 18/4/1639. AGS, GA, Leg. 1.261.

72 Sobre el reclutamiento en estos territorios: VILA LÓPEZ, C.M. (1979-80): "La aportación valenciana a la guerra con Francia (1635-1640)", Estudis, n 8, pp. 125-142. SOLANO CAMÓN, E. y SANZ CAMAÑES, P. (1998): "La contribución de Aragón en las empresas militares al servicio de los Austrias", Studia Historica. Historia moderna, n 18, pp. 237-264.

73 Junta de Coroneles, 17/1, 11 y 22/3/1639. AGS, GA, Leg. 1.261. Carta del Virrey de Mallorca, 19/6/1639. Carta del Gobernador de Aragón, Zaragoza, 24/5/1639. AGS, GA, Leg. 1.262 .

74 Testimonio del Corregidor de Ronda, 1/3/1639. Fe de la vecindad de Ronda y sus arrabales, 24/1/1639. AGS, GA, Leg. 1.261.

75 Carta del Corregidor de Jaén, 22/12/1638. AGS, GA, Leg. 1.266.

76 Junta de Coroneles, 17/1/1639. Relación de la gente remitida hasta el 10/12/1639. Relación de lo que escriben los corregidores, 1639. AGS, GA, Legs. 1.261, 1.273 y 1.277.

77 Relación de los corregidores a quien se han encargado levas, 1/3/1639. Relación de la gente remitida hasta el 10/12/1639. AGS, GA, Legs. 1.278 y 1.273 .

78 Carta del Corregidor de Granada, 15/5/1639. AGS, GA, Leg. 1.261. SALAS ALMELA, L. (2008): Medina Sidonia. El poder de la aristocracia 1580-1670. Madrid, Marcial Pons, pp.361-362. 
de la fuerza, pidiendo algunos que incluso las autoridades judiciales no tomaran cartas en el asunto y propiciaran la liberación de los apresados. Otros, como el corregidor de León, pidió expresamente que se le permitiese actuar contra los estudiantes que "solo lo son en el nombre", al considerarles ociosos. En algunos casos los municipios pagaron voluntarios. Pero lo habitual fue la aplicación de forzados: alistándose a los penados por delitos leves o capturando a vagabundos, transeúntes y ociosos. Con ello se pretendía evitar la realización de cualquier sorteo que propiciara la salida de hombres casados con una ocupación estable. Los enrolados debían ser retenidos en algún lugar, por lo que algunos corregidores -como el de Málaga- evacuaron de la cárcel a todos los galeotes y esclavos que había para meter en su lugar a los soldados. La utilización de la fuerza no fue un verdadero problema, o una de las principales dudas de los corregidores, pero el tema económico fue uno de los más recurrentes. ${ }^{79}$ Cuestión que ya había sido uno de los grandes problemas localizados en el pasado, ya que muchos bienes de propios de las ciudades estaban embargados. Para resolverlo se determinó que para cubrir los gastos se echara mano a distintas rentas reales cobradas en cada partido, por lo que el reclutamiento no sobrecargaba con más costes a los municipios, allanándose la colaboración de los corregidores y las elites locales. Con esta gran novedad se daba más libertad a los ejecutores para agilizar trámites y concluir la leva, cargando la mayoría de los costes sobre diversos impuestos, especialmente las alcabalas, los Millones y el papel sellado. ${ }^{80}$

La programación de la leva, estimada en 8.079 hombres, también era algo diferente. Por un lado, porque no se esperaba llenar todos los presidios, sino que sólo se pretendía enviar tropas a 6 de ellos -los cuales recibirían más fondos para evitar los problemas del pasado-, los antemurales de la defensa contra Francia: Navarra, Guipúzcoa, Cataluña y Aragón; además de Portugal y Cádiz. ${ }^{81}$ Al quedar la gestión en manos de la Junta de Coroneles, muy pronto ésta dejó de lado las pretensiones iniciales y se centró en reclutar al menos 6.000 hombres, los cuales debían remitirse a La Coruña, Cádiz, Cartagena y Málaga, que servirían para reforzar las posiciones

79 Cartas del Corregidor de Granada, 4/1, 15/2 y 8/3/1639. AGS, GA, Leg. 1.261. Relación de lo que escriben los corregidores, 1639. AGS, GA, Leg. 1.277.

80 Carta del conde de Castrillo, Madrid, 15/11/1640. AGS, GA, Leg. 1.273. Relación del gasto que han hecho los corregidores, 1639. AGS, GA, Leg. 1.274.

81 Consejo de Guerra, 16/2/1639. AGS, GA, Leg. 1.255. 
españolas en Italia y Flandes. ${ }^{82}$ Los informes que valoraban el cumplimiento de los cupos son algo confusos. Los realizados internamente por los secretarios del Consejo de Guerra parecen incompletos, ya que no coinciden con los informes de embarques y llegadas remitidos desde los puertos. Los informes internos, indican que se habrían remitido 4.781 soldados, de los que 4.094 llegarían a los puertos y se admitirían; lo que indica que el $14 \%$ de los enviados no llegó a su destino; estando otros 624 preparados para salir. ${ }^{83}$ Dichos informes no coinciden con los remitidos desde Cádiz, en donde hasta mayo habían entrado 2.157 hombres, casi el doble de los que manejaban los informes internos del Consejo de Guerra; ${ }^{84}$ incluso durante los meses siguientes llegaron más hombres. ${ }^{85}$ Algo parecido a lo que ocurrió en La Coruña y Cartagena. ${ }^{86}$ De hecho, una vez finalizado el servicio se demostró que se necesitaba un cómputo y una verificación más precisa, al ser la mayoría de los informes demasiado simples para indagar qué territorios no habían cumplido. Además, era imposible cotejar los datos, que en demasiadas ocasiones no coincidían al estar en manos de diversos secretarios y juntas. ${ }^{87}$

\section{El Reclutamiento: de las ideas de la Corona a las realidades del reino}

En la propuesta inicial quedaba claro que la Corona buscaba voluntarios, por lo que para motivar su alistamiento se determinaron diferentes privilegios a los soldados y premios a los hijosdalgo que se alistaran, garantizándose algunas ventajas a las personas principales que optaran por servir, como un ascenso más rápido dentro del escalafón. También se estipularon

82 Junta de Coroneles, 17/1/1639. AGS, GA, Leg. 1.261. Relación de la gente que está ajustada para Italia, $s / f$. Relación de las personas con quien se ha ajustado levas por la Junta de Coroneles, 24/2/1639. AGS, GA, Leg. 1.258. Relación de las personas que se han ajustado levas y gente que han remitido, $s / f$. Memorias de la gente ajustada para Flandes y para Italia, s/f. AGS,GA, Leg. 1.277.

83 Relación de los corregidores, 1/3/1639. Relación de la gente remitida, 10/12/1639. AGS, GA, Legs. 1.278 y 1.273

84 Relación de la gente que ha entrado, Cádiz, 23/5/1639. AGS, GA, Leg. 1.261.

85 Relaciones de la gente que hubo en Cádiz, Cádiz, 23/7 y 6/8/1639. AGS, GA, Leg. 1.255.

86 Relaciones de la infantería de nuevas levas, La Coruña, 12/2 y 13/3/1639. Relación de la infantería que se ha recibido, Cartagena, desde $11 / 9$ al 3/10/1639. AGS, GA, Leg. 1.273 y 1.279 .

87 Carta del Conde de Castrillo, Madrid, 15/11/1640. AGS, GA, Leg. 1.273. 
Tabla 3: Evolución de las peticiones de levas para los presidios (16341641)

\begin{tabular}{|c|c|c|c|c|}
\hline & Fecha & Número repartido & Motivos & Destinos \\
\hline $1^{\circ}$ Repartimiento & $3 / 3 / 1634$ & 12.000 & & $\begin{array}{l}\text { La Coruña } 284 \\
\text { Guipúzcoa } 1.084 \\
\text { Navarra } 436 \\
\text { Aragón } 638 \\
\text { Cataluña } 3.439 \\
\text { Portugal } 3.305 \\
\text { Cádiz } 1.494 \\
\text { Larache y La } \\
\text { Mámora } 1.320 \\
\end{array}$ \\
\hline $2 \div$ Repartimiento & $4 / 12 / 1635$ & 5.572 & $\begin{array}{l}\text { 2.064 de los que } \\
\text { faltan de } \\
\text { entregar, y } \\
3.508 \text { de los } \\
\text { huidos y muertos } \\
\text { en los presidios }\end{array}$ & $\begin{array}{l}\text { Cádiz } 472 \\
\text { Portugal } 2.644 \\
\text { Guipúzcoa } 542 \\
\text { Cataluña } 1.914\end{array}$ \\
\hline $3^{\circ}$ Repartimiento & $11 / 6 / 1636$ & 2.000 & $\begin{array}{l}2.000 \text { de los que } \\
\text { faltan de los } \\
\text { otros dos } \\
\text { repartimientos }\end{array}$ & $\begin{array}{l}\text { Portugal } 563 \\
\text { Cádiz, Larache y } \\
\text { La Mámora } 1.012 \\
\text { Gibraltar } 303 \\
\text { Melilla } 122 \\
\end{array}$ \\
\hline $4^{\circ}$ Repartimiento & $10 / 4 / 1637$ & 7.027 & $\begin{array}{l}1.629 \text { de lo que } \\
\text { faltaba del } 3^{\circ} \\
\text { repartimiento, y } \\
5.398 \\
\text { nuevamente }\end{array}$ & $\begin{array}{l}\text { Cataluña } 1.500 \\
\text { Guipúzcoa } 1.000 \\
\text { Galicia } 2.500 \\
\text { Cádiz } 1.500\end{array}$ \\
\hline $\begin{array}{l}\text { 50 Repartimiento } \\
\text { (denominado como } \\
\text { leva de uno por } \\
\text { ciento) }\end{array}$ & $22 / 11 / 1638$ & 8.079 & $\begin{array}{l}\text { Del anterior } \\
\text { faltaron } 1.807\end{array}$ & $\begin{array}{l}\text { Cataluña } 1.500 \\
\text { Cádiz } 2.000 \\
\text { Portugal } 1.500 \\
\text { Guipúzcoa } 2.000 \\
\text { Aragón y } \\
\text { Navarra } 1.073\end{array}$ \\
\hline 6 Repartimiento & $13 / 2 / 1641$ & 8.049 & & \\
\hline Total: & & 42.727 & & \\
\hline
\end{tabular}

Fuente: AGS, GA, Legs. 1.121, 1.132, 1.144 y 1.147. 
premios, favorables cuidados sanitarios, la posibilidad de pasar a los ejércitos de campaña y diversos privilegios que se concederían al jubilarse tras servir 20 años. A pesar de las condiciones ofrecidas, se tenía claro que no se encontrarían muchos voluntarios, por lo que se regularon las diversas fórmulas mediante las cuales las autoridades "echaran mano de la gente ociosa y malentretenida de la república, sin perdonar a nadie", permitiendo que las ciudades se desembarazaran de ellos. Aun así, se recomendaba a las jurisdicciones que procuraran encontrar el número requerido sin quintar a la población, recurso que sólo se pondría en práctica en última instancia. La colaboración de las audiencias y chancillerías del reino era esencial, ya que se permitía que las autoridades locales se pudieran valer de delincuentes y gente ociosa y de mal ejemplo para cumplir con el cupo, intentándose que éstos se alistaran y que nunca volvieran; persiguiéndose a los infractores. Si como último recurso se efectuaba un sorteo, éste debía incidir especialmente entre los solteros o viudos sin hijos, de 17 a 50 años, para evitar que saliera gente pobre o que dejara a sus hijos desamparados. Incluso, para aliviar el servicio, se reguló un sistema de licencias que permitía que tras cinco años los voluntarios pudieran volver a sus casas, mientras que los sorteados podrían licenciarse tras tres años. ${ }^{88}$

En la práctica las autoridades municipales -ante la imposibilidad de captar voluntarios-, debieron completar los cupos alistando forzosamente a distintos sectores sociales como los vagabundos, ociosos, forasteros y jornaleros que estaban de paso, delincuentes o a cualquiera que trastocara el orden de la comunidad. Así se entiende las escasas tensiones generadas por esta clase de reclutamientos y los pocos disturbios y motines que generaron. ${ }^{89}$ Al dar importantes atribuciones de carácter militar a los mediadores locales de las ciudades, éstos empezaron a actuar como reclutadores directos a cambio de aumentar su poder sobre la población, ${ }^{90}$ poniéndose las bases de futuros reclutamientos forzosos por cupos, que ponían las miras en alistar a todos los delincuentes $\mathrm{u}$ ociosos posibles para evitar los sorteos. ${ }^{91} \mathrm{En}$ 1634 la mayoría de los municipios cumplieron enviando malentretenidos, delincuentes por delitos menores y otros maleantes, ya que al ser ésta la primera vez que se realizaba esta clase de reclutamiento estos sujetos se

88 Forma que las provincias han de guardar en juntar la infantería, s/f. Consejo de Guerra, 20/5/1634. AGS, GA, Leg. 1.095.

89 Sobre posteriores sistemas de reclutamiento obligatorio: RODRÍGUEZ HERNÁNDEZ, Los Tambores de Marte..., pp. 145-196.

90 Sobre la gestión en Murcia: RUIZ IBÁÑEZ, J.J. (1995): Las dos caras de Jano. Monarquía, ciudad e individuo Murcia, 1588-1648. Murcia, Ayuntamiento-Universidad de Murcia, pp. 322-327 y $351-361$. 
podían encontrar con facilidad. La ciudad de Sevilla rápidamente informó que no había encontrado ni un solo voluntario, por lo que recogía a los alistados en las cárceles, temiendo que si no se les enviaba por barco a Cádiz la mayoría se fugaría por el camino. ${ }^{92}$ Durante los años que duró el servicio fue habitual que se buscaran hombres en las cárceles, enviando a todos los condenados posibles, por lo que las galeras perdieron remeros. ${ }^{93}$ Los problemas más graves ocurrieron cuando las justicias y ministros locales aprovechaban la coyuntura para imponerse sobre el común y sacar partido de los nuevos gravámenes. Los informes realizados en Jerez de los Caballeros sacaron a la luz los distintos abusos de las autoridades locales, que en vez de intentar apresar a los vagabundos que nada tenían que ofrecer, se encargaban de molestar y presionar a los hombres honrados con oficio conocido, para que éstos pagaran para librarse. En vez de seguir los cupos, se violentaba a cualquiera que pudiera aportar dinero, que se utilizaba para comprar sustitutos forasteros que se encargasen de servir por los municipios del partido, y llenaba los bolsillos de las autoridades. ${ }^{94}$ Las irregularidades abundaron, y en muchos lugares se procedió a contratar a cualquiera que quisiera servir. ${ }^{95}$

Con el paso de los años la acción de las autoridades locales fue esencial para que el reclutamiento tuviera éxito, pero el problema fue determinar quiénes eran ociosos. En muchos casos se realizaban levas arbitrarias que pretendían capturar a los transeúntes, aunque no fueran vecinos del lugar. En 1637 llegaron a Lisboa nueve soldados del cupo que correspondía a la villa de Porcuna, de los que cuatro pertenecían a la jurisdicción de Trujillo, sujetos que se habían trasladado en busca de trabajo, y que habían sido prendidos sin causa alguna; práctica que fue muy frecuente. ${ }^{96}$ También de manera general se establecieron pautas de servicio, y muchas ciudades intentaron que los soldados fueran siempre voluntarios, ante los problemas que ocasionaba apremiar a distintos sujetos a alistarse. Algunos cabildos

91 Carta del corregidor de Salamanca, 26/2/1636. AGS, GA, Leg. 1.207.

92 Junta de la defensa de estos reinos, 3/6/1634. AGS, GA, Leg. 1.095.

93 Consejo de Guerra, 9/10/1637. AGS, GA, Leg. 1.184.

94 Consejo de Guerra, 21/8/1634. Cartas de algunos clérigos de Jerez, 3/8/1634. AGS, GA, Leg. 1.095.

95 Consejo de Guerra, 30/4 y 28/6/1634. AGS, GA, Leg. 1.095.

96 Carta de la Princesa Margarita, Lisboa, 6/8/1637. AGS, GA, Leg. 1.210. 
como el de Burgos -sensible a la pobreza de la tierra y a su creciente despoblación-, intentaban que sólo se enviasen a servir a los sujetos que menos falta hacían en sus comunidades de origen. ${ }^{97}$ Madrid siempre intentó enviar voluntarios, e incluso acudió a asentistas para que se encargaran de reclutarlos, evitándose problemas a cambio de un importante coste económico. ${ }^{98}$

Durante los últimos repartimientos las órdenes fueron más precisas a la hora de indicar la calidad de los soldados, ante la creciente mala disposición de los enviados. En 1641 se pedía expresamente que los soldados no fueran casados o extranjeros -especialmente portugueses, franceses o catalanes-, al estar en guerra con todos ellos. No siempre conocemos datos precisos de los reclutados, pero esporádicamente algunos archivos municipales han conservado esta documentación. En 1641 la villa de Morón de la Frontera debía contribuir con 32 hombres, aunque sólo pudo remitir 28 a Cádiz en dos tropas a lo largo del verano, de los que 11 no se aceptaron (el 38\%) por diversos motivos. Algunos eran demasiado mayores para servir, otros eran portugueses, tenían enfermedades infecciosas -como la tiña- o estaban lisiados, lo que no les hacía aptos. Incluso uno fue rechazado -al presentar una calentura continua, y fístulas por todo el cuerpo-, ante el miedo de que contagiase al resto. ${ }^{99}$ En enero 1642, ante los incumplimientos de la villa, se volvieron a exigir con urgencia 21 hombres. Las nuevas órdenes intentaban luchar contra el fraude, insistiendo en que se debían entregar sujetos sanos que tuvieran una edad aceptable y sin lesión alguna. Se preferían voluntarios; aunque en caso contrario se debía acudir a los vecinos que fueran ociosos o malentretenidos, evitando capturar a los forasteros que estuvieran de paso en la villa por algún motivo justificado. Si con ello no se podía llenar el número se debía proceder al sorteo a través de las parroquias, admitiéndose sustitutos, especialmente si se trataba de vecinos impedidos o con muchos hijos a los que cuidar y alimentar, los cuales podían pasar esta obligación a alguno de ellos. ${ }^{100}$

La villa cumplió enviando en pocas semanas 12 reclutas, de los que sólo uno fue rechazado por ser un emigrante portugués. La rapidez se debió a

97 Acuerdos del 12/11/1635. AMBurgos, LA de 1635 f. 150v-151v.

98 Papel del marqués de Hinojosa sobre las levas, 1637. AGS, GA, Leg. 1.196.

99 Carta del Veedor Francisco Lorenzo de Losada, Cádiz, 17/7/1641. Carta del Contador Matías Ochoa, Cádiz, 17/3/1642. AMMorón, Leg. 649.

100 Cédula de García Sarmiento de Sotomayor, Asistente de Sevilla, Sevilla, 18/1/1642. Cédula Real, Madrid, 4/1/1641. AMMorón, Leg. 649. 
la aplicación a la recluta de 4 sujetos que salían directamente de la cárcel. Todos ellos eran delincuentes menores -como Juan de Barahona, un quinceañero condenado por "hurtar un cochino"-, a los que se conmutó su pena al alistarse. ${ }^{101}$ Del total de 40 que entregó la ciudad, 13 habían sido condenados. Tres de ellos por deserción, ya que habían huido de las tropas de milicias que se habían sacado por la villa para la frontera. Otros penados lo eran por motivos varios. Alonso Coronil, de 30 años, iba preso -a pesar de estar casado-, al ser condenado por la justicia local por "vagamundo y fama de ladrón". Benito Ximénez, de 34 años, había sido procesado por "amenazas y maltratamiento a su mujer, con peligro de su vida". Juan de Alvarado, de 33 años, por robar una yegua -aunque no había pruebas en su contra-, y por tener causa por vagamundo. Manuel Núñez, de 50 años, había sido condenado por fugitivo de la compañía de milicias de la villa que servía en Ayamonte -y haber vuelto "a la vista de todos"-, y por convivir con una mujer casada, y ser un "hombre inquieto, vagamundo y escandaloso". ${ }^{102}$ A Juan Ríos, de 22 años, se le había apresado por "amancebamiento continuado de mucho tiempo", conmutándosele la pena al alistarse. Gonzalo Gutiérrez, de 40 años, también fue apresado por estar amancebado con una mujer casada, con la que había convivido durante más de 10 años. ${ }^{103}$ El carácter forzado de muchos hacía que las tropas fueran enviadas fuertemente custodiadas por hombres armados. El primer grupo de 18 soldados que salió de Morón fue acompañado por un comisario montado, tres alguaciles a caballo y otros dos guardas a pie: un escolta por cada tres soldados. Además, los hombres llevaban 11 pares de esposas, para utilizarlas de dos en dos; gastándose un total de 651 reales. ${ }^{104}$

101 Listado de la tropa, Morón de la Frontera, 22/1/1642. Carta del veedor Juan López, Cádiz, 25/2/1642. AMMorón, Leg. 649.

102 Cédula de García Sarmiento de Sotomayor, Asistente de Sevilla, Sevilla, 10/4/1641. Cédula Real, Madrid, 13/2/1641. Listado de los soldados, Morón de la Frontera, julio 1641. AMMorón, Leg. 649.

103 Listado de los soldados, Morón de la Frontera, 3/8/1641. AMMorón, Leg. 649.

104 Tasación y Auto de los costes, julio 1641. Carta del Veedor Francisco Lorenzo de Losada, Cádiz, 17/7/1641. Carta del contador Matías Ochoa, Cádiz, 17/3/1642. AMMorón, Leg. 649. 
La mayoría de los reclutados decían ser originarios de la villa o los alrededores según las filiaciones que reconocían en los listados; a pesar de lo cual varios fueron rechazados por los oficiales reales de Cádiz por ser portugueses. Respecto a la edad media de los reclutas había mucha más variedad. Más del $60 \%$ eran sujetos de menos de 30 años, aunque también se mandaron en las compañías a 3 sujetos de 50 años o más; sin duda personas demasiado mayores para la milicia, que fueron rechazadas por los veedores de Cádiz. La baja edad media de los reclutas nos indica que muchos habían sido elegidos por no tener oficios ni familia.

Edades de los hombres aportados por Morón de la Frontera (1641-42)

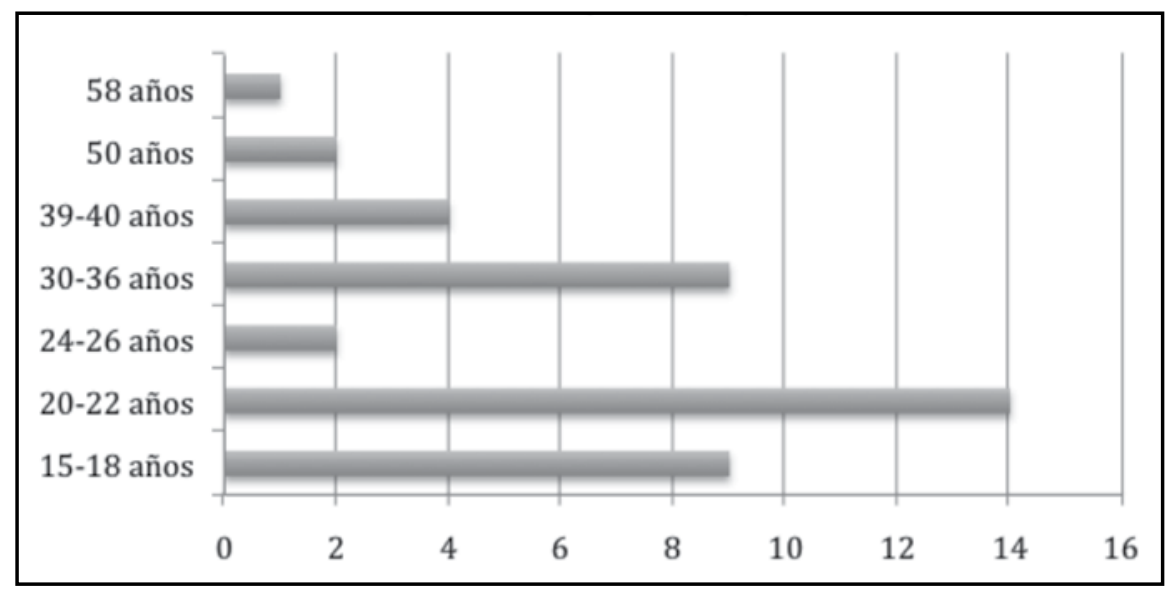

Fuente: AMMorón, Leg. 649.

\section{4. ¿Reclutar los presidios O los ejércitos de la monarquía?}

Los presidios hispanos de Portugal se beneficiaron especialmente de la llegada de nuevos reclutas, ya que desde hacía tiempo faltaban hombres. En febrero de 1634 en los castillos del reino había sólo 695 hombres. ${ }^{105}$ Un año después eran ya 1.335, incluidos los enfermos, gracias a que durante los meses anteriores habían llegado 1.163 bisoños. La calidad de éstos dejaba bastante que desear para los mandos militares, que no confiaban demasiado en su capacidad militar, ya que se necesitaban veteranos para defender adecuadamente el reino y participar en las expediciones marítimas a Brasil. Además, su número se reducía con rapidez debido a las fugas, y especialmente a la mortandad. Entre agosto de 1634 y febrero del 
año siguiente habían muerto en el hospital 55. ${ }^{106} \mathrm{El}$ notable incremento de la dotación permitió que se enviaran refuerzos a los presidios dependientes que mantenían una guarnición española. A finales de año se remitieron 100 hombres a la isla de Madeira y otros 90 a las Azores; algo que hacía tiempo que no era posible. ${ }^{107}$

Gracias a la documentación relativa a la dotación real -mes por mes- presente en Portugal durante 1637, y los informes de llegadas de los reclutas, podemos obtener una imagen bastante precisa de la importancia de la llegada de estos refuerzos, y el papel de los presidios como correas de distribución del poder militar de la monarquía. Según los datos de llegadas, entraron en los presidios 1.171 soldados, aunque faltarían varias partidas por computarse, como la relativa a octubre. ${ }^{108}$ La dotación real del presidio fue variando progresivamente por diferentes factores, siendo básico para comprender su descenso la amplia participación de las tropas en otros frentes. Según las órdenes, entre finales de 1635 y finales de 1637 debían haber llegado teóricamente 3.948 nuevos soldados. ${ }^{109}$ Pero muchos de los recién llegados se remitieron a otros frentes o se embarcaron en la Armada. En octubre de 1636 el duque de Nájera sacó 1.340 infantes de Lisboa para tripular 10 navíos -la mayoría mercantes embargados que carecían de infantería-, que se movilizaban para engrosar la Armada que debía combatir a los franceses. ${ }^{110}$ A comienzos de 1637 se envió un refuerzo de

106 Carta de la Princesa Margarita, Gobernadora de Portugal, Lisboa, 14/2/1635. Carta de Fernando de Toledo, Lisboa, 17/2/1635. Relación de las tropas de infantería, Lisboa, 17/2/1635. Relación de los oficiales y soldados del Tercio, Lisboa, 17/2/1635. Relación de los soldados que han muerto en el hospital, s/f. AGS, GA, Leg. 1.145.

107 Carta de la Princesa Margarita, Gobernadora de Portugal, Lisboa, 3/9/1635. AGS, GA, Leg. 1.140.

108 Varias relaciones de los oficiales y soldados que están de guarnición en Portugal, enero a agosto de 1637. Dos relaciones de las tropas que han entrado en el reino, Lisboa, 11/7 y 20/9/1637. AGS, GA, Leg. 1.195. Relaciones de los oficiales y soldados del tercio, septiembre y noviembre de 1637. Relación de las tropas que han entrado en el castillo, Lisboa, 28/11/1637. AGS, GA, Leg. 1.205.

109 Relación de lo que toca a cada presidio, s/f. Notas del segundo y tercer repartimiento, s/f. AGS, GA, Leg. 1.194.

110 Junta de Armadas, 25/4 y 25/7/1636. AGS, GA, Leg. 3.167. Memoria que se ha sacado para enviar a Fernando de Contreras, s/f. AGS, GA, Leg. 1.194. Carta de la princesa Margarita, Gobernadora de Portugal, Lisboa, 8/10/1637. Relación de la gente de mar y guerra embarcada, Lisboa, 7/10/1637. AGS, GA, Leg. 1.201. 
100 hombres a las Azores. ${ }^{111}$ Pero a lo largo de ese año fundamentalmente los hombres de los presidios fueron reclamados para reforzar las Armadas que se pertrechaban en Lisboa. De hecho, más de una veintena se fugaron al embarcar, llegando a fugarse un cabo de escuadra que estaba de guardia. ${ }^{112}$ Los continuos envíos a otros frentes, y las fugas, justifican que la dotación del presidio no aumentase significativamente -como podemos observar en la gráfica-, lejos de cubrir los 3.640 hombres asignados.

No es fácil valorar en conjunto la contribución real de los distintos repartimientos del reino sobre la evolución general de la guarnición de los presidios, pero sí queda claro que después del primer reparto los siguien-

\section{Presidios de Portugal (1637): relación entre la llegada de nuevos re- clutas y su dotación}

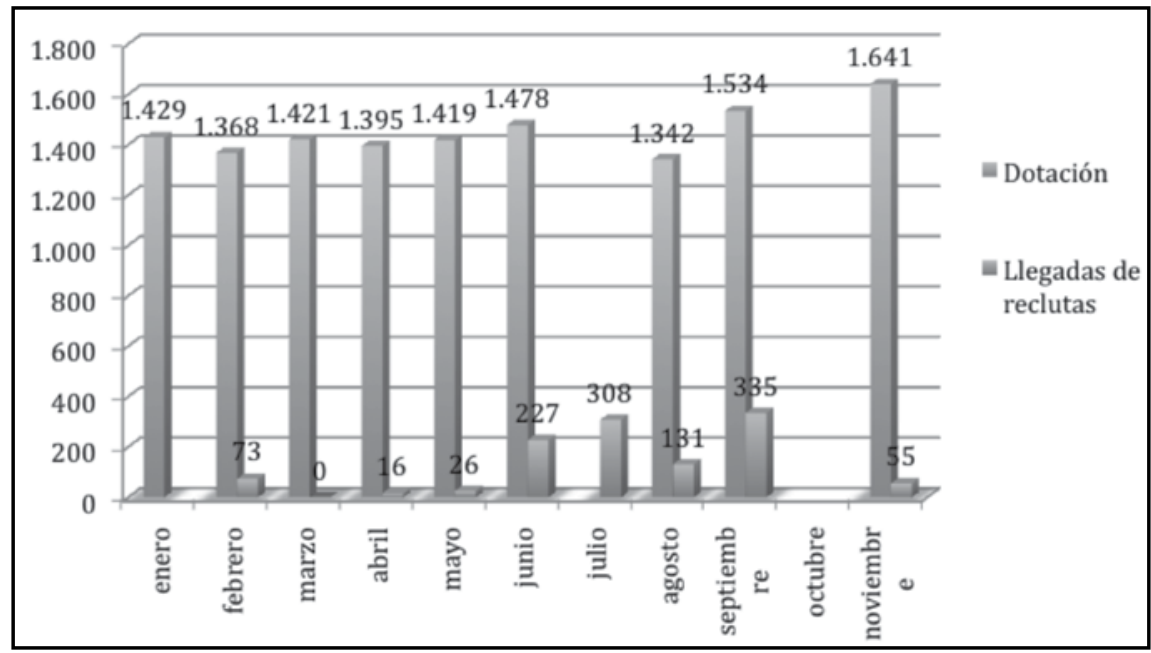

Fuente: AGS, GA, Legs. 1.194, 1.195 y 1.205.

111 Relación de la gente que hay en los presidios, Madrid, 24/3/1637. AGS, GA, Leg. 1.094.

112 Junta de Armadas, 9/2/1636. AGS, GA, Leg. 3.167. Carta de Fernando de Alvia de Castro, Lisboa, 17/1/1637. AGS, GA, Leg. 1.201. Cartas de la princesa Margarita, Gobernadora de Portugal, Lisboa, 11/5, 7 y 14/6/1637. Carta de Tomás de Ibio Calderón, Lisboa, 7/6/1637. AGS, GA, Leg. 1.206. Cartas de Tomás de Ibio Calderón, Lisboa, 3 y 5/7/1637. AGS, GA, Leg. 1.207. 
tes no valoraron o cuantificaron la necesidad real de los presidios. Eso contradecía las bases del servicio realizado por el reino, ya que una vez llegaron los nuevos reclutas a los presidios se debía cuidar el fraude y las plazas supuestas para evitar nuevas levas. Se pretendía que cada dos meses se pasara muestra para saber así los soldados que faltaban y atender a la persecución de los fugitivos, pudiendo contabilizarse cuantos soldados eran necesarios como reemplazo. ${ }^{113}$ Todo ello quedó bajo la vigilancia de la Junta de Presidios, ${ }^{114}$ que periódicamente insistía en tener relaciones pormenorizadas de la gente que faltaba. ${ }^{115}$ Pero en los sucesivos repartos la cuantía de hombres no se fijó en relación a las bajas surgidas. Es cierto, como podemos ver en la tabla adjunta, que los presidios mejoraron sus dotaciones gracias al servicio aprobado por las Cortes, pero su incremento no fue tan notable ante la continua práctica de enviar a parte de las tropas a otros frentes y las numerosas fugas. De hecho, a lo largo de un año podían entrar casi tantos nuevos reclutas como soldados morían, se fugaban o eran licenciados. Entre marzo de 1636 y el mismo mes del año siguiente entraron en Fuenterrabía y San Sebastián 266 nuevos reclutas, frente a los 220 que se dieron de baja, mayoritariamente por fuga. A pesar de los grandes esfuerzos del reino difícilmente los presidios permanecían llenos. ${ }^{116}$

En Cádiz el impacto de la continua llegada de soldados parece que fue menor que en otros presidios, debido a lo poco que las nuevas tropas contribuyeron a reforzar la dotación. Es cierto que en los primeros años las excesivas fugas no ayudaron, pero éstas tendieron a controlarse, a pesar de que las condiciones de vida no cambiaron significativamente. En 1637 algunos oficiales se quejaban de que los nuevos reclutas debían estar encerrados en los castillos, y que en ellos no se les procuraba el alojamiento adecuado, siendo escaso el socorro que se les suministraba. Durante el invierno debieron dormir en el suelo, estando desnudos y descalzos, sin que se pudiera atender su falta de abrigo. Eso producía que muchos quisieran huir y que se tiraran por la muralla para intentar escapar, lo que había producido algunos accidentes y muertes. Aun así las deserciones no estaban

113 Forma que las provincias han de guardar en juntar la infantería. AGS, GA, Leg. 1.095.

114 Sobre esta Junta: BALTAR RODRÍGUEZ, J.F. (1998): Las Juntas de gobierno de la Monarquía Hispánica (S. XVI-XVII). Madrid, Centro de estudios políticos, pp. 377 y ss.

115 Junta de Presidios, 12/12/1634. AGS, GA, Leg. 1.096.

116 Relaciones de las tropas que han entrado en San Sebastián y Fuenterrabía, 9/4 y 1/5/1637. AGS, GA, Legs. 1.195 y 1.197. 
Tabla 4: Dotación teórica y real de los Presidios (1634-1640)

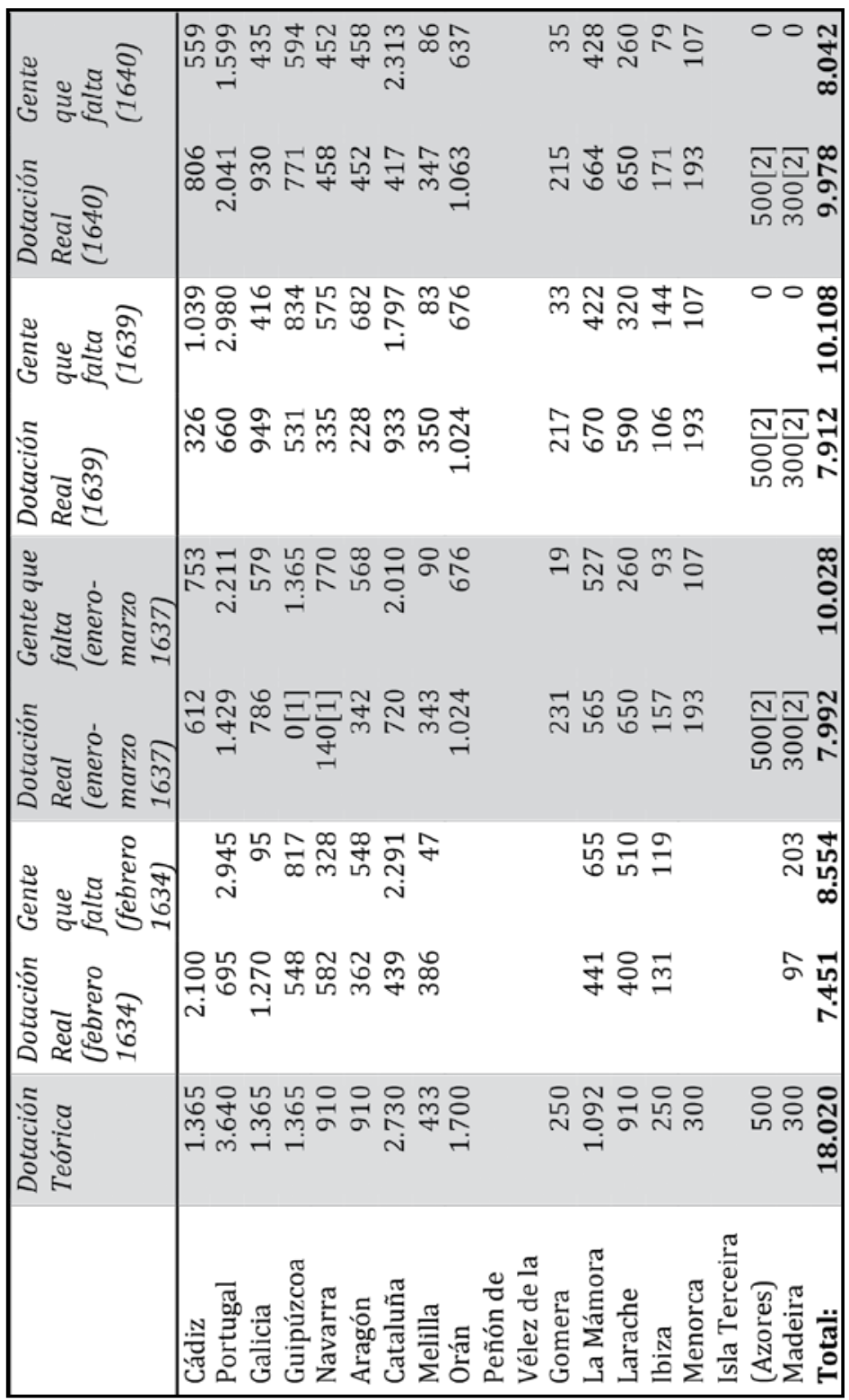

Fuente: AGS, GA, Legs. 1.038, 1.194, 1.095, 1.277 y 1.387. Notas: [1]: Están movilizados con el ejército en la frontera. Según la muestra de junio de 1637, en el ejército de Fuenterrabía había 11 compañías sacadas de distintos presidios: 307 hombres de los presidios de Navarra y Aragón, 495 de los presidios de Guipúzcoa y 272 de los presidios de Galicia: 1.074 en total (Relación de los oficiales y soldados..., Fuenterrabía, 26/6/1637. AGS, GA, Leg. 1.202). [2]: Cifras supuestas. 
siendo tan significativas. En enero de 1637 habían llegado 830 hombres de las levas del reino, de los cuales 300 habían pasado a reforzar Larache y La Mámora, 370 se agregaron a las compañías del presidio y 160 habían huido. ${ }^{117}$ Entre abril y octubre de ese mismo año pudieron entrar en el presidio 506 nuevos reclutas de diferentes levas, de los que sólo uno fue despedido, otro murió y 10 se fugaron; lo que dejaba un balance bastante positivo. Pero en general la dotación media del presidio fluctuó durante todo el año, y dependió demasiado de la llegada de nuevos refuerzos y lo poco que persistían los nuevos reclutas. ${ }^{118}$ En 1639, de los 2.157 hombres remitidos a Cádiz, muy pocos se fugaron, fueron despedidos o murieron: 130 en total. Pero lo más preocupante es que sólo 11 de ellos se habían agregado a las compañías fijas del presidio, y aunque otros 115 estaban todavía en Cádiz -tanto en el hospital como fuera-, éstos estaban a la espera de ser enviados a otros lugares. De hecho 963 se habían remitido a Flandes, 495 a las Indias, 179 habían reforzado la Armada y 264 se habían enviado a los presidios norteafricanos; lo que significaba que 3 de cada 4 se enviaban a servir fuera de la península o la Armada, y que muy pocos realmente estaban reforzando los presidios peninsulares o africanos. ${ }^{119}$ Datos que dejan en evidencia que, especialmente desde 1639, la leva de los presidios se convirtió en un sistema de reclutamiento encubierto para otros destinos.

Ciertamente la permanencia de los soldados no siempre era la deseada, lo que unido a la continua necesidad de la monarquía de reforzar sus posiciones en Europa contribuyó a que buena parte de los reclutados se enviaran fuera de España. Muchos terminaron engrosando los ejércitos de campaña que se formaron en las fronteras peninsulares. Cuando se completaba el cupo de algunos presidios -e incluso sin que éstos estuvieran completos-, los soldados que sobraban en vez de repartirse por el resto de presidios a los que faltaba dotación se solían embarcar en la Armada o se enviaban a los ejércitos de Italia o Flandes. Esa práctica se convirtió en habitual. A finales de 1635 llegaron a Málaga 366 hombres de la leva para Melilla

117 Cartas de Juan de Velasco y de Leonardo Camargo, Cádiz, 18/1 y 1/2/1637. Carta del duque de Medina Sidonia, Sanlúcar de Barrameda, 18/1/1637. AGS, GA, Leg. 1.209.

118 Seis relaciones de los soldados bisoños que han entrado en Cádiz entre abril y mayo, junio, julio, agosto, septiembre y octubre. AGS, GA, Leg. 1.205.

119 Relación de la gente que ha entrado en este presidio de Cádiz, 23/5/1639. AGS, GA, Leg. 1.261 . 
y el Peñón Vélez de la Gomera. Tras enviar a esas dotaciones 150, se dio orden para que los otros 254 que quedaban se enviaran a Italia. ${ }^{120}$

La práctica de tomar prestados hombres de los presidios para otros destinos fue demasiado común y muy confusa. En el verano de 1635 el duque de Cardona avisaba de que esperaba con urgencia 400 hombres de los presidios de Aragón que se le habían prometido para reforzar Cataluña, si bien al mismo tiempo se habían ofrecido al marqués de Villafranca otros 500 de los mismos presidios para reforzar sus galeras. En esos momentos había 350 en la raya de Aragón, pero no se sabía para quién eran. ${ }^{121}$ En otros casos se daba orden de embarcar a parte de los hombres de los presidios en las flotas, a pesar de que no había suficientes. ${ }^{122}$ En 1635 se dio orden para enviar a Flandes a 800 hombres del presidio de Pamplona, tarea imposible ya que no había tantos. ${ }^{123}$ En muchos casos se enviaban tropas de los presidios a los ejércitos de campaña peninsulares o a las fronteras más amenazadas como una medida temporal para intentar reforzar la zona con tropas medianamente preparadas. A comienzos de 1637 se mandaron a la frontera guipuzcoana 400 infantes de los presidios gallegos, los cuales colaboraron activamente en el sitio de Fuenterrabía y las operaciones militares de la región. Tres años después se permitió que estas compañías se reincorporaran a sus destinos, aunque para entonces ya sólo disponían de un puñado de oficiales ante el desgaste padecido. ${ }^{124}$ De hecho, la mayoría de los enviados en 1637 eran nuevos reclutas aportados por el reino de Galicia, que reunió 461 hombres a cargo de los tres primeros repartimientos. En 1637 el $85 \%$ del total seguía en sirviendo al rey: 328 en la Armada, Flandes o la frontera con Francia, y sólo 65 estaban de guarnición en La Coruña, su verdadero destino. ${ }^{125}$

120 Consejo de Guerra, 13/9 y 8/11/1635. AGS, GA, Leg. 1.124. Relación de la infantería embarcada, Barcelona, 27/11/1635. AGS, GA, Leg. 1.125.

121 Carta del duque de Cardona, Perpiñán, 12/7/1635. AGS, GA, Leg. 1.147.

122 Junta de Armadas, 7/7/1636. AGS, GA, Leg. 3.167.

123 Carta del marqués de Valparaíso, Pamplona, 20/4/1635. AGS, GA, Leg. 1.146.

124 Consejo de Guerra, 28/2/1637 y 15/1/1639. Carta del duque de Nochera, Fuenterrabía, 10/3/1637. AGS, GA, Legs. 1.185, 1.255 y 1.200 .

125 Tres relaciones de la infantería que ha entrado en la ciudad a cargo de los repartimientos, La Coruña, 19/4/1637. AGS, GA, Leg. 1.205. 


\section{El final del SeRVicio}

Las Cortes de Castilla prorrogaron el servicio en agosto de 1640, hasta que terminase el servicio económico de los veinticuatro millones asociado, que expiraba en $1644 i^{126}$ asegurándose al reino posteriormente que no se volverían a sacar soldados forzados. ${ }^{127}$ Pero el verdadero elemento decisivo para su final fue que el último repartimiento coincidió con una coyuntura muy diferente, al haber estallado las rebeliones de catalanes y portugueses, colisionando el sistema con los apercibimientos y la salida general de las milicias en las zonas fronterizas, lo que hacía imposible que el reparto se desarrollara de manera adecuada, especialmente en la frontera con Portugal. ${ }^{128}$

Ya antes el sistema estaba herido de muerte, ante los incumplimientos de cupos, ${ }^{129}$ y la extensión de todo tipo de reclutamientos por la geografía castellana. Las levas para los presidios no fueron las únicas que se produjeron en Castilla, ya que las condiciones negociadas en las Cortes no se respetaron, y en la práctica las levas no cesaron, sino más bien se multiplicaron, ante la creciente demanda de soldados. Con el tiempo se vieron los resultados de tan importante actividad, y sus consecuencias demográficas. Según un informe de la ciudad de Sevilla, desde abril de 1634 -cuando se instauró el primer repartimiento- hasta 1641, habían salido de su partido 6.300 hombres, siendo la mayoría prendidos por vagabundos o delincuentes. ${ }^{130}$ Muy pronto las levas hicieron mella, y diferentes autoridades regionales avisaron que año tras año había menos mozos a los que recurrir, ${ }^{131}$ incluso algunos se casaban tras haber sido reunidos en la cárcel para intentar eximirse. ${ }^{132}$

126 MACKAY, Los límites..., p. 71

127 Cédula para que se guarde al reino condición sobre que no se saquen soldados involuntarios para la presidios, Toro, 29/7/1650. BN, ms.934 f. 156

128 Junta de Ejecución, 11/3/1641. AGS, GA, Leg. 1.374.

129 Relación de las provincias a quienes les faltan de entregar soldados de los tres repartimientos que se han hecho, s/f. AGS, GA, Leg. 1.259.

130 Carta de García Sarmiento de Sotomayor, Maestre de Campo General de Sevilla, Sevilla, 13/1/1641. AGS, GA, Leg. 1.383.

131 Carta de Juan de Salazar y Velasco, Burgos, 8/4/1637. AGS, GA, Leg. 1.185.

132 Carta del corregidor de Salamanca, 28/4/1637. AGS, GA, Leg. 1.207. Cédula de García Sarmiento de Sotomayor, Asistente de Sevilla, Sevilla, 10/4/1641. Cédula Real, Madrid, 13/2/1641. AMMorón, Leg. 649. 
La proliferación de levas y servicios fue muy importante. Entre 1640 y 1641 la ciudad de Burgos recibió dos llamamientos para cumplir con nuevos cupos de la leva de los presidios y acudir a los pasados, al mismo tiempo que atendía continuos y nuevos requerimientos militares que la ciudad a duras penas podía soportar ante su "acabamiento y falta de vecinos". En enero de 1640 recibía la orden de reclutar 10 hombres para el Regimiento de Guardia del Conde Duque, al mismo tiempo que la provincia reunía 120 mulas para el ejército y seguía pagando los gastos ocasionados por el alojamiento de soldados napolitanos. En abril se daba orden para que los hijosdalgo salieran formando una compañía de caballos; y en octubre las milicias eran convocadas a acudir a Molina de Aragón. Pero durante ese año el cabildo recibió tres condutas de capitanes que reclutaban voluntarios en la ciudad y otros lugares. Todo ello a pesar de que el primer capitán tuvo tan poco éxito que se debió marchar a otros distritos en busca de reclutas. En 1641 el panorama fue parecido, y a los requerimientos de los presidios se sumó la salida de las milicias en agosto; presentándose en la ciudad cuatro capitanes que pretendían reclutar sus compañías. ${ }^{133}$

Otro gran problema -que se sumaba a que muchos municipios no cumplían los cupos-, estaba en la alta tasa de hombres rechazados; la cual parece que pudo crecer con el tiempo ante la falta de voluntarios útiles. Eso suponía un gasto en balde para los municipios, que debían reponer los hombres no entregados. Entre 1634 y 1635 sabemos que el número de hombres no recibidos en Cádiz, de 2.033 casos contabilizados, ascendió al 8,3\%. ${ }^{134}$ En 1639 entre los 141 remitidos a Barcelona por Cuenca y Soria, otro $8,6 \%$ no fue admitido; siendo bastante reveladores los motivos: ser demasiado jóvenes (4), tener mal el corazón (3), padecer "mal de asma" (1), por loco (1), por estar muy sordo (1), estar tullido de un pie (1), o ser extranjero (1). ${ }^{135}$

A todo ello había que sumar el clamor popular que pretendía que estos reclutamientos finalizasen, ante lo poco efectivos que eran y lo mal vistos que empezaban a estar. Los propios veedores y oficiales reales les permitían la vuelta a sus casas a cambio de dinero, y éstos desertores formaban pequeñas cuadrillas que se dedicaban a habitar despoblados, robar para subsistir, e incluso algunos habían ocupado algunas dependencias de la

133 AMBurgos, LA de 1640 f. 21, 38, 51, 53, 55, 66, 140, 157 y 178; y 1641 f. 50, 68, 75, $82,86,127,163$ y 179

134 Relación de la gente que ha llegado, Cádiz, 31/7/1635. AGS, GA, Leg. 1.147.

135 Relación de la gente que han remitido Soria y Cuenca, Barcelona, 30/4/1640. AGS, GA, Leg. 1.272. 
Alhambra de Granada al no habérselo podido impedir el corregidor. ${ }^{136} \mathrm{~A}$ comienzos de ese año el obispo de Cádiz escribía a Madrid diciendo que en el Castillo de Santa Catalina había 156 mozuelos -de 15 a 16 añosencerrados desde hacía año y medio. Muchachos "arrebañados" de las ciudades de la comarca a título de soldados de leva. Sujetos que por su edad sólo podían servir como mochileros, y que dormían en el suelo sin ningún tipo de abrigo, recibiendo para mantenerse sólo pan y agua. Todos estaban "en carnes", y algunos padecían sarna y otras enfermedades, por lo que muchos estaban en el hospital. El obispo pedía que se les sacase de alli, "aunque sea para el infierno", porque la población comenzaba a aborrecer la milicia. La Junta de Ejecución ordenó su liberación ante la mala prensa que suponía mantenerlos encerrados, queja que empezaba a colmar el vaso. ${ }^{137}$

\section{Conclusiones}

Gran parte de los acuerdos tomados en Cortes de Castilla fueron incumplidos. La recluta de los presidios no acabó con el reclutamiento -y su problemática-, y tampoco acabó con la necesidad de reclutas. Es cierto que la monarquía dejó de enviar capitanes comisionados a las ciudades para que reclutarán directamente en su nombre, pero estos fueron sustituidos por multitud de agentes de la nobleza que se comprometió a formar sus coronelías, y de distintos particulares y asentistas que a cambio de dinero y honores se hicieron cargo del reclutamiento. Intermediarios que provocaron un mayor número de quejas. ${ }^{138}$ Incluso, como se demostró, el reclutamiento aprobado por Castilla no estaba sirviendo para su propia defensa -o la defensa del Norte de África, o los reinos de Navarra, Aragón o Cataluña-, sino especialmente para suministrar reclutas de dudosa calidad a los ejércitos españoles de Italia y Flandes. El esfuerzo militar realizado fundamentalmente por Castilla fue loable, y contribuyó a mejorar las defensas peninsulares -especialmente las de Cataluña-; pero con el tiempo sería un esfuerzo en vano al no destinarse los suficientes recursos para mantener a largo plazo a los hombres que se enviaban.

La leva sería muy importante al marcar un antes y un después dentro de los sistemas de reclutamiento, y allanar el camino a otros métodos coerci-

136 Carta del Corregidor de Granada, 15/5/1639. AGS, GA, Leg. 1.261.

137 Carta del obispo de Cádiz, 3/2/1641. Junta de Ejecución, 19/2/1641. AGS, GA, Leg. 1.374 .

138 Consejo de Guerra, 23/11/1635. AGS, GA, Leg. 1.124. 
tivos que aparecerían posteriormente. Sería la primera recluta obligatoria elaborada en base a cupos distribuidos territorialmente, algo que imitarán otras muchas reclutas en Castilla durante la segunda mitad del siglo XVII. También tendría el dudoso honor de ser la primera leva que intente centrar su atención en alistar de manera general vagabundos, ociosos y penados por delitos leves para intentar así no realizar sorteos o quintar a la población; política que generará pocas resistencias sociales, pero que tendrá como resultado soldados de ínfima calidad muy proclives a la deserción. En contraposición a lo que ocurría con el sistema voluntario tradicional, que no aseguraba resultados, pero sí calidad; esta clase de levas eran efectivas y cubrían cupos humanos importantes que no se podían alcanzar reuniendo voluntarios. Además, la gestión realizada demostrará la enorme potencialidad que tenían los corregidores y presidentes de chancillerías a la hora de abordar reclutamientos, algo que será aprovechado rápidamente. ${ }^{139}$ También el sistema demostró que lo más eficaz para sufragar los gastos era utilizar los impuestos reales que se cobraban in situ, algo que generaba ahorro y evitaba problemas; especialmente si los costes debían ser remitidos directamente por los pagadores del Consejo de Guerra, o recaían en las mismas autoridades municipales. 


\title{
MERCENARIES OR SOLDIERS OF THE FAITH? THE PONTIFICAL ZOUAVES IN THE DEFENSE OF THE ROMAN CHURCH (1860-1870)
}

\author{
¿MERCENARIOS O SOLDADOS DE LA FE? LOS \\ ZUAVOS PONTIFICIOS EN LA DEFENSA DE LA \\ IGLESIA CATÓLICA (1860-1870)
}

\author{
SimON SARLIN \\ Université Paris Nanterre
}

\section{BASTRACT}

From 1861 to 1870, more than 7,000 men came from all over Europe and even from beyond the Atlantic to voluntarily join the Papal army and defend the Holy See against the threat of Italian nationalism. Who were these men and what drove them to abandon their ordinary lives to take up arms in the defense of the Pope? Were they mercenaries in the service of a lost cause or idealistic and heroic combatants ready to sacrifice themselves for the Church, as their contemporaries saw them in contradictory views? Based on letters, journals, memoirs and various archival sources, this paper investigates the motivations and the experience of the Pontifical Zouaves.

Keywords: Italy, Risorgimento, Nationalism, Papal Zouaves, Catholicism, Holy See, War Volunteering, XIXth century.

\section{RESUMEN}

Desde 1861 a 1870 más de 7.000 hombres llegaron procedentes de toda Europa, incluso de más allá del Atlántico, para unirse voluntariamente al ejército papal y defender la Santa Sede contra la amenaza del nacionalismo italiano. ¿Quiénes fueron estos hombres y que les empujó a abandonar sus vidas cotidianas para tomar las armas en defensa del Papa?, ¿fueron mercenarios al servicio de una causa perdida o combatientes idealistas y heroicos listos para sacrificarse por la Iglesia, tal y como los vieron sus contemporáneos en visiones contradictorias? A partir de cartas, diarios, memorias y diferentes fuentes de archivo, este artículo analiza las motivaciones y la experiencia de los zuavos pontificios.

Palabras clave: Italia, Risorgimento, nacionalismo, zuavos papales, catolicismo, Santa Sede, voluntariado de guerra, siglo XIX. 


\section{RESUM}

\section{Mercenaris o soldats de la fe? Els zuaus pontificis en la defensa de l'Església catòlica (1860-1870)}

Des de 1861 a 1870, més de 7.000 homes van venir d'arreu d'Europa i fins i tot de més enllà de l'Atlàntic per unir-se a l'exèrcit papal i defensar la Santa Seu davant l'amenaça del nacionalisme italià. Qui eren aquests homes i què els va fer abandonar les seves vides ordinàries per prendre les armes en defensa del Papa? Van ser mercenaris al servei d'una causa perduda o combatents idealistes i heroics preparats per sacrificar-se per l'Església, tal i com van ser vistos pels seus contemporanis en visions enfrontades? Mitjançant cartes, diaris i memòries, així com diferents fonts arxivístiques, aquest article investiga les motivacions i l'experiència dels zuaves pontificis.

Paraules clau: Itàlia, Risorgimento, nacionalisme, zuaus papals, catolicisme, Santa Seu, voluntariat de guerra, segle XIX 
The photograph was taken in Rome, in 1860, in the workshop of the brothers D'Alessandri, photographers of the papal court. The man who poses in uniform, leaning on a column, wears the characteristic outfit of the Tirailleurs franco-belges, inspired by that of the native troops of the French army in Africa, with its puffy canvas trousers, woolen belt and open waistcoat. The Franco-Belges were a force of Catholic volunteers set up at the beginning of 1860 to protect the Holy See against further attacks of Italian nationalists, following the events of 1859 that had severed two-thirds of the Pontifical State.' Like this man -Joseph-Lovis Guérin, a native of the Nantes, who had engaged in August 1860 and died in the battle of Castelfidardo-, many recruits, most of them anonymous, took the pose in front of the camera in order to get a photographic portrait to be distributed to their relatives at home or to their new companions in arms, as was fashionable at that time among the upper and middle classes. Between 1861 and 1870, more than 7,000 men came from all over Europe and even from beyond the Atlantic to voluntarily join the papal army, for varying periods of time ranging from six months to ten years. ${ }^{2}$ Who were these men and what drove them to abandon their ordinary lives to take up arms in the defense of the Holy See? For their detractors, they were merely mercenaries in the service of a lost cause, who had nothing to do on Italian soil. For the catholic propagandists, the Zouaves -the name they took from 1861-were the incarnation of the devotion of the faithful to the Sovereign Pontiff and defended with heroism and idealistic self-denial a great struggle. At the time of the "Roman Question"

1 On the historical context, see: BEALES, D., and BIAGINI, E. (2002): The Risorgimento and the Unification of Italy. London, Longman, chap. 7; DUGGAN, C. (2008): The Force of Destiny: A History of Italy Since 1796. Boston-New York, Houghton Mifflin Harcourt, chap. 10.

2 ANONYME (1910-1920), Matricule des zouaves pontificaux. Lille, Imp. Ducoulombier. On the history of this force, the bibliography is mainly in French: BITTARD DES PORTES, R. (1894): Histoire des zouaves pontificaux. Paris, Bloud et Barral; CERBELAUD SALAGNAC, G. (1963): Les zouaves pontificaux. Paris, Editions France-Empire; GUÉNEL, J. (1998): La dernière guerre du pape: les zouaves pontificaux au secours du Saint-Siège : 1860-1870. Rennes, Presses universitaires de Rennes. In English: COULOMBE, C. A. (2009) : The Pope's legion : the multinational fighting force that defended the Vatican. Basingstoke, Palgrave Macmillan. 


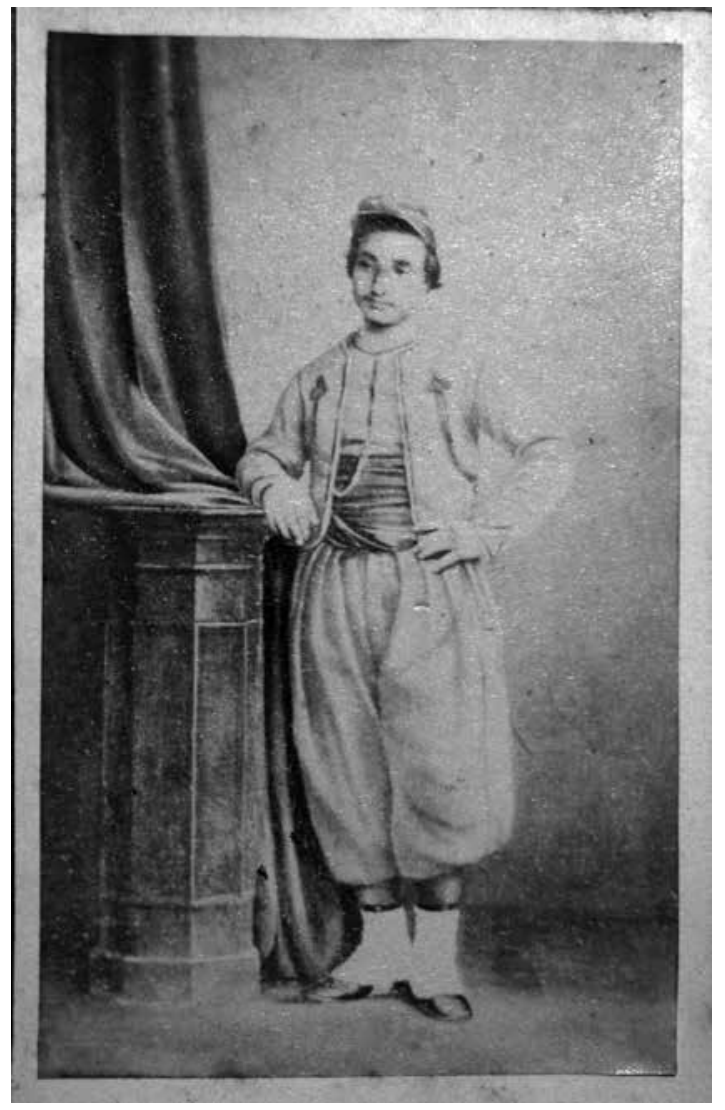

Fig.- 1: Fratelli D'Alessandri, "Joseph-Louis Guérin", Photograph (Albumin), 1860. (Private collection of Amaury de la Pinsonnais)

which divided the opinion of virtually all countries, the gaze way their contemporaries looked on the Zouaves was never neutral.

Throughout contemporary times, the struggles of the counter-revolutionary camp have inspired phenomena of international solidarity. Before 1860, Don Miguel's army in Portugal in 1833-34 and Don Carlos' war in Spain between 1834 and 1840 had also welcomed volunteer fighters from all over Europe to defend the cause of absolutism against liberalism, as would the second Carlist war of $1872-76 .^{3}$ At the same time, when catholic volunteers joined in the service of the Pope, the cause of the King of Naples in exile attracted foreign volunteers, of whom the most famous, the Spaniard José Borges, died shot by the Italian army after five months at the head of the legitimist guerilla in the south of the peninsula ${ }^{4}$ Later, the resistance of 
the Boers in South Africa reactivated the memory of these engagements in the eyes of the French legitimist aristocracy, and the ideological conflicts of the 20th century renewed the ground for international mobilization, especially in the ranks of Franco's army during the Spanish Civil War. ${ }^{5}$ In the light of these various manifestations of the internationalisation of the counterrevolutionary struggle, historians like Jean-Clément Martin and Jordi Canal have spoken of a "white (or black) international" that was born from the civil and political conflicts of the contemporary period and acted on the same grounds and with the same weapons as the liberal or democratic internationals. ${ }^{6}$ During the first half of the $19^{\text {th }}$ century, military volunteers became a model of political engagement that was new and attractive, endowed with a strong emotive and symbolic charge. ${ }^{7}$ Without any doubt, the success of this model owes much to the new conceptions of citizenship and heroism forged by the French Revolution and Romanticism, but the attraction of the volunteer force was not exclusive to the revolutionary ideas and ideals. The new romantic representations of volunteers in arms resonated perfectly with the reactionary mentality and lent itself to the recuperation of traditional values and conceptions such as the ideal of chivalric heroism, the spirit of a crusade or the sense of personal sacrifice.

3 HADENGUE, A : (1925). «Une équipée française au Portugal (1833) d'après des documents inédits». Revue des Questions Historiques, pp. 42-74 and 406-429; COUTANT DE SAISSEVAL, G. (1952): «La chouannerie espagnole, 1832-1936». Bulletin des sciences, arts et lettres de Cholet, pp. 49-55.

4 SARLIN, S. (2009): «Fighting the Risorgimento: foreign volunteers in the conflicts of Southern Italy (1860-1863)». Journal of Modern Italian Studies, n 14 (4), pp. 476-490.

$5 \mathrm{KEENE}$, J. (2001): Fighting for Franco : international volunteers in nationalist Spain during the Spanish Civil War, 1936-1939. London, Leicester University Press.

6 MARTIN, J-C. (2001): La contre-révolution en Europe, XVIIle-XIXe siècles: réalités politiques et sociales, résonances culturelles et idéologiques. Rennes, Presses universitaires de Rennes; CANAL, J. (2011): «Guerres civiles en Europe au XIXe siècle, guerre civile européenne et Internationale blanche». ZUNIGA, J.-P. (ed.), Pratiques du transnational : terrains, preuves, limites. Paris, Centre des recherches historiques, pp. 57-77.

7 For Italy as ground of military volunteerism during the Romantic Age, see: PÉCOUT, G. (2009): «The international armed volunteers: pilgrims of a transnational Risorgimento». Journal of Modern Italian Studies, $\mathrm{n}^{\circ} 14$ (4), pp. 413-426; RIALL, L. (2012): «Men at War: Masculinity and Military Ideals in the Risorgimento». PATRIARCA, S. and RIALL, L. (eds.), The Risorgimento revisited : nationalism and culture in nineteenth-century ltaly. Basingstoke, Palgrave Macmillan, pp. 152-170; More generally on conceptions about military volunteerism: MOSSE, G. (1991): Fallen soldiers: reshaping the memory of the World Wars. Oxford, Oxford University Press. 
Pope's soldiers have inspired abundant apologetic literature that often quotes their letters or their companions' testimonies to illustrate their spirit of sacrifice and their devotion to the Catholic cause. Many of the former volunteers published memoirs, and their relatives gave to the public their journals and correspondence. ${ }^{8}$ These sources should be used with caution, as they -no less than guns- aimed at serving the objectives of the clerical movement by providing young militants and the entire Catholic community with idealistic models. Nevertheless, caution should not lead to reject any idea of sincerity from them. Together with other archival sources -the papers of general Lamoricière (commander of the Roman army in 1860) at the Archives Nationales in Paris; of the Pontifical Ministero delle Armi in Rome; and of various fonds in the Vatican Archivio Segreto- it is possible to investigate the motivations and the experience of those who voluntarily entered the ranks of the Zouaves during the last decade of the Papal Rome.

\section{"We need a bloody protest": an army Of volunteers fOr the Pope}

Firstly, why were volunteers called upon to defend the Holy See? It was during the winter of 1859-1860 that the project to strengthen the Pontifical Army by appealing to the voluntary work of Catholics was conceived. The context was then marked by the developments of Italian nationalism, with the corollary of the precipitation of the "Roman question" (i.e. the maintenance of a temporal power for the papacy). In the wake of the war between Piedmont and Austria in northern Italy, nationalist insurrections during the summer in the Legations, Marches and Umbria had clearly shown the limits of the policy of reliance on the Catholic powers pursued by the papacy since $1815 .{ }^{9}$ The passivity of the latter, especially of Austria, entangled in an internal crisis after its defeat in Italy, and of France, governed by $\mathrm{Na}$ poleon III, torn between its external ambitions and the pressure of Catholic opinion, forced the papal government to rely on its own strength. The deployment of Swiss regiments made possible to regain militarily control of Umbria and the Marches, showing that the Pontifical State could defend itself. However, the situation remained precarious: despite the fact that pa-

8 For an overview, see HARRISON, C. E. (2007): «Zouave Stories: Gender, Catholic Spirituality and French Responses to the Roman Question». Journal of Modern History, n 79 (2), pp. 274 305.

9 VIAENE, V. (2002): «The Roman Question. Catholic Mobilisation and Papal Diplomacy during the Pontificate of Pius IX (1846-1878)». LAMBERTS, E. (ed.), The Black International, 18701878: the Holy See and militant catholicism in Europe. Bruxelles, Institut historique belge de Rome, pp. 135-178. 
pal forces had easily overcome insurgents badly organized and armed, the concentration of various nationalist volunteer troops in Central Italy under the command of Garibaldi caused a much more serious danger. At the same time, diplomatic pressure from London and Paris for reforms of the Pontifical State did not weaken, with the support of liberal public opinion aroused by the indignation in front of the "Perugia massacres".

In 1859, the turn of the internal and international political situation pushed Pius IX towards positions more and more intransigent on the ground of the pontifical temporal. Shortly before his troops entered in Perugia on June $18^{\text {th }}$, the pope issued his encyclical Qui Nuper, in which he reaffirmed the need for the Holy See to retain its "civil power, so that nothing prevents it from exercising, in the interests of religion, his sacred magisterium", and also affirmed his firm determination to "incur all dangers and endure all kind of suffering" before abandoning his apostolic duty. This uncompromising attitude was derived both from his ecclesiological conceptions - i.e. the belief in the necessity of the temporal to ensure the effective and visible independence of the spiritual leader of the Roman Catholic Church-and from political, secondary but effective considerations: the hostility to the liberal government of Turin, the categorical condemnation of liberalism and nationalism, and the awareness of close theoretical and pragmatic links between the defense of the temporal rights of the Holy See and the cause of other Italian sovereigns threatened by the nationalist revolution. ${ }^{10}$ The position of Pius IX didn't vary. The Pope renewed it with firmness on September 26 th (Maximo Animi), the day after the Legations were annexed to Victor Emmanuel's crown, and again on January 19th 1860 (Certe verbis), in response to the semi-official pamphlet Le Pape et le Congrès, which called upon the pope to renounce voluntarily his civil power. The growing intransigence of Pius IX laid down the framework of the policy of the pontifical government led by Cardinal Antonelli, who himself was in favor of a policy of temporization which would not have jeopardized French military protection. The Cardinal rejected any idea of reform without obtaining strong guarantees for the maintenance of the Papal States, or even their restoration in the territories lost during the summer.

Increasingly skeptical about the results to be expected from diplomacy, Pius IX lent an ever more attentive ear to the most intransigent sectors of the Curia and the episcopacy, the Zelanti. Those pleaded for endowing the papacy with material means that would allow it to resist internal and external pressures for reform, and even to dispense with the protection of France. 
An anonymous note of September 1859, preserved in the private archives of Pius IX, clearly sets forth this point of view. ${ }^{11}$ While "the princes were unfaithful and their advisors won over to the revolution," it said, the Holy Father found supporters among "those faithful Catholics who are numerous but wrapped in the unity of their respective nation and must accept in spite of themselves a policy which they disavowed". "For the moment they are weak because they were separated" but should "the Vicar of Jesus Christ make himself heard," it asserted, "we do not doubt that a unanimous cry of faith and obedience will answer him and that thousands of volunteers from all corners of the globe will gather for the fulfillment of a sacred duty. They will be obedient and strong, for they will devoutly bring to the Holy Father the moral power of the profession of faith of many". The author of the note believed that a call from the pope would be enough to make possible the formation of an army of Catholic volunteers of 40 to 50,000 men, enough to bring the rebellious provinces into obedience and to decide "all by one the famous objection of the foreign occupying bodies to the Roman states", for "it would be from then the whole catholicity that would guarantee the independence of the pope".

The principal advocate of this project in the entourage of Pius IX was a Belgian prelate, Bishop Xavier de Mérode. Before embracing his priestly vocation, he had served as an officer in the French army, and since 1850 occupied the function of Secret Chamberlain. A boiling character, at once ardent Monarchist and uncompromising Catholic, he had imposed himself in the Curia as the leader of the Zelanti opposition to the policy of Cardinal Antonelli (and no doubt that he used the project of military reform also to weaken the position of the Secretary of State). ${ }^{12}$ As early as December 1859, Mérode had begun secret negotiations with a French general, Lovis Juchault de Lamoricière, whom he wanted to convince on behalf of Pius IX to become the head of the Pontifical army. The name of Lamoricière was associated with the French conquest of Algeria (Mérode served there under his command), but also with the opposition to the coup d'état of December 1851. In 1859, this choice was clearly a provocation against Napoleon III ("it is a small affront that we give to the emperor", the Belgian prelate would have affirmed). The French general arrived in Rome at the beginning of April 1860, where he was officially appointed Generalissimo of the Pon-

11 ARCHIVIO SEGRetO VATICANO, Archiv. Part. Pio IX, Oggetti Vari, b. 1537 : «Note sur le Saint-Siège» (Turin, 15 September 1859).

12 AUBERT, R. (1956): «Mgr. de Mérode, ministre de la guerre sous Pie IX». Revue générale belge, $n^{\circ} X C I l$, pp. $1102-1116$ and 1316-1332. 
tifical Army, while Mérode took the lead of a newborn Pro-Ministry of Arms. Despite Antonelli's opposition, Mérode-Lamoricière's plan consisted of doubling the size of the Pontifical Army, from 15-16,000 to 25 or 30,000 men. To achieve this result, voluntary enlistment of foreigners was called for, and it had previous precedents in the Roman army. The presence of foreigners had been reinforced in the aftermath of the revolutionary episode of 1849, when it had been necessary in order to rebuild the army without resorting to indigenous recruitment, that was deemed unreliable ${ }^{13}$. A law of 1852 regulated the "conditions and treatment of foreign individuals called by the Holy See to constitute special military bodies".${ }^{14}$ Deposits were opened in France and in the Austrian Empire since, until 1859, the bulk of the volunteers came from Switzerland, Austria and the German States. In 1860, the commitment period was reduced from 4 years to 1 year to facilitate recruitment. The Swiss, Austrians and Germans still constituted the majority of the recruits, and allowed the creation of a battalion of Carabinieri and six battalions of foreign Bersaglieri, in addition to the two regiments of infantry and the two existing battalions of foreign Cacciatori. ${ }^{15}$ The arrival of volunteers from other countries led to the formation of new bodies on the basis of national membership: French and Belgians were regrouped in a battalion of Tiragliatori (known as Franco-Belgians), who at the end of the summer of $1860 \mathrm{had}$ a modest manpower of 450, while a battalion of Saint-Patrick welcomed the 1,300 volunteers sent by Ireland. ${ }^{16}$

The Roman army reached a number of 22,000 in September 1860, when the Piedmontese government-eager to take control of the South where the kingdom of the Two Sicilies had collapsed under the blows of Garibaldithreatened to invade the Pontifical State, taking precisely as a pretext the presence of "foreign mercenaries" in the Roman troops. Faced with an

13 MANCINI BARBIERI, A. (1986): «Nuove ricerche sulla presenza straniera nell'esercito pontificio 1850-1870». Rassegna storica del Risorgimento, $n^{\circ} 73$, pp. 161-186.

14 SEGRETERIA DI STATO (1852). Legge colla quale il governo pontificio viene a determinare le condizioni ed il trattamento degli individui di nazione estera che chiama al servizio della $S$. Sede per costituirne dei corpi militari speciali. Rome, Tip. della Rev. cam. Apostolica.

15 VIGEVANO, A. (1920): La fine dell'esercito pontificio. Rome, Stab. poligr. per l'amministrazione della guerra.

16 On the Irish Battalion, see: O'CARROLL, C. (2014): «The Irish Papal Brigade: Origins, Objectives and Fortunes». BARR, C., FINELLI, M. and O'CONNOR, A. (eds.), Nation, nazione: Irish nationalism and the Italian Risorgimento, 73-95. Dublin, University College Dublin Press; PANCIANI, M. C. (1986): «New Light on the Background to the Irish Participation in the Papal Army of 1860». The Irish Sword. The Journal of the military Society of Ireland, $\mathrm{n}^{\circ} 16$ (64), pp. 155-164. 
army far more powerful in numbers and resources, the Pontifical leaders could only hope for a reversal of the international situation and a conservative reaction from the Catholic powers, which Pius IX and his entourage believed was inevitable. ${ }^{17}$ Without any illusion about the balance of power, the pope hoped that the army commanded by Lamoricière would "resist long enough to allow Europe to intervene before it is confronted with accomplished facts". ${ }^{18}$ Some went further in their calculations and thought that a defeat of the pontifical troops would also serve the cause of the papacy, as it would arouse the emotion of the European Catholics. That was the meaning of what Lamoricière is reported to have said at eve of the battle: "We need a bloody protest". ${ }^{19}$

The history of a transnational voluntary force at the service of the papacy could have ended in October 1860. The crushing defeat of the Roman army and the absence of reaction from the Catholic powers, which resulted in a reduction of the Pontifical State to the mere "Patrimony of St. Peter", completely changed the situation and even greatly questioned the usefulness of maintaining an army of volunteers. The Catholic committees continued nevertheless to encourage the recruitment and departure of volunteers, but wondered who would be responsible for organizing and using them in Rome. Pius IX, for his part, declared in several occasions "that he could not bear a second Castelfidardo" and "that he never wanted to allow anyone to use his name, nor would make any call himself, and that he did not want in the present situation throwing anyone in the midst of perils", but "that he expressed to those who came his gratitude for the sacrifice they made, instructing them to let their parents know that he was giving them his special blessing". ${ }^{20}$ In spite of these hesitations, the Ministero delle Armi formed a new corps of volunteers, with the debris of the Franco-Belgian and Irish battalions, joined by the new recruits, who took the name of "battalion of the Pontifical Zouaves" under the commandant of the French colonel count of Becdelièvre.

17 MARTINA, Pio IX, p. 103.

18 JACINI, S. (1931): II Tramonto del Potere temporale : nelle relazioni degli ambasciatori austriaci a Roma (1860-1870). Bari, Laterza, p. 31.

19 BECDELIÈVRE, L.A. de. (1867): Souvenirs de l'armée pontificale. Paris, Lecoffre fils, p. 65.

20 ARCHIVES NATIONALES, 289AP/76\&78: Armand Chaurand, 7 December 1860 ; Xavier de Mérode, Rome, 26 February 1861, and Gaston de Chevigné, Nantes, 11 March 1861 (reporting a conversation with the Archbishop of Rennes on his return from Rome). 
The raison d'être of this force could no longer be of an offensive nature but a symbolic one. This orientation became clear when a beginning of military reconquest of the Sabine (presumably planned by Mérode himself) was attempted at the end of January 1861. Not only the move was immediately arrested and disavowed by the Pontifical Government, at the request of Antonelli, but the latter claimed and obtained the head of Becdelièvre who was replaced by Colonel Allet, a Swiss and quiet officer who had long been in the service of the Papacy. From this time onwards, the Zouaves were quartered far from the frontier zone, whose defense was assured only by the French troops until their withdrawal in 1865, and their missions were no longer very clear. In 1862, the Zouaves were even employed in the excavation work of Castro Pretorio, in order, as Mérode justified, to "occupy them" and "put them to work to avoid inaction". ${ }^{21}$

Not without some irony, an officer saw as "one of the great miracles of modern times" the maintenance of a body charged with conducting an "armed and inactive protest". ${ }^{22}$ The remoteness of the prospects for action and the vagueness surrounding the missions of the volunteer battalion put an obstacle to the recruitment. From one thousand in 1861, commitments were limited to only two or three hundred in the following years. These arrivals barely compensated for departures and leaves, so that the battalion barely maintained its modest strength (between 620 and 750 men). The implementation of the Convention of September 1864, which planned the withdrawal of French troops (in exchange for the commitment of the Kingdom of Italy to respect the integrity of the Papal State), led to the rekindling of Catholic opinion's mobilization: the number of Zouaves increased to nearly 2,250 in May 1865. ${ }^{23}$ After 1865, new missions were entrusted to them, such as the fight against the brigandage which raged in the south of Latium and which the pontifical government was thus trying to repress more actively, after having long tolerated it. ${ }^{24}$ The Zouaves also participated in the campaign of 1867 that stopped the Garibaldian attempt of invasion at Mentana and Monterotondo. After that dramatic event, the arrivals of volunteers reached a peak in 1867, with more than 3,000 recruits, justifying the passage of the rank of battalion to that of regiment: the Garibaldian invasion had elec-

21 ARCHIVES NATIONALES, 289AP/78:X. de Mérode, Rome, December 1861.

22 Ivi: B. de Morelle, no date (1863).

23 CERBELAUD SALAGNAC, Les zouaves pontificaux, p. 112.

24 GRUAZ, L. (2016): «La répression du brigandage et la lutte contre le choléra : deux exemples de "campagnes militaires" menées par les Zouaves pontificaux dans les États du Pape à la fin du XIXe siècle». Revue Historique des Armées, n 284, pp. 103-112. 
trified Catholic opinion on both sides of the Atlantic. The regiment reached its maximum at the beginning of 1870 with 2,900 fighters. The Zouaves formed the fifth of the Roman army when Rome was invaded by Italian troops and ceased to belong to the Pope.

\section{Mercenaries or Crusaders? A matter of complex motivations}

From January $1^{\text {st }} 1861$ to September $20^{\text {th }} 1870$, the regiment of the Pontifical Zouaves issued about 11,000 enlistments of soldiers and non-commissioned officers and of 250 officers (ie, in view of the re-engagement, about 7,000 men). ${ }^{25}$ What prompted thousands of young people to abandon everything to take up arms in defense of the papacy? For their contemporaries, this question gave rise to two opposing answers, the antinomy of which merely reflected the intense ideological opposition provoked by the "Roman question". For the partisans of Italian unity the Zouaves were merely mercenaries attracted by the lure of gain or the spirit of adventure, while the defenders of the papacy saw in them volunteers who were enamored of religious ideals and ready to sacrifice themselves for the Church.

In 1860 and 1870, the Italian leaders did not hesitate to point the use of "foreign mercenary" to justify their military interventions against the Papacy. When invading the Marches and Umbria, General Manfredo Fanti, who commanded the invading corps, called upon his soldiers to expel "from Italian soil foreign bands rushed from all over Europe" in order to plant "the false flag of a religion they flout". In his order of the day, General Enrico Cialdini vituperated "against a band of foreign drunkards whom the thirst for gold and the desire for pillage have led to our country". On the other hand, Catholic polemicists have not ceased to fight these accusations through the publication of apologetic works, hagiographic biographies or martyrologies that celebrate the idealistic and chivalrous epic of the Zouaves. In a work published in 1861 in homage to the "Martyrs of Castelfidardo", that would end as a true Catholic bestseller (he had known seventeen editions until 1892), Count Anatole de Ségur attacked "the enemies of the Holy See" who "slandered (the volunteers) with the name of mercenaries" and who "transformed into factious attitude the purest, most sincere religious of devotion". For him, the "heroic young men" who fell on the battlefield were "martyrs of the Catholic faith, immortal martyrs of the papacy!" 26 In a chapter ironically entitled "the mercenaries", the journalist Louis Veuillot claimed that it was enough to demonstrate the falsity of ac-

25 ANONYME, Matricule des zouaves pontificaux.

26 SÉGUR, A. de. (1861): Les martyrs de Castelfidardo. Paris, A. Bray, p. 25. 
cusations against volunteers to quote their written letters to their parents. "I have shed my blood for my religion, defending the temporal power of the Holy Father," wrote Louis Gicquel in a letter to his bishop. The young Lanfranc de Beccary, who died in Castelfidardo at the age of 17, had "given his life for justice". At the resolution of Léopold de Lippe, "no human motive was mingled," for he "aspired only to devote himself to a holy cause". ${ }^{27}$ The catholic literature on the Zouaves systematically emphasized the youth of the volunteers, their innocence and virtue, in order to make them models for the Catholic youth, following the same models provided by the life stories of saints and martyrs in use in religious colleges. ${ }^{28}$ The comparison with the Crusaders of the Middle Ages was also common, like in Veuillot's book. "At the call of the threatened Church", Count Gaston du Plessis de Grénédan "set off with chivalric abnegation to take the sack and gun of modern knights". The Belgian captain Georges Guelton "was indeed a son of the crusaders, and Godefroy and Baudoin had said to him: 'Come with us to Palestine"

A careful examination of the sources shows -unsurprisingly- that it is impossible to interpret the commitment of the volunteers to the Pope solely in terms of idealism. The pontifical authorities were aware of the risk of attracting to their service elements that might compromise the image or efficiency of their armed forces, even if the necessity of rapidly filling the ranks of the Roman army has led them to reduce their conditions to the minimum. The Foreign Recruitment Act of 1852, which was in force until 1870, stipulated that volunteers should report spontaneously to the various recruitment deposits, have no obligation to serve in their own country, be in good health, unmarried or widowers without offspring; it also asked the recruits to "profess the Catholic, Apostolic and Roman religion" and to produce a certificate attesting their "moral and political conduct". In order to attract the largest number of candidates, the duration of the appointment was reduced from one year to six months for the Zouaves; on the other hand, financial difficulties of the Pontifical State led to the abolition of the commitment allowance of ten scudi provided by the law of 1852 .

The maintenance of discipline in the corps of volunteers was also an object of constant concern for military authorities. The military penal code in use for foreign regiments indicted sentences for acts of treason and desertion, but also a whole range of offenses including homicide, rape, fire, counterfeiting and smuggling, extortion, theft (with aggravation for the theft of

27 VEUILLOT, E. (1861): Le Piémont dans les États de l'Église: documents et commentaires. Paris, Gaume frères et J. Duprey éditeurs, chap. 5.

28 HARRISON, «Zouave Stories». 
sacred objects) and even the desecration of sacred objects or places. ${ }^{29} \mathrm{Mil}$ itary court registers reveal a significant number of convictions for desertion, "misconduct", sale of military effect, theft or fraud. ${ }^{30}$ In July 1861, Captain Le Caron de Troussures estimated at a hundred the number of refusals or expulsions of the battalion, in reaction to a hostile article by La Presse; such a figure, he said, showed that the Zouaves "would not have anyone improper among them". ${ }^{11}$ In his memoirs, an officer admitted that "the need to send as soon as possible" recruits and the lack of means and time "to organize investigations on the precedents" explained "the lack of men that were experimented, serious, skilled in military art"; but "gradually, as the regularity of the administration was established, we proceeded with more rigor and eliminated all elements more or less suspect" ${ }^{\prime 2}$

In other words, we must emphasize the limits of an interpretation made solely in terms of idealism or opportunism. In an article about Canadian volunteers in the struggles of the Risorgimento, Matteo Sanfilippo emphasizes how "our vision of volunteerism in the $19^{\text {th }}$ century derives in reality from the romantic imagination: whether he is a revolutionary or an uncompromising bigot, the volunteer is always considered an idealist ready to sacrifice himself". The examination of individual realities often shows a more complex picture, in which the volunteers obeyed a skein of motivations among which idealism was only one dimension. Whether they were Garibaldian volunteers (such as Arthur Buies who followed Garibaldi in Sicily in 1860) or the Pope's soldiers, it appears that volunteers could enlist for "the most disparate reasons": in order to flee their creditors, give vent to their spirit of adventure or because they were attracted by the promised rewards. These reasons are not the only ones, "but they must not be forgotten or undervalved" - and they are not necessarily incompatible with the expression of idealistic motives or the pursuit of ideal. ${ }^{33}$

It is difficult to draw a sociological profile of the volunteers, both because the sources provide incomplete information and because the available data show a real diversity. In the first place, those who responded to the call to

29 ARCHIVIO DI STATO DI ROMA, Ministero delle Armi, 1 144. Codice Penale e Militare per uso dei reggimenti esteri (1852).

30 See ARCHIVIO DI STATO DI ROMA, Ministero delle Armi, Rassegne.

31 ARCHIVES NATIONALES, 289AP/78 : Le Caron de Troussures, Anagni, 19 juillet 1861.

32 MAUDUIT, H. de. (2013): Souvenirs d'Henry de Mauduit, zovave pontifical. Saint-Martin-desTilleuls, p. 8.

33 SANFILIPPO, M. (2007): «Fuggitivi e avventurieri: volontari nord-americani tra Garibaldi e Pio IX. Una proposta di ricerca». Ricerche di Storia Politica, $\mathrm{n}^{\circ}$ 1, pp. 67-78. 
arms of the papacy between 1860 and 1870 belonged to all classes of society. The predominance of noble names among the French officers should not be delusive -the Piedmontese general Cugia is said to have exclaimed, commenting on the list of wounded and dead of the Franco-Belgian battalion in Castelfidardo: "What names! It seems like a ball invitation to the court of Louis XIV!" The nobility represented indeed a significant part of the contingent of French volunteers (a fifth in the case of the diocese of Nantes). The bulk of recruits, however, came from the middle and upper-middle classes, although the sources give only sparse indications of the volunteer's origins. Among the dead and wounded Franco-Belgians of Castelfidardo, Joseph-Guérin was the son of innkeepers in Noirmoutier; Paul Saucet belonged to a family of craftsmen of Nantes; Jacques Nalbert was the son of the owner of the Hotel des Missions Aliments in Paris; Louis Gicquel, who was 21 years old who had been an apprentice carpenter.

One social limitation of the recruitment of volunteers was that the transport and equipment were responsibility of the volunteers themselves, that is to say, for a private soldier the sum of 600 francs (the equivalent of the annual wage of a farm worker). For the Guides de Lamoricière, a body of cavalry, the first expense, with mount, harness and armament, amounted to more than $6,000 \mathrm{fr}$, so that there were only rich aristocrats in its ranks. This barrier was partially lowered by the collective material assistance provided by the Catholic committees to the elements of the lower classes or their families. Among the Zouaves was a discreet number of servants and peasants. For B. de Morelle, the latter formed "the fundamental part of the battalion," but they were also those more ready to quit because they felt "the homesickness". ${ }^{34}$ It was mainly in the Dutch contingent that the peasants were most present, with a quarter of the recruits, the second group after the artisans and the petty bourgeoisie. ${ }^{35}$ The plebeian origins of some volunteers have been put forward by Catholic commentators, like the Belgian journalist Guillaume Verspeyen, for whom the fact that "sons of the Crusaders [...] did their duty alongside the son of the craftsmen" was a veritable "miracle of Christian fraternity" that seemed to revive the "first centuries of the Church". Age was another element of diversity. Many volunteers were young, even very young people. Of the 61 volunteers who joined from the diocese of Nantes in 1860, half (32) were under 20 years of age, and more than $80 \%$ were under $25 ; 8$ had not reached the minimum age of 18 years the-

34 B. de Morelle, Rome, 26 December 1862, quoted.

35 ZAAL, W. (1996): De vuist van de paus: de Nederlandse zouaven in Italië, 1860-1870. Nieuwegein, Uitg. Aspekt. 
oretically required by the law of $1852 .{ }^{36}$ Hagiographic Catholic literature emphasized the youthfulness of many volunteers, associating them with the qualities of innocence in order to exalt the value of their sacrifice. "This gentle and delicate adolescent", exclaimed Mgr. Pie in the funeral oration of Georges d'Héliand (who fell in Castelfidardo at 19), was "the model of fervor and innocence". "The young soldier", wrote the Marquis de Segur, "was full of youth and health, he radiated life, innocence, and beauty". Like Georges Miyonnet, Lanfranc de Beccary was 17 when he joined the papal army, "just emerging from childhood," and in him "a soul as a hero" was clad in "an adolescent body". Alfège de Beaudiez "died at the age of 20 [...] in all the flower of youth". Alfred de Nanteuil, who died at the age of 21 , bore the "triple crown of youth, beauty, and virtue" ${ }^{37}$ But other volunteers abandoned, on the contrary, a well-established life. Philippe de Tournon, aged 40, was "rich, considered, married". The average age was also higher among those who dropped out of a military career in the army of their country of origin or a foreign army.

Religiosity is another variable that is difficult to measure. Many young volunteers had just left the benches of religious colleges: the most prolific, that of St. Francis Xavier held by the Jesuits at Vannes in Brittany, sent no less than 120 pupils between 1860 and 1870 . Some clerics have even taken up arms, but their number is marginal -between 1860 and 1870 there were 10 or so former seminarians and a novice of the Society of Jesus. On the other hand, more than 130 Zouaves entered the religious orders after their engagement in the Pontifical Army, with a predilection for missionary missions, and became Jesuits, Lazarists, priests of Foreign Missions, Missionaries of the Sacred Heart or White Fathers in Africa. There are, however, some indications that religious beliefs animated most of the volunteers, such as attendance at the religious ceremonies (military masses every Sunday and holydays, prayers every night at the barracks, retreats), or the formation of groups of piety (Congregations of the Blessed Virgin, Perpetual Adoration of the Blessed Sacrement, or Conferences of St. Vincent de Paul). ${ }^{38}$ Neither ideology nor social origin, education and age are the only variables to be taken into account in order to understand voluntary commitments: social bonds play an important role in the dynamics that lead an individual to commit himself. This is illustrated by the contribution made by religious

36 ANONYME, Matricule des zouaves pontificaux.

37 SÉGUR, Les martyrs de Castelfidardo, pp. 154, 129 and 95.

38 ALLARD, J.-S. (1880): Les zouaves pontificaux ou Journal de Mgr Daniel aumônier des Zouaves. Nantes, Bourgeois. 
colleges to the contingent of volunteers, which can be explained by two phenomena: the fact that the religious colleges played an crucial role in the formation and the transmission of a clerical culture based on uncompromising combat for Catholicism and political conservatism; and the driving effect of solidarity or emulation between classmates. Other logics of networks and driving effects have been at work. The aristocratic clienteles appear when, as in the Mauges or the Mayenne, the map of castles and that of recruitments can be superimposed. Elsewhere, it is the parochial dynamics and the strength of the ecclesiastical framework that play a decisive part. That is so in the little parish of Campbon in Brittany, which, with its 4,500 inhabitants, sent no less than 29 volunteers, where played the combined action of Vicar Dabin and that of the old Marquis de Coislin (who at the age of 59 asked in 1860 to engage as a private soldier). Geldrop, a small town of 2000 souls in North Brabant (Holland), had 20 soldiers in the Pope's army in 1868. Enlistment among the Zouaves has often been a family affair, and among them there are whole bunches of brothers, cousins, uncles and nephews -such as the four brothers Charette, the many Villèle, Sioc'han de Kersabiec, Cathelineau, Villiers de I'Isle-Adam and other great noble families. "It could be said now that there is no army where there are as many family affairs as in that of the Holy Father: and this crusade would have served only to develop the family spirit, it would already be something," wrote Captain Le Caron de Troussure. ${ }^{39}$

The use of armed volunteering was not really a novelty in the Catholic-Conservative camp. During the 1830s and 1840s, in Portugal and Spain, volunteers were engaged in the service of the causes of Dom Miguel and Don Carlos. To those who accused Spaniard José Borges of having landed in Calabria in 1860 to combat Italian unification, the Catholic journalist Charles Garnier replied that the Legitimists had "sowed enough drops of their blood on the various beaches of the world, in order not to reproach Borges for not being stingy with his own", and that "they finally realized that the revolutionaries of all countries were making common cause, and that solidarity should be opposed to solidarity". ${ }^{40}$ Although these mobilizations had mostly a "political" character in favor of the thrones threatened by the revolution, the struggle against "impiety" was part of the slogans of the traditionalist militants, and the Church had often supported those strug-

39 Le Caron de Troussure, Anagni, 19 July 1861, quoted.

40 GARNIER, C. (1861): Le Général Borgès. Paris, E. Dentu, p. 29. 
gles. Political conservatism was not without an echo in the mobilization of the Catholic world in favor of the papacy. On his way to Rome, Henri de Cathelineau, grandson of the Vendean Généralissime, was going to "crush the revolutionary hydra and save society". ${ }^{41}$ We have already noted the presence among the officers of Zouaves with great names of the French legitimist aristocracy, to which were added, after 1868, the Carlist exiles around their pretender Don Alfonso de Bourbon. The pontifical authorities had not ignored the risk of a political instrumentalisation of voluntary service in the pope's army and tried to prevent too noisy political protests, especially for fear of antagonizing the French government. The refusal opposed to Cathelineau and his project of "Crusaders of St Peter", an army corps both religious and military on the model of the chivalrous orders of the Middle Ages, was explained by reasons of internal discipline but also because of the political problem it would have posed for Napoleon III: it was perilous to grant a command to someone who represented the Legitimist party in France and who was suspected of wanting "to revive the legitimist party by the formation of an order of Crusaders gathered under the flag of religion". ${ }^{42}$

The success of the Catholic mobilization of the 1860s can also be explained by evolutions specific to Catholicism that during the first half of the century gave rise to a first form of Catholic internationalism, oriented behind the slogans of uncompromising Catholicism and the defense of the papacy. Throughout Western Europe, secularization had produced intense conflagrations between churches and states, which have embraced all spheres of social life in real "Culture Wars". ${ }^{43}$ The various combats of Catholics in the 1830 s and 1840s -for freedom of education in France and Belgium, for emancipation in Ireland and Prussia, for Greek and Polish independenceshad given rise in every country to an organized Catholic movement using modern means of mobilization, in which the laity occupied a more active place, at the head of committees and newspapers. Most of the members of the committees set up in 1860 for the financial collections and the recruitment of volunteers in defense of the papacy (Oeuvre du Denier de Saint-Pierre

41 CATHELINEAU, V. de (1909): Le général comte de Cathelineau: chevalier de la Légion d'honneur, commandeur de l'ordre de Pie IX, chevalier de la Tour et de l'Épée et de Don Miguel de Portugal : sa vie et ses mémoires. Rome-Paris-Bruxelles, Desclée De Brouwer, p. 131.

42 ARCHIVIO SEgRetO VATICANO, Archiv. Part. Pio IX_Oggetti Vari_1638. Progetti Cathelineau.

43 CLARK, C., and KAISER, W. (ed.) (2003): Culture Wars. Secular-Catholic Conflict in Nineteenth-Century Europe. Cambridge, Cambridge University Press. 
in Belgium, Comité de Saint Pierre in France, Committee of St. Michael in Germany, Central Committee of Montreal in 1868) had a long past of clerical militancy. At the same time, the Catholic world underwent a process of standardization through a movement of centralization of the Church and the encouragement given to the universal cults (the Sacred Heart, the Virgin, the "Roman" saints). This devotional uniformity "gave expression to a borderless economy of salvation that powerfully helped Catholics to reimagine themselves as a transnational community in the modern world". ${ }^{44}$ The figure of the pope -"vicar of Jesus Christ" and "supreme pontiff of the universal Church"- had occupied an increasingly important place on the horizon of Catholics, thanks to an active campaign of ultramontanes, and has given birth to a genuine devotion to the pope sometimes pouring into what Mgr. Landriot (a Gallican prelate) denounced as mere "idolatry". Many in 1860 had the impression that the mobilization of the Catholic world revived the spirit of crusade dropped in Late Modernity. The enemies of the Church were no longer "the ferocious hordes" which threatened to invade Europe to spread Islam, according to the most uncompromising Bishop of Poitiers, Mgr. Pie, but the new and implacable barbarians "who rejected the reign of God on Earth", the apostles of a "politics without God". The commitment of the Zouaves was thus the incarnation of an uncompromising struggle for which the Catholics of the whole world were to unite their forces.

\section{A multinational force in hostile terRain, OR the challenges of COHEsion}

The Zouaves formed a truly international force. No less than 21 nationalities were represented, but among them the largest contingents were provided by the French and the Dutch, followed by the Belgians, the Swiss, the Germans and the Italians. In May 1865, of the 2.251 men, the national groups were consisting in 857 Dutch (38\%), 651 French (29\%), 485 Belgians $(22 \%)$ and 146 from other countries $(5 \%) .{ }^{45}$ After the episode of Mentana (1867), an opinion campaign tried to launch the recruitment of volunteers across the Atlantic. In Canada, Bishop Ignace Bourget, the ultramontane bishop of Montreal, supported his appeal on the publication of the Pontifical Brief of 17 November (in which Pius IX praised the courage and value of his troops who had been able to stop "i funesti nemici del nome cattolico") and on the example of the Canadian pontifical Zouave, Alfred La Rocque,

44 VIAENE, V. (2012): «Nineteenth-Century Catholic Internationalism and Its Predecessor». GREEN, A. and VIAENE, V. (eds.), Religious Internationals in the Modern World: Globalization and Faith Communities since 1750. Basingstoke, Palgrave Macmillan, p. 89.

45 CERBELAUD SALAGNAC, Les zouaves pontificaux, p. 112. 
wounded during the campaign. A recruiting office was set up in the early days of 1868 and soon received more than 800 engagements, but limited means of arming and transport lowered the number of actual recruits to 240. For reasons not well known, the four American archbishops discarded a similar initiative in the United States. ${ }^{46}$

Maintaining the cohesion of such a heterogeneous force was not an easy task, especially since a social dimension was added to differences in nationality and language. While many French volunteers were inexperienced young people from upper-class families, including many aristocratic offsprings, or military officers that belonged to the same milieux, recruits from Belgium or Holland had a large number of peasants who spoke only Flemish, or former soldiers who had no experience of command. The French were thus overrepresented in the command, among the non-commissioned officers (132 against 42 Belgians and 22 Dutch) and even more among the officers (36 against 6 Belgians and no Dutchman). This situation could only produce tensions on both sides. In a report to the Paris Committee, the French captain Charette complained of the "numberless recriminations" of the Dutch who demanded promotions, which he deemed impossible to satisfy because, if those were "active, intelligent, hard-working soldiers", it was difficult to "find among them the elements needed to form cadres"; as for the (Flemish) Belgians, the French officer wrote, "I defy anyone to find an officer among them" ${ }^{47}$ If the defense of the papal State gathered the volunteers under the banner of Pius IX, it did not obliterate cultural and social prejudices, as evidenced by a letter written in 1866 by Joseph Rialan, a young bourgeois from Brittany (a son of a sollicitor). He was afraid by the influx of new recruits being mostly made up of Flemish and the "French element" becoming a minority: "It follows that, if this continues, we will hear only the Flemish language spoken, which may be beautiful and agreeable to the inhabitants of Brussels and Ghent, but has the privilege of tearing my ears. Also I would like to see the French arrive here". ${ }^{48}$

Internal cohesion was not the only factor weighing on the life of the Zouaves. The relations with the rest of components of the Roman army constituted another. On the one hand, the Zouaves received all kinds of attention of the pontifical leaders, who saw in them the window of the Catholic mobi-

46 MARRARO, H. (1944): «Canadian and American Zouaves in the Papal Army, 1868-1870». CCHA Report, $\mathrm{n}^{\circ} 12$ (45), pp. 83-102.

47 CERBELAUD SALAGNAC, Les zouaves pontificaux, p. 112.

48 OHEIX, R. (1868) : Joseph Rialan, sergent aux Zouaves pontificaux. Paris, J. Lecoffre, p. 151. 
lization on behalf of the papacy. The choice of their uniform, which mixed the costume of the native troops of Africa and of the French infantry, among all the models proposed to the Ministry of Arms, held both practical reasons -the trousers puffed more adapted to the moves of the infantry and to the Roman heat- and of aesthetic considerations which should make of the uniform a constituent element of the identity and the image of the Zouaves: "it will be beautiful, it will attract people", assured Colonel de Becdelièvre to defend his model. ${ }^{49}$ For the same reason, however, and due to both the susceptibilities of the French military command and the initial difficulties of organization, the Zouaves were kept in an isolated position and confined to unimportant missions. The cantonment of the troops between Anagni and the convent of Saint Paul Outside the Walls on the outskirts of Rome, devoid of tactical sense, had the advantage of "proving that [the papal authorities] are no longer afraid to produce the Zouaves in broad daylight, and to destroy this opinion, that they did not dare to show to anyone this battalion of volunteers so unruly and ill-kept" ${ }^{50}$ To compensate for the semi-abandonment of the volunteer corps, Pius IX went several times to visit his soldiers for assuring them of his interest. In May 1862, the organization of a large military camp at Porto d'Anzio was to enable the Zovaves to parade before the pope, surrounded by his cardinals, and had the effect of establishing a "truly cordial entente" with the other foreign and indigenous bodies. The Pope regularly received in the Vatican the officers and families of the soldiers who had died in service, and handed over signed photographs with autographs praising their abnegation. After the midnight mass of 1863, Pius IX addressed the officers present, saying: "You are the representatives of the army, of the Pope's little army. You are part of this army for justice. So you are truly the army of God". ${ }^{51}$

The Zouaves served a state whose legitimacy was contested by a section of its population, and the opinion of the locals about them reflected these divisions, as well as a more general mistrust about the presence of foreigners. They therefore operated largely in hostile terrain, as evidenced by the frequency of cases of assault or assassination attempted on the volunteers. The first victim was a Belgian, the young Count Alfred de Limminghe, murdered in Rome under dubious circumstances, whose death many wanted to make a political affair. "The Zouaves spread imprudent rumours", warned B. de

49 BECDELIÈVRE, Souvenirs de l'armée pontificale, p. 55.

50 Le Caron de Troussure, Anagni, 26 October 1861, quoted.

51 ALLARD, Les zouaves pontificaux, p. 106-107. 
Corcelle, because such stories risked "making people believe that Rome is a horribly agitated place" and discourage families from letting their children enroll. ${ }^{52}$ The peculiar uniform of the Zouaves made them easy targets in the streets of Rome. "They murder prodigiously here," wrote the Belgian volunteer Alexander de la Faille de Leverghem a few months later, after four assaults in two days and in the middle of the street. He himself never "went out alone and always with his pistol in his pocket," nor "allowed himself to be approached at a distance where he could receive a stab". ${ }^{53}$ In 1867 two young Roman workers with nationalistic ideas chose a barracks of the Borgo Santo Spirito where Zouaves lived to carry out a bomb attack intended to kick off a Garibaldian insurrection, killing 23 soldiers. They were immediately arrested and condemned to death for the crime of lese-majesté with the other conspirators, and executed the following year, in spite of the intervention of Victor Emmanuel himself. For their part, some Zouaves did not hesitate to express their royalist opinions and to attack the "patriots". In December 1863 a brawl between foreign soldiers of the Dragoons" squadron and inhabitants in a cafe in Castel Gandolfo ended in an armed clash between the Pontifical soldiers and the French gendarmerie sent to the scene, with some dead and wounded. Administrative records often contain complaints from local authorities and the ecclesiastical hierarchy about the behavior of drunken soldiers, often involved in altercations with locals or with the Frenchmen of the expeditionary force.

The main peril that concerned the discipline of the corps of volunteers, however, was not the hostility of the populations or the disagreements between nationalities: it was boredom. A former soldier recalled that the garrison at Anagni "was none but frisky". "In the first weeks the conscripts were not too bored, for the military training, vigorously pushed, left them little leisure; but once incorporated, it happened to us, as to everybody, to be in a hurry to leave". The soldiers killed time by going on excursions "in the surrounding countryside, or on the nearby peaks, to enjoy the picturesque sites and beautiful points of view that were not wanting in the country", or visiting the local sanctuaries and the villages reachable by foot. ${ }^{54}$ The garrison life was uncomfortable especially for young people who had no prior military

52 ARCHIVES NATIONALES, 289AP/78 : Corcelle, Rome, 19 avril 1861.

53 LORETTE, J. (1966): «Documents sur la question romaine : la correspondance du volontaire pontifical Alexandre de la Faille de Leverghem». Risorgimento, n 9, pp. 122-23.

54 DELAPORTE, V. (1905): Le P. Pierre Le Tallec, zovave pontifical, docteur du Collège Romain, jésuite (1843-1903). Saint-Brieuc, R. Prud'homme, pp. 34-36. 
experience. At St. Paul, the Zouaves were confined "in an old convent of famous unhealthiness, especially during the heat, but which freezes in the winter." 55 For lack of means, the worn uniforms were not replaced and soon the Zouaves were covered with "rags". The cantonment in the Roman outskirts had at least the advantage that "the neighborhood of Rome allows the young people [...] to see the city, visit the churches, etc., that is a happy diversion". ${ }^{56}$

The remoteness of the perspectives of action, the vagueness surrounding its missions and the boredom of the garrison life directly affected the cohesion of the troop. At the end of its first year of operation, "the Pope's little army [...] tired of its leisure, without future or prospect, wondered what was its role", and "many young people were thinking about retirement". ${ }^{57}$ The main reason for the young men's departure was "lassitude and its too long duration of a life they had only embraced for a moment". Many people felt the "homesickness". If the number of those who requested a final leave was still limited, "others more often would take temporary leave, for a month or two", which should not be granted too scantily "for fear of disgusting the postulant and to lose it altogether." ${ }^{\prime 58}$ The hemorrhage continued in 1862 and there was, according to one officer, "nothing to do to prevent these departures". In order to stop it, Zouaves were allowed to re-engage for a month only but, "in spite of this measure, there are many who leave". 59 A library was set up to "give a little nourishment to spirits weighed down by idleness", and the expense of 600 to 800 francs for the purchase of books and newspapers seemed quite justified because this library was "an important resource" for volunteers. ${ }^{60}$ During religious retreats, preachers of renown were invited: Bishops Pie, Dreux-Brézé, Berthaud, Dupanloup, Mermillod or Le Cosquer had addressed the Zouaves. In spite of all these efforts, in 1863 again "the battalion of the Zouaves diminishes every day" because "voluntary recruitment [...] cannot compensate for the vacuum produced by the leaves", and the situation "may give rise to fear of a near dissolution". By the end of 1864, the battalion's strength was "decreasing rather than increasing" ${ }^{61}$ In 1865-66, the struggle against brigandage in the province

55 Le Caron de Troussures, Anagni, 26 October 1861, quoted.

56 B. de Morelle, Rome, no date (1863), quoted.

57 ARCHIVES NATIONALES, 289AP/78 : C. de Latreiche, Lorète, 18 September 1861.

58 ARCHIVES NATIONALES, 289AP/78 : Le Caron de Troussures, Anagni, 26 October 1861.

59 ARCHIVES NATIONALES, 289AP/78 : B. de Morelle, Rome, 26 December 1862.

60 ARCHIVES NATIONALES, 289AP/78 : Lamoricière, «Affaires de Rome» (c. 1863).

61 ARCHIVES NATIONALES, 289AP/78 : Latreiche, Rome, 20 February \& 20 October 1863, 29 December 1864. 
of Velletri offered "a happy diversion" to the idleness, but it was ungrateful, for it obliged the troop to go on continual marches on rugged terrain and often with no purpose for the bands of brigands almost never allowed to be reached. ${ }^{62}$ After the campaign of 1867, the regiment regained its garrison life, but the fear of a nationalist insurrection or a European war deemed imminent kept the spirits alert.

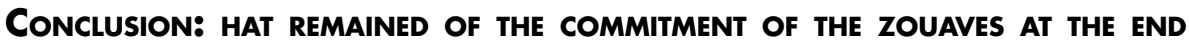 OF THE CENTURY?}

In 1867, in the aftermath of the Mentana and Monterotondo battles, Pius IX had erected a monument in the Roman cemetery of the Verano in honor of all the pontifical soldiers who had fallen for the defense of the Holy See. Since the end of 1861, this cemetery had received the remains of Zouaves dead during their service in the Papal State. In 1862, the tomb of Achille de Bligny, who died of illness during the summer at the military hospital in $\mathrm{Ma}$ rino, had even been monumentalized: it was surmounted by a statue of the volunteer lying as a giant, his hands crossed on his saber. The monument erected in 1867, designed by Virginio Vespignani, was formed by a high octagonal base, set on two steps, crowned by alternating semi-circular or triangular tympana, flanked by acroteria, and surmounted by a sculptural marble group, made by the sculptor Vincenzo Lucardi, that depicted St. Peter in the act of delivering the sword to a crusader, with a Latin inscription saying "accipe sanctum gladium munus a deo in quo deiicies adversarios populi mei israel" (Take this holy sword as a gift from God in order to overthrow the adversaries of Israel). The 7 meters high monument was made of bronze and white marble. On the basis of stood a pedestal decorated with the allegorical figures of Faith and Fortitude, and on each prospect of the octagon, the names of all who had died in battle. The message was clear: the Zouaves were new crusaders who had put their swords at the service of religion, ready to go so far as to sacrifice their lives, and the Roman Church had found in them a bulwark against the revolution. This homage of stone to the volunteers, through the memory of their dead, sublimated the reality of an armed engagement whose importance had been more symbolic than military. Actually, diseases were by far the leading cause of mortality among the Zouaves, far ahead from heroic death on the battlefield to which many volunteers aspired. On the whole, among all the Zouaves that died in service (476), only one fifth (68) lost their lives by fighting in

62 CHARETTE DE LA CONTRIE, A. (1876): Souvenir du régiment des zouaves pontificaux. Rome 1860-1870, France 1870-1871. Notes et récits. Tours, Impr. Mame, p. 21-24. 
1867 or 1870 ; the vast majority succumbed to diseases such as smallpox, cholera, typhoid or malaria. The peak of mortality occurred in 1868, with 152 deaths, a year in which there was no fighting. ${ }^{63}$ However, these figures are not surprising for the armies of that time. And if the Pontifical forces had been able to face the attempt to invade an irregular troop in 1867, neither the Zouaves nor the small Roman army as a whole were able to delay more than a few hours the advance of the regular army of Victor Emmanuel in 1870. Only the diplomatic and military protection of France, undermined by the collapse of the imperial regime, had been the basis of the survival of the Papal State during the ten years after the proclamation of the Kingdom of Italy.

Despite their modest military contribution, the decadal experience of the Pontifical Zouaves was of great symbolic importance. The Italian government's decision to dissolve their corps and to expel them to their respective countries immediately after the seizure of Rome is the best proof. The formation of a corps of volunteers in arms firstly testified the rise of a Catholic internationalism capable of mobilizing by all means on behalf of the uncompromising struggle against secularization that was crystallized by the defense of the papacy and based on national clerical movements united by transnational solidarity. From the Catholic mobilization of the $1860 \mathrm{~s}$ emerged new political and military commitments. A large part of the Zouaves dismissed in September 1870 engaged in the Franco-Prussian war, under the standard of the Virgin and the French flag, while others joined the Don Carlos camp in Spain in the hope of restoring the traditional monarchy beyond the Pyrenees. ${ }^{64}$ At the very moment when the Pontifical State was living its twilight and representatives of the Catholic world flocked to Rome to prepare the council of 1870, plans were made for international coordination, a 'Black internationale' led by a network of laity activists organised by a permanent office whose goal was to act openly at the head of a new crusade to restore the "social reign of Jesus Christ" -not thought armed fights anymore but with the same weapons and in direct rivalry with the Workers' Internationale. ${ }^{65}$ For more than two decades, the captain Charette animated in France the association of the former Zouaves and volunteers

63 GUÉNEL, J. (1995): «Service de santé, morbidité et mortalité dans le régiment des zouaves pontificaux en Italie (1861-1870)». Histoire des sciences médicales, XXIX/3, pp. 261-269.

64 LAUNAY, M. (1996): "Charette après Charette : des zouaves pontificaux aux volontaires de I'Ouest (1860-1871)». Enquêtes et documents, n²3, pp. 127-134. 
of the West, that the republican police suspected of being the nucleus of a paramilitary organization to be ready to support the hoped return of the Legitimate claimant on the throne. In 1885 , for the $25^{\text {th }}$ anniversary of the creation of the regiment, Charette exclaimed in his castle of La Basse-Motte in Brittany: "Does this mean that our silver wedding is the last act of our legend? [...] As Colonel d'Albiousse said, 'As long as there is a cross and a sword in France, we have the right to hope.' How many times did we believe that everything was lost, and then a fact, on which we could not count, arose, and we found ourselves together, ready to fight and to die, if necessary, for God and the Fatherland, because we have no right to belie our legend!" 66 At the end of the century, international solidarity in favor of the Boer peasants in the struggle against Protestant and industrial England was not without echo with the commitment of the Zouaves and, still more, the wars of Vendée, in a continuity embodied by the presence of French and Ducth former soldiers of Pius IX among the foreign fighters.

After 1870, the memory of the commitment of the Zouaves continued dividing and inspiring opposing interpretations. On the one hand the clerical circles celebrated the epic of the pope's soldiers through the publication of memoirs, apologetic works or bulletins (such as L'Avant-Garde, published in France from 1892 to 1907). On the other hand the "official" memory in united Italy had engraved in the marble the imputation of mercenarism. In Rome, which became the capital of the unitary state, the epigraphs hostile to the pope's soldiers flourished: "mercenaries of the pope" ["mercenari pontifici", on the Salario bridge], "foreign mercenaries" ["mercenari stranieri", on the Verano Monument], "hired, base and ferocious mercenaries" ["prezzolati, vili e feroci mercenari", on Ajani Palace where patriots had resisted Zouaves who had been sent to arrest them], "foreign militias of mercenaries who defended the temporal power of Popes" (on the Garibaldian ossuary of the Janiculum). No experience of international armed volunteerism, however, has escaped this ambivalence in the eyes of their contemporaries: had not Garibaldi been described by his opponents at the same time as a filibuster or a condottiere, an adventurer, a braggart soldier or a brave with an empty head? This ambivalence merely reflected the ideological divisions of conflicts that were both civil wars and episodes of a vaster international ideological struggle. The interpretation of volunteering from a Manichean point of view must be disregarded, as its motivations use to be complex on an individual scale: idealism, opportunism or thirst for 
adventures are mixed in to varying degrees, without excluding one another. The experience of the pontifical volunteers between 1860 and 1870 is not exempt from this rule. Seen from a different perspective, it participates in a romantic conception of political commitment based on the notion of fraternity and international solidarity and on the mobility of small committed groups that fed international armed volunteerism throughout the century and after, of which all political groups have taken part.

\section{BibLIOGRAPHY}

ALLARD, J.-S. (1880): Les zouaves pontificaux ou Journal de Mgr Daniel aumônier des Zouaves. Nantes, Bourgeois.

ANONYME (1910-1920), Matricule des zouaves pontificaux. Lille, Imp. Ducoulombier.

AUBERT, R. (1956). « Mgr. de Mérode, ministre de la guerre sous Pie IX ». Revue générale belge, XCIl, pp. 1102-1116 \& 1316-1332.

BEALES, D., and Biagini, E. (2002). The Risorgimento and the Unification of Italy. Londres, Longman.

BECDELIÈVRE, L.-A. de. (1867). Souvenirs de l'armée pontificale. Paris, Lecoffre fils.

BITTARD DES PORTES, R. (1894). Histoire des zouaves pontificaux. Paris, Bloud et Barral.

CANAL, J. (201 1). "Guerres civiles en Europe au XIXe siècle, guerre civile européenne et Internationale blanche ». At ZUNIGA, J.-P. (ed), Pratiques du transnational : terrains, preuves, limites. Paris, Centre des recherches historiques, pp. 57-77.

CATHELINEAU, V. de (1909). Le général comte de Cathelineau: chevalier de la Légion d'honneur, commandeur de l'ordre de Pie IX, chevalier de la Tour et de l'Épée et de Don Miguel de Portugal : sa vie et ses mémoires. Rome-Paris-Bruxelles, Desclée De Brouwer.

CERBELAUd SALAGNAC, G. (1963). Les zouaves pontificaux. Paris, Editions France-Empire.

CHARETTE DE LA CONTRIE, A. (1876). Souvenir du régiment des zouaves pontificaux. Rome 1860-1870, France 1870-1871. Notes et récits. Tours, Impr. Mame.

CLARK, C., and KAISER, W., (ed.) (2003). Culture Wars Secular-Catholic Conflict in Nineteenth-Century Europe. Cambridge, Cambridge University Press.

COULOMBE, C. A. (2009). The Pope's legion: the multinational fighting force that defended the Vatican. Basingstoke, Palgrave Macmillan. 
COUTANT DE SAISSEVAL, G. (1952). " La chouannerie espagnole, $1832-$ 1936 ». Bulletin des sciences, arts et lettres de Cholet, pp. 49-55.

DELAPORTE, V. (1905). Le P. Pierre Le Tallec, zouave pontifical, docteur du Collège Romain, jésuite (1843-1903). Saint-Brieuc, R. Prud'homme.

DUGGAN, C. (2008). The Force of Destiny: A History of Italy Since 1796. Boston-New York, Houghton Mifflin Harcourt.

GARNIER, C. (1861). Le Général Borgès. Paris, E. Dentu.

GRUAZ, L. (2016). "La répression du brigandage et la lutte contre le choléra: deux exemples de "campagnes militaires" menées par les Zouaves pontificaux dans les États du Pape à la fin du XIXe siècle ». Revue Historique des Armées, n.284, pp 103-112.

GUÉNEL, J. (1998). La dernière guerre du pape : les zouaves pontificaux au secours du Saint-Siège : 1860-1870. Rennes, Presses universitaires de Rennes.

-. (1995). «Service de santé, morbidité et mortalité dans le régiment des zouaves pontificaux en Italie (1861-1870) ». Histoire des sciences médicales, XXIX/3, pp. 261-269.

HARRISON, C. E. (2007). «Zouave Stories: Gender, Catholic Spirituality and French Responses to the Roman Question ». Journal of Modern History, n.79/2, pp. 274-305.

HADENGUE, A. (1925). «Une équipée française au Portugal (1833) d'après des documents inédits ». Revue des Questions Historiques, pp. 42-74 \& 406-429.

JACINI, S. (1931). II Tramonto del Potere temporale : nelle relazioni degli ambasciatori austriaci a Roma (1860-1870). Bari, Laterza.

KEENE, J. (2001). Fighting for Franco : international volunteers in nationalist Spain during the Spanish Civil War, 1936-1939. London, Leicester University Press.

LAMBERTS, E. (2002). The Black International, 1870-1878: the Holy See and militant catholicism in Europe. Bruxelles, Institut historique belge de Rome.

LAUNAY, M. (1996). "Charette après Charette : des zouaves pontificaux aux volontaires de l'Ouest (1860-1871) ». Enquêtes et documents, n.23, pp. 127-134.

LORETTE, J. (1966). "Documents sur la question romaine : la correspondance du volontaire pontifical Alexandre de la Faille de Leverghem ». Risorgimento, n.9, pp. 103-167.

MANCINI BARBIERI, A. (1986). « Nuove ricerche sulla presenza straniera 
nell'esercito pontificio 1850-1870 ». Rassegna storica del Risorgimento, n.73/2, pp. 161-186.

MARRARO, H. (1944). "Canadian and American Zouaves in the Papal Army, 1868-1870 ». CCHA Report, n. 12/45, pp. 83-102.

MARTIN, J-C. (2001). La contre-révolution en Europe, XVIIle-XIXe siècles : réalités politiques et sociales, résonances culturelles et idéologiques. Rennes, Presses universitaires de Rennes.

MARTINA, G. (1986). Pio IX. 2, 1851-1866. Rome, Ed. Pont. Univ. Gregoriana.

MAUDUIT, H. de. (2013). Souvenirs d'Henry de Mauduit, zouave pontifical. Saint-Martin-des-Tilleuls.

MOSSE, G. (1991). Fallen soldiers: reshaping the memory of the World Wars. Oxford, Oxford University Press.

NOUAILLE-DEGORCE, P. (2005). " Les volontaires de l'ouest : histoire et souvenir, de la guerre de 1870-1871 à nos jours ». Nantes, Université de Nantes.

O'CARROLL, C. (2014). "The Irish Papal Brigade: Origins, Objectives and Fortunes ». At BARR, C., FINELLI, M. and O'CONNOR, A. (ed.) Nation, nazione: Irish nationalism and the Italian Risorgimento, 73-95. Dublin, University College Dublin Press.

OHEIX, R., (1868). Joseph Rialan, sergent aux Zouaves pontificaux. Paris, J. Lecoffre.

PANCIANI, M. C. (1986). «New Light on the Background to the Irish Participation in the Papal Army of 1860 ». The Irish Sword. The Journal of the military Society of Ireland, n. 16/64, pp. 155-164.

PÉCOUT, G. (2009). «The international armed volunteers: pilgrims of a transnational Risorgimento ». Journal of Modern Italian Studies, n. 14/4, pp. 413-426.

RIALL, L. (2012). "Men at War: Masculinity and Military Ideals in the Risorgimento ». At PATRIARCA, S. and RIALL, L. (ed.) The Risorgimento revisited: nationalism and culture in nineteenth-century Italy. Basingstokev Palgrave Macmillan, pp. 152-170.

SANFILIPPO, M. (2007). « Fuggitivi e avventurieri: volontari nord-americani tra Garibaldi e Pio IX. Una proposta di ricerca ». Ricerche di Storia Politica, n. 1, pp. 67-78.

SARLIN, S. (2009). "Fighting the Risorgimento: foreign volunteers in the conflicts of Southern Italy (1860-1863) ». Journal of Modern Italian Studies, n. 14/4, pp. 476-490. 
SEGRETERIA DI STATO (1852). Legge colla quale il governo pontificio viene a determinare le condizioni ed il trattamento degli individui di nazione estera che chiama al servizio della S. Sede per costituirne dei corpi militari speciali. Rome, Tip. della Rev. cam. apostolica.

SÉGUR, A. de. (1861). Les martyrs de Castelfidardo. Paris, A. Bray.

VEUILLOT, E. (1861). Le Piémont dans les États de l'Église: documents et commentaires. Paris, Gaume frères et J. Duprey éditeurs.

VIAENE, V. (2002). «The Roman Question. Catholic Mobilisation and Papal Diplomacy during the Pontificate of Pius IX (1846-1878) ». At LAMBERTS, E. (ed.) The Black International, 1870-1878: the Holy See and militant catholicism in Europe. Bruxelles, Institut historique belge de Rome, pp. 135-178. - (2012). « Nineteenth-Century Catholic Internationalism and Its Predecessor ». At GREEN, A. and VIAENE, V. (ed.), Religious Internationals in the Modern World: Globalization and Faith Communities since 1750. Basingstoke, Palgrave Macmillan, pp. 82-1 10.

VIGEVANO, A. (1920). La fine dell'esercito pontificio. Rome, Stab. poligr. per l'amministrazione della guerra.

ZAAL, W. (1996). De vuist van de paus: de Nederlandse zouaven in Italië, 1860-1870. Nieuwegein, Uitg. Aspekt. 


\section{DE TRABAJADORES A SOLDADOS: TRABAJO FORZADO Y CONSCRIPCIÓN EN LA GUINEA ESPAÑOLA Y LA NIGERIA ORIENTAL, 1930-1970'}

\section{WORKERS TO SOLDIERS: COERCED LABOR AND CONSCRIPTION IN SPANISH GUINEA AND EASTERN NIGERIA, 1930-1970}

Samuel Fury Daly

Duke University

\section{RESUMEN}

Este artículo conecta dos formas de coacción que raras veces son analizadas de forma conjunta en los estudios sociales y de la guerra. Se trata de la experiencia de la mano de obra forzosa emigrante y la experiencia de ser soldado. Los nigerianos orientales, y especialmente los del grupo étnico igbo, fueron sometidos a estas dos formas de coerción en los años 60, que para los muchos hombres que las experimentaron quedaron relacionadas entre sí. El reclutamiento para labores agrícolas en la isla de Fernando Po, en la Guinea española, desde los años 30 a los 60 y el reclutamiento en el ejército de la República secesionista de Biafra durante la Guerra Civil nigeriana (1967-1970) fueron fenómenos contemporáneos entre sí, siguiendo en ambos casos patrones muy similares de violencia y arbitrariedad. Analizar ambos episodios de la historia de la Nigeria oriental en un solo marco interpretativo sugiere que, para aquéllos implicados, la línea entre el servicio militar y el trabajo forzoso fue tenue.

Palabras clave: Biafra, Nigeria, Guinea Ecuatorial, trabajo, modo de hacer la guerra

\section{ABASTRACT}

This article connects two forms of compulsion which are seldom considered together in studies of war and society. These are the experience of coerced migrant labor, and the experience of being a soldier. Eastern Nigerians, and especially members of the lgbo ethnic group, were subjected to these two distinct forms of coerced in the 1960s, which to many of the men who experienced them were related to one another. Recruitment for agricultural labor on the island of Fernando Po in Spanish Guinea between the 1930s and 1960s and recruitment into the army of the secessionist Republic of Biafra during the $\mathrm{Ni}$ gerian Civil War (1967-1970) were contemporaneous with one another, and they followed similar patterns of violence and arbitrariness. Considering these two episodes in eastern Nigeria's history in one frame suggests that, to those involved, the line between military service and coerced labor was indistinct.

Keywords: Biafra, Nigeria, Equatorial Guinea, labor, warfare.

1 Traducción realizada por David Alegre Lorenz. 


\section{RESUM \\ De treballadors a soldats: treball forçat i reclutament a la Guinea Espanyola i la Nigèria oriental, 1930-1970}

Aquest article connecta dues formes de coacció que poques vegades són analitzades de forma conjunta en els estudis socials i de la guerra. Es tracta de la experiència de la mà d'obra forçosa emigrant i l'experiència de ser soldat. Els nigerians orientals, $i$ especialment els del grup ètnic igbo, van ser sotmesos a les dues formes de coerció durant els anys 60, que van quedar relacionades entre sí en el cas de molts homes que van experimentar-les. El reclutament per a treballs agrícoles a la illa de Fernando Po, part de la Guinea espanyola, des dels anys 30 als $60 \mathrm{i}$ el reclutament dins de l'exèrcit de la República secessionista de Biafra durant la Guerra Civil nigeriana (1967-1970) van ser fets contemporanis entre sí, seguint en els dos casos patrons molt semblants de violència i arbitrarietat. Analitzar ambdós episodis de la història de Nigèria oriental en un sol marc interpretatiu suggereix que, per aquells implicats, la línia entre el servei militar i el treball forçat va ser molt borrosa.

Paraules clau: Biafra, Nigèria, Guinea Equatorial, treball, mode de fer la guerra. 
En una entrevista realizada en 2014, un veterano del ejército secesionista de la República de Biafra recordaba su experiencia como soldado raso durante la guerra civil nigeriana. A sus ojos aparecía como un periodo de grandes privaciones y dificultades, tanto que su patriotismo hacia el nuevo país quedó rápidamente ensombrecido por las condiciones de su servicio militar. Reclutado en un mercado a finales de 1968, fue sometido a un breve y brutal periodo de adiestramiento en un campamento militar del ejército cerca de Orlu, destinado a una unidad de jóvenes conscriptos y enviado al frente. Una vez allí estuvo ocupado la mayor parte del tiempo en cavar trincheras. Tal y como le ocurrió a muchos otros conscriptos, no recibió ni un uniforme ni un arma, al tiempo que se le ordenó compartir un rifle con otros tres hombres. La comida era escasa, sus movimientos eran estrictamente controlados y era humillado de forma habitual por sus superiores. "Sin embargo", recordaba, "nada de aquello me resultaba extraño, ya que había estado en Fernando Po" . ${ }^{2}$ Así pues, la conexión que establecía este antiguo soldado entre su servicio militar y su anterior experiencia como trabajador emigrante en las plantaciones de cacao de la Guinea española, frente a la costa de Nigeria oriental, sugiere una continuidad entre el trabajo forzoso y la vida del soldado que probablemente compartió con muchos otros reclutas.

La historia de la emigración laboral de los igbo a Fernando Po ha permanecido en el olvido durante mucho tiempo, sin embargo esta historia jugó un pequeño aunque notable papel en la historia de la guerra civil de $\mathrm{Ni}$ geria. Para muchos de los que apoyaron la declaración de independencia de Biafra, la percepción de haber sido "abandonados" por los gobiernos británico y nigeriano en Fernando Po contribuyó a aportar un argumento convincente para la secesión de la República de Biafra frente a Nigeria. Por lo general, los argumentos sobre el fracaso del gobierno nigeriano a la hora de proteger la vida y los intereses de los igbos fueron movilizados en relación a los actos de violencia étnica que tuvieron lugar al norte de Nigeria en 1966 contra dicha comunidad. Sin embargo, la experiencia de los igbos en la Guinea española también estaba presente en la mente de

2 Entrevista con Johnson Okeke, Okpara Avenue, Enugu, 10 de agosto de 2014. 
muchos de los habitantes de Biafra. Este artículo no defiende que existiera una línea directa que condujera de los sucesos de Fernando Po al estallido de la guerra civil en Nigeria. No obstante, es importante tener en cuenta las diferentes vías a través de las cuales la larga y agónica crisis de la emigración de los igbos a Fernando Po dio lugar a los marcos de referencia de los igbos y a su particular modo de entender su lugar en Nigeria. Además, para algunos soldados biafreños su estancia en el ejército de Biafra y su experiencia como trabajadores forzosos en la Guinea española estaban interconectadas. Esto pone de relieve de qué modo la conscripción y el trabajo forzoso pueden llegar a confundirse entre sí, al menos para aquellos que experimentaron ambos. Así pues, por medio de documentación procedente de los archivos del consulado británico en Fernando Po este artículo describe la experiencia de los igbos que fueron trasladados a la Guinea española como trabajadores entre los años 30 y 60 . A continuación, cambiando el foco a la propia Nigeria oriental analiza los mecanismos de reclutamiento en el ejército de la secesionista República de Biafra en el marco de la guerra civil nigeriana (1967-1970), identificando el solapamiento entre estos dos regímenes de "trabajo" forzoso -uno económico y el otro militar.

Habitualmente, la guerra civil de Nigeria es recordada como un conflicto en que los mercenarios jugaron un papel importante, especialmente en el bando biafrano. De hecho, en los primeros dieciocho meses de conflicto el gobierno de Biafra experimentó con el uso de mercenarios, incluyendo europeos, americanos, sudafricanos y rodesios. Sin embargo, rápidamente los líderes militares biafranos se volvieron críticos frente a la presencia de mercenarios; una serie de fracasos tácticos y actos de insubordinación, junto con el alto coste de utilizar "soldados de fortuna" de origen foráneo dejaron claro que la guerra no podría ganarse por un ejército liderado por un puñado de extranjeros -al menos algunos de ellos eran insensatos e impulsivos. Una versión ampliamente divulgada cuenta que el jefe de estado de Biafra decidió expulsar a los mercenarios en 1968 después de ser reprendido por uno de ellos, quien a su vez se encontraba claramente bajo los efectos del alcohol. El papel de esos mercenarios extranjeros, extravagante al igual que lo fue su comportamiento en líneas generales, fue exagerado en las crónicas periodísticas de la guerra, algo que ha continuado vivo dentro de muchos relatos históricos de Biafra. Sin embargo, en lo que se refiere a la comprensión del conflicto, fue mucho más importante la experiencia de los soldados ordinarios de origen biafrano, muchos de los cuales eran conscriptos que por lo general no atraían la atención de la prensa internacional. Son estos mercenarios, más que los mercenarios que ocuparon los titulares en la época, quienes se sitúan en el centro el presente análisis. 
Ligar la historia de la emigración laboral a Fernando Po y la guerra civil de Nigeria modifica la amplia historia de la emigración africana por motivos de trabajo. En el pasado, los historiadores de África vieron ésta habitualmente como un fenómeno interno de las colonias, y desde regiones pobres - improductivas a otros espacios donde se producían cultivos industriales o donde eran extraídos minerales. ${ }^{3}$ La emigración interterritorial en el África colonial es una preocupación historiográfica relativamente reciente; aunque fue un objeto preferente de atención por parte de teóricos y administradores coloniales, durante el periodo en que el análisis histórico del colonialismo se expandió, la historiografía de las emigraciones coloniales por lo general no lo hizo. Como han demostrado trabajos recientes, la emigración laboral africana cruzó de forma recurrente las fronteras de territorios individuales y, también, de imperios europeos. El análisis de Isaie Dougnon sobre la emigración laboral desde el País Dogón a la Costa de Oro discurre por premisas similares a las de este artículo: una de reclutamiento depredador de mano de obra, ansiedad imperial en torno a la emigración africana hacia el territorio de otros imperios y, por otro lado, la dificultad para determinar el status de los emigrantes individuales. ${ }^{4} \mathrm{El}$ trabajo de Eric Allina sobre el intento del gobierno colonial portugués de proteger y expandir sus reservas de mano de obra en Mozambique demuestra además que el reto de obtener trabajo por la fuerza fue algo común en territorios más grandes que la propia Guinea española. ${ }^{5}$ La interpretación de François Manchuelle acerca de la emigración laboral de soninkes anima a los historiadores a ver este fenómeno en términos de oportunidad, riqueza y tradición, más que en unos de desesperación, pobreza y ruptura. ${ }^{6}$ La emigración laboral nigeriana hacia Fernando Po se situó en algún punto entre la coerción abierta y el movimiento "libre"; ésta estuvo impulsada tanto por las expectativas de oportunidades económicas por el lado de los emigrantes individuales y por el lado del gobierno colonial español y sus agentes nigerianos.

3 Véase por ejemplo el mapa de Nigeria de Basil Davidson en el que aproximadamente toda la migración laboral es interna, dentro de la colonia. En DAVIDSON, B. (1994): Modern Africa: A Social and Political History. Longman, London, p. 28.

DOUGNON, I. (201 1): "Child Trafficking or Labor Migration?: A Historical Perspective from Mali's Dogon Country". Humanity, n 2, p. 85.

5 ALLINA, E. (1997): "Fallacious Mirrors:" Colonial Anxiety and Images of African Labor in Mozambique, ca. 1929". History in Africa, n. 24, p. 12.

6 MANCHUELLE, F. (1997): Willing Migrants: Soninke Labor Diasporas, 1848-1960. Ohio University Press, Athens, p. 4. 


\section{Emigración laboral nigeriana a Fernando Po}

La escasez de mano de obra había sido un problema de largo alcance en la Guinea española, iniciado por las guerras de ocupación que consolidaron el dominio español en los siglos XIX y XX y dieron lugar a una disminución de la población. ${ }^{7}$ Las políticas pronatalistas y los intentos por traer trabajadores de otras regiones del mundo tuvieron poco éxito a la hora de suplir a la colonia con un suministro constante de mano de obra. ${ }^{8}$ En las primeras décadas del siglo XX, la densamente poblada región de Nigeria oriental, accesible desde Fernando Po por medio de una corta travesía marítima, pasó a ser una atractiva fuente de mano de obra para el gobierno colonial español. Para los nigerianos orientales, especialmente para los igbos, la falta de oportunidades económicas en el ámbito local y el sistema de tenencia de la tierra que forzó a los jóvenes a buscarse el sustento lejos de sus hogares continuó estimulando la emigración a Fernando Po incluso después de que comenzaran a llegar noticias sobre las realidades que enfrentaban allí los trabajadores nigerianos. ${ }^{9}$

El problema de la mano de obra se agudizaría durante la Segunda Guerra Mundial, cuando la Guinea española se convirtió en una de las principales fuentes de productos tropicales para la España metropolitana. ${ }^{10} \mathrm{~A}$ lo largo de este periodo, se intensificó el reclutamiento clandestino en la Nigeria oriental. Esta mano de obra era nominalmente libre, pero en la práctica estaba fuertemente coaccionada. ${ }^{11}$ Aparecieron formas de reclutamiento cada vez más predadoras, hasta el punto que los nigerianos orientales las comparaban en algunas ocasiones con la esclavitud. ${ }^{12}$ Entre el final de la Segunda Guerra Mundial y la independencia en 1968, el gobierno colonial de la Guinea española exigió numerosas obligaciones de trabajo gratuito de las comunidades indígenas fang y bubi. Cuando esta mano de obra se mostraba insuficiente, el gobierno español y sus agentes acostum-

7 CANTUS, L. (2007): "El comienzo de la masacre colonial del pueblo Bubi. La muerte del Botuko Sás, 1904". Centre d'estudis internacionals de biologia i antropologia, Barcelona, p. 25.

8 YGLESIAS DE LA RIVA, A. (1947): Política indígena en Guinea. Instituto de Estudios Africanos, Madrid, p. 266.

9 KORIEH, C. (2010): The Land Has Changed: History, Society and Gender in Colonial Eastern Nigeria. University of Calgary Press, Calgary, p. 253.

10 De forma general véase NERIN, G. (2008): Un guardia civil en la selva. Ariel, Barcelona.

11 HAILEY, M. (1968): An African Survey: A Study of Problems Arising in Africa South of the Sahara. Oxford University Press, London, p. 1376.

12 Véase, por ejemplo, Drum (West African Edition, Lagos), 'This Child Was Sold Into Slavery,' March 1958, p. 78. 
braban a centrarse en Nigeria, donde se dirigían a los jóvenes e impresionables prometiendo trabajo bien pagado y altos niveles de vida. ${ }^{13}$ Otros eran reclutados a través de métodos más contundentes, hasta el punto que las historias de patrullas de reclutamiento forzoso circulaban ampliamente por Nigeria oriental. Para muchos igbos estas variedades de "reclutamiento" eran similares al secuestro.

A pesar de todo, la emigración desde el este de Nigeria continuaba a buen ritmo, canalizaba por lo general a través del puerto de Calabar. Cuando llegaban a Fernando Po, los nigerianos pasaban a ser introducidos en un régimen de trabajo restrictivo que aseguraba una fuerza de trabajo estable a través de la limitación de movimiento de los trabajadores africanos, tanto autóctonos como extranjeros. ${ }^{14} \mathrm{~A}$ primeros de los años 60 los nigerianos componían cerca de un tercio de la mano de obra de la Guinea española. ${ }^{15}$ En Fernando Po, los nigerianos representaban la mayoría de la población; en cifras aproximadas hablamos de unos 85.000 sobre un total de 100.000 residentes. ${ }^{16}$ La gran mayoría de ellos eran igbos, cuya situación en la sociedad de la Guinea española era insegura a nivel social y legal, ello a pesar de que eran vitales desde un punto de vista económico. ${ }^{17} \mathrm{Tal}$ era la situación que España y Gran Bretaña negociaron varios compromisos sobre la regulación de la mano de obra nigeriana en Fernando Po, pero salvo en raras ocasiones ello no implicaba que las condiciones de bienestar estipuladas por los acuerdos fueran cumplidas.

Por su parte, el reclutamiento no estaba regulado, de manera que los agentes nigerianos responsables de dicha misión sobre el terreno eran pagados por sus jefes. A causa de ello fueron reclutadas muchas personas incapaces de realizar trabajos físicos, incluidos niños y ancianos incapaces de subsistir por sí mismos cuando llegaban a Fernando Po. Solamente en torno al veinte por ciento de los emigrantes eran mujeres, la mayoría de las cuales habían marchado con sus maridos. Las jornadas de trabajo podían superar las catorce horas, habitualmente no se cobraban los salarios y el castigo

13 SUNDIATA, I. (1990): Equatorial Guinea: Colonialism, State Terror, and the Search for Stability. Westview Press, Boulder, p. 41.

14 BELMONTE MEDINA, P. "Penología e indigenismo en la antigua Guinea española". Espacio, Tiempo y Forma, n 11, pp. 113-138.

15 OSUNTOKUN, A. (1978): Equatorial Guinea-Nigerian Relations: The Diplomacy of Labour. Oxford University Press, Ibadan, p. 50.

16 SUNDIATA, Equatorial Guinea, p. 47.

17 OYONO SA ABEGUE, V. (1985) : "L'évolution des structures productives et sociales de l'économie de la Guinée Équatoriale 1858-1968." Tesis Doctoral, Universidad de Lyon, p. 23. 
corporal estaba a la orden del día. Los administradores coloniales británicos comentaban que muchos de aquellos que volvían a Nigeria desde Fernando Po mostraban signos de haber sufrido abusos físicos. ${ }^{18}$ Los nigerianos tenían poco control sobre el destino que se les designaba para trabajar o el tipo de labores que habían de realizar. Aunque aquellos que habían inmigrado legalmente estaban nominalmente contratados al servicio de plantadores particulares en la práctica su destino era determinado por administradores españoles que "reclutaban" trabajadores "a aquella granja que en opinión de las autoridades sufre una mayor necesidad de mano de obra para mantener su producción media". ${ }^{19}$ Cuando los trabajadores tenían contratos los tribunales y administradores españoles los ignoraban de manera habitual, hasta el punto que para las autoridades españolas su condición de personas se limitaba a su capacidad para trabajar. Pero para los propios emigrantes y para aquellos que habían dejado atrás en Nigeria su experiencia como trabajadores tenía implicaciones importantes en cuestiones de nacionalidad e identidad política.

En estas circunstancias extremas, y muchas veces incapaces de pagar su billete de vuelta a casa, los nigerianos orientales acudían en busca de ayuda al consulado británico en Santa Isabel, quedando muy a menudo decepcionados con lo que el gobierno colonial les ofrecía. En los informes trimestrales elaborados por el vicecónsul para el Foreign Office queda muy clara esa indiferencia de las autoridades de la que se quejaban los nigerianos. Algunos cónsules despachaban sin más trámite a aquéllos que buscaban el apoyo de la misión diplomática y más tarde eran reprendidos por actuar así. Unos pocos permitieron a los nigerianos dormir en el suelo del consulado en los días siguientes a su audiencia con el vicecónsul, pero muchos regresaban de vuelta al interior de una ciudad donde no tenían permiso oficial para residir. ${ }^{20}$ Los funcionarios no sabían qué hacer con los trabajadores que recurrían a ellos en busca de ayuda, de manera que escribían a sus superiores en Londres, Brazzaville y Duala para pedir consejo, incluso en casos claros. Un vicecónsul escribió a un superior en Monrovia en 1944 para preguntar qué debía hacerse con una mujer sospechosa de ser una prostituta que había llegado al consulado después de ser violada por un policía. El cónsul británico respondió con nerviosismo

18 National Archives of the United Kingdom [en lo sucesivo NAUK] FO 371/108190, 'Confidential - From Brazzaville to Foreign Office,' 15 de septiembre de 1954.

19 NAUK FO 371/22669, Vice Consul, Santa Isabel to Vice Consul, Monrovia, 11 de julio de 1938.

20 NAUK FO 371/26908, "Labour Conditions in Spanish Guinea," 1946. 
que "no es costumbre de esta oficina decidir las cuestiones de Fernando Po". ${ }^{21}$ En este caso particular el vicecónsul decidió pagar el pasaje de dicha mujer para que pudiera regresar a Nigeria, pero en muchos otros la decisión era no actuar.

El vicecónsul británico se puso del lado del gobierno español en casos en que parecía que los nigerianos habían infringido de algún modo la ley, incluso si no estaba claro el contenido de la ley española que habían quebrantado. En 1938, los nigerianos se quejaban de estar siendo registrados en gran parte en busca de dinero y otros bienes que no estaban autorizados para acarrear consigo fuera de Fernando Po, al tiempo que los funcionarios portuarios españoles estaban confiscando bienes que supuestamente sí podían llevarse consigo los retornados. El caso es que el vicecónsul no se mostró empático. "He estado presente durante dichos registros en más de una ocasión", escribía, "pero hasta ahora no he visto ni una muestra del tratamiento brutal referido por los nativos en su carta colectiva al Secretario Jefe. La razón para llevar a cabo un registro exhaustivo tiene que ver con los múltiples intentos realizados, algo que continúa hoy, de pasar de contrabando plata de aquí". ${ }^{22}$ Sobreseimientos de este tipo enfurecieron a los trabajadores y a aquellos que habían dejado atrás en Nigeria.

Perder su escaso dinero a manos de los funcionarios españoles en su regreso a Nigeria no era el mayor de los problemas de los trabajadores nigerianos, de hecho el consulado decepcionó a los nigerianos en circunstancias mucho más directas que éstas. Cientos de nigerianos fueron encarcelados en prisiones españoles por crímenes reales e imaginados, y muchas muertes injustas nunca fueron investigadas. El asesinato de Ekpenyong Edem en 1945 fue uno de estos casos. Edem, descrito en el informe consultar como "original de Calabar, hijo de Okon y Adet Okon", trabajaba como porteador en una embarcación que operaba entre Fernando Po y la Guinea española continental. Cuando intentó desertar del barco en Santa Isabel el español que estaba al mando a bordo lo retuvo a la fuerza. Al hacerlo empujó a Edem al atracadero, acabando así con su vida. De hecho, como decía, hubo abundantes casos de muertes arbitrarias que implicaron a trabajadores nigerianos, muchos de los cuales no recibieron nada más que un párrafo en los informes trimestrales oficiales del consulado sobre relaciones laborales. Este caso fue de algún modo único porque Edem era un miembro de la marina mercante, de modo que la investigación se llevó a cabo de

21 NAUK FO 371/26904, Consul, Monrovia to Vice Consul, Santa Isabel, 8 de mayo de 1944

22 NAUK FO 371/22669, Vice Consul, Santa Isabel to Consul General, Monrovia, 4 de julio de 1938. 
forma más minuciosa que la mayoría. Sin embargo, no estaba más claro de lo que era habitual qué debía hacerse con su cuerpo, como tampoco estaba claro si debían tomarse medidas en los tribunales españoles contra su patrón. En la breve descripción del informe del vicecónsul sobre los orígenes de Edem y en su declaración de que era una Persona Británica Protegida [a British Protected Person] no prescribía ningún procedimiento a seguir en concreto. Identificar al individuo en cuestión era por lo general todo lo que podía hacer el consulado. En este caso, el vicecónsul se sintió obligado a escribir a su superior en Duala "de modo que puedas informar a las autoridades nigerianas de los hechos y notificarme, si es necesario, qué medidas se están llevando a cabo o qué medidas deben ser adoptadas por mí. He aquí un reconocimiento tácito de que era poco lo que se podía hacer para llevar a la justicia a aquellos que acababan con las vidas de los nigerianos o abusaban de ellos. En el caso de Edem la implicación del consulado terminó cuando el informe del incidente fue archivado. No se prosiguieron acciones legales contra el patrón de la embarcación y los restos de Edem no fueron repatriados. ${ }^{23}$

El gobierno colonial nigeriano envió un mensaje contradictorio sobre reclutamiento ilegal de mano de obra en el sureste. A finales de los años 30 los británicos habían creado una fuerza policial especial para combatir ese sistema predador de obtención de trabajadores por parte de los plantadores españoles y sus agentes nigerianos, pero la policía nigeriana sólo persiguió a los traficantes de manera esporádica. ${ }^{24}$ Una serie de ordenanzas de trabajo aprobadas a principios de los 50 estipularon una multa de quinientas libras o cinco años de prisión para los reclutadores que no registraran de forma adecuada a los emigrantes, sin embargo este castigo sólo fue aplicado en muy raras ocasiones. ${ }^{25} \mathrm{En}$ un caso que se dio a conocer ampliamente en 1954, la policía de Calabar arrestó a dos empleados nigerianos de una firma española por "obtener pasaportes para los emigrantes bajo la falsa declaración de que marchaban a Fernando Po como comerciantes," 26 pero este arresto fue una excepción en medio de la incapacidad general del gobierno para hacer valer las regulaciones en materia de emigración. De vez en cuando, incluso no estaba claro cuáles eran las regulaciones; éstas cambiaban constantemente, y los funcionarios no se

23 NAUK FO 371/49598, Vice Consul, Santa Isabel to Consul General, Douala, 30 de enero de 1945.

24 OSUNTOKUN, Equatorial Guinea-Nigerian Relations, p. 30.

25 West African Pilot, 25 de agosto de 1954, p. 1.

26 West African Pilot, 21 julio de 1954, p. 1. 
ponían de acuerdo sobre qué organismo del gobierno nigeriano tenía la autoridad para permitir a los emigrantes marchar o para prevenirlos frente a ello. Las instituciones gubernamentales, desde la policía municipal de Calabar hasta el Protectorado de Nigeria Meridional emitieron documentos de forma independiente los unos de los otros, y hasta mediados de los 50 no hubo consenso sobre qué implicaba un proceso de registro adecuado. ${ }^{27}$ Desde los años 30 a los 50, los documentos consulares ponen de manifiesto una profunda inquietud entre los miembros del servicio diplomático británico con respecto a sus obligaciones para con los trabajadores nigerianos, así como también sobre los procedimientos apropiados a seguir en casos de abusos. La ambigüedad en torno a la nacionalidad de los implicados y la ausencia de un protocolo diplomático claro para lidiar con sus casos atrapó a los nigerianos en un vacío diplomático. La situación se exacerbó por el alto índice de rotaciones en el personal administrativo -Fernando Po no era un destino atractivo para los miembros del servicio diplomático, de modo que sólo en raras ocasiones los vicecónsules y los funcionarios encargados de cuestiones laborales permanecían en sus puestos más de un año. Los cierres esporádicos del consulado hicieron que fuera difícil para su reducido personal desarrollar cualquier tipo de política estable o consistente hacia los nigerianos necesitados de asistencia. A pesar del hecho que el personal del consulado recibía al menos diez casos urgentes a la semana en el momento álgido a mediados de los años 50, la institución no desplegó una política coordinada. Las respuestas a casos de abusos continuaron siendo en gran medida improvisadas.

En Fernando Po la responsabilidad de salvaguardar los intereses de las Personas Británicas Protegidas contradecían habitualmente la orden de mantener buenas relaciones con España. Cuando se trataba de decidir si defender a los nigerianos, y en este caso posiblemente poner en peligro las relaciones diplomáticas británicas con España, o por el contrario rechazar que había una crisis y arriesgarse a alienar a los nigerianos, los vicecónsules británicos tendían a elegir la segunda opción. Los funcionarios consulares británicos expresaron dudas en privado sobre su capacidad para dar protección a los trabajadores nigerianos frente al estado colonial español, sin embargo presentaban una imagen muy diferente a la prensa nigeriana y al Foreign Office en Londres. Las relaciones diplomáticas con la España de Franco fueron frágiles a lo largo de todo el periodo objeto de estudio aquí. Como resultado de ello, los funcionarios consulares se mantuvieron

27 NAUK FO 371/60392, "Status of British West Africans in the Spanish Territories," septiembre de 1945 . 
de forma constante al margen de las denuncias públicas contra España, al tiempo que rechazaron que la situación requiriera medidas que fueran más allá de la asistencia consular normal. Un editorialista en el West African Pilot especulaba con la idea de que el gobierno británico era reticente a reconocer públicamente lo extendido de los abusos españoles porque Gran Bretaña quería ocultar su incapacidad para interferir en las actuaciones y decisiones españolas, al menos a ojos de sus súbditos nigerianos, que supuestamente veían al imperio británico como omnipotente. ${ }^{28}$

Los predicadores protestantes que daban guía espiritual a los emigrantes igbos a veces se veían envueltos en esta representación de equilibrio político. En una investigación de dos policías que fueron acusados de azotar a un nigeriano acusado robo en Santa Isabel, el vicecónsul Eric Twigge-Molecey utilizó el testimonio de un pastor metodista para asegurar al Foreign Office que no había razones para preocuparse en la Guinea española. "El reverendo Shepherd me informa", escribía, "que ha hecho investigaciones muy exhaustivas entre los miembros de su congregación y en todos los casos el resultado ha sido el mismo... que ellos consideraban que el tratamiento que estaban recibiendo ahora no dejaba nada que desear" ${ }^{29}$ Ciertamente, no fue esta por lo general la reacción más común; otros pastores estaban tan frustrados con las condiciones de vida que enfrentaban sus feligreses y con la incapacidad del consulado británico para intervenir que apelaron a la Sociedad para la Protección de los Aborígenes [Aborigins' Protection Society]. ${ }^{30}$

Aunque los nigerianos sin papeles se encontraban en la situación más precaria, los trabajadores que seguían todos los protocolos de emigración adecuados se encontraban con que apenas podían recurrir a la asistencia consular a la que teóricamente tenían derecho. El caso de Sunday Achonu, un carpintero de Ukwu que solicitaba al consulado un pasaje con destino a Nigeria después de haber sido robado, ilustra bien esta realidad. Achonu no sólo tenía su documentación en orden, sino que estaba alfabetizado y era un trabajador cualificado. De algún modo se había procurado un informe policial de las autoridades españolas demostrando que había sido robado y que no había la ley española, todo lo cual planteaba un caso sólido y convincente para proveer asistencia consular en forma de dinero o de un pasaje de vuelta a casa. Sin citar ni una sola razón el vicecónsul de-

28 West African Pilot, 22 de marzo de 1946, p. 2.

29 NAUK FO 371/22669, Vice Consul, Santa Isabel to Consul General, Monrovia, 4 de agosto de 1938.

30 NAUK FO 371/49598, M. Jenkins to Vice Consul, Santa Isabel, 8 de junio de 1945. 
cidió no hacerlo. ${ }^{31}$ No hay pruebas de que hubiera un complot consciente por parte de los funcionarios y diplomáticos consulares o los negociadores de acuerdos laborales para abandonar o subordinar a los trabajadores igbos en particular. Sin embargo, abandono e indiferencia por parte de las autoridades fueron los mensajes que llegaron a Nigeria oriental, y su percepción -sin entrar a considerar si tal cosa era cierta-conformó la percepción popular del lugar que los igbos ocupaban dentro de Nigeria y el imperio británico. Desde su perspectiva, las garantías legales prometidas por el imperio parecían cada vez más falsas y vacías a lo largo del periodo final del dominio colonial.

\section{Agravios igbos y separatismo en Biafra}

Los escándalos continuaron sucediéndose en Fernando Po a lo largo de los años 50, creando por lo general descontento civil en Nigeria oriental. En 1958, las noticias de que un comerciante español en Calabar había estado subastando pertenencias de trabajadores nigerianos fallecidos catalizó amplias manifestaciones públicas en ese mismo puerto. Lo mismo ocurrió en Aba y Enugu tras una mediática serie de asesinatos de emigrantes de origen nigeriano en Fernando Po. ${ }^{32}$ No está claro que fue lo que se dijó en esas manifestaciones o qué era exactamente lo que pedían quienes se congregaron en ellas. Sin embargo, las críticas aparecidas en la prensa de Nigeria Oriental son un poco más claras. Éstas recogieron una ira considerable frente al maltrato de los trabajadores, percibiendo la indiferencia del consulado ante esta situación. Esto llevó a algunas personas a cuestionarse si los británicos eran los más adecuados para defender el bienestar de los igbos en el extranjero. Un periodista preguntaba, "¿qué tiene que esperar [de parte del funcionario británico de trabajo en Fernando Po] la gente sino indiferencia y falta de interés real por lo sufrimientos del pobre trabajador? Como cónsul británico tiene una mansión y un espléndido salario. No tiene nada que temer, pero todo y todos tienen que temerlo y adorarlo. Y viviendoen reclusión, tal y como él lo hace, al trabajador africano le es denegado no sólo un acceso fácil al cónsul británico, sino que también enfrenta el desalentador espectro del 'castiga' [castigo] si se atreve a quejarse contra su amo español." ${ }^{33}$ En este caso el gobierno nigeriano se sintió obligado a responder públicamente a la crítica, asegurando en una carta al editor que

31 NAUK FO 371/26911, "Labour Conditions in Spanish Guinea," 1950.

32 Eastern States Express, 11 May 1958, p. 1.

33 West African Pilot, 20 December 1948, p. 2. 
"la queja sobre la indiferencia y falta de interés real de su parte contradice todo los informes previos, tanto oficiales como no oficiales". ${ }^{34}$

El hecho de que la mayoría de los emigrantes fueran igbos no era un tema de discusión para los funcionarios consulares, pero sí que lo era de forma muy evidente para esta comunidad. Mucha gente interpretó la naturaleza ad hoc de la asistencia consular y la actitud de no compromiso de los diplomáticos como prueba de la deserción británica respecto a los igbos que continuó viva en el periodo posterior a la independencia. A principios de los 50, la devolución del control directo de los británicos al gobierno nigeriano, incluyendo a los administradores nigerianos, conllevó que aquéllos a cargo de asegurar el bienestar de los igbos también cambiaron. Aunque los funcionarios del servicio diplomático británico todavía era formalmente responsables de la asistencia consular, muchos nigerianos fueron destinados al consulado. Y lo que es más importante, africanos miembros del gobierno nigeriano se encontraban en posición de hacer algo con la situación reinante en Fernando Po. A ojos de muchos igbos, la visita en 1953 de Samuel Akintola, ministro nigeriano de trabajo, fue una prueba importante del compromiso del gobierno nigeriano con la protección de esta comunidad. Aunque Akintola tuvo éxito a la hora de negociar un incremento del $25 \%$ en los salarios de aquellos que habían llegado ilegalmente, la mayoría de la sociedad de Nigeria oriental vio en su visita un fracaso. Akintola volvió a Lagos afirmando que no había pruebas del maltrato español contra los trabajadores igbos -una conclusión que parecía contradecir el constate flujo de emigrantes retornados de Fernando Po físicamente rotos y en la indigencia. Las visitas posteriores fueron exitosas a la hora de lograr las promesas españolas de hacer cumplir las provisiones de protección social, que en teoría estaban vigentes desde los años 40 , a pesar de que los abusos continuaron en las plantaciones. No deja de ser significativo que Akintola fuera yoruba, procedente de una región al oeste de Nigeria que no había sido afectada por el reclutamiento de mano de obra para Fernando Po. Los periodistas y políticos de Nigeria oriental mencionaban este hecho para afirmar que el gobierno nigeriano no estaba interesado en el bienestar de los igbos, tal y como ya había ocurrido con las autoridades británicas. ${ }^{35}$

La independencia formal de Nigeria en 1960 no cambió sustancialmente la situación en la Guinea española. Las acusaciones de los igbos de impotencia y traición por parte del gobierno de su país continuaron, pero no fueron dirigidas a la República Federal de Nigeria. Después de 1960 algo se

34 West African Pilot, 23 December 1948, p. 1.

35 West African Pilot, 8 July 1958, p. 2. 
puso de manifiesto de manera dolorosa para los trabajadores emigrantes: si la categoría de Persona Británica Protegida servía de poco a modo de protección aún podía ofrecer menos el gobierno nigeriano. El Foreign Office británico se preocupó de que el gobierno nigeriano independiente no sería capaz de destinar suficientes recursos para la protección de sus ciudadanos en Fernando Po, y el consulado permaneció bajo la administración del organismo metropolitano durante el año 1961. El último caso que fue investigado por un vicecónsul británico implicaba a un capataz español en la finca de Pradesa que golpeaba a sus trabajadores y "lanzaba habitualmente a su perro tras ellos cuando intentaban escapar de sus castigos". ${ }^{36}$ Como la mayoría de los demás, el caso quedó sin respuesta ni solución.

La prensa de Nigeria oriental se refirió habitualmente a las dificultades de los trabajadores en Fernando Po como "crisis", y para muchos observadores esa crisis duró más de treinta años. De forma similar a otras comunidades nigerianas fuera del país, los trabajadores emigrantes en Fernando Po se encontraron en lo que C. Bawa Yamba ha denominado en un contexto similar como un "estado de liminalidad prolongado". ${ }^{37}$ Los acuerdos en materia de trabajo iban y venían y los gobiernos tenían grados de interés variables en el bienestar de los nigerianos en Fernando Po, pero las dinámicas migratorias permanecieron en buena medida similares a lo largo de todo el periodo comprendido entre los años 30 y 60 . Incluso cuando las políticas de descolonización estaban reconfigurando la región en aspectos importantes, los igbos continuaron siendo explotados en Fernando Po. Sus gobiernos continuaron estando bloqueados respecto a lo que hacer con ellos; hacia el año 1965 un emigrante nigeriano en Fernando Po estaría atrapado en una situación muy similar a la que podía haber vivido su padre en 1935. Los igbos de Nigeria oriental que habían sobrevivido a la experiencia de ser enviados ilegalmente a Fernando Po, y aquellos que todavía tenían familiares allí, mencionaban la aparente impotencia de su gobierno para protegerlos como una razón entre otras invocadas por los territorios orientales del país para perseguir un camino político independiente respecto a la República Federal de Nigeria.

A lo largo de los años 60, en Nigeria oriental se estaba fraguando una confrontación política. En julio de 1966, seis años después de que Nigeria hubiera conquistado su independencia de Gran Bretaña y seis meses después de que un golpe militar hubiera derribado la Primera República

36 NAUK FO 371/154686, "Confidential Report," 4 de mayo de 1961.

37 BAWA YAMBA, C. (1995): Permanent Pilgrims: The Role of Pilgrimage in the Lives of West African Muslims in Sudan. Edinburgh University Press, Edinburgh, p. 2. 
nigeriana, un grupo de generales del norte del país organizó otro golpe y situó al teniente general Yakubu Gowon como jefe de estado. A finales de ese mismo año, en los momentos posteriores a los hechos estallaron una serie de pogromos contra los igbos y otras comunidades de la región oriental del país que vivían en el norte, la mayoría de los cuales se habían asentado allí a lo largo del siglo XX como mercaderes y empleados del gobierno. En tres meses fueron asesinados entre 80 y 100.000 igbos a lo largo de los territorios septentrionales de Nigeria. El gobierno del país se veía incapaz de parar los pogromos, dando a mucha gente la impresión de que éstos estaban planeados y sancionados en realidad por el nuevo régimen militar de Nigeria. ${ }^{38}$ Entre tres y cinco millones de igbos y otras comunidades procedentes de la parte oriental del país "regresaron" al lugar de origen de sus familias como resultado de la violencia. Después de un periodo de negociaciones no concluyentes, en mayo de 1967 los territorios del este se separaron como la República de Biafra, esencialmente sobre la base de que Nigeria había fracasado para proteger a los ciudadanos de dicha región -y especialmente a los igbos- residentes en otras partes del país. El líder de Biafra era el teniente coronel Chukwuemeka Odumegwu Ojukwu, un oficial que había sido elevado a la condición de soldado nigeriano modelo. En cualquier caso, Nigeria no estaba dispuesta a perder los territorios reivindicados por Biafra, en buena medida porque la mayor parte de sus reservas de petróleo estaban localizadas allí. El gobierno impulso una "acción policial" para recuperar el este del país, algo que no tardó en dar lugar a una escalada hacia una auténtica guerra.

Aunque Biafra consiguió congregar un grado importante de solidaridad internacional, Nigeria tenía clara ventaja en términos militares. Después de la captura de Port Harcourt en mayo de 1968 Biafra quedó aislada del mundo exterior, dando como resultado además una gran hambruna. Los combates duraron hasta la derrota de Biafra en enero de 1970, dando lugar a un número muy alto de bajas civiles -el número preciso es objeto de debate. La vida cotidiana en Biafra fue extremadamente difícil; las muertes por hambre, los bombardeos, las amenazas internas a la libertad como las levas obligatorias fueron cada vez más comunes conforme la guerra avanzaba, hechos que en algunos casos fueron recogidos por la prensa internacional, que mostró un marcado interés por el conflicto. Después de la rendición de Biafra sus territorios fueron reintegrados en Nigeria, y esto

38 Para una historia detallada de este preludio de la guerra véase ANTHONY, D. (2002): Poison and Medicine: Ethnicity, Power, and Violence in a Nigerian City, 1966 to 1986. Heinemann, London y OSAGHAE, E. (1998): Crippled Giant: Nigeria Since Independence. Indiana University Press, Bloomington, p. 63. 
fue posible porque el gobierno militar nigeriano persiguió una política en la que reclamaba que no había habido "ni vencedores ni vencidos" -lo cual se plasmó en un proceso de reconciliación nacional en el que los ciudadanos ordinarios de origen igbo que habían combatido por la independencia de Biafra no serían castigados, al tiempo que les sería permitido reclamar las propiedades que muchos de ellos habían dejado atrás en otras partes de Nigeria. Se trató de un proceso polémico, y el coste humano y material de la guerra se continuaría sintiendo mucho después de que ésta finalizara.

\section{De emigrantes a soldados: la conscripción en la República de Biafra}

El tránsito entre Nigeria y Fernando Po se ralentizó durante la guerra, pero incluso en los momentos más desesperados de la lucha nunca se frenó del todo. Muchos igbos que ya estaban en la Guinea española en el momento en que se produjo la secesión de Biafra permanecieron allí durante toda la guerra, habitualmente en circunstancias miserables. Sea como fuere, en octubre de 1968la Guinea española se independizó de España bajo el nombre de Guinea Ecuatorial, con Francisco Macías Nguema como jefe de estado, pero esta transición (por el momento) no cambió sustancialmente la economía agraria de Fernando Po, incluyendo su dependencia de la mano de obra emigrante nigeriana. En cualquier caso, la economía agrícola de la antigua colonia española se estancó durante la guerra, y sólo tras el final del conflicto se reanudaría el flujo de mano de obra forzada. Guinea Ecuatorial mantuvo unas relaciones complicadas con Biafra, y Fernando Po (rebautizada Bioko tras la independencia) jugó un pequeño aunque importante rol desde el punto de vista táctico durante el conflicto. A mediados de 1968, cuando la isla todavía estaba bajo control español, las negociaciones entre el Comité Internacional de la Cruz Roja y el gobierno nigeriano desembocaron en un acuerdo por medio del cual la isla sería utilizada como base de operaciones para vuelos de asistencia y socorro con destino a Biafra, siempre sometida a inspección por parte de Nigeria. ${ }^{39}$ El gobierno Macías puso fin a este acuerdo por deseo de Nigeria, una decisión que también estuvo motivada por el miedo a que la numerosa población igbo de la isla pudiera intentar unirla a una Biafra independiente. Sin embargo, la política fue ejecutada de forma inconsistente y Guinea Ecuatorial continuó permitiendo ocasionalmente vuelos de auxilio desde Bioko. ${ }^{40}$

39 NAUK FCO 38/303, International Committee of the Red Cross, Press release, 25 de agosto de 1968

40 STREMLAU, J. (1977): The International Politics of the Nigerian Civil War. Princeton University Press, Princeton, p. 285. 
Pero las políticas de humanitarismo internacional y diplomacia no fueron las únicas vías por las cuales los acontecimientos en Guinea Ecuatorial influyeron en la guerra civil nigeriana. También hubo una importante continuidad entre la memoria y práctica de la emigración igbo a Fernando Po y el estallido de la guerra; más que ser "conscriptos" para el trabajo agrícola en la isla, ahora los jóvenes se vieron reclutados para el servicio militar en el ejército biafrano. Aunque existían diferencias innegables entre el reclutamiento para el trabajo agrícola y la conscripción militar, las similitudes entre estas formas de trabajo forzoso fueron evidentes para muchos jóvenes igbos que habían experimentado ambas realidades. Las dos formas de coacción fueron violentas $y$, también de forma muy similar, permanecieron sin regular. Este tipo de conscripción -irregular, coaccionada y llevada a cabo por agentes que no respondían ante nadie que no fueran ellos mismos- era marcadamente similar al modo en que había operado la emigración laboral a Fernando Po durante las tres décadas previas a la guerra. ${ }^{41}$ La base documental con que contamos a la hora de realizar la historia de la conscripción en Biafra es mucho más pequeña que para lo que se refiere a la cuestión laboral en Fernando Po, pero la historia oral y la documentación del gobierno biafrano revelan que muchos combatientes de las tropas de su ejército tenían alguna experiencia como trabajadores en Fernando Po. No es posible contabilizar el número de soldados biafranos que habían trabajado allí, pero las escasas fuentes archivísticas de Biafra sugieren que en algunas regiones de la antigua república secesionista la proporción era alta. Los documentos del reclutamiento en el ejército biafrano del primer año de la guerra centrados en el área en torno a Calabar recogen que muchos de los hombres que fueron reclutados en el ejército habían viajado a Fernando Po, y unos pocos habían sido multados por el gobierno colonial por haberlo hecho. ${ }^{42}$

La conscripción fue un aspecto extremadamente importante de la historia social de la guerra en Biafra. Los civiles biafranos soportaron una buena parte de la violencia del conflicto, pero en algunos casos la más incisiva tuvo lugar en el contexto del reclutamiento militar. En los primeros meses de la guerra circulaba por Biafra un panfleto propagandístico representando a un niño de diez años vestido con un uniforme holgado. La leyenda decía: "no hay nadie demasiado pequeño o demasiado grande para la gran tarea de defender la patria. El joven 'oficial' de arriba a jurado traer de vuelta diez cabezas de soldados nigerianos en estricta obediencia a su

41 Nigerian National Archives, Calabar [en lo sucesivo NNAC] 609 CAD 396/1/vol. x 3/3/356, "Recruitment Into Biafra Army," 7 de julio de 1967.

42 NNAC 609 CAD 396/1, "Register of men recruited into army," s.f. [1967]. 
obligación para con la nación". ${ }^{43}$ Esto no significaba que una afirmación así hubiera de tomarse al pie de la letra al principio de la guerra, pero en sus compases finales el ejército biafrano contaba entre sus filas tanto con niños como con ancianos. La conscripción de adolescentes, hombres de edad avanzada y de los incapacitados física y mentalmente no era "legal", pero estuvo tan extendida en Biafra que de forma frecuente se dieron notificaciones judiciales en los tribunales de la república. ${ }^{44}$ La conscripción fue mucho más despiadada en la práctica que sobre el papel. Las empresas, las parroquias y las instituciones gubernamentales podían pedir al gobierno de Biafra eximir a sus empleados del servicio militar, pero eso no podía ponerlos a salvo de ser conscriptos por milicias y por unidades aisladas del ejército. ${ }^{45}$ Las campañas de conscripción fueron un rasgo permanente de la vida en la nueva república. Éstas dieron a los soldados una autoridad sin límites para detener hombres de cualquier edad y origen y podía servir también como pretexto para diferentes formas de extorsión. La coerción violenta de la mano de obra que tal situación implicó recordaba a algunas personas al trabajo forzoso del periodo colonial, incluyendo comparaciones explícitas con lo vivido en Fernando Po. ${ }^{46}$

Los asuntos de vida y muerte habitualmente se volvieron en contra de la conscripción. Un administrador escribió a una provincia que no había cumplido con los objetivos de reclutamiento que "las negligencias e indiferencia a la hora de lidiar con el problema son un suicidio. Bien podéis entender porqué se considera que cualquier población que falla a la hora de contribuir plenamente a los requerimientos de nuevas tropas trabaja contra los intereses de Biafra. La advertencia no será repetida". ${ }^{47} \mathrm{~A}$ las diferentes poblaciones se les hizo saber que eran responsables de la concentración y transporte de sus hombres hacia un punto de encuentro establecido donde serían contados e inmediatamente reclutados por el ejército. Las consecuencias en caso de no alcanzar el número requerido de hombres eran serias. Una circular del ejército advertía que "el fracaso a la hora de cumplir

43 Biafra Sun, 12 de julio de 1967, p. 5.

44 Por ejemplo en el siguiente caso judicial: Nigerian National Archives, Enugu [en lo sucesivo NNAE] MINJUST 116/1/8, En el Tribunal Especial de Biafra, Holden en Nbawsi, No. ST/24c/69, The State v. Benedict Emene, 18 de noviembre de 1969.

45 National War Museum, Umuahia [en lo sucesivo NWM] colección no catalogada, H.E. Meniru, B.G.C. Ltd. To Chairman, Civil Defence, Orlu, 30 de julio de 1969.

46 Colecciones no catalogadas del NWM, "Provincial Zone F Defense," 27 de noviembre de 1969.

47 Colección no catalogada del NWM, "Recruitment into the Biafran Army," 15 de noviembre de 1969. 
con esta directiva obligará al mando a poner en marcha una conscripción abierta en todas las localidades que no respondan al llamamiento tal y como se espera. Por lo tanto estáis advertidos de que hacer uso de esta oportunidad poniendo a disposición a vuestros varones es la mejor manera de evitar las penalidades de la conscripción". ${ }^{48}$ De hecho, las campañas de conscripción fueron por lo general punitivas, y mucha gente recuerda que en los compases finales de la guerra "el único momento en que verías un hombre en uniforme es si éste estaba intentando reclutar hombres o recaudar dinero". ${ }^{49}$ En el último año de la guerra uno de los modos en que el gobierno biafrano estaba más presente en la vida de las personas era a través de la recogida de impuestos para la compra de material militar. Los de mayor envergadura eran los "impuestos a discreción" [jet levies], que reclamaban a las localidades recaudar cientos de libras en efectivo y en especia, teóricamente para adquirir aviones de combate, pero en realidad la mayor parte de las veces para mantener la solvencia financiera del gobierno de Biafra. Habitualmente, los pueblos eran incapaces de reunir el dinero que se les pedía, y cuando no lo lograban eran seleccionados para ser sometidas a campañas de reclutamiento particularmente brutales. ${ }^{50}$

Tal y como había ocurrido con el reclutamiento de mano de obra, la conscripción militar fue desorganizada y arbitraria. Conforme la guerra avanzó fue en disminución la consistencia de los métodos mediante los cuales eran reclutados los hombres y dejó de estar claro incluso para el gobierno biafrano quién estaba autorizado para llevar a cabo levas o quién podía ser movilizado. En la práctica cualquier hombre de casi cualquier edad podía ser forzado a hacer el servicio militar. La conscripción significaba una pérdida de libertad inmediata e irreversible, llegando a afectar ocasionalmente a las mujeres, aunque no fuera lo más común. De hecho, cuando un grupo de muchachas fue sumado a los reclutas enviados a un campo militar cerca de Orlu un oficial las rechazó. ${ }^{51}$ El trabajo de los hombres físicamente aptos fue también requisado para tareas auxiliares como cavar trincheras. A medidos de 1968 no había uniformes que entregar ni apenas adiestramiento que impartir a los nuevos reclutas, y eran afortunados si recibían un arma antes de ser enviados al frente. Hacia el final de la guerra

48 Colección no catalogada del NWM, "Recruitment into the Commando," 25 de junio de 1969.

49 Entrevista con Barrister Mike Onwuzunike, Holy Ghost Cathedral, Enugu, 14 de septiembre de 2014

50 Colección no catalogada del NWM, Civil Defence Committee, Umuobom to Provincial Secretary, Orlu, 26 de septiembre de 1969.

51 Colección no catalogada del NWM. "Recruitment into BA," [1969]. 
la conscripción se había convertido, tal y como reflejaban las quejas de un burócrata biafrano, una batalla campal. ${ }^{52} \mathrm{El}$ caos y la arbitrariedad del proceso fue una reminiscencia del reclutamiento para Fernando Po, aunque a una escala más extrema de lo que había ocurrido en este último caso.

\section{Conclusión}

Es un cliché de la historiografía nigeriana que los igbos que componían la mayor parte de la población de Biafra eran "extraños" dentro de la propia Nigeria. Muchas historias del siglo XX en Nigeria señalan esta cuestión haciendo referencia a la guerra civil y a los pogromos que condujeron a esta. ${ }^{53}$ De hecho, esta percepción de marginalidad es el producto de una historia que va más allá en el tiempo. La experiencia de los emigrantes laborales en Fernando Po en una parte importante de la historia nigeriana del siglo pasado, incluyendo su guerra civil, así como también es parte de la historia del colonialismo español. Dicha experiencia tuvo implicaciones políticas al otro lado del mar, en Nigeria, que fueron mucho más allá del valor económico del trabajo que hicieron. Reducir a los emigrantes a su trabajo los hace sólo partes alienables de un sistema económico, cuando lo cierto es que sus experiencias y sus acciones fueron importantes para los debates sobre el status personal y el significado de la protección en el imperio británico y en la Nigeria independiente -debates que llegarían a un punto crítico en la forma de una guerra civil. Las dinámicas que hicieron posible la emigración laboral a Fernando Po no fueron tan diferentes de aquéllas que llevaron a los hombres al ejército biafrano, y para muchos jóvenes igbos las miserias que acarrearon estas experiencias fueron de algún modo igual de duras. Identificar las formas en que el trabajo forzoso puede ser similar al servicio militar -o puede ser percibido como tal- nos ofrece nuevas vías para comprender tanto el trabajo como la vida del soldado.

52 NNAE MINJUST 21/1/2, M.O.I. Idigo to Solicitor-General, Enugu, 17 de marzo de 1969.

53 Este argumento es planteado de formas diversas en, por ejemplo, OJELEYE, O. (2010): The Politics of Post-War Demobilisation and Reintegration in Nigeria. Ashgate, Aldershot y OYEWESO, S., ed. (2000): Perspectives on the Nigerian Civil War. Campus Press, Lagos. 


\section{Bibliografía}

ALLINA, E. (1997): "Fallacious Mirrors:" Colonial Anxiety and Images of African Labor in Mozambique, ca. 1929". History in Africa, n. 24.

ANTHONY, D. (2002): Poison and Medicine: Ethnicity, Power, and Violence in a Nigerian City, 1966 to 1986. Heinemann, London.

BAWA YAMBA, C. (1995): Permanent Pilgrims: The Role of Pilgrimage in the Lives of West African Muslims in Sudan. Edinburgh University Press, Edinburgh.

BELMONTE MEDINA, P. "Penología e indigenismo en la antigua Guinea española". Espacio, Tiempo y Forma, n 11.

CANTUS, L. (2007): "El comienzo de la masacre colonial del pueblo Bubi. La muerte del Botuko Sás, 1904". Centre d'estudis internacionals de biologia i antropologia, Barcelona.

DAVIDSON, B. (1994): Modern Africa: A Social and Political History. Longman, London, p. 28.

DOUGNON, I. (201 1): "Child Trafficking or Labor Migration?: A Historical Perspective from Mali's Dogon Country". Humanity, n 2.

ESIEMHOKAI, E. (1986): The Colonial Legal Heritage in Nigeria. Fagbamigbe Publishers, Akure.

HAILEY, M. (1968): An African Survey: A Study of Problems Arising in Africa South of the Sahara. Oxford University Press, London.

KORIEH, C. (2010): The Land Has Changed: History, Society and Gender in Colonial Eastern Nigeria. University of Calgary Press, Calgary.

MANCHUELLE, F. (1997): Willing Migrants: Soninke Labor Diasporas, 1848-1960. Ohio University Press, Athens.

OJELEYE, O. (2010): The Politics of Post-War Demobilisation and Reintegration in Nigeria. Ashgate, Aldershot.

OSAGHAE, E. (1998): Crippled Giant: Nigeria Since Independence. Indiana University Press, Bloomington.

OSUNTOKUN, A. (1978): Equatorial Guinea-Nigerian Relations: The Diplomacy of Labour. Oxford University Press, Ibadan.

OYEWESO, S., ed. (2000): Perspectives on the Nigerian Civil War. Campus Press, Lagos.

OYONO SA ABEGUE, V. (1985) : "L'évolution des structures productives et sociales de l'économie de la Guinée Équatoriale 1858-1968." Doctoral dissertation, University of Lyon. 
STREMLAU, J. (1977): The International Politics of the Nigerian Civil War. Princeton University Press, Princeton.

SUNDIATA, I. (1990): Equatorial Guinea: Colonialism, State Terror, and the Search for Stability. Westview Press, Boulder.

YGLESIAS DE LA RIVA, A. (1947): Política indígena en Guinea. Instituto de Estudios Africanos, Madrid. 
Estudis 


\title{
EL CORREO CARLISTA EN EL MAESTRAZGO \\ (1872-1875)
}

\section{THE CARLIST MAIL IN THE MAESTRAZGO (1872-1875)}

\section{Gerhard Lang-Valchs}

\section{RESUMEN}

El presente artículo describe el sistema del correo en el Maestrazgo organizado por los insurgentes durante la última de las Guerras Carlistas (1872-1876). Incluye también, además de los aspectos de administración postal, algunos filatélicos referentes a los sellos allí usados, basándose mayormente en un mapa postal carlista olvidado y los documentos del archivo de la familia Borbón-Parma.

Palabras clave: Carlismo, filatelia, Maestrazgo

\begin{abstract}
The present article describes the organisation of the postal system at the Spanish Maestrazgo-region (provinces of Valencia, Castellón, Teruel) established by the insurgents during the last Carlist War in Spain (1872-1876). Beside the aspects of the postal administration it takes in account as well some philatelic ones concerning the use of the stamps supposedly issued there. The study is mainly based on a forgotten carlist post route map and the documents accessible at the archive of the Borbón-Parma family.
\end{abstract}

Keywords: Carlism, philatelic, Maestrazgo 


\section{RESUM}

\section{El correu carlista en el Maestrazgo (1872-1875)}

Aquest article descriu el sistema de correus al Maestrat organitzat pels carlins durant la darrera guerra (1872-1876). Inclou també, a més dels aspectes d'administració postal, alguns filatèlics referents als segells utilitzats basant-nos majoritàriament en un

mapa postal carlí oblidat i als documents de l'arxiu de la família Borbón-Parma. Paraules clau: Carlisme, filatèlia, Maestrat 
De todo lo escrito sobre la última Guerra Carlista (1872-1876), la zona del Maestrazgo es la que menos ha atraído la atención de los investigadores. ${ }^{\prime}$ Existen varias publicaciones sobre el correo durante las contiendas provocadas por las insurrecciones carlistas entre las que la organización del correo en País Vasco y Navarra se lleva, por cierto, la palma en cuanto al número. Pero dentro de este ámbito no hay ninguna obra que se dedique exclusivamente a nuestro tema. La administración de Correos allí crea- da llegó a funcionar durante más de dos años con notable eficacia y hasta con una "estafeta inoficial" en Francia lo que generó documentos de toda clase, lo que invita a su estudio. ${ }^{2}$

Bastante menos se ha publicado sobre el correo carlista de Cataluña, debido a la escasez de documentación. Y, que se sepa, el correo carlista del Maestrazgo se menciona por las mismas razones tan sólo en un reducido apartado de algún artículo generalista sobre el correo de los insurgentes. ${ }^{3}$

La situación del correo en el Maestrazgo es un reflejo de la situación militar y administrativa en la zona controlada por los carlistas en aquellos años. Al mando de cabecillas como Ramón Cabrera o Pascual Cucala ocupaban con sus seguidores pueblos para establecer desde allí y en las zonas colindantes su dominio y así poder llevar a cabo sus acciones bélicas, que les llevaban a veces lejos de su punto de partida, desde su base en un sitio relati-

1 Véase la bibliografía al final del artículo. No es éste el lugar de discutir si hay que incluir o no la Guerra dels Matiners (1846-1849) en este recuento y hablar de dos o de tres guerras. Hablaremos de la última Guerra Carlista refiriéndonos a la de 1872-1876.

2 ESCALADA, E. (2000): La organización del correo carlista (1873-1876), Academia Hispánica de la Filatelia, Madrid. El autor enfoca principalmente la zona del País Vasco y Navarra.

3 Lo más consistente, aparte de lo arriba citado, se encuentra en una página y media de un librito de IGLESIAS, L.: Numismática y filatelia del carlismo, Boletín de Estudios Históricos sobre San Sebastián, $n^{\circ} 42$ [Separata], San Sebastián 2008-2009, p. 236-237. La falta de citas, sin embargo, no da opción a contrastar algunas informaciones potencialmente interesantes que no coinciden con los datos en los que se basa el presente artículo. 
vamente seguro. En esta guerra de guerrillas sin frentes ni fronteras claras apenas había una coordinación entre las diferentes facciones. Cada uno de los líderes locales hacía su propia guerra y no se sometía, en la práctica, al mando del Ejército de Cataluña y Valencia y de su representante al que teóricamente pertenecía.

Esta falta de coordinación y planificación se iba lógicamente notando también en el campo de la administración civil que poco a poco dejó de cumplir sus funciones, servicio de correo incluido. Durante algún tiempo y en algunas partes del territorio dominado hubo hasta tres servicios postales paralelos: el estatal, el carlista militar y el carlista civil. Hay muy pocos documentos o noticias sobre la situación administrativa durante la contienda. Aparte de noticias cortas y muy dispersas en algún que otro periódico $\circ$ alguna mención, por regla general poco crítica y sin documentar, disponemos de algunos mapas postales oficiales inmediatamente anteriores o posteriores a la guerra, de un mapa postal carlista, ${ }^{4}$ también de una memoria del ministro de la Gobernación, ${ }^{5}$ de un libro que nos ha conservado unos decretos con disposiciones del general carlista Dorregaray, ${ }^{6}$ así como de la correspondencia y otros documentos conservados en el archivo de la famila Borbón-Parma. ${ }^{7}$

\section{El correo estatal}

La insurrección carlista del Maestrazgo no condujo, como en el Norte, al colapso casi inmediato de la administración civil y con ella también a la de los servicios de Correos. De esta forma se produjo una rápida creación de un servicio postal propio que, ya a principios de 1874, funcionaba plenamente. En la primera fase de la guerra hasta mediados de 1874 en la zona del Centro, como se llamaba oficialmente este territorio, la situación postal tuvo que ser parecida a la descrita para el pueblo conquense de Cañete, ubicado no muy lejos de la zona que enfocamos. ${ }^{8} \mathrm{~A}$ pesar de tener una pequeña guarnición car-

4 Mapa de Correos de la zona de Castellón trazado por los carlistas..., Museo postal [MP], Legado Thebusem [LT], BMPT A-5 5(8) R.6026.

5 Memoria presentada el 2 de enero de 1874 a las Cortes Constituyentes por el ministro de la Gobernación D. Eleuterio Maisonnave (1874), Imprenta Nacional, Madrid.

6 OLIVER, A. (1876): Dorregaray y la traición del centro: Apuntes para la historia de la última guerra civil, Bayona.

7 Archivo Histórico Nacional [AHN], Fondo de la familia Borbón-Parma [BP], en parte digitalizado y accesible por internet.

8 Cuerpo del Estado Mayor del Ejército: Narración de la Guerra Carlista de 1869 a 1876, (1889) tomo XIV, Madrid, p. 202. 
lista permanente, el correo estatal seguía funcionando. Los rebeldes toleraban el servicio y se servirían en más de una ocasión de sus ventajas, aunque ciertamente no para fines militares y revolucionarios, y dejaban que también la población siguiera disfrutando igualmente de él. Esto tuvo que ser la tónica general en gran parte de la zona puesto que la ya citada Memoria no habla, a pesar de mencionar algunos problemas puntuales, de ninguna situación difícil o alarmante en cuanto al suministro de correo hacia finales del año 1873. ${ }^{9}$

Todo esto tenía su lógica. Por un lado los insurgentes no tenían instalado ni previsto todavía un correo propio en esta zona, sólo disponían de su correo militar, que por razones obvias, no querían poner, ni siquiera de forma camuflada, en manos civiles o de funcionarios no necesariamente afectos a su causa. Así que la correspondencia privada y comercial dentro de la zona rebelde y hacia fuera estaba asegurada mientras que el gobierno central a través de la Dirección de Correos no retirara este servicio y esto no solía ocurrir siempre que los funcionarios y carteros no fueran molestados, agredidos o detenidos por los carlistas.
Las acciones militares carlistas pretendían asegurar el dominio de su zona inicial de influencia, principalmente rural, y extenderlo a los centros urbanos, aislar y conquistar finalmente también las ciudades con Madrid como meta final. Por esto los rebeldes empezaron a interrumpir y destruir parte de la red telegráfica sobre todo en los tramos que unían Madrid con las capitales de provincia. También las comunicaciones a larga distancia como los trenes-correo se convirtieron en objetivo preferido de los ataques tanto en Cataluña como en el Centro.

La situación se agravó con la creación de una administración postal carlista para Cataluña en primavera de 1874. A través de diferentes decretos tanto la administración estatal -referiéndose a todas las zonas en rebeldía- como la carlista catalana prohibieron a sus funcionarios admitir el uso de los sellos postales del lado opuesto, la conducción de correspondencia sin franquear o franqueada con sellos de ambos lados a la vez. ${ }^{10}$ Esto implicó el final del suministro de la zona insurgente por el correo estatal y al hostigamiento de los carteros carlistas por las fuerzas liberales.

La zona del Maestrazgo era atrave-

9 OLCINA, E. (1974): El Carlismo y las autonomías regionales, Seminarios y Ediciones, p. 52 es de la misma opinión. La falta de referencias impide saber en qué documentos se basa. Memoria, p. $210-211$.

10 PEÑA, J. (2005): Los sellos carlistas de Cataluña. Contexto histórico, Colección: Monografías Filatélicas de Afinet $n^{\circ} 7$, Barcelona . 
sada cerca del litoral por la línea férrea que transportaba la correspondencia de Murcia, Alicante y Valencia vía Castellón y Tarragona a Barcelona y desde allí a Francia. El hostigamiento de los trenes-correo por los carlistas tuvo sus efectos. La conducción ferroviaria llegó a pararse, pero, según los criterios de Correos, recurriendo a diligencias y a veces a la vía marítima se podía salvar razonablemente bien la situación. Así, aunque en un principio se barajó como vía alternativa, finalmente no se adoptó una conducción continuada por barco entre Valencia, Tarragona y Barcelona.

La comparación de los mapas postales de 1871 y 1877 con el mapa carlista [Figura 1] deja patente la falta de conexiones postales transversales a través del Maestrazgo durante los años de la guerra así como la interrupción del suministro de puntos importantes de distribución como Morella y Lucena normalmente servidos desde Castellón que no estaba en manos de los rebeldes. Quedó afectada también la conducción por diligencia entre las capitales Valencia y Teruel vía Segorbe y Sarrión, cosa que, sin embargo, apenas podría afectar al suministro de la zona.

\section{El CORREO MILITAR}

Sobre la estructura del correo militar y sobre su funcionamiento sabemos muy poco. Se tuvo que adaptar, como es natural, a las necesidades de la guerra y de las partidas. A pesar de su confusa estructura debido a la guerra de guerrillas y la consiguiente falta de una organización militar convencional, su servicio fue por lo visto satisfactorio. En gran parte asumió las tareas del correo estatal cuando éste dejó de funcionar. Prueba de su eficacia es su uso para fines privados y comerciales, lo que provocó, sin embargo, una sobrecarga y ralentización del servicio. Es precisamente este abuso lo que Dorregaray prohíbe expresamente en su decreto de febrero de 1875. Quiere ver separados claramente ambos servicios sancionando severamente su incumplimiento. ${ }^{11}$

Al trazar las líneas de su reorganización postal militar Dorregaray se basa en las administraciones militares, ya creadas o por crear, que parecen coincidir con los seis antiguos distritos de la zona.

\section{El MAPA DEL CORREO CARLISTA}

El mapa postal carlista del que disponemos es una copia (Figura 1). El mapa original estaba entre los documentos incautados por las tropas

11 OLIVER: Dorregaray, p. 104-106. 


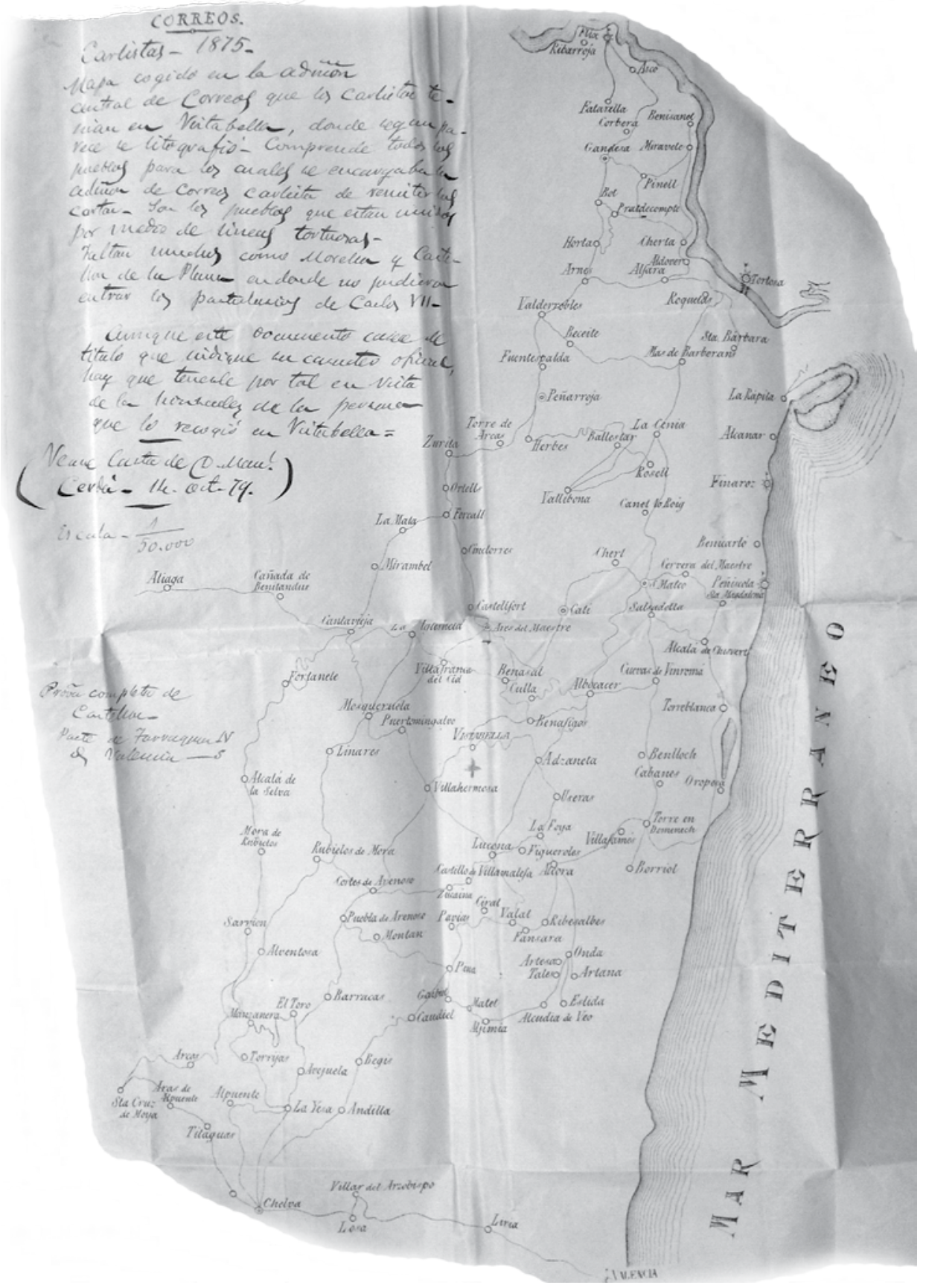

Fig.- 1. Mapa del correo carlista. 
liberales con motivo de la conquista del bastión carlista de Vistabella en 1875. El fondo al que pertenece, si es que existe todavía, se encuentra probablemente en el Archivo Histórico Militar de Madrid. ${ }^{12}$ La foto que presentamos muestra la copia que Mariano Pardo de Figueroa, famoso filatélico conocido también bajo el seudónimo de Dr. Thebussem, tenía en su colección de documentos filatélicos y que actualmente se encuentra en el Museo Postal de Madrid. El propio Mariano de Pardo lo describe en uno de sus libros dentro de un largo listado de otros mapas postales. ${ }^{13}$ Desde entonces sólo un autor que ha escrito sobre el tema se ha referido a la existencia de dicho mapa, sin aprovechar apenas la información ahí contenida. ${ }^{14}$

Antes de utilizar datos sacados del mapa sería conveniente preguntarse sobre su fiabilidad o si refleja tan sólo un sueño, una planificación, una utopía en base a un plan por realizar, deseable, pero nunca alcanzado. Podría describir la planeada o proyectada extensión de la red postal carlista del Maestrazgo dentro del territorio bajo su control. En este caso sería la aplicación de las directrices y preceptos que el general Dorregaray publicó en su decreto de 16 de febrero de $1875 .^{15}$ Podría tratarse de un mapa que refleja las conducciones realmente existentes o un mapa de uso oficial, ya que el original es una litografía como reza la nota marginal en su parte superior izquierda.

El diseño del mapa cubre la zona costera entre Valencia y Tortosa, se adentra en su parte superior a la altura de la desembocadura del Ebro hasta Flix desde donde baja en línea casi recta, paralela a la línea costera, hasta Santa Cruz de Moya, ya en la provincia de Cuenca, para llegar desde allí en ángulo recto vía Chelva y Liria hasta su punto de salida.

Nuestro mapa no es el que Dorregaray libró al lanzar el mencionado decreto sobre la reorganización del correo y que lo acompañaba en un principio. ${ }^{16}$ Aquí no se indican ni las conducciones que él establece y manda crear en su decreto. El texto determina con letras y números las diferentes conducciones y sin el mapa que llevaba las correspondientes indicaciones no somos capaces de reconstruirlas. Comparan-

12 Se trata de un fondo sin clasificar $y$, por consiguiente, inaccesible de momento.

13 DE PARDO, M. (1895): Fruslerías postales, Madrid, p. 238.

14 ESCALADA: La organización, p. 56-59.

15 OLIVER: Dorregaray, Anexo, p. 46-47.

16 El mapa referido de Dorregaray que acompañó su decreto no se encuentra en el libro. 


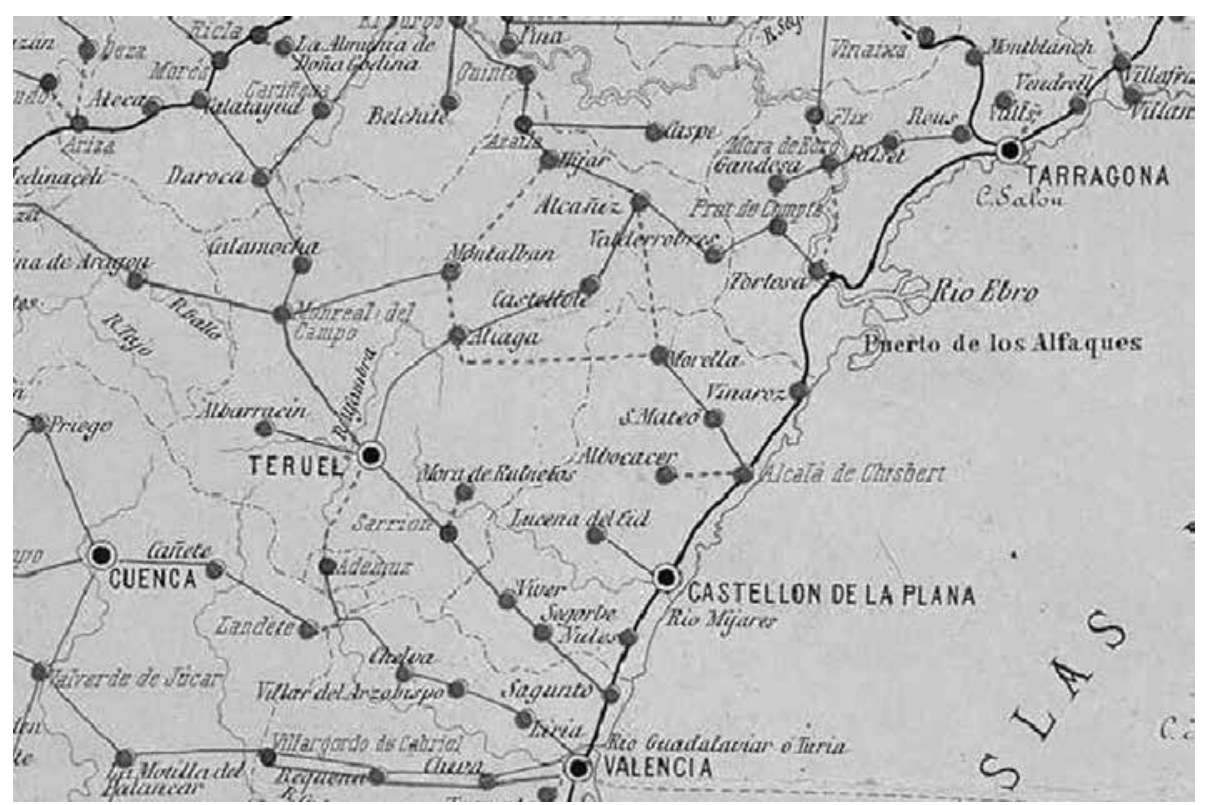

Fig.- 2. Mapa postal. Dirección General de Correos. 1873.

do la relación de los pueblos pertenecientes a las cinco administraciones postales según el proyecto de Dorregaray (Gandesa, San Mateo, Castellón, Segorbe y Chelva) se vislumbra la estructura de la red con sus distintos itinerarios.

Quedan lagunas, sobre todo, porque el mapa no indica en qué pueblos estaban realmente ubicadas las administraciones subalternas, ni siquiera indica la administración central que pudo estar en Vistabella, como dice el mapa, o en la vecina Villahermosa adonde se había trasladado en 1875 la Imprenta Real. También es raro que Dorregaray no mencionara ninguno de estos dos pueblos tan importantes para la infraestructura militar y adminis- trativa carlista ni los incluyera en su esbozo. Pensamos que finalmente, siguiendo la lectura del mapa, se creó otro sexto distrito administrativo postal en la zona turolense por el que trancurría la línea de Santa Cruz de Moya vía Sarrión y Mora de Rubielos a Cantavieja y otra casi paralela de Chelva, Rubielos de Mora y Mosquervela a Cantavieja. De todas formas queda poco claro cuál era el papel real de la administración central de Vistabella o Villahermosa y si el suministro de este supuesto sexto distrito era organizado desde allí.

A pesar de las incertidumbres descritas, el origen del mapa no parece dudoso. Su uso como mapa postal tiene su lógica por el lugar dónde 
fue requisado, concretamente en la administración (¿̇centralę) del correo carlista en Vistabella. También está claro que no se puede tratar de un simple mapa geográfico ni de un mapa militar, ya que el diseño no representa importantes ciudades como Sagunto, Segorbe y Castellón - Teruel ni contiene signos característicos de este tipo de mapas. La ausencia de muchas ciudades tiene su explicación. Dichas ciudades no estuvieron, sino corto tiempo como en el caso de Segorbe, en manos de los carlistas. Otras como Vinaroz o Benicarló están representadas, pero no unidas a la red postal. Las partes extremas (Aliaga y Santa Cruz de Moya) son sitios en donde hubo guarniciones carlistas permanentes. La única excepción a la regla es la conducción de Chelva a Valencia de la que hablaremos más tarde.

Al haber sido el mapa original una litografía, tuvo que ser impreso en el único taller litográfico que existía en toda la zona en guerra, taller del que salió también el sello carlista valenciano. ${ }^{17}$ Asi que es de suponer que en su día existieran más ejemplares, destinados a las administraciones subalternas. El mapa refleja, pues, la situación real del servicio interno del territorio controlado.

\section{EL CORREO CIVIL CARLISTA}

En la primavera de 1874 se crea un servicio postal con sellos propios en Cataluña. La consiguiente reglamentación del servicio tanto por la parte estatal como la carlista marcan el comienzo de una nueva fase para el suministro postal. ${ }^{18}$ Todo ello obligó o a la creación en el Maestrazgo de un servicio propio, o a la reorganización del hasta ahora existente aprovechando, donde se prestaba la oportunidad, la cooperación de los anteriores funcionarios. Esto lo intentó primero el general Palacios desde la zona turolense y luego Alfonso de Borbón Parma, hermano del pretendiente Carlos VII, desde Chelva donde tenía instalado su cuartel general en verano de 1874. Esta localidad se había quedado sin servicio estatal en octubre de 1873, y no se restablecería hasta el final de la guerra en esta zona en el verano de 1875. ${ }^{19}$ No sabemos, sin embargo, cuáles eran las medidas concretas. Cuando hacia finales del año 1874 el pretendiente Carlos VII separó los mandos del ejército de Cataluña y de Valencia, su hermano Alfonso se retiró de Chelva y el general Dorregaray tomó el mando del Ejército del Centro a principios de 1875 . Su

17 Véase la nota marginal del mapa.

18 El Volante de la Guerra, nº 6, p.4 en AHN, PB, Diversos, 116, exp. 2, 27.

19 LLATAS, V. (2014): Efimérides de las Guerras Carlistas en el Villar del Arzobispo, $2^{a}$ ed., Villar del Arzobispo, p. 39. 
análisis de la situación administrativa coincide con el que Alfonso de Borbón había hecho apenas medio año antes, lo que hace pensar que las medidas tomadas hasta la fecha no habían sido muy eficaces en su conjunto o al menos en la parte central y norte del territorio dominado.

En el campo postal Dorregaray desarrolla un plan para la correspondencia y la telegrafía con medidas concretas para la instalación de una línea eléctrica entre los centros militares de Villahermosa y Cantavieja y de una línea óptica desde Flix a Chelva atravesando el territorio de norte a sur, y con ramales hacia Castilla y Aragón, forman parte de él. ${ }^{20} \mathrm{El}$ material, cableado, hilo, aparatos transmisores etc., requisado a propósito a lo largo de la línea férrea de la costa siguiendo las instrucciones oficiales, no era suficiente, y la falta de personal cualificado para ambos sistemas fue finalmente la causa principal por lo que todo se quedó en un intento. ${ }^{21}$

La organización postal llega, sin embargo, mucho más lejos. Según Evarist Olcina "... dentro de sus limi- taciones, [en Cataluña y] en el País Valenciano, llegando a extenderse en 1875 hasta las últimas aldeas". ${ }^{22}$ A falta de datos y citas verificables, este dato tiene que quedar como opinión particular suya.

El plan de Dorregaray preveía una red de peatones que debían desplazarse a diario desde su pueblo base al vecino siguiendo los iterinarios trazados en su decreto. Los pueblos vecinos más pequeños, no suministrados directamente, tenían que encargarse por su propia cuenta de la recogida y entrega de su correspondencia en los pueblos ubicados en las líneas principales.

Nuestro mapa marca solamente los caminos y conexiones entre los pueblos ubicados en dichas líneas, sin más comentarios ni signos, omitiendo los pueblos más o menos pequeños fuera de ese recorrido. Pero no nos permite ver cuáles eran los centros administrativos subalternos o centros de distribución. Ni siquiera Vistabella, supuesto centro administrativo, destaca por ninguna señalización especial. La orientación del sistema de distribución en los centros

21 Algunos autores se confunden de bando cuando hablan de las obras para la instalación de una línea de telegrafía óptica por la parte del Ebro y adjudican la obra, realizada según un proyecto del general Salamanca, al bando carlista. GONZÁLEZ, C., GUAL, V., PARDO, R.: La telegrafía óptica en Castellón [www.aulamilitar.com; 31.5.2016, 11.40] explican la instalación con muchos detalles.

22 OLCINA: Carlismo, p. 52. 
administrativos militares, propuesta por Dorregaray, no parece haberse realizado sino parcialmente.

\section{LAS CONEXIONES CON EL EXTERIOR}

Uno de los problemas principales que tenía el correo carlista tanto en el Norte, como en Cataluña y el Maestrazgo, estribaba en que se trataba en el fondo de un sistema de conducción de correspondencia inoficial, no reconocido por ningún Estado, ni, por supuesto, por Madrid. Vivía en una burbuja, en una especie de circuito cerrado, que marcaba los límites del comercio y de una correspondencia para la que justo en 1874, durante el Congreso Postal de Berna, las naciones más avanzadas estaban buscando formas y fórmulas para facilitar el intercambio internacional del correo.

En el Norte y en Cataluña el problema del aislamiento internacional se pudo salvar instalando oficinas inoficiales de correo en Bayona y Prats de Molló para Cataluña, toleradas durante algún tiempo por la política francesa. Un Encargado de la correspondencia carlista organizaba la reexpedición de los envíos postales de las zonas carlistas para el extranjero aplicando el franqueo francés oficial. Luego, viéndose obligados a cerrar esta oficina, el así llamado Servicio de Fronteras se encargaría desde Irún de la tarea de encaminar la correspondencia hacia el extranjero. Parece que también en la parte catalana existió una pequeña organización parecida que se encargaba de reexpedir la correspondencia carlista en Perpiñán. ${ }^{23}$

Para enviar correspondencia a la España liberal había que acudir a las oficinas postales de las grandes ciudades que habían quedado en manos del Gobierno. Desde allí militares escoltaban los correos a través del territorio carlista circundante.

En el Maestrazgo no existía frontera con un país extranjero ni había ciudades importantes en manos de los liberales que finalmente conservaran su contacto postal y desde donde se pudiera mandar correspondencia fuera de la zona dominada. Así que uno de los mayores problemas era cómo recibir correspondencia desde fuera del territorio bajo control carlista o incluso desde el extranjero y cómo hacer llegar la correspondencia al exterior. Como zona rural y relativamente pobre, el comercio no tenía tanta importancia como en las otras dos regiones. ${ }^{24}$ Pero, no todos los soldados carlistas venían de la zona del Maestrazgo y de vez en cuando sentían la nece-

23 AHN, PB, Correspondencia 95, exp. 3, n' 378.

24 CARRERAS CANDI, F. (1908): Estudios postales I. Disquisiciones filatélicas y postales, Barcelona, p. 61-67. La tinta para imprimir los sellos de correo tuvo que encargarse en Valencia. 
sidad de dar a sus familias señales de vida.

El problema de la conexión con el exterior se agudizó con la presencia de Don Alfonso y la instalación del cuartel general del Ejército de Valencia en Chelva. Alfonso de Borbón y Austria-Este vino acompañado de su joven esposa Nieves de Braganza. Esta situación obligó a buscar una posibilidad de comunicación tanto para fines oficiales como privados, tanto para ellos como para otros oficiales y acompañantes extranjeros. La nutrida correspondencia con Chelva desde el extranjero que se conserva en el fondo Borbón-Parma demuestra que existía tal necesidad y que, efectivamente, se pudo encontrar una solución: un enlace parecido al existente en el Norte y arriba descrito.

¿Qué perfil debería tener este enlace? Por un lado tuvo que tener la posibilidad de recibir correspondencia desde el extranjero sin que esto llamara la atención de ningún funcionario de Correos. Por otro lado la de recibir visitas y cierta cantidad de correspondencia entregada por personas particulares y forasteras, así como tener la posibilidad de reexpedir cartas, meterlas en buzones $y / o$ entregarlas en una oficina de correos sin llamar la atención de los funcionarios o de otra gente. Ade- más tuvo que poder adquirir cierto cantidad de sellos de correo sin que esto tampoco llamara la atención en los estancos.

Analizando la correspondencia conservada que a todas luces tuvo que tomar el descrito camino, podemos afirmar que el encargado tuvo que ser un comerciante, abogado, notario o un funcionario de algún consulado. El necesario contacto seguro con el extranjero hace pensar en lo último. Entre las tres zonas rebeldes principales no había servicio postal, así que el correo recibido no pudo tomar la vía terrestre a través del Maestrazgo y Cataluña, el saliente tampoco. Además hubiera tardado unas cuatro semanas como mínimo, si nos basamos en un caso concreto de una carta remitida desde la catalana Solsona con destino Biarritz que tuvo que pasar primero por Perpiñán. Tardó 15 días, incluidos los dos desde Perpiñán a su destino final. ${ }^{25}$

El contenido de algunas de las cartas conservadas en el ya citado fondo Borbón-Parma del Archivo Histórico Nacional nos permite conocer algo más sobre el correo. Contiene mucha correspondencia de carácter político-militar dirigida durante la contienda a Don Alfonso de Borbón y Austria-Este tanto desde fuera como desde dentro del 
territorio dominado por los carlistas. Además conserva parte de su correspondencia privada y de la de su esposa que le acompañaba tanto en el teatro de guerra catalán como en el Maestrazgo.

El contacto con Francia se mantenía a través del vicecónsul francés de Benicarló, Juan O'Connor y de un tal Mariano Boix, también vecino de la misma ciudad. ${ }^{26}$ Para el contacto con Austria e Italia el enlace fue, posiblemente, el vicecónsul de Austria-Hungría y de la Santa Sede en Valencia, Francisco Royo Salvador, diputado carlista por Morella y abogado. ${ }^{27}$ Hay que admitir que en el segundo caso no tenemos pruebas concretas que apoyen nuestra suposición que se basa en la búsqueda de personas que cumplieran con el perfil arriba desarrollado.

Con todo, esta vía no podía ser utilizada para el correo normal. Aún a falta de evidencias documentales habrá que pensar, si no en cierta "censura" del correo por funcionarios liberales en puntos como Valencia, Castellón o Reus, en una vigilancia de los envíos con desti- nos "sospechosos" como se había practicado en conflictos anteriores. Aparte de la conducción de la correspondencia privada y oficial del cuartel general estaba la de los soldados y alguna comercial que salía vía Valencia. Si no hubiera existido esta posibilidad, no se habría anunciado de forma oficial en los mapas postales que podemos suponer en las oficinas del correo carlista tanto para la información de los funcionarios como para los usuarios. No sabemos cómo funcionó exactamente, sabemos que había como mínimo dos vías para mantener el contacto con el extranjero dependiendo del país de destino o de procedencia y que probablemente no tenían, por razones de seguridad, el mismo enlace.

¿Cómo debió de funcionar el servicio? Primero no funcionaría de forma regular, sino ocasional. Un peatón-cartero carlista saldría desde el cuartel general de Chelva y entregaría y recogería en Valencia los sobres con la correspondencia saliente y entrante. Por el aislamiento de la zona la correspondencia comercial

$26 \mathrm{AHN}, \mathrm{BP}$, Correspondencia 95, exp. 3, n 115-117.

27 Royo asistió al Congreso de Vevey, junta de los carlistas exiliados, donde se acordaron los preparativos para la insurrección. El Vizconde de la Esperanza: La Bandera Carlista en 1871. Madrid 1871, p. 37-45. DEL BURGO, J. (1994): Carlos VIl y su tiempo, Pamplona. Parece que se puede excluir que el vicecónsul de Alemania y Suecia en Valencia, el sueco (i!) Harald Johann Dahlander, (también) estuviera implicado. Igual que su pariente Karl Adolf, vicecónsul en Alicante $\mathrm{y}$ "ardiente defensor de la fe luterana", guardaba seguramente pocas simpatías por el carlismo. VILAR, J.B. (1994): Intolerancia y libertad en la España contemporánea, Madrid, p. 252. 
debió de ser mínima. La privada de los soldados solía ser unidireccional. Además se evitaría en lo posible el envío de correo hacia la zona rebelde desde España para proteger esta vía de comunicación y para no revelar el punto de entrega y su enlace.

El Volante de la Guerra, periódico de campaña y en un principio también boletín oficial carlista para la zona del Centro, señala Chelva como sede del Encargado del Correo Carlista. ${ }^{28}$ La correspondencia hacia el extrior debía de llegarle en sobre doble. El sobre exterior llevaba la dirección del encargado. Dentro iban la carta y uno o varios sellos carlistas sueltos, según el peso de la carta, a modo de pago. El encargado franqueaba las cartas con sellos liberales y las entregaba al cartero que las llevaría a los enlaces en territorio liberal, encargados de echar las cartas a diferentes buzones o entregarlas en pequeño número en una o varias oficinas.

El mapa postal carlista marca dos líneas que salen de dicho territorio: una desde Chelva vía Liria a Valencia y otra hacia Aliaga (desde Vistabella o Villahermosa); posiblemente habría un tercer enlace vía Santa Cruz de Moya y Ademuz.

\section{El mito del "sello mellizo"}

Una administración postal moderna necesita sellos de correo propios. Son una fuente de ingresos verifica- ble para las arcas públicas además de medio de propaganda. Siguiendo los ejemplos del País Vasco, Navarra y Cataluña, también para el Centro se diseñó e imprimió un sello propio que se puso en circulación antes del verano de 1874 . Lo particular de esta emisión es que no existe ningún documento oficial carlista que nos confirme la fecha de su puesta en circulación ni que nos certifique su diseño exacto.

Si consultamos los catálogos de sellos actuales sobre los sellos carlistas de Valencia, nos encontramos bajo el apartado de la Guerra Carlista, con una información que realmente debiera de sorprender hasta a los filatélicos que se consideran medianamente críticos. Con el número 159 no se nos presenta un sello, sino dos. Ambos tienen el mismo dibujo. Sobre un fondo de líneas radiales se ve en un óvalo central el busto del pretendiente al trono, Carlos VII, sobre líneas horizontales, mirando hacia su izquierda. El óvalo está flanqueado por dos lises borbónicas. Dos banderolas, con la leyenda "España Valencia" arriba y "Correos 1 12 Real" abajo, se interponen entre el óvalo y los marcos inferior y superior del sello. Se trata de una litografía en color rojo.

Es obvio que las diferencias del diseño no pueden ser casuales, debidas a defectos del cliché o del reporte, de desgaste u otras razones pare- 

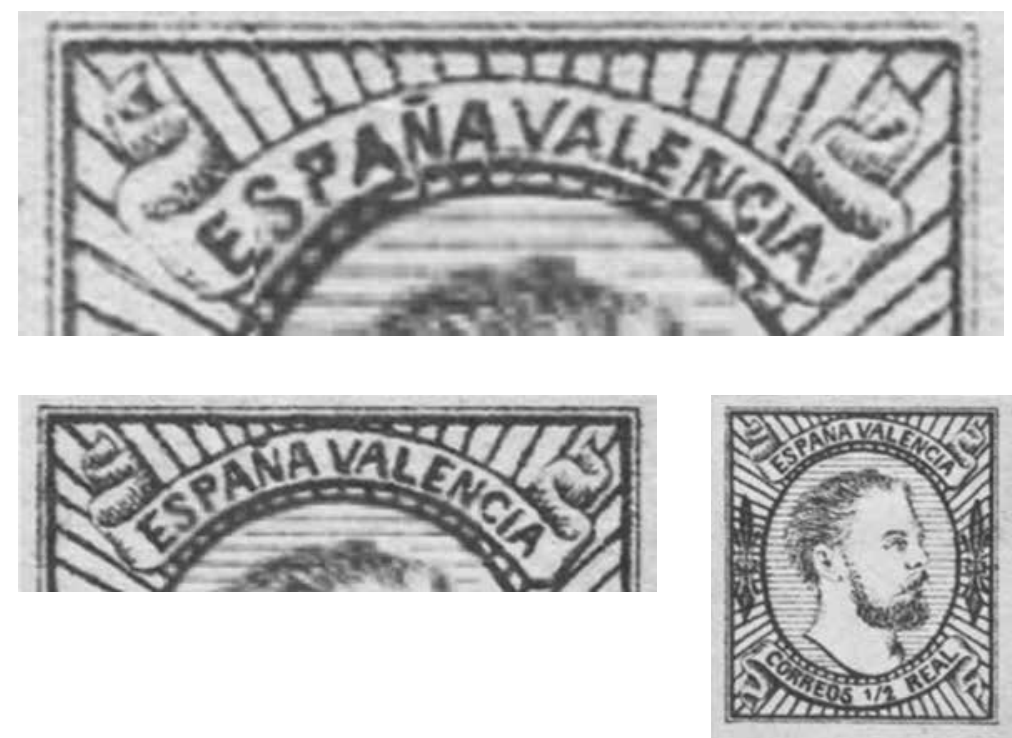

Fig.- 3. El "sello mellizo". (Detalles). Catálogo Gálvez, 1960.

cidas. Se deben, supuestamente, a la voluntad creadora de su grabador, Juan Vilás, ex-oficial carlista y responsable del taller litográfico de Vistabella, luego trasladado a Villahermosa, la única que había en todo el territorio dominado por los carlistas del Maestrazgo.

Las diferencias entre las dos versiones del sello consisten en el diferente número de líneas de fondo horizontales, en la colocación de la banderola superior que toca 0 no toca el marco del sello y la diferente colocación de las cifras del valor, más centrado o más pegado a la palabra "Real", según el tipo. Los sellos se encuentran en oposición vertical con su "hermano mellizo" de la fila anterior en cada una de las filas de la piedra litográfica original con la que se imprimieron.

El hecho de la existencia de un "se"lo mellizo" en sí, del mismo color y del mismo valor, es algo nuevo o al menos novedoso, hasta la fecha nunca visto y merecería ya de por sí un sitio señalado dentro de la historia postal y filatélica de España. Si tenemos en cuenta las dificultades a las que tenía que enfrentarse su creador a la hora de diseñar su obra y grabarla, todavía se torna más meritorio este esfuerzo. ${ }^{29}$ Pero 
a pesar de esto, esta original creación no parece merecer ni necesitar ninguna explicación más en el citado catálogo. Tampoco en otras publicaciones se encuentra explicación alguna, tan sólo se constata el mero hecho de su existencia.

Es, sin embargo, un hecho desconcertante que ni los mismos filatélicos, coleccionistas, comerciantes y expertos se pongan de acuerdo sobre cuál de las diferentes versiones de parejas verticales del sello valenciano ofrecidos en el mercado filatélico es la auténtica. Hay varias y se distinguen, entre otras cosas más difíciles de detectar, por el número diferente de líneas de fondo del óvalo central del primero de los dos sellos, que el catálogo llama tipo I. El holandés Hans Vinkenborg fue el primero en poner el dedo en la llaga, sin ir, desgraciadamente, al fondo de la cuestión. ${ }^{30}$ La discrepancia existente sobre el número de líneas de fondo del ejemplar auténtico no permite más que llegar a la única explicación lógica de que algunos de estos ejemplares tienen que ser a la fuerza falsificaciones.

Aquí no vamos a intentar determinar cuál es, o cuáles son, los sellos auténticos porque creemos poder demostrar a continuación, como ya reza el título de este capítulo, que la idea del "sello mellizo" es una falsedad convertida en mito. A su propagación contribuyó, y no poco, el prestigio de Jean-Baptiste Moens, editor de la revista belga Le Timbre Poste comerciante filatélico y autor de más de una decena de libros, considerado por muchos el "padre de la filatelia europea". En España, cuna del presunto "sello mellizo", es el filatélico, abogado e historiador Francisco Carreras Candi quien, al no ser comerciante, tenía y sigue teniendo prestigio dentro del mundo de la filatelia y era poco sospechoso de defender con sus tesis intereses comerciales. Además fue el primero y único en ahondar en la cuestión. Aunque luego aparecieran opiniones diferentes a la suya, nadie se ha atrevido públicamente a poner en tela de juicio sus conclusiones, someterlas a un examen crítico o incluso contradecirlas. Parece casi inevitable pensar que los motivos para tan escasa voluntad crítica fueran económicos y comerciales.

Para salir de dudas no nos queda otra alternativa que someter lo publicado por Carreras Candi a un examen crítico. Más de 30 años después de la creación del sello carlista valenciano, el historiador catalán nos presenta en su libro Disquisiciones la historia de todos los sellos carlistas, acudiendo para los de Valencia incluso al testimonio de su creador. El libro, que incluye partes importantes de la entrevista, nos presenta al final también una lámina con ilustraciones de dichos 
sellos. Lo que a primera vista parece tarea fácil, no lo es.

El capítulo del libro que habla del correo carlista del Maestrazgo se titula "Centro 1874". A modo de subíndice enumera los temas que tratará. Los tres primeros son: "Sello de correos emitido para el Centro en 1874. -Sus dos variedades.Falsificaciones del mismo". La enumeración incita ya a una todavía leve sospecha de que hay algo raro entre la presentación del sello y el relato del grabador que viene después. La primera frase después de la presentación del sello, dedicada a introducir este testimonio, confirma nuestro principio de sospecha ya que empieza: "Conocido ya el sello emitido para uso de los pueblos que el ejército carlista ocupaba..."

El autor nos acaba de presentar el sello valenciano como "sello mellizo" y ha establecido cuáles son sus dos falsificaciones. Su referencia más importante es Jean-Baptiste Moens quien había descrito en dos artículos de diciembre de 1874 y junio de 1875 cuatro diferentes sellos carlistas del Centro que le habían sido presentados y del que, como mínimo, uno había estado en circulación, aunque, presuntamente, como falso postal, o sea un ejemplar para engañar a la administración postal y no a coleccionistas. ${ }^{31}$ La afirmación de Carreras al presentar los falsos de que, según Moens, dichos sellos "son reconocidas imitaciones que a pesar del origen más o menos auténtico que a veces se les ha atribuido [...] comenzaron a circular entre los coleccionistas" es gratuita ya que ni uno ni el otro pueden presentar ninguna prueba. Es más, la historia que cuenta Moens, según la cual el general carlista Marco de Bello estaba implicado directamente en la falsificación de uno de dichos sellos que incluso ya había circulado como falso postal, pone en tela de juicio la fiabilidad de la información recibida y difundida por el belga, ${ }^{32}$ quien, por cierto, fue uno de los que se encargaron de su circulación filatélica al ofertarlos en su propia revista. ${ }^{33}$

Pero volvamos al texto. El hecho de que un sello presuntamente autén-

31 LANG-VALCHS, G. (2016): ¿̇Falso filatélico o falso postal?, Eco Filatélico y Numismático n 1248, pág. 24-25.

32 Moens cuenta incluso más tarde que Marco de Bello fue acusado y juzgado por la falsifiacción de dicho sello y castigado con una pena de cárcel por haber sido considerado autor del fraude. Un completo despropósito. TP, n 293, mayo 1887, p. 54.

$33 \mathrm{TP}, \mathrm{n}^{\circ} 150$, p. 48. 
tico exista en pareja "melliza" se afirma sin más. La fuente de esta información, que no nombra, es una escueta nota de febrero de 1875 en la revista de Moens que no solamente no da ninguna explicación adicional, sino que tampoco se completa, como se podía esperar, con una ilustración de tan singular ejemplar. En ningún número de su revista Moens es capaz de presentar una pareja vertical de este sello aunque volverá a tratar este tema en varios artículos posteriores. ${ }^{34} \mathrm{~A}$ pesar de lo que Carreras anuncia, su lámina sí presenta dos sellos de $1 / 2$ Real diferentes, pero tampoco puede presentar una pareja vertical. A cambio presenta una pareja horizontal con un presunto matasellos carlista. ${ }^{35}$

A continuación de la presentación reproduce al pie de la letra el relato del litógrafo Juan Vilás que, por lo visto, Carreras anotó en su día y que contiene "algunos datos, en estremo curiosos, relativos a su confección". $O$ sea, Carreras no tiene ninguna duda sobre el diseño del sello, aunque no ha traído ningún ejemplar, no hace ninguna pregunta específica ni sobre su diseño, ni el por qué de su duplicidad, ni sobre la fecha de puesta en circulación. ${ }^{36}$

Este comportamiento, casi desinteresado y pasivo, cambiará sustancialmente en la segunda parte de la entrevista. Ahora toca hablar del asíllamado sello de Cantavieja, un segundo sello valenciano, supuestamente creado en los últimos días de la guerra en el Maestrazgo. El interés del autor en este tema se nota enseguida. Ha concertado la entrevista con el litógrafo para hablar con él sobre este sello y disipar las dudas que tenía. Ha traído una copia o incluso un ejemplar de este y hace preguntas muy precisas para aclarar las circunstancias de su creación. Vilás, tras admitir que había diseñado otros timbres fiscales, dice no haber visto nunca este sello, ni litografiado ni en tinta, y niega haberlo creado o participado en su creación. En estas afirmaciones

34 En ninguno de los muchos catálogos de sellos españoles o extranjeros, en ninguna otra revista (filatélica) ni en ninguno de los libros que publican algo sobre este caso hasta principios del siglo XX se encuentra una ilustración, copia o foto de los "mellizos".

35 Este sello en tinta debe ser un falsificación. No se corresponde con ninguno de los sellos y encabezamientos que se encuentran en los documentos y la correspondencia carlistas.

36 En el subíndice habla de marzo, pero con una interrogación. 
se basa Carreras para llegar a la conclusión en este caso, a nuestro juicio correcta, de que tal sello es una falsificación. ${ }^{37}$

Después de haber analizado aunque tan sólo someramente la presentación de ambos sellos por Carreras Candi en su libro, no debiera extrañar la sospecha que expresamos y la primera impresión que tuvimos ya al leer el subíndice. El relato de $\mathrm{Vi}$ lás es, para Carreras, mero adorno, un apéndice de su presentación. Ninguna de las informaciones allí contenidas es aprovechada ni para contrastar ni para apoyar su preestablecida opinión sobre los auténticos sellos valencianos, basada en las afirmaciones de Moens. Como veremos en el siguiente análisis detallado del relato del grabador, Vilás, sin contestar preguntas sobre el tema que nos preocupa, deja en evidencia a su interlocutor.

Primero Vilás relata las condiciones de trabajo en su improvisado taller que son bastante precarias y sus herramientas rudimentarias. Instalado primero en una finca de las inmediaciones de Vistabella no dispone ni de silla ni de mesa de trabajo. De buril le sirve una aguja de coser fijada en un palito de madera, el busto del pretendiente lo tiene que grabar sin tener ni una foto o retrato de Don Carlos.

Vilás cuenta también que tuvo problemas para conseguir la tinta. Habla de un solo tiraje y parece haberse tenido que contentar con una tinta y un solo color. El sello se imprimió con una tirada única de 200.000 ejemplares en pliegos de 104 sellos, o sea unos 2000 pliegos. No da ninguna fecha concreta de la terminación del trabajo.

Cuando se refiere a su obra, Vilás siempre habla en singular, habla en repetidas ocasiones de "el sello grabado por mí", del "tan conocido sello carlista de Valencia", de la "confección del sello de correos". ${ }^{38}$ No satisfecho con el resultado de su trabajo, se dispone, una vez cambiado y reorganizado su taller en Villahermosa, a preparar una nueva edición bajo mejores condiciones, sobre todo contando ahora con un retrato del pretendiente. Entonces graba "dos sellos de correos,

37 Moens tenía este sello por falso. Algún catálogo español, sin embargo, lo daba por bueno. José María Sempere demuestra en varios artículos la inconsistencia de la argumentación que pretende defender su autenticidad. Véase SEMPERE, J.M.: A vueltas con el 3 cuartos carlista y El 3 cuartos carlista de Cataluña. Un sello fantasma. [http://www.filateliadigital.com/a-vueltas-con-el-3-cuartos-carlista/; $31.5 .2016,10.33$ y [http://www.filateliadigital.com/el-3-cuartos-carlista-de-cataluna/; $31.5 .2016,10.37]$.

38 CANDI: Disquisiciones, pág. 63. 
para reemplazar, en el año 1875, al que circulaba desde el año anterior". ${ }^{39}$ Pero ya no puede "proceder al nuevo trabajo" porque tiene que huir con la tropa ante el acoso del ejécito liberal.

Queda bastante claro que el creador habla durante la entrevista de un sólo sello. A este hecho se suma la imposibilidad de encontrar durante treinta años ni un solo ejemplar del pretendido "sello mellizo", ni una sola ilustración o foto de este conjunto que no aparecería publicado hasta bien entrado el siglo XX.40 Ninguna de las parejas (verticales) presentadas hasta el día de hoy como candidatos auténticos cumple los criterios que ofrecen las descripciones del (supuesto) fenómeno en la revista Le Timbre-Poste y en un estudio publicado en 1879 por la Royal Philatelic Society de Londres. ${ }^{41}$

En el caso de la revista belga la descripción de los dos ejemplares sueltos, no unidos, que supuestamente componen el conjunto, es anterior a la noticia de su supuesta particular posición en la misma plancha. ${ }^{42} \mathrm{En}$ el caso de la publicación inglesa se comenta la (supuesta) posición en la plancha además de la existencia de una línea fina de separación entre ambos, sin que quede claro si estas informaciones se basan en la observación y descripción directa de dicho fenómeno de una pareja vertical real y presente o si se trata simplemente de la repetición de la información sacada de la revista de Moens mezclado con la noticia de The Philatelist sobre una línea separatoria. ${ }^{43}$

Teniendo en cuenta todo esto no queda más remedio que relegar la idea de un "sello mellizo" al campo de la fantasía y de la mitología filatélica.

Llegados a este punto se impone la pregunta: ¿Cuál es, pues, el auténtico sello carlista valenciano? Este tema, sin embargo, es más compli-

39 Ibidem, pág. 65.

40 Friederich, primero en ilustrar con fotografías una publicación que incluye nuestros sellos, sólo puede presentar ejemplares sueltos. FRIEDERICH, R. (1894): Die Postwertzeichen Spaniens und seiner Kolonien", $2^{a}$ edición, Berlin, lámina X.

41 El diferente número de líneas de fondo horizontales y el número de líneas entre la cabeza y la parte superior del óvalo para Le Timbre Poste se complementan por el estudio británico con un recuento del número de líneas radiales que tocan el marco del sello por la parte interior, diferente también en cada lado, ofreciendo así una serie de criterios difícilmente contestables. Royal Philatelic Society: Catalogue of Postage Stamps, Stamped Envelopes and Post Cards, Spain and Colonies (1879), London, p. 30.

42 TP, $n^{\circ} 144$, dic 1874 , p. 89 y n 145 , ene 1875 , p. 5.

43 The Philatelist (1874), p. 161 (Recent and Undescribed Emissions. Spain) habla de un solo sello. 
cado de lo que parece, necesita de un enfoque filatélico y merece un estudio y análisis tan rigurosos como el aquí presentado. Dicho esto queda claro que tal tarea no tiene cabida dentro del marco de este artículo, la cantidad de información desbordaría los límites sensatos de un artículo y aburriría al lector. Este tema será tratado en otro artículo o librito de próxima publicación.

\section{Distritos postales Carlistas según el DeCreto de Dorregaray}

Gandesa:

+Alfara; +Arnes; +Ascó; +Beceite; Benisanet; Bot; Castellfort; +Cherta; Cinctorres; Corvera: Fatarella; +Flix; Forcall; +Fuentespalda; Hervés; Horta; Hortells [Ortells]; La Mata; +Miravet; +Peñarroya; Pinell; +Roquetes; +Santa Bárbara; +Torre de Arcos; +Valderrobres; Vilafranca del Cid; Zorita

\section{San Mateo:}

Aldover; Ares del Maestre; Vallestar; Canet lo Roig; Catí; +Cervera del Mestre; +Chert; +La Senia; Mas de Barberans; Pobla de Benifasá; Regués; Rosell; Salsadella; +Santa Magdalena; Sierra Engarcerán; *Tirig

Vallibona

Segorbe:

Alcudia de Veo; +Aljimia; *Argelita; +Artesa; Barracas; +Cau- diel; El Toro; *Espadilla; +Eslida; Gaibiel; Mater; +Montán; +Onda; Pavias; Pina; Puebla de Arenoso

Chelva:

Alpuente; +Arcos; Aras de los Olmos (Alpuente); *Calles; ${ }^{*} \mathrm{Ca}$ nales; ${ }^{*}$ Casas Bajas; La Yesa; La Cruz de Moya; Titaguas; *Tuéjar; +Abejuela; +Andilla; +Begis; +Líria; +Losa; +Torrijas; + Villar del Arzobispo

Castellón:

+Albocácer; +Alcalá de Chisvert; +Alcora; +Adzaneta; Artana; Ayódar; +Benafigós; +Benasal; Benlloch; Cabanes; Castillo de Villamalefa; +Certes de Arenosa; *Chodos; +Cirat; +Cuevas de Vinromá; Culla; +Fansara; Figueroles; +Lucena; Ribesalbes; Tales; +Torreblanca; Torre Endomenech; +Oropesa; Useres; +Vallat; Villafamés; +Zucaina

\section{Vistabella**:}

+Alcalá de la Selva; +Aliaga; +Alventosa; +Arbejuela; +Cantavieja; +Cañada de Benatanduz; +Fortanete; +Linares; +Manzanera; +Mirambel; +Mora de Rubielos; +Mosqueruela; +Puertomingalvez; +Rubielos de Mora; +Sarrión; +Torroya

** Este distrito, no presente en el proyecto de Dorregaray, pudo haber sido administrado también desde $\mathrm{Vi}$ - 
llahermosa. No queda claro cuáles eran los pueblos dependientes de la administración central, ni si ésta cambió su sede y estaba finalmente ubicada en Villahermosa. Es probable que en algún que otro caso la aquí propuesta pertenencia de ciertos pueblos, que solamente están presentes en el mapa carlista, a un distrito postal, basada en criterios geográficos y subjetivos del autor, esté equivocada.

* pueblo que no aparece en el mapa carlista

+ pueblo que aparece en el mapa, pero no en el proyecto de Dorregaray

\section{Fuentes}

Archivo Histórico Nacional (Madrid), Fondo de la familia Borbón-Parma.

Museo Postal (Madrid), Legado Thebussem

Le Timbre-poste [TP]

El Volante de la Guerra

The Philatelist

\section{Biblografía}

BAUTISTA VILAR, J. (1994): Intolerancia y libertad en la España contemporánea, Madrid.

CARRERAS CANDI, F. (1908): Estudios postales I. Disquisiciones filatélicas y postales, Barcelona.

CUERPO del Estado Mayor del Ejército (1889) Narración de la Guerra Carlista de 1869 a 1876, tomo XIV, Madrid.

DE PARDO FIGUEROA, M. (1895): Fruslerías postales, Madrid.
DEL BURGO, J. (1966): Bibliografía de las Guerras Carlistas y de las luchas políticas del siglo XIX, Pamplona.

DEL BURGO, J. (1994): Carlos VII y su tiempo, Pamplona.

ESCALADA-GOICOECHEA,E. (2000): La organización del correo carlista (1873.1876), Academia Hispánica de Filatelia, Madrid.

IGLESIAS BALDEÓN, L. (20082009): Numismática y filatelia del carlismo, Boletín de Estudios Históricos sobre San Sebastián, $n^{\circ} 42$ [Separata], San Sebastián.

LANG-VALCHS, G. (2016): ¿̇Falso filatélico o falso postal?, Eco Filatélico y Numismático n 1248, pág. 24-25.

LECLERCQ, A., Waroquiers, G. (1981): Jean-Baptiste Moens 1833-1900, Père de la Philatélie, Bruxelles.

LLATAS BURGOS, V. (2014): Efimérides de las Guerras Carlistas en el Villar del Arzobispo, $2^{a}$ ed., Villar del Arzobispo.

MEMORIA presentada el 2 de enero de 1874 a las Cortes Constituyentes por el ministro de la Gobernación D. Eleuterio Maisonnave, (1874) Imprenta Nacional, Madrid. OLCINA, E. (1974): El Carlismo y las autonomías regionales, Seminarios y Ediciones.

OLIVER, A. (1876): Dorregaray y la traición del centro: Apuntes para la historia de la última guerra civil, Bayona. PEÑA ARTERO, J. (2005): Los sellos carlistas de Cataluña. Contexto histórico, Colección: Monografías Filatélicas de Afinet $n^{\circ} 7$, Barcelona. 
ROYAL Philatelic Society (1879): SEMPERE LUQUE, J. M. María: El Catalogue of Postage Stamps, 3 cuartos carlista de Cataluña. Stamped Envelopes and Post Cards, [http://www.filateliadigital.com/ Spain and Colonies, Londres.

SEMPERE LUQUE, J. M.: A vueltas con el 3 cuartos carlista y El 3 cuartos carlista de Cataluña. Un sello fantasma. [http://www.filateliadigital.com/a-vueltas-con-el-3-cuartosel-3-cuartos-carlista-de-cataluna/; 31.5.2016, 10.37].

VINKENBORG, H.: De Carlistenzegel vit Valencia, Iberia, $\mathrm{n}^{\circ} 100, \mathrm{p}$. 50-57.

carlista/; $31.5 .2016,10.33$ ] 


\section{A LA DRA. ROSA MONLLEÓ PERIS, PROFESORA}

\section{Inmaculada Badenes-Gasset Ramos}

El pasado 31 de agosto la profesora Rosa Monlleó iniciaba un nuevo ciclo con su jubilación, aunque quienes la conocemos bien y hemos sido sus compañeros de trabajo, sabemos que nunca abandonará la Universitat a la que tan generosamente ha dedicado su tiempo, sus conocimientos y su buen hacer de lo que, sin duda, pueden dar fe sus numerosos alumnos, sus compañeros de Departamento o los datos proporcionados por su extenso curriculum.

Es cierto que su jubilación le permitirá dejar atrás horarios, obligaciones, informes, reuniones, las cuestiones tradicionales de la cotidianidad del trabajo, pero el pensamiento no se jubila, y sé que en su nueva función de Profesora Colaboradora, seguirá llevando a cabo nuevos proyectos vinculados a lo que durante su vida ha sido más que una profesión, una pasión: la Historia.

Es difícil resumir en pocas líneas la trayectoria vital y profesional de la profesora Rosa Monlleó

Nacida en Nules (Castellón), esta Catedrática de Escuela Universitaria, inició sus estudios de Historia Contemporánea en la Universidad de Valencia en donde obtuvo su Licenciatura en 1971.

En la antigua Escuela de Magisterio inició su carrera docente e investigadora para después integrarse en la Universitat Jaume I

Sus primeras investigaciones las realizó sobre el Sexenio Democrático en Valencia y Castellón y su incidencia social y política. Vendría después el Doctorado con una Tesis sobre Los Diputados Valencianos en la Primera República publicada en 1996.

Compaginando con gran esfuerzo docencia e investigación ha conseguido que sus conocimientos no hayan quedado reducidos a las aulas: libros, numerosísimas conferencias, artículos en prensa y revistas especializadas nacionales e internacionales, todo ha hecho posible la extensión de esos conocimientos a la sociedad

Sus investigaciones actuales están centradas en la ciudad de Castellón y sus comarcas durante las primeras décadas del siglo XX; sus transformaciones urbanas, el impulso que la construcción del puerto dio a la ciudad, el sector de la naranja, la vida cotidiana y los espacios de sociabilidad y ocio.

Mención aparte lo constituye sus investigaciones sobre los modelos identitarios de género y la acción colectiva de las mujeres de Castellón desde finales del siglo XIX hasta el primer franquismo. 
Coordinadora del Grupo de Estudios de Historia Local y Fuentes Orales, integrado por profesionales de la Historia y Archivos y grupo creado con la finalidad de rescatar la memoria colectiva de momentos históricos tan significativos como la Segunda República, la Guerra Civil o el Franquismo; Directora del Centro de Recuperación de la Memoria Histórica de la Universitat Jaume I, desde hace años trabaja dos fuentes específicas de la Historia Contemporánea: las fuentes orales y la fotografía. Consecuencia de ello ha sido el nacimiento de una nueva colección de la que es editora, Història y Memòria que en la actualidad cuenta con cuatro volúmenes publicados,

Como miembro de la Comissió de la Veritat, ha organizado diversos congresos sobre la represión franquista en el País Valencià.

En otra vertiente, la dirección de numerosísimas tesis ha hecho posible el amor por la investigación que ha sabido transmitir a todos sus doctorandos Son miles los alumnos los que a lo largo de su larga y fructuosa carrera docente han recibido sus enseñanzas en materias diversas en estudios de licenciatura, grado, doctorado y máster.

Tu carácter humanista, tu predisposición al dialogo, tus enseñanzas y tus investigaciones quedarán permanentemente como legado.

Rosa, directora de mi Tesis, todo mi eterno reconocimiento y mi cariño. 


\section{Autors/es}

\section{David Alegre Lorenz}

Es Doctor Europeo en Historia Comparada, Política y Social por la Universitat Autònoma de Barcelona con la tesis titulada Experiencia de guerra y colaboracionismo políico-militar en Bélgica, Francia y España bajo el Nuevo Orden (1941-1945). Desde el año 2014 es coeditor de la Revista Universitaria de Historia Militar. Ha publicado diversos artículos, capítulos y libros sobre los estudios de la guerra, la identidad del combatiente, la experiencia de guerra y el fascismo, por lo general centrados en la guerra civil y la Segunda Guerra Mundial.

david.alegre.lorenz@gmail.com

\section{Miguel Alonso Ibarra}

Es licenciado en Historia por la Universidad de Zaragoza y actualmente cursa su doctorado en Historia Contemporánea en la Universitat Autònoma de Barcelona, con una tesis centrada en el análisis de la experiencia de combate de los soldados sublevados en la Guerra Civil Española como elemento para la comprensión del proceso constructivo del régimen fascista español. Es co-director de la Revista Universitaria de Historia Militar. Ha publicado diversos artículos en revistas como Rúbrica Contemporánea, Ayer o Spagna Contemporánea. Sus principales líneas de investigación son el fascismo; la experiencia de guerra vista desde la perspectiva de los combatientes; los procesos de socialización ideológica asociada a los conflictos bélicos; la contrarrevolución europea de entreguerras; y la guerra como fenómeno de transformación social y cultural. miguel.alonso.ibarra@gmail.com

\section{William Caferro}

Especialista en la historia de la Italia medieval y renacentista. Su investigación se ha centrado en la transición del periodo medieval al del Renacimiento, en las diferencias entre ambos, particularmente en lo que respecta al ámbito económico. Caferro es autor de diversos trabajos como Mercenary Companies and the Decline of Siena (Johns Hopkins, 1998) o John Hawkwood, English Mercenary in Fourteenth Century Italy (Johns Hopkins, 2006), el cual ganó el Otto Grundler Prize del International Medieval Congress como el mejor libro de historia medieval de 2008. Es co-autor de The Spinelli: Fortunes of a Renaissance Family (Penn State, 2001) y co-editor de The Unbounded Community: Papers in Christian Ecumenism in Honor of Jaroslav Pelikan (Routledge, 1996). Su último libro, Contesting the Renaissance (Wiley-Blackwell, 2010), rastrea el uso y significado del término "Renacimiento" en los principales debates historiográficos.

william.p.caferro@vanderbilt.edu 


\section{Samuel Fury Daly}

Investigador en el African Studies Institute de la Universidad de Columbia (NY) Durante su trayectoria investigadora ha realizado estancias en la Universidad de Dar es Salaam (Tanzania), en la School of Oriental and African Studies de Londres, y en la Universidad de Cambridge. Sus intereses de investigación discurren por el estudio del naciente estado nigeriano en la década de los 60 y, más concretamente, sobre el concepto de ciudadanía en Nigeria a través de la participación en la Guerra de Biafra (1967-1970).

samuel.daly@duke.edu

\section{Gerhard Lang-Valchs}

Estudios superiores de Historia, Teología, Germánicas e Hispánicas. Profesor jubilado, traductor e intérprete jurado. Una docena de libros en diferentes editoriales alemanes Tesis doctoral: Los obispos de la Seo de Urgel como copríncipes de Andorra, Hamburgo 2011.

Más de una veintena de artículos en revistas españolas, andorranas, italianas, alemanas, francesas e inglesas sobre aspectos de la historia moderna de Andorra y otros temas de carácter postal y filatélico.

España y el correo de Andorra, Biblio 3W, Universidad de Barcelona.

langvalchs@hotmail.es

\section{Alan V. Murray}

Senior Lecturer in Medieval Studies en la University of Leeds. También es miembro de la Royal Historical Society, de la Baltische Historische Kommission, y pertenece a la Society for the Study of the Crusades and the Latin East, la Oswald von Wolkenstein-Gesellschaft y la Scottish Place-Names Society. Sus principales líneas de investigación son las Cruzadas, la cristianización del Báltico y el warfare medieval. Actualmente se encuentra trabajando en un proyecto sobre las identidades étnico-lingüísticas en la época de las Cruzadas, tanto en Tierra Santa como la zona del Báltico, así como en una biografía del rey Balduino II de Jerusalén. Es autor de The Franks in Outremer: Studies in the Latin Principalities of Syria and Palestine, 1099-1 187 (2015).

a.v.murray@leeds.ac.uk

\section{Eduardo Pitillas Salañer}

Licenciado en Filosofía y Letras (Historia) por la Universidad de Valladolid (1976). Profesor de Enseñanza Secundaria, actualmente jubilado. En los años 1994 y 2005 leyó respectivamente, en las Universidades de Valladolid y Oviedo, tesina y tesis doctoral. Autor de una cincuentena de artículos y de un conjunto de libros sobre Historia de Roma. El último lleva por título: La diplomacia romana de época republicana (241-27 a. C.), Zaragoza, 2015.

epitillass@hotmail.es 


\section{Antonio José Rodríguez Hernández}

Licenciado en Historia por la Universidad de Valladolid, y posteriormente Doctor en Historia Moderna por el Instituto Universitario de Historia Simancas de esa misma universidad, gracias a la tesis titulada Los Tambores de Marte. El Reclutamiento en Castilla durante la segunda mitad del siglo XVII (1648-1700). En su etapa post-doctoral ha trabajado en la Universidad de Almería, y ha sido Visiting Scholar en el University College Dublin (Irlanda). Actualmente es Profesor Ayudante Doctor dentro del Departamento de Historia Moderna de la UNED, y secretario del mismo Departamento. Sus investigaciones se han centrado fundamentalmente en el estudio del ejército de la Monarquía Hispánica durante el siglo XVII. Ha sido galardonado con el Premio Ejército en Investigación en Humanidades y Ciencias Sociales 2006, gracias a la monografía: España, Flandes y la Guerra de Devolución (1667-1668), Madrid, 2007. Ha publicado otras tres monografías y una treintena de trabajos en revistas y publicaciones científicas sobre el reclutamiento de soldados, la guerra, la composición de los ejércitos, las relaciones entre los soldados y la población civil, la concesión de nobleza o la venta de honores y cargos.

ajrodriguez.uned@gmail.com

\section{Simon Sarlin}

Profesor de historia del siglo XIX en la Université de París Nanterre. Su formación ha discurrido por diversos temas, como la historia y las civilizaciones, la historia de la Edad Moderna, la historia del mundo contemporáneo o la historia del arte y de la música, entre otras. Sus principales líneas de investigación giran en torno a la Europa mediterránea y, dentro de ella, acerca de las derechas contrarrevolucionarias, los exilios y el voluntariado de guerra. Ha publicado diversas obras y artículos como Le Légitimisme en armes. Histoire d'une mobilisation internationale contre l'Unité italienne, Roma, École française de Rome, coll. B.E.F.A.R., 2013 o «Fighting the Risorgimento: foreign volunteers in the conflicts of Southern Italy (1860-1863)», Journal of Modern Italian Studies, 14/4, 2009, pp. 476-49.

ssarlin@parisnanterre.fr

\section{Matthew Trundle}

Es Chair y Professor of Classics and Ancient History en la University of Auckland. Sus intereses de investigación gravitan, principalmente, en torno a la historia de la Grecia Clásica, y sus publicaciones se centran en los aspectos sociales y económicos de este periodo. Es autor de Greek Mercenaries from the Late Archaic Period to Alexander (London y New York, 2004), y ha editado diversos volúmenes como New Perspectives on Ancient Warfare (Leiden, 2010) y Beyond the Gates of Fire: New Perspectives on the Battle of Thermopylae (Bradford, 2013). Ha publicado numerosos artículos cmo 'Mercenaries', 
en The Oxford Handbook of Classical Warfare (Oxford 2013), pp. 330-351; ¿Greek Athletes and Warfare in the Classical Period» en Nikephoros 25 (2012 [2014]), pp. 221-237, 'Coinage and the Economics of the Athenian Empire' en Circum Mare (Leiden 2016), pp. 65-79 y The Spartan Krypteia' en The Topography of Violence (Ann Arbor, MI. 2016), pp. 60-76.

M.Trundle@auckland.ac.nz 


\section{NORMES PER A LA PRESENTACIÓ D'ORIGINALS}

1. Els treballs seran originals $i$ inèdits. La temàtica versarà sobre les àrees d'Història, Geografia i Història de l'Art.

Els treballs tindran una extensió entre 8.000 i 10.000 paraules.

Es podran presentar textos en català, espanyol, francés, italià, anglés i portugués.

Al primer full hauran de figurar les següents dades: títol de l'article en castellà/ català i anglès, seguit del nom i cognoms de l'autor/a o autors/es, institució a la qual pertanyen i una adreça de correu electrònic de contacte. A continuació, un resum de 80/100 paraules, en la llengua de l'article i en anglés, a més de 4 o 5 paraules clau en les mateixes llengües.

2. La numeració en el text de la nota a peu de pàgina anirà sempre darrere de la puntuació.

3. Només s'admetran dos nivells de subapartats dins el cos de l'article. El títol del primer nivell anirà en negreta i minúscula. Si es fan servir subapartats de segon nivell aniran en minúscula, cursiva i negreta.

4. Igualment es lliurarà un breu nota biogràfica dels autors/es (màxim 80 paraules).

5. Si inclou taules, gràfics o altres figures, aquestes aniran degudament numerades fent constar la seua correcta ubicació en el text i la referència al peu. Als peus de foto haurà de constar l'autoria, així com el títol de l'obra, data i localització quan s'escaiga.

6. Les notes s'ordenaran numèricament en el text $i$ es colllocaran a peu de pàgina.

També podrà utilitzar-se el sistema de cites entre parèntesi fent referència a la bibliografia recopilada al final del treball.

7. La resolució de les imatges serà, com a mínim 300 dpi, i es publicaran en blanc i negre.

8. La bibliografia es presentarà en el seu cas al final de l'article. El sistema per citar la bibliografia, tant en les notes a peu de pàgina com en el recull final, serà: COGNOM, Nom de l'autor/a o autors/es (any d'edició), "Títol de l'article" o Títol del llibre; Títol de la revista, número o volum de la revista, editorial, lloc d'edició i pàgines. Exemples:

FRADERA, Josep Maria (1999), Filipinas, la colonia más peculiar. La hacienda pública en la definición de la política colonial, 1762-1868, CSIC, Madrid. 
YUSTA, Mercedes (2008), "La 'recuperación de la memoria histórica': ¿una reescritura de la historia en el espacio público? (1995-2005)", Revista de Historiografía, vol. 9, pp. 105-117.

AGUADO, Ana M. (2013), "La cárcel como espacio de resistencia y de supervivencia antifranquista", a NASH, Mary (ed.), Represión, resistencias, memoria: las mujeres bajo la dictadura franquista, Comares, Granada, pp. 37-52.

En cites successives de bibliografia ja citada s'usarà COGNOM, Títol de llibre o "Títol d'article" o "Títol de capítol" de forma abreujada.

9. Els articles rebuts seran avaluats per dos especialistes externs designats pel Consell de Redacció. La seua publicació estarà condicionada a la introducció de les observacions indicades en aquest procés, del qual els autors seran puntualment informats.

10. La proposta dels articles i la correspondència s'adreçarà a:

Cristina lgual MILLARS. ESPAI I HISTÒRIA

Departament d'Història, Geografia i Art

Universitat Jaume I

Avda. Sos Baynat, $\mathrm{s} / \mathrm{n}$

12071 CASTELLÓ DE LA PLANA

Telèfon: (+34) 964729636

Adreça electrònica: cigual@his.uji.es 


\section{NORMAS PARA LA PRESENTACIÓN DE ORIGINALES}

1. Los trabajos serán originales e inéditos. La temática versará sobre las áreas de Historia, Geografía e Historia del Arte.

Los trabajos tendrán una extensión entre 8.000 y 10.000 palabras.

Se podrán presentar textos en catalán, español, francés, italiano, inglés y portugués.

En la primera página han de figurar los siguientes datos: título del artículo en castellano/catalán e inglés, seguido del nombre y apellidos del autor/a o autores/a, institución a la que pertenecen y una dirección de correo electrónico de contacto. A continuación, un resumen de $80 / 100$ palabras, en la lengua del artículo y en inglés, además de 4 ó 5 palabras clave en las mismas lenguas.

2. La llamada en el texto a la nota a pie de página irá siempre detrás de la puntuación.

3. Solo se admitirán dos niveles de subapartados dentro del cuerpo del artículo. El título del primer nivel irá negrita y minúscula. Si se utilizan subapartados de segundo nivel irán en mínuscula, cursiva y negrita.

4. Igualmente se entregará una breve nota biográfica de los autores/as (máximo 80 palabras).

5. Si incluye tablas, gráficos u otras figuras, estas irán debidamente numeradas haciendo constar su correcta ubicación en el texto, la referencia en los pies de foto. En los pies de foto deberá constar la autoría, así como el título de la obra, fecha y localización cuando se requiera.

6. Las notas se ordenarán numéricamente en el texto y se colocarán a pie de página.

También podrá utilizarse el sistema de citas entre paréntesis haciendo referencia a la bibliografía recopilada al final del trabajo.

7. La resolución de las imágenes será, como mínimo 300 dpi, y se publicarán en blanco y negro.

8. La bibliografía se presentará, en su caso, al final del artículo. El sistema para citar la bibliografía, tanto en las notas en pie de página como en la sección final, será: APELLIDO, Nombre del autor/a o autores/as (año de edición), "Título del artículo" Título del libro; Título de la revista, número o volumen de la revista, editorial, lugar de edición y páginas. Ejemplos:

FRADERA, Josep Maria (1999), Filipinas, la colonia más peculiar. La hacienda pública en la definición de la política colonial, 1762-1868, CSIC, Madrid.

YUSTA, Mercedes (2008), "La 'recuperación de la memoria histórica': ¿una reescritura de la historia en el espacio público? (1995-2005)", Revista de Historiografía, vol. 9, pp. 105-117. 
AGUADO, Ana M. (2013), "La cárcel como espacio de resistencia y de supervivencia antifranquista", en NASH, Mary (ed.), Represión, resistencias, memoria: las mujeres bajo la dictadura franquista, Comares, Granada, pp. 37-52.

En citas sucesivas de bibliografía ya citada se usará APELLIDO, Título de libro o "Título de artículo" o "Título de capítulo" de forma abreviada.

9. Los artículos recibidos serán evaluados por dos especialistas externos designados por el Consejo de Redacción. Su publicación estará condicionada a la introducción de las observaciones indicadas en este proceso, del que los autores serán puntualmente informados.

10. La propuesta de artículos y la correspondencia se dirigirá a:

Cristina lgual MILLARS. ESPAI I HISTÒRIA

Departament d'Història, Geografia i Art

Universitat Jaume I

Avda. Sos Baynat, s/n

12071 CASTELLÓ DE LA PLANA

Teléfono: (+34) 964729636

Dirección electrónica: cigual@his.uji.es 


\section{GUIDELINES FOR THE SUBMISSION OF ORIGINAL MANUSCRIPTS}

1. The manuscripts submitted must be original and unpublished. They must deal with topics in the fields of history, geography and art history.

The manuscripts should have between 8.000 and 10.000 words.

Manuscripts could be sent in Catalan, Spanish, French, Italian, English or Portuguese.

The first page should contain the following information: title of the article in Spanish/Catalan and English, followed by the name and surname(s) of the author(s), the institution they belong to and an e-mail address. A 80-100 words abstract written in the language of the article and in English, or Spanish if English is the language of the article, and should include 4 or $5 \mathrm{e}$ keywords in the same languages.

2. The call to the footnote in the text always will go after the punctuation.

3. Only two levels of subheadings will be accepted for the body of the article. The first-level heading should be written in boldface and lowercase. If authors use second-level subheadings, they will be boldfce, lowercase, but italicised.

4. A short biographical data of the article's author(s) (maximum, 80 words) should be also provided.

5. If the article includes tables, graphs or other figures, these should be appropriately numbered by indicating their location in the text, and foot referenced. The photo captions should acknowledge authorship, as well as the work title, date and location, when appropriate.

6. Notes should be sorted numerically in the text and should be inserted at the foot of the page.

The author/date text citation system can also be used.

7. The images should have a resolution of at least $300 \mathrm{dpi}$, and will be published in black and white.

8. The bibliography, in case, should be presented at the end of the article. The citation system to be used for references both in the footnotes and in the final section should be as follows: SURNAME, Name of the author(s), (year of edition), "Article title" or Book title; Journal name, journal number or volume, publisher, place of publication, and number of pages. Examples:

FRADERA, Josep Maria (1999), Filipinas, la colonia más peculiar. La hacienda pública en la definición de la política colonial, 1762-1868, CSIC, Madrid.

YUSTA, Mercedes (2008), "La 'recuperación de la memoria histórica': ¿una reescritura de la historia en el espacio público? (1995-2005)", Revista de Historiografía, vol. 9, pp. 105-117. 
AGUADO, Ana M. (2013), "La cárcel como espacio de resistencia y de supervivencia antifranquista", in NASH, Mary (ed.), Represión, resistencias, memoria: las mujeres bajo la dictadura franquista, Comares, Granada, pp. 37-52.

In successive aforementioned literature citations will be used SURNAME, Book title or "Title of article" or "Chapter title" for short.

9. The articles received will be reviewed by two external specialists, chosen by the Editorial Board. Their publication will depend on the incorporation of the remarks made during this process, of which the authors will be duly informed.

10. The proposed articles and all correspondence should be addressed to:

Cristina lgual MILLARS. ESPAI I HISTÒRIA

Departament d'Història, Geografia i Art

Universitat Jaume I

Avda. Sos Baynat, s/n

12071 CASTELLÓ DE LA PLANA- SPAIN

Telephone: (+34) 964729636

e-mail: cigual@his.uji.es 


\section{Dossier}

\section{Miguel Alonso Ibarra y Dayid Alegre Lorenz (Coords.) \\ Mercenarios, conscriptos, voluntarios y ciudadanos-soldado}

\section{Miguel Alonso Ibarra y David Alegre Lorenz}

Reclutamiento, encuadramiento y experiencia de guerra desde la antigüedad hasta nuestros días

\section{Matthew TRUndle}

Hiring Mercenaries in the Classical Greek World. Causes and Outcomes?

\section{Eduardo Pitillas Salañer}

Los soldados del ejército romano durante la etapa del Alto Imperio. Sus componentes más básicos: el ciudadano-soldado (legionario) y el soldado auxiliar

\section{Alan V. Murray}

Warriors and Civilians in the Crusade Movement. Military Identities and Status in the Liberation and Defence of the Holy Land (1096-1204)

\section{Willam Caferro}

The Florentine Army in the Age of the Companies of Adventure

\section{Antonio José Rodríguez Hernández}

El primer modelo de reclutamiento forzoso en España durante la Edad Moderna: las levas para los Presidios (1634-1642)

\section{SIMON SARLIN}

Mercenaries or Soldiers of the Faith? The Pontifical Zouaves in The defense of the Roman Church (1860-1870)

\section{Samuel Fury Daly}

De trabajadores a soldados: trabajo forzado y conscripción en la Guinea Española y la Nigeria oriental, 1930-1970

\section{Estudis}

\section{Gerhard Lang-Valchs}

El correo carlista en el Maestrazgo (1872-1875) 